Andrea Cherman

\title{
VALORAÇÃO DO CONHECIMENTO NAS ORGANIZAÇÕES: Percepções dos indivíduos e impactos nas práticas organizacionais
}

Tese de Doutorado

Tese apresentada ao Programa de Pós-Graduação em Administração de Empresas da PUC-Rio como requisito parcial para obtenção de título de Doutor em Administração de Empresas.

Orientadora: Profa. Sandra Regina da Rocha Pinto

Rio de Janeiro

Novembro de 2013 


\section{Andrea Cherman}

\section{Valoração do conhecimento nas organizações: Percepções dos indivíduos e impactos nas práticas organizacionais}

Tese apresentada como requisito parcial para obtenção do grau de Doutor pelo Programa de Pós-graduação em Administração de Empresas da PUC-Rio. Aprovada pela Comissão Examinadora abaixo assinada.

Profa. Sandra Regina da Rocha Pinto

Orientadora

Departamento de Administração - PUC-Rio

Profa. Angela Maria Cavalcanti da Rocha

Departamento de Administração - PUC-Rio

Profa. Flávia de Souza Costa Neves Cavazotte

Departamento de Administração - PUC-Rio

Profa. Lucia Barbosa de Oliveira

Faculdades IBMEC-RJ

Prof. Roberto Lima Ruas

UNINOVE

Profa. Mônica Herz

Vice-Decana de Pós-Graduação do CCS

Rio de Janeiro, 22 de novembro de 2013 
Todos os direitos reservados. É proibida a reprodução total ou parcial do trabalho sem autorização da universidade, da autora e do orientador.

\section{Andrea Cherman}

Graduou-se em Comunicação Social pela Universidade Federal do Rio de Janeiro, ECO/UFRJ, em 1985. Cursou Pós-Graduação em Marketing, em 1988, e Pós-Graduação em Management, em 1999, pelo Departamento de Administração da Pontifícia Universidade Católica do Rio de Janeiro, PUC-Rio. Graduou-se no Mestrado em Administração pelo Departamento de Administração da PUC-Rio em 2003. Ganhou o Prêmio ANPAD 2003 da Área de Gestão Social e Ambiental, concedido pela Associação Nacional de Pós-Graduação e Pesquisa em Administração. Desde 2004, exerce atividade docente na PUCRio, onde realiza pesquisa e ensino na área de Estudos Organizacionais. Atua como Coordenadora de Atividades Internacionais da Graduação em Administração desde 2009. Possui 25 anos de experiência como profissional e gestora de marketing em empresas multinacionais de grande porte.

Ficha Catalográfica

Cherman, Andréa

Valoração do conhecimento nas organizações: percepções dos indivíduos e impactos nas práticas organizacionais / Andréa Cherman; orientadora: Sandra Regina da Rocha-Pinto.

$234 \mathrm{f} . ; 30 \mathrm{~cm}$

Tese (doutorado) - Pontifícia Universidade Católica do Rio de Janeiro, Departamento de Administração, 2013.

Inclui bibliografia

1. Administração - Teses. 2. Conhecimento organizacional. 3. Valoração do conhecimento. 4. Conhecer na prática e na ação. 5. Método fenomenográfico. 6. Sociologia da associação. I. Rocha-Pinto, Sandra Regina da. II. Pontifícia Universidade Católica do Rio de Janeiro. Departamento de Administração. III. Título. 
Este trabalho é dedicado ao muito, muito e muito querido amigo José Roberto Gomes da Silva, que, com toda sua gentileza, generosidade e desprendimento, duramente me ensinou que amizade é para além da vida e que devemos dizer todos os dias o que sentimos às pessoas a quem amamos. De sua primeira e última orientanda de doutorado, daquela que nunca escreveu com você, mas que nunca deixou de pensar em você enquanto escrevia essa tese. Zé, agora podemos fechar a agenda reaberta em 2009, pois nosso compromisso se cumpriu.

Dedico com todo amor e carinho aos meus muito queridos Márcia, Francisco, Kiko e Laura, Bruno e Cassie, e Kika, cujo acolhimento em sua família me permitiu sonhar. 


\section{Agradecimentos}

A Deus, com toda sua sabedoria, que ilumina o caminho.

A todos que colaboraram para que este estudo se realizasse: Ana Raquel Rocha, Andrea Landim, Andrea Motta, Cristina Trencher, Edmundo Eutrópio, Elmo Gomes, Enrique Alfredo Peralta, Fábio Minervini, Haroldo de Paiva Lorena, Helmar Pecly de Oliveira, Hugo Motta Bacello Mósca, Janaína Caldas Dias, Katia Paiva Werneck, Luiz Abiel Martins, Marcelo Chamma, Marcos Villas, Matheus Barauna, Nelson Dabul, Paulo Roberto Maisonnave, Renata Buarque Coutinho, Renato Lyra, Tania Tisser Beyda, Walther Galvão Krause e ao apoio institucional do IAG Área de Desenvolvimento de Carreira. Um muitíssimo especial agradecimento a Renata Barbieri Coutinho e a Renata Machado Ribeiro Nunes. Obrigada pelas indicações profissionais e generosa atenção dada por vocês.

A todos os 25 entrevistados, que cederam seu tempo, compartilharam comigo uma parte das suas vidas, enfrentaram perguntas difíceis e desconhecidas. Obrigada pela disponibilidade de vocês.

À professora Sandra Regina, um especial muito obrigada por me proporcionar escrever outra história.

Aos professores membros da banca de projeto, Angela da Rocha, Flávia Cavazotte e Roberto Ruas. Suas sugestões e contribuições nos vários momentos de desenvolvimento do projeto e/ou pesquisa foram preciosas! Obrigada pela inestimável coorientação.

Ao professor Jorge Ferreira da Silva, muito obrigada pelo apoio em todos os momentos em que precisei. Não foram poucos... Mas também não foram tantos assim!!!

Ao professor Paulo Cesar Motta, com muito carinho; aos professores do IAG, aos colegas de doutorado, pela travessia. 
Aos secretários Fábio Etienne e Teresa Campos, um especial agradecimento pela ajuda sempre solidária. 'Tamos' juntos!

Às queridas estagiárias Pillar Hernandez e Thais Ferraz, pelas páginas transcritas com tão boa vontade, muito obrigada.

Aos queridos amigos Alessandra Costa, Ana Heloísa Lemos, Ana Luiza Szuchmacher Veríssimo Lopes, Ana Raquel Rocha, Angela da Rocha, Bruno Pavanelli de Azeredo, Camila Reis, Claudia Duarte Soares, Danilo Marcondes, Flávia Cavazotte, Francis Berenger, Francisco Eduardo Moreira de Azeredo, Francisco Azeredo, João Renato Benazzi, Jorge Ferreira da Silva, Jorge Manuel Carneiro, Janaína Caldas Dias, Lea Mara Assaid, Letícia Franca, Liana Ribeiro, Luis Rovere, Luis Alexandre Grubits Pessoa, Marcelo Chamma, Marcus Wilcox Hemais, Márcia Azeredo, Marcos Rego, Maria do Carmo Leite de Oliveira, Melissa Senra, Mila Desouzart Viana, Renata Barbieri Coutinho, Renata Céli, Renata Kurtz, Renata Machado Ribeiro Nunes, Roberto Gil Uchôa, Sandra Regina da Rocha-Pinto, Tânia Tisser Beyda, Veranise Dubeux.

À PUC-Rio e ao CNPq, pelos auxílios concedidos para a realização deste trabalho.

Aos meus pais amados, Nelson e Zilda, e ao meu irmão Fernando.

Aos meus queridos psitinhos, que alegram o meu dia. 


\section{Resumo}

Cherman, Andrea; Pinto, Sandra Regina da Rocha. Valoração do conhecimento nas organizações: percepções dos indivíduos e impactos nas práticas organizacionais. Rio de Janeiro, 2013. 234 p. Tese de Doutorado - Departamento de Administração, Pontifícia Universidade Católica do Rio de Janeiro.

O estudo objetiva apresentar proposições teóricas acerca dos diferentes modos pelos quais os membros organizacionais percebem e experimentam a valoração do conhecimento no contexto do trabalho, e seus impactos nas práticas organizacionais. O Método Fenomenográfico buscou a compreensão mais ampla do fenômeno por meio da variação nos modos dos indivíduos em conceber partes desse fenômeno (MARTON, 1981; MARTON e BOOTH, 1997; SANDBERG, 2001). As concepções foram organizadas em categorias inclusivas e ordenadas no Mapa do Espaço de Resultado. Adicionalmente, foi conduzido um grupo de foco com entrevistados para obter validade interna do Mapa do Espaço de Resultado. Para o estudo, foram realizadas 22 entrevistas em profundidade, com profissionais de Recursos Humanos. Delas, emergiram cinco concepções relativas ao fenômeno de valoração do conhecimento nas organizações, da mais estreita à mais ampla: Aplicação no Trabalho, Consideração do Trabalho-Indivíduo, Realização do Indivíduo no Trabalho, Transformação do Trabalho e do Indivíduo, Criação Emergente para a Vida. As concepções constituíram-se em um continuum fluido, bidirecional e transitório, demonstrando ser acessadas pelos indivíduos de modo mais dinâmico e ativo do que o exposto no método. A Fenomenografia revelou a construção social da valoração do conhecimento, enquanto a Sociologia da Associação (LATOUR, 2012), inserida no enfoque do conhecer (knowing) na prática e na ação (GHERARDI, 2002; 2006; ORLIKOWSKI, 2000; PATRIOTTA, 2003a), comportou a dimensão explicativa. As práticas organizacionais foram abordadas pela perspectiva das rotinas inseridas na ação (FELDMAN e ORLIKOWSKI, 2011; FELDMAN e PENTLAND, 2003; 
PARMIGIANI e HOWARD-GRENVILLE, 2011). Dentre os achados propostos, emergiram: As diferentes dimensões de interação social (pares, alta gestão, liderança e organização) exercem influências distintas nas concepções de valoração do conhecimento, devido às percepções do indivíduo e à consequente importância atribuída a esses níveis/grupos. A organização e seus mediadores diretos exercem maior influência sobre o conhecimento valorado a ser adotado pelos membros organizacionais. A identificação com a identidade organizacional (ASHFORTH et al., 2008; CORLEY et al., 2006) é um mecanismo pelo qual os indivíduos expressam o alinhamento entre sua concepção de conhecimento de valor e o conhecimento valorado pela organização. Decorrem desse aspecto, mecanismos de poder sutis ou declarados. Para cada tipo de arranjo organizacional encontrou-se uma concepção dominante de valoração do conhecimento, dado que a construção relacional, resultante das interações entre os atores daquele coletivo, produz tanto a forma de conceber a organização como o conhecimento valorado nela; constrói ainda o que é ser um profissional competente e as regras de viver nesse arranjo. Sugere-se que o conhecimento nas organizações seja um fenômeno relacional, único e indissociável entre conhecimento individual-organizacional (ELKJAER, 2003; LATOUR, 2012). Por fim, a valoração do conhecimento no contexto do trabalho demonstra ser um fenômeno preponderantemente autorreferencial e autorreproduzido nas organizações, onde pouco do conhecimento valorado incorpora-se nas práticas organizacionais. O estudo aponta caminhos para a inclusão do conhecimento do indivíduo, pleno em suas potencialidades, nas organizações.

\section{Palavras-Chave}

Conhecimento organizacional; valoração do conhecimento; conhecer na prática e na ação; método fenomenográfico; sociologia da associação 


\section{Abstract}

Cherman, Andrea; Pinto, Sandra Regina da Rocha (Advisor). Valuing of knowledge in organizations: perceptions of the individuals and impacts on organizational practices. Rio de Janeiro, 2013. 234 p. Doctoral Thesis Departamento de Administração, Pontifícia Universidade Católica do Rio de Janeiro.

The aim of this study is to present theoretical propositions for structuring the various ways that organizational members perceive and deal with the valuing of knowledge in the work context and its impacts on organizational practices. The Phenomenographic Method was used in this study because it seeks to achieve a broader understanding of the phenomenon by analyzing the various ways in which individuals conceive parts of it (MARTON, 1981; MARTON e BOOTH, 1997; SANDBERG, 2001). The conceptions were organized into inclusive categories and ordered in an Outcome Space Map. In addition, a focus group was conducted with interviewees in order to obtain an internal validation of the Outcome Space Map. For the study, 22 in-depth interviews were undertaken with human resource professionals. Five conceptions regarding the phenomenon of the knowledge valuing in organizations, from the narrowest to the most wide-ranging, emerged from these interviews: Application to Work, Consideration of the IndividualWork Relation, Realization of the Individual at Work, Transformation of Work and the Individual, Emerging Creation for Life. The conceptions constituted a fluid, bidirectional and transitory continuum, demonstrating that they were accessed by individuals in a more dynamic and active way than could be expected according to the method. Phenomenography revealed that knowledge valuing is a social construction, while the Sociology of Translation (LATOUR, 2012), with its approach of knowing-in-practice and action (GHERARDI, 2002; 2006; ORLIKOWSKI, 2000; PATRIOTTA, 2003a), provided the explanatory dimension. Organizational practices were analyzed as routines embedded in action (FELDMAN and ORLIKOWSKI, 2011; FELDMAN and PENTLAND, 2003; 
PARMIGIANI and HOWARD-GRENVILLE, 2011). Several findings emerged: different dimensions of social interaction (peers, top management, leadership and organization) exercise distinct influences on conceptions of knowledge valuing, due to the individual's perceptions and the resulting importance attributed to these levels/groups. The organization and its direct mediators exercise a greater influence on the valued knowledge to be adopted by organizational members. Identification with the organizational identity (ASHFORTH et al., 2008; CORLEY et al., 2006) is a mechanism through which individuals express the alignment between their conception of valuable knowledge and the knowledge valued by the organization. This results in subtle or declared power mechanisms. Each type of organizational arrangement has its corresponding dominant conception of knowledge valuing, given that the relational construction formed by the interactions between the actors of that collective, produces both the way of conceiving the organization and the knowledge valued in it. It is suggested that knowledge in organizations is a relational, unique and indissociable individualorganizational knowledge phenomenon (ELKJAER, 2003; LATOUR, 2012). Finally, the valuing of knowledge in the work context is shown to be a preponderantly self-referential and self-produced phenomenon in organizations, where only a small amount of valued knowledge is incorporated into organizational practices. The study shows the various ways that individual knowledge, with all its potentialities, could be included in organizational practices.

\section{Keywords}

Organizational knowledge; knowledge valuing; knowing-in-practice and action; phenomenographic method; sociology of translation. 


\section{Sumário}

1. O Problema 16

$\begin{array}{ll}\text { 1.1. Introdução } & 17\end{array}$

1.2. Objetivos 22

1.2.1. Objetivo Final 22

1.2.2. Objetivos Intermediários 22

1.3. Definições-Chave no Contexto do Estudo 23

1.4. Relevância do Estudo 25

1.5. Recorte do Estudo $\quad 27$

1.6. Estrutura da Tese 27

2. Conhecimento Organizacional 30

2.1. Aprendizagem e Conhecimento Organizacionais: Delimitação e Inter-relação dos Campos de Estudo $\quad 30$

2.2. Conhecimento Organizacional 32

2.2.1. Perspectivas do Conhecimento Organizacional 32

2.3. Perspectiva do Conhecer (Knowing) na Prática e na Ação 42

2.3.1. Enfoques na Perspectiva do Conhecer (Knowing) na Prática e na Ação 44

2.3.2. Enfoque do Conhecer (Knowing) na Prática e na Ação e Método

Fenomenográfico $\quad 59$

3. Valoração do Conhecimento $\quad 60$

3.1. Valor: Uma Definição $\quad 60$

3.2. Valoração do Conhecimento e os Enfoques da Revisão de Literatura 62

3.2.1. Valor do Conhecimento como um Número: Enfoque sobre Mensuração ou Depreciação do Conhecimento 62

3.2.2. Valor do Conhecimento como um Recurso ou Capacidade: Enfoque sobre Criação de Valor Estratégico e Desempenho Organizacional 64

3.2.3. Valor do Conhecimento como Interpretação e Significado: Enfoque sobre Percepção do Indivíduo $\quad 67$

3.3. Valoração do Conhecimento e o Enfoque do Conhecer (Knowing) na Prática e na Ação 


\section{Rotinas Organizacionais}

4.1. Origens das Rotinas 85

4.2. Correntes no Campo das Rotinas Organizacionais $\quad 87$

4.3. Corrente das Rotinas Organizacionais como Prática 89

4.3.1. Estudos Empíricos na Corrente das Rotinas Organizacionais como Prática

5. Metodologia de Pesquisa

5.1. Etapa 1: Pesquisa Bibliográfica para Revisão Sistemática da Literatura 95

5.1.1. Revisão da Literatura Seminal 96

5.1.2. Revisão da Literatura Relevante 97

5.1.3. Revisão da Literatura Recente (Últimos Onze Anos) 97

5.2. Abordagem Qualitativa 100

5.3. Etapa 2: A Escolha do Método de Pesquisa 102

5.4. Etapa 3: A Pesquisa Empírica com o Método Fenomenográfico 104

5.4.1. Definição e Características do Método 105

5.4.2. Sobre Paradigma de Pesquisa, Epistemologia e Ontologia 115

5.4.3. "Contextos" de Fenomenografia 118

5.4.4. Aplicação do Método em Estudos Organizacionais 122

5.4.5. Fases do Método Fenomenográfico 127

5.4.6. Critérios de Confiabilidade e Rigor 141

5.5. Etapa 4: Grupo de Foco com Profissionais Participantes da Pesquisa Empírica para Validação Interna do Mapa do Espaço de Resultado 143

5.6. Limitações do Método 145

6. Análise dos Dados Emergentes do Campo 146

6.1. As Concepções dos Indivíduos acerca da Valoração do Conhecimento no Contexto do Trabalho 146

6.1.1. Valoração do Conhecimento é Aplicação no Trabalho 148

6.1.2. Valoração do Conhecimento é Consideração (Reconhecimento) do Trabalho-Indivíduo 152

6.1.3. Valoração do Conhecimento é Realização do Indivíduo no Trabalho 156

6.1.4. Valoração do Conhecimento é Transformação do Trabalho e do Indivíduo 159

6.1.5. Valoração do Conhecimento é Criação Emergente para a Vida 164 
6.1.6. Resultados do Grupo de Foco para Validação Interna do Mapa do Espaço de Resultado

7. Discussão e Proposições acerca da Valoração do Conhecimento no Contexto do Trabalho e os Impactos nas Práticas Organizacionais

7.1. Proposições Teóricas acerca do Método Fenomenográfico Aplicado ao Fenômeno da Valoração do Conhecimento

7.2. Proposições Teóricas acerca da Valoração do Conhecimento no Contexto do Trabalho

7.3. Nem Organizacional, Nem Individual: Proposição Teórica acerca do Conhecimento Valorado como uma Relação

7.4. Os Impactos da Valoração do Conhecimento nas Práticas Organizacionais

7.5. Uma Reflexão Final: E Quanto ao Conhecimento Valorado?

8. Conclusão, Recomendações e Sugestões para Futuras Pesquisas

\section{Referências Bibliográficas}

10. Apêndice

10.1. Apêndice 1: Roteiro Semiestruturado - Valoração do Conhecimento \# 2

10.2. Apêndice 2: Perguntas Apresentadas nas Rodadas de Debate do Grupo de Foco 


\section{Índice de Figuras}

Figura 1: Modelo Geral do Sistema de Atividade Socialmente

Distribuído

Figura 2: Relação entre os mecanismos de valoração do

conhecimento com as dimensões de interações .....................................83

Figura 3: 'O que' e 'Como'. .......................................................................... 108

Figura 4: 'Como' e as facetas 'ato' e 'objeto indireto'. ....................................108

Figura 5: 'Um modo de experimentar algo' ..................................................110

Figura 6: Exemplo de Modelo Constitutivo do Outcome Space........................113

Figura 7: Aspecto Relacional da Fenomenografia..........................................114

Figura 8: Objeto de estudo em Fenomenografia, abordagem

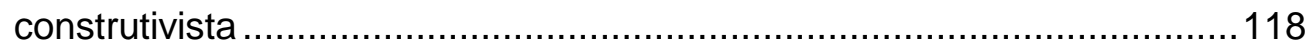

Figura 9: Mapa do Espaço de Resultado para as Concepções acerca da Valoração do Conhecimento (VdC) no Contexto do Trabalho 169

Figura 10. Mapa do Espaço de Resultado conforme proposto pelos participantes do grupo de foco

Figura 11: Esquema ilustrativo das dimensões de interação social envolvidas nas concepções de valoração do conhecimento no contexto do trabalho

Figura 12: Modelo de Conhecimento nas Organizações - Visão

Tradicional 203

Figura 13: Modelo de Sabedoria nas Organizações 206 


\section{Índice de Quadros}

Quadro 1: Perspectivas do Conhecimento Organizacional ..............................40

Quadro 2: Enfoques do Conhecer na Perspectiva da Prática e da

Ação.

Quadro 3: Pressupostos das Correntes das Capacidades e da

Prática. .89

Quadro 4: Listagem de Posição dos Periódicos Internacionais no

Ranking JCR para Management e Rating ABS para General

Management. 98

Quadro 5: Classificação dos Periódicos no Rating Qualis CAPES

(2011) para Administração 100

Quadro 6: Relação de Artigos em Estudos Organizacionais com

Aplicação do Método Fenomenográfico 126

Quadro 7: Relação de Artigos Nacionais em Estudos

Organizacionais com Aplicação do Método Fenomenográfico .................126

Quadro 8: Quadro de Variação Demográfica da Amostra Intencional..............129

Quadro 9: Quadro Final de Perfis dos Sujeitos Entrevistados..........................132

Quadro 10: Espaço de Resultado para as Concepções acerca da

Valoração do Conhecimento (VdC) no Contexto do Trabalho 172 
The endless cycle of idea and action,

Endless invention, endless experiment, Brings knowledge of motion, but not of stillness;

Knowledge of speech, but not of silence;

Knowledge of words, and ignorance of the Word. All our knowledge brings us nearer to our ignorance, All our ignorance brings us nearer to death,

But nearness to death no nearer to God.

Where is the Life we have lost in living?

Where is the wisdom we have lost in knowledge? Where is the knowledge we have lost in information?

The cycles of Heaven in twenty centuries Bring us farther from God and nearer to the Dust. T. S. Eliot, The Rock (1934) 


\section{1 \\ O Problema}

A pesquisa em conhecimento organizacional é um dos temas recentemente explorados no campo de estudos organizacionais. Muito se tem abordado sobre conteúdo, localização, natureza, processos de transferência, compartilhamento e geração de conhecimento nas organizações. Embora algumas linhas tenham caminhado para a visão do conhecimento enquanto construção social, emergente da ação, encontram-se visões dominantes que abordam o conhecimento de modo instrumental e reducionista, como algo a ser aplicado aos problemas organizacionais. Ainda de modo insatisfatório, se investiga acerca de como os indivíduos percebem a atribuição de valor de importância aos seus conhecimentos no contexto do trabalho.

O presente capítulo contextualiza esse problema de pesquisa, trazendo as abordagens e questões que têm direcionado os estudos recentes relacionados à valoração do conhecimento. A partir da definição do problema, são apresentados os objetivos, as definições-chave utilizadas pelas escolhas teóricas, a relevância do estudo bem como a sua contribuição teórica e o recorte adotado no estudo. A estrutura da tese fecha o capítulo.

\subsection{Introdução}

É reconhecida a relevância atual da questão do conhecimento para o contexto organizacional. A principal característica da sociedade pós-industrial consiste na transformação dos modos de produção, trabalho e produto, precipuamente baseados no conhecimento como principal matéria-prima e produto final das organizações (DRUCKER, 1992; KUMAR, 1997). O conhecimento se apresenta, sob essa visão, como um ativo intangível, desejável de ser gerenciado por tratar-se de um capital valioso para a organização (SVEIBY, 1998; STEWART, 1998), capaz de viabilizar o desenvolvimento de novas competências organizacionais. 
A importância do conhecimento adquire uma nítida visibilidade quando se encontra ligada às decisões estratégicas das organizações. Nesse âmbito, cabe mencionar as correntes estratégicas baseadas em recursos (BARNEY, 1991; 1996; PENROSE, 2006, original de 1959; WERNERFELT, 1984) e em conhecimento (GRANT, 1996; PRAHALAD e HAMEL, 1991; SPENDER e GRANT, 1994; 1996), nas quais os recursos, capacidades e competências, sob a forma de ativos de conhecimento, tornam-se peças-chave para que a organização obtenha vantagem competitiva sustentável, com vistas à antecipação no ambiente competitivo dinâmico e ao incremento do desempenho organizacional.

No contexto interno das organizações, igualmente o conhecimento ganha relevância, uma vez que é parte da ação de trabalhar e constitui o próprio indivíduo em sua identidade, permeando os modos de fazer as coisas, ser e se comportar no ambiente, participar das atividades que constroem o trabalho e a organização (BROWN e DUGUID, 1991; ELKJAER, 2003; LAVE e WENGER, 1991; WENGER, 2008, original 1998).

Entretanto, o acesso ao conhecimento organizacional, seja para compartilhamento seja para aquisição entre os membros organizacionais com fins de utilização e transformação estratégica, não é tão direto e imediato quanto seria desejável neste mundo tão dinâmico e competitivo (CHERMAN e MACEDOSOARES, 2011; SZULANSKI, 1996; 2000). Concorre a existência de uma lógica dominante na alta gestão, em que a organização constrói, reforça e, por fim, cristaliza determinadas formas de pensar, tomar decisões, fazer escolhas sobre o que a organização precisa aprender e quais são os conhecimentos desejados, com base no mapa mental da alta gerência que reproduz os modelos, processos e decisões que, no passado, tenham logrado êxito e a tenham conduzido ao estado de sucesso ou equilíbrio em que se encontra (BETTIS e PRAHALAD, 1995; BETTIS e WONG, 2003).

Assim, a capacidade de aprender coisas novas e desaprender as antigas, de gerar novos modos de tomar decisões amparadas em novos conhecimentos, advindos da experiência prática e da assunção do risco de errar, é muito duvidosa em todos os níveis organizacionais, devido ao mapa mental interiorizado na cultura, que chega a impedir o surgimento de novas competências organizacionais e individuais, assim como o aprendizado coletivo (ANTAL et al., 2001; BETTIS e 
PRAHALAD, 1995; BETTIS e WONG, 2003, STARBUCK e HEDBERG, 2001; STARBUCK et al., 2008).

Em consequência, como as pesquisas demonstram, há uma dificuldade, por parte das organizações, de perceber as mudanças dinâmicas do ambiente ou de enxergá-lo de modo diferente, o que as faz continuar a atuar da mesma forma anterior e já conhecida. Nelas, o modo de aprendizagem é apenas o refinamento dos conhecimentos que a organização já possui em um determinado esquema incremental, e o planejamento nada mais é do que uma reprodução do passado, acabando a organização por tornar-se vítima de sua incapacidade de pensar de forma diferente (HEDBERG e WOLFF, 2001).

Se resulta árduo para a alta gestão da organização pensar de modo diferente do mapa mental e aprender com as mudanças, parece ser válido e benéfico compreender o valor atribuído ao conhecimento existente na organização ou mesmo como ele é percebido pelos indivíduos e pelo coletivo. Um primeiro sinal dessa necessidade foi apontado por Nonaka, Toyama e Byosière (2001) ao afirmarem que a captura do valor do conhecimento ainda é uma lacuna e um tema a ser explorado e estudado na área de conhecimento organizacional.

Os autores se referiam a um valor mensurável, concreto, capturável por algum sistema organizacional contábil (NONAKA, TOYAMA e BYOSIÈRE, 2001) e foi possível identificar, na revisão da literatura internacional e nacional para os últimos onze anos no tema de conhecimento organizacional, o desenvolvimento de uma vertente de estudos que aborda a valoração do conhecimento por meio de um número, visando a cobrir essa lacuna. Ele foi denominado e classificado, no presente trabalho, como enfoque sobre mensuração e depreciação do conhecimento.

Nesse enfoque, o conhecimento é reconhecido como um ativo de valor da organização que deve ser medido, uma vez que causa impacto no desempenho organizacional ou pode depreciar e perder valor. Assim, o conhecimento é considerado um objeto concreto, com um valor de utilidade e troca, passível de apropriação e mensuração por um número financeiro-contábil, em boa parte dos casos. Ele se subdivide em três correntes de estudo com base em: ativos intangíveis (ANTUNES e MARTINS, 2007; BONTIS 1998; 2001; BONTIS e FITZ-ENZ, 2002; MASSINGHAM, 2008; MAURER et al., 2011); curvas de aprendizagem (EPPLE et al., 1991; FANG, 2011; REAGANS et al., 2005) e; 
conhecimento especializado passível de depreciação e valorização (ARGOTE e EPPLE, 1990; BOONE et al., 2008; DARR et al. 1995; GAIMON et al., 2011; GROYSBERG et al., 2008; MADSEN e DESAI, 2010).

Além dessa vertente, a revisão da literatura também revelou um enfoque no qual o conhecimento é um antecedente ou mediador que possibilita a geração de valor estratégico, sendo responsável por um desempenho organizacional superior. O conhecimento é visto como recurso ou como uma capacidade prioritária para a criação de valor da organização e encontram-se os estudos relacionados às correntes estratégicas baseadas em recursos (RBV) e em conhecimento (KBV).

Nesse enfoque sobre valor estratégico, o conhecimento possibilita certas atividades e resultados da organização, tais como estratégia, inovação, articulação em redes e alianças, e desempenho. A unidade principal de análise dos estudos é a organização.

O amplo número de artigos no enfoque, dadas as correntes de estratégia, abrange uma grande diversidade de linhas, relacionando o valor gerado pelo conhecimento com: transferência de conhecimento intraorganizacional (DENRELL et al., 200; LEVINE e PRIETULA, 2011; WATSON e HEWETT, 2006) ou em firmas em rede (KARAMANOS, 2003; MOLLER E SVAHN, 2006); capacidades organizacionais (HAAS, 2006; KING e ZEITHAML, 2003); lócus ou meios da criação de valor (FELIN e HESTERLY, 2007; HAAS e HANSEN, 2005; KANG et al., 2007; REUS et al., 2009); mudança organizacional em ambientes mutantes (POSEN e LEVINTHAL, 2011); governança em estratégia interorganizacional (SUBRAMANI e VENKATRAMAN, 2003); entre diversos outros temas.

O terceiro enfoque encontrado na referida revisão de literatura, relacionado à valoração do conhecimento, recai sobre a percepção dos indivíduos, de como eles interpretam e significam a importância do conhecimento - ou de quais conhecimentos - nas organizações. Trata-se de um conjunto de estudos que, de modo indireto, aborda porque determinados conhecimentos possuem mais relevância, são incorporados ou rejeitados pelos membros organizacionais, e, por decorrência, são considerados de maior ou menor valor.

Desse modo, os artigos exploram a atribuição de importância e, indiretamente, o valor do conhecimento, que geram impactos na escolha do conhecimento e na sua utilização pelos indivíduos na organização. Na revisão da 
literatura, foram encontrados os seguintes temas relacionados: identidade social (GAO e RILEY, 2010; HARMAN, 2012; MENON e BLOUNT, 2002; MENON e PFEFFER, 2003; MENON et al., 2006; THOMAS-HUNT et al., 2003; WONG, 2008); identificação e identidade organizacional (BROWN e STARKEY, 2000; CHERMAN e ROCHA-PINTO, 2013; COLMAN e LUNNAN, 2011; NAG et al., 2007; RAVISHANKAR e PAN, 2008); relações de poder, política e hierarquia (ANTONACOPOULOU, 2006; CONTU e WILLMOTT, 2003; HARMAN, 2012; HEIZMANN, 2011; KAMOCHE et al., 2011; NAG et al., 2007; OBORN e DAWSON, 2010; SWART, 2011), legitimação (HEUSINKVELD E BENDERS; 2005; INKPEN, 2008; STURDY et al., 2009) e confiança (trust) (MULLERSEITZ e GÜTTEL, 2012; RENZL, 2008).

Os artigos apontam, alguns mais fortemente enquanto outros mais implicitamente, que há uma relação entre como os indivíduos percebem, interpretam e significam o conhecimento com consequentes atitudes de adoção, internalização, aplicação, ou não, desses conhecimentos. Entretanto, é importante evidenciar que nenhum artigo ou estudo investiga diretamente as percepções dos indivíduos acerca da valoração do conhecimento (como o conhecimento de valor é significado pelos indivíduos e como a valoração ocorre no contexto do trabalho), nem as relações e influências possíveis nos comportamentos individuais e coletivos, com reflexos nas práticas e nas rotinas organizacionais. Adicionalmente, partindo dos temas mencionados acima, o olhar dos estudos, além de indireto, encontra-se fragmentado em análises isoladas.

Assim, entende-se que as pesquisas abordaram a valoração do conhecimento na organização pela percepção dos indivíduos de modo fragmentado e indireto, sem considerar a perspectiva dos sujeitos participantes da organização, resultando em uma abordagem insatisfatória para a compreensão mais profunda e detalhada de como ocorre a atribuição de importância e valoração do conhecimento.

Dada a relevância da perspectiva do indivíduo na contribuição para o conhecimento coletivo no contexto organizacional, apresenta-se o foco da tese. Desse modo, a questão central que esse estudo buscou responder é: Como os indivíduos percebem e experimentam a valoração do conhecimento no contexto do trabalho e a incorporação desses conhecimentos nas práticas organizacionais? 


\subsection{Objetivos}

O estudo aborda o tema do Conhecimento Organizacional a partir da perspectiva dos indivíduos, membros organizacionais. Tal ângulo de análise toma por base a perspectiva do conhecer na prática, enquanto ação. Nesta perspectiva, é por meio dos indivíduos que a aprendizagem e o conhecer fluem, ou seja, são transmitidos, transferidos, traduzidos, transformados, construídos e reproduzidos continuamente na organização, onde, por fim, se legitimam e se incorporam ao denominado conhecimento organizacional - se é que é possível separar os fenômenos conhecimento individual e conhecimento organizacional (ELKJAER, 2003; GHERARDI, 2006; LATOUR, 2012; ORLIKOWSKI, 2002).

De todo modo, no decorrer do processo de ação organizacional, de trabalhar em determinado contexto, os conhecimentos são valorados ou não, atribuindo-se importância a determinados conhecimentos em detrimento de outros. Assim, a seguir, configuram-se os objetivos da tese.

\subsubsection{Objetivo Final}

Apresentar proposições teóricas acerca dos diferentes modos pelos quais os membros organizacionais percebem e experimentam a valoração do conhecimento no contexto do trabalho (concepções), e seus impactos nas práticas organizacionais.

\subsubsection{Objetivos Intermediários}

A fim de responder a questão central de pesquisa e apresentar o objetivo final, em sua questão central e secundária, torna-se necessário analisar os seguintes objetivos intermediários identificados abaixo:

- Identificar os conceitos do que é conhecimento no contexto do trabalho para os indivíduos;

- Identificar os diferentes modos pelos quais os indivíduos percebem e experimentam a valoração do conhecimento no contexto do trabalho;

- Analisar as respectivas significações atribuídas às distintas experiências de valoração do conhecimento. 
- Analisar os impactos na incorporação, utilização e compartilhamento do conhecimento pelos membros, nas práticas organizacionais, em decorrência das percepções e significações atribuídas ao conhecimento valorado.

\subsection{Definições-Chave no Contexto do Estudo}

Foi adotada, no presente estudo, a perspectiva do conhecimento como o conhecer (knowing) na prática e na ação, ou seja, a visão practice-based theorizing (GHERARDI, 2000; 2006; ORLIKOWSKI, 2002). Deste modo, foi considerado que as experiências de valoração do conhecimento, trazidas pelas narrativas dos indivíduos, são emergentes e dadas na ação e na prática de trabalhar naquele contexto específico, e ainda se levou em consideração que o conhecimento está intrinsecamente presente nas experiências de realização de uma atividade. Ao ser desempenhado, o conhecimento é aprendido, transformando o indivíduo em quem ele é (ELKJAER, 2003), ou seja, constrói a sua identidade para que o indivíduo faça sentido (sense making) naquele ambiente.

Conceitualmente, sob essa perspectiva, o conhecimento está imerso na ação e na prática do trabalho, em que o conhecer (knowing) encontra-se situado e distribuído em um sistema de práticas contínuas (LAVE e WENGER, 1991; ORLIKOWSKI, 2002; TSOUKAS, 1996; WENGER, 2008, original de 1998). Como é desempenhado na ação de fazer qualquer atividade (ORLIKOWSKI, 2002), ele está enraizado no contexto em que ocorre a interação, e pressupõe alguma forma de participação na comunidade de prática (BROWN e DUGUID, 1991; LAVE e WENGER, 1991; WENGER, 2008), seja ela a organização, equipe, departamento, rede interorganizacional, dentre outras coletividades. Assim, o conhecer é indutivo e emergente destas práticas, sendo, portanto, indeterminado a priori (ORLIKOWSKI, 2002; TSOUKAS, 1996).

Essa perspectiva adota o conhecer (knowing) como um fenômeno social e cultural, situado no contexto histórico, sociomaterial e cultural em que ele ocorre (GHERARDI E NICOLINI, 2000), e abandona a noção do conhecimento apenas como resultado de um processo mental e cognitivo. Além disso, a tradicional 
distinção entre conhecimento e aprendizagem desaparece da mesma forma que a dicotomia processo-resultado (BLACKLER, 1995).

$\mathrm{O}$ conhecer (knowing) é relacional e mediado por artefatos, tais como a linguagem, a tecnologia, os objetos, os indivíduos e o dinheiro (CALLON, 1980; 1991; LATOUR, 1999; 2012; LAW, 1992; 1999; LAW e HASSARD, 1999) em uma rede de intermediação. Deste modo, é continuamente reproduzido e negociado, sendo sempre dinâmico e provisório. Como é passível de legitimação para tornar-se durável e provisoriamente permanente, é também composto por conflito, tensão e poder, sendo sempre contestável (LATOUR, 1999; 2012; LAW, 1992; 1999; LAW e HASSARD, 1999).

Apesar da variedade de enfoques presentes nesta perspectiva, Patriotta (2003a; 2003b) reitera que eles são complementares. Trata-se de diferentes aproximações do mesmo fenômeno ou objeto de estudo: o conhecimento nas organizações.

Quanto à valoração do conhecimento, buscou-se uma definição de valor que possuísse a mesma propriedade da perspectiva do conhecer na prática e na ação, ou seja, aquela na qual o valor seja construído na ação e inserido no contexto social. Deste modo, este trabalho conceitua valor como modo pelo qual as pessoas acessam a importância do que fazem, enquanto estão fazendo, ganhando sentido sobre si mesmas e sobre suas ações (GRAEBER, 2001). Esse aspecto está inserido no contexto social, e neste caso, valor também representa a criação de relações sociais.

No enfoque sobre a percepção dos indivíduos, acerca da forma como eles interpretam e significam o valor do conhecimento, e sob a perspectiva do conhecer na ação, Swart (2011) define valor como um senso coletivo de apreciação mútua. Valor é construído socialmente. O grupo, em determinado contexto, atribui valor a um mesmo resultado emergente de uma atividade (SWART, 2011). O conhecer na prática é especialmente relevante, pois é através da prática, da ação no contexto que o valor do conhecimento se torna visível para os membros organizacionais (NAG et al., 2007). 


\subsection{Relevância do Estudo}

O conhecimento organizacional é uma linha de estudos recente, mas bastante profícua. Muito se tem estudado acerca do uso do conhecimento para consecução de estratégias sustentáveis e na visão de um ativo intangível, mas de alto valor para a sobrevivência das organizações. Entretanto, saindo dessas visões dominantes e buscando compreender como o conhecimento se processa internamente nas empresas, descobre-se que ainda aparecem questões não completamente resolvidas.

Uma dessas questões é central: se tanto se sabe acerca da importância do conhecimento para o trabalho e tanto se estuda o tema, por que é tão difícil para as organizações incorporar novos modos de pensar, aceitar novos paradigmas descartando crenças que já não funcionam mais, permitir uma maior contribuição dos membros organizacionais - independente de cargo, posição e formação - no conhecimento coletivo da organização? E, se as organizações são povoadas por pessoas, o que elas pensam sobre o uso de seus conhecimentos no trabalho, qual significado o conhecimento possui para elas, quais conhecimentos possuem valor e a qual conhecimento elas entendem que a organização, por sua vez, atribui valor?

As pesquisas existentes, que tangenciaram o tema da valoração do conhecimento na organização pela percepção dos indivíduos, o fizeram de modo fragmentado e indireto. $O$ resultado encontrado na literatura encerra uma abordagem insatisfatória para auxiliar na construção de respostas a essas questões. A perspectiva dos sujeitos participantes da organização é pouco considerada, e nenhum estudo investigou diretamente as percepções dos indivíduos sobre o conhecimento de valor, aquele que, de fato, deveria ser incorporado nas organizações.

Alguns estudos apontam indiretamente, porém, que a forma como os indivíduos e a própria organização valoram e atribuem importância aos conhecimentos que fazem parte dos indivíduos e coletividades gera impactos nas escolhas e na incorporação de conhecimentos no contexto organizacional (ANTONACOPOULOU, 2006; MENON e PFEFFER, 2003; NAG et al., 2007; OBORN e DAWSON, 2010; WONG, 2008). 
Entretanto, ainda não foram suficientemente explorados quais são os aspectos percebidos pelos indivíduos que se relacionam com atribuição de valor, e em que medida isto influencia nas práticas organizacionais. Deve-se considerar, ainda, que, sobre essas escolhas e conhecimentos valorados, os indivíduos e a organização constroem a ação organizacional, com consequências na transformação, ação e desempenho organizacional.

Assim, a presente tese procura contribuir na construção teórica para o campo de estudos do conhecimento organizacional, abordando diretamente os pontos discutidos acima. Primeiramente, esse estudo contribui na classificação da produção da área em três linhas relacionadas ao conceito de valoração do conhecimento nas organizações. Em segundo, o trabalho busca diretamente a perspectiva dos indivíduos, com base em suas percepções e experiências relacionadas a como o conhecimento individual é valorado e significado nas organizações, fornecendo um quadro conceitual das concepções e dimensões correlatas encontradas, conjugadas às práticas e rotinas organizacionais e aos arranjos e modelos organizacionais. Em terceiro, contribui com proposições teóricas acerca dos mecanismos que fazem parte desse processo de valoração do conhecimento no trabalho, resultando em comportamentos individuais e coletivos associados. O estudo, de modo geral, tem o intuito de contribuir na tentativa de construção de um primeiro conceito acerca da valoração do conhecimento no trabalho enquanto linha de pesquisa. Adicionalmente, o trabalho traz contribuições ao Método Fenomenográfico (MARTON, 1981; MARTON e BOOTH, 1997, SANDBERG, 2001), na linha de pesquisa qualitativa, por meio de proposições teóricas ao método.

Para a prática profissional, a presente tese busca evidenciar os fatores existentes nos arranjos organizacionais que favorecem ou inibem a plena utilização das capacidades individuais e dos conhecimentos existentes na organização. Nesse sentido, são apontados caminhos para melhores modelos, que devem ser considerados pelos indivíduos na posição de gestão. 


\subsection{Recorte do Estudo}

Quanto à delimitação de escopo do presente estudo, a pesquisa limita-se a uma categoria de atuação profissional: profissionais de Recursos Humanos (RH). Desde o final dos anos 1990, a área de Recursos Humanos procura reivindicar um papel mais central nas decisões e ações das organizações, pleiteando a posição de RH estratégico (ULRICH, 1998). Entende-se que o RH seria a área em que o entendimento e a percepção acerca do conhecimento deveria ter um espectro mais amplo. Ao mesmo tempo, seriam os profissionais que promoveriam uma visão do conhecimento compartilhado entre os diversos grupos da organização e que trabalhariam para proporcionar condições para o trânsito/fluxo, transformação e tradução do conhecimento no contexto do trabalho.

Desse modo, este estudo considerou que os profissionais de RH seriam aqueles por quem, em princípio, passariam rotinas, cultura, estrutura, estratégias e competências organizacionais, sendo responsáveis por Desenvolvimento Humano, Treinamento-Desenvolvimento-Educação (TDE) e pelo fluxo de conhecimento da organização. Outras categorias profissionais não são contempladas no presente trabalho.

Quanto à delimitação geográfica, a pesquisa foi conduzida com profissionais em organizações sediadas no Rio de Janeiro. Foram contempladas apenas organizações privadas, de origem nacional e multinacional, de vários portes. A exclusão de profissionais pertencentes às empresas públicas ou de capital misto deveu-se ao modo particular de como estas organizações são geridas no Brasil e aos seus objetivos não estarem necessariamente vinculados ao desempenho superior no mercado. $\mathrm{O}$ estudo não contempla uma delimitação temporal definida, pois os indivíduos acessaram suas experiências de vida profissional para narrar suas percepções de atribuição de valor e significado do conhecimento.

\subsection{Estrutura da Tese}

Esse relatório, fruto da pesquisa de tese, foi estruturado em dez partes, especificadas a seguir. O presente capítulo de introdução ao problema de pesquisa, com os já referidos objetivos, relevância e recorte. 
A revisão de literatura é tratada nos três capítulos subsequentes. O capítulo 2 apresenta o campo de estudo do Conhecimento Organizacional, especialmente a perspectiva do conhecer (knowing) na prática e na ação e seus enfoques, bem como a relação do enfoque do conhecer (knowing) na prática e na ação e Método Fenomenográfico, utilizado no estudo.

O capítulo 3 trata do Valor e a classificação da literatura em três enfoques: valor do conhecimento como um número e o enfoque sobre mensuração ou depreciação do conhecimento; valor do conhecimento como um recurso ou capacidade e o enfoque sobre criação de valor estratégico e desempenho organizacional; valor do conhecimento como interpretação e significado e o enfoque sobre percepção do indivíduo.

O capítulo 4 aborda as Rotinas Organizacionais, as origens, as correntes no campo das rotinas organizacionais e a corrente das rotinas organizacionais como prática.

O capítulo 5 descreve os procedimentos metodológicos utilizados no desenvolvimento da tese, que foram divididos em quatro etapas: a pesquisa de revisão da literatura acerca da valoração do conhecimento organizacional, a escolha do método de pesquisa empírica, a descrição detalhada do método na pesquisa empírica com o Método Fenomenográfico e, finalmente, o grupo de foco com profissionais participantes da pesquisa empírica para validação interna do mapa do espaço de resultado. Nesse capítulo, a cada etapa do Método Fenomenográfico - seleção da amostra intencional, coleta de dados, tratamento de dados - foi incorporado um item que trata da experiência da pesquisadora em cada fase do método, com objetivo de traduzir a vivência de campo e a realidade da análise dos dados para os leitores e possíveis usuários da Fenomenografia.

Os resultados são tratados em dois capítulos. O capítulo 6 descreve a Análise dos Dados Emergentes do Campo, em que são apresentadas as cinco concepções acerca da valoração do conhecimento no contexto do trabalho. Também é explicitada a consolidação dos resultados do grupo de foco com a validação interna do mapa do espaço de resultado.

Já o capítulo 7 aborda Proposições Teóricas, considerando: o Método Fenomenográfico e a valoração do conhecimento no contexto do trabalho, o conhecimento valorado como uma relação individual-organizacional, os impactos 
da valoração do conhecimento nas práticas organizacionais e, por último, traz uma reflexão final quanto ao conhecimento valorado.

O capítulo 8, de Conclusão, Recomendações e Sugestões para Pesquisas Futuras, busca consolidar o trabalho empreendido e abordar as questões ou lacunas não respondidas na direção de novas pesquisas.

Por fim, os capítulos 9 e 10 trazem, respectivamente, as Referências Bibliográficas utilizadas e o Apêndice com o roteiro de entrevista semiestruturada e as perguntas pertinentes às rodadas de debate do grupo de foco. 


\section{2 \\ Conhecimento Organizacional}

O presente capítulo trata da origem da linha de estudos em conhecimento organizacional, bem como as perspectivas conceituadas na literatura e os enfoques encontrados no tema, até a abordagem utilizada no presente estudo, o enfoque do conhecer (knowing) na prática e na ação.

\subsection{Aprendizagem e Conhecimento Organizacionais: Delimitação e Inter-relação dos Campos de Estudo}

Easterby-Smith e Lyles (2003) classificaram os quatro campos de estudo interligados e complementares que se desenvolveram na área da aprendizagem e do conhecimento no contexto das organizações. Os autores partiram de duas dimensões em matriz: 1) o aspecto tratado por este campo de estudo, ou seja, processo/aprendizagem ou conteúdo/conhecimento; e 2) a forma de abordagem do aspecto, isto é, se de vertente teórica ou de intervenção prática na organização.

O primeiro campo de estudo, que despontou em fins dos anos 1950 e se disseminou a partir da década de 1970, foi o da aprendizagem organizacional, que abrange a teorização acerca dos processos de aprendizagem pelos quais se dá o conhecimento nas organizações. O trabalho seminal de March e Simon (1958) foi o primeiro a cunhar a expressão, posteriormente disseminada nos trabalhos fundamentais de Argyris e Schön (1974; 1978).

Em seguida, no final dos anos 1980, emergiu o conceito de organização de aprendizagem, entendida como sendo a instituição capaz de possuir características e arranjos estruturais e culturais capazes de viabilizar a realização, dos processos de aprendizagem. Este campo possui uma vertente eminentemente prática e foi disseminado por meio de trabalhos de consultores (como Senge, 1998) e executivos (como De Geus, 1988).

Os conceitos seminais do conhecimento organizacional foram estabelecidos em período bem anterior, com os trabalhos de Hayek (1945) e Penrose (2006; 
original de 1959), provenientes da economia, e de Ryle (1945) e Polanyi (1966), originários da filosofia. Porém, foi somente no final dos anos 1980 e principalmente nos anos 1990, que esse conceito ganhou popularidade, graças aos trabalhos de Nonaka (1994) e Nonaka e Takeuchi (1997). Entretanto, no ano de 1996, a edição especial do Strategic Management Journal, Special Issue on the Knowledge and the Firm trouxe uma contribuição definitiva para conferir autonomia ao conhecimento organizacional enquanto campo de estudos.

De acordo com a classificação de Easterby-Smith e Lyles (2003), o conhecimento organizacional é considerado o entendimento sobre a natureza do conhecimento contido nas organizações, abrangendo, assim, os aspectos de conteúdo, localização (individual e/ou coletiva), tipologias e classificações, modos de disseminação por meio de transferência ou compartilhamento, modos de alavancagem para desempenho, barreiras à sua realização, retenção e vazamento (stickiness-leakiness), capacidade de utilização e aplicação na organização (absorptive capacity), meio de aquisição (exploration-exploração por incursão em novas oportunidades de conhecimento, exploitation-exploração por utilização do conhecimento existente, ambidexterity ou uso combinado de explorationexploitation). Enfim, o conceito compreende a teoria acerca do conhecimento no contexto das organizações e dos indivíduos nas organizações.

A gestão do conhecimento foi o último campo de estudo a surgir, no final da década de 90, com o trabalho fundamental de Davenport e Prusak (1998), e com os trabalhos sobre capital intelectual e ativos intangíveis (STEWART, 1998; SVEIBY, 1998). A gestão do conhecimento pode ser compreendida como sendo o modo de intervenção prática e intencional, por parte da organização, para a geração de conteúdo de conhecimento organizacional (EASTERBY-SMITH e LYLES, 2003). O movimento ganhou legitimidade e intensa disseminação com a apropriação dos trabalhos de Nonaka a este campo de estudo e mediante a alavancagem proporcionada pelos outros campos de estudo ao longo do tempo.

A revisão de Easterby-Smith e Lyles (2003) demarca uma fronteira teóricoconceitual entre estes quatro campos, muito útil para determinados estudos. Contudo, os próprios autores argumentam que a dinâmica, a complementaridade e a sequência de surgimento dos campos de estudo, juntamente com o desenvolvimento dos conceitos interligados, não permitem a realização de delimitações tão distintas como se poderia ou se gostaria de supor. 
Em contraposição a essa demarcação, Gherardi (2006), Patriotta (2003) e Orlikowski (2002), dentre tantos outros autores que abordam a visão do conhecimento na ação, afirmam que sequer é possível pensar em separar aprendizagem e conhecimento. Trata-se de um processo único, no qual o elemento constitutivo é inseparável do elemento que o constitui, uma vez que são tecidos reflexiva (GHERARDI, 2006) e recursivamente (ORLIKOWSKI, 2002).

\subsection{Conhecimento Organizacional}

Patriotta (2003b) argumenta que o conhecimento é um fenômeno multifacetado, discutido sob uma variedade de contextos disciplinares, a saber, à luz da filosofia, sociologia, psicologia social, ciências cognitivas, economia, gestão empresarial e análise organizacional, o que dificulta a genealogia das atuais teorias do conhecimento. Por este motivo, optou-se por tratar a evolução das perspectivas e visões relacionadas ao conhecimento organizacional a partir da consolidação das revisões realizadas por um conjunto de autores, escolhidos por sua influência na construção do conhecimento enquanto uma ação na prática.

Em função das diferentes perspectivas apresentadas por estes autores em suas revisões, transparecem variadas conceituações sobre o conhecimento e o conhecimento organizacional. Ademais, a perspectiva do conhecimento na ação também evoluiu no tempo. Nos tópicos abaixo, ela será explorada mais detidamente, assim como os enfoques que a compõem.

\subsubsection{Perspectivas do Conhecimento Organizacional}

Tsoukas (1996) consolida duas perspectivas nas pesquisas em torno do conhecimento organizacional. A primeira é a perspectiva taxonômica, em que os estudos procuram classificar os diferentes tipos de conhecimento organizacional, descrevendo as implicações de cada tipo. Embora os modelos da visão taxonômica tenham trazido avanços na compreensão da natureza multifacetada do conhecimento nas organizações, eles trazem limitações no modo de pensamento formatado, inerente a qualquer tipologia que enquadre a realidade e que a considere estável e separável (TSOUKAS, 1996). 
Exemplos dessa linha seriam observados nos trabalhos de Daft e Weick (1984), onde a organização seria vista como um sistema de interpretação, em quatro modos de fazer sentido sobre a realidade; de Mitroff (1990), no qual a organização seria um sistema de produção e teste de ideias, por meio do sistema social que promove o questionamento de ideias capaz de produzir conhecimento sobre ela e seu ambiente; de Spender (1996), em sua epistemologia pluralística, buscando capturar os diferentes tipos de conhecimento que as organizações utilizam, modelados em uma matriz na qual o conhecimento pode ser mantido pelo indivíduo ou pela coletividade, em um eixo, e ser articulado de modo explícito ou manifestado de modo implícito, no outro eixo, gerando quatro tipos de conhecimento organizacional (consciente, objetivado, automático e coletivo); e de modo similar, nos trabalhos de Nonaka e Takeuchi (1997), baseados em Polanyi (1966), que concebem duas formas de conhecimento, tácito e explícito,, passíveis de ser convertidos por meio da interação social, dando origem a quatro modos de conversão do conhecimento (socialização, externalização, combinação e internalização).

O segundo grupo de estudos em matéria de conhecimento organizacional, proposto por Tsoukas (1996), procura modelar as organizações como cérebros humanos (MORGAN, 1986), onde o conhecimento é redundante e distribuído coletivamente, para que os grupos cumpram com suas tarefas, ou como mente individual (WEICK e ROBERTS, 1993). No caso de Weick e Roberts (1993), a mente individual é um estilo de ação que se localiza em atividades individuais nas quais os indivíduos se engajam, ou seja, dão ensejo a um padrão que se manifesta na ação. Do mesmo modo, a mente coletiva se manifesta na maneira como os indivíduos se inter-relacionam nas suas ações.

Assim, os indivíduos constroem suas ações (contribuem), enquanto preveem o sistema social de ações conjuntas (representam) e inter-relacionam a ação construída com o sistema previsto (subordinam). As contribuições individuais e a mente coletiva se constituem mutuamente, razão pela qual a mente coletiva é uma realização conjunta emergente, um sistema distribuído. Tsoukas (1996) argumenta, no entanto, que estes autores não conseguem explicar o modo como os indivíduos constroem suas ações ou como se forma a distribuição do caráter do sistema social. 
Gherardi (2000; 2006), por sua vez, destaca três aspectos do discurso comum nos estudos de conhecimento nas organizações, que derivam da metáfora criada pela combinação dos termos aprendizagem e organização, cunhada a partir dos anos 1970.

O primeiro aspecto desse discurso declara que o conhecimento reside na cabeça das pessoas, onde ele é apropriado, transmitido e estocado por meio de um processo mental. Este aspecto trabalha com as dicotomias mente-corpo, pensamento-ação, individual-organizacional. Nesta categoria se enquadram a Aprendizagem Organizacional, o framework cognitivo e a tradicional Teoria de Aprendizagem Cognitiva. Ele implica na existência do conhecimento a priori e independente do sujeito conhecedor, que não cria qualquer conhecimento no ato/momento de apropriação. A produção, circulação e consumo de conhecimento são vistos como atividades autônomas (GHERARDI, 2000).

Gherardi (2006) destaca, ainda, que o discurso da aprendizagem organizacional se interliga ao discurso da organização de aprendizagem, uma vez que a ocorrência do primeiro se relaciona às receitas prescritivas do segundo. Ambos os discursos compartilham do mesmo viés e contribuem para a institucionalização do campo como um discurso disciplinar (de poder, com base em Foucault) que sustenta formas de comportamento normativo, fundamenta reivindicações de conhecimento e promove recursos de normalização. Assim, este discurso exorta que a aprendizagem organizacional: busca melhorias, embora seu conteúdo já seja pré-selecionado, pois somente os detentores do poder sabem as coisas certas a serem aprendidas; é intencional, incorporado nas rotinas operacionais, sendo "a melhor forma de aprender"; resulta em extorsão, em que o poder usado para a transferência de conhecimento é silenciado, mostrando-se voluntária e transparente, sem o surgimento de qualquer conflito e negociação; e, por fim, presume mudança, mas não a sua compreensão pelos indivíduos.

Já o segundo aspecto do discurso foi construído com base nas visões da economia do conhecimento e da gestão do conhecimento. Este aspecto identifica o conhecimento como um fator de produção distinto do capital, do trabalho e da terra, que o torna "estratégico" e que, portanto, deve estar localizado na cabeça da organização, ou seja, na gestão. Por meio desta, o conhecimento determinaria o desempenho da organização. Nesta categoria, a visão baseada em recursos (RBV, de BARNEY, 1991; 1996) e a visão baseada em conhecimento (KBV, de 
GRANT, 1994; 1996; PRAHALAD e HAMEL, 1995; SPENDER, 1996) conceituam o conhecimento como capacidades ou competências centrais. O conhecimento é reificado, corporificado como um ativo que pode ser transformado em objeto a ser transferido, podendo ser intencionalmente criado, disseminado, controlado e incorporado em produtos e sistemas. O conhecimento operacional existe no âmbito tácito da organização, sendo carregado pelas rotinas. A rotinização das atividades torna-o concreto e, assim, as organizações podem "saber", independentemente dos seus membros. A transferência deste conhecimento, nesta visão, implica na sua não transformação (GHERARDI, 2000).

O terceiro aspecto do discurso apresentado por Gherardi (2000; 2006) tem sua origem na filosofia e em diversas tradições de pensamento que geraram as várias correntes do conhecimento na prática, na ação, que serão abordadas no tópico 2.2.3. Pensar a aprendizagem por meio da participação em uma prática diária implica na ocorrência da aprendizagem em pleno fluxo da experiência, seja consciente ou inconscientemente. Na vida organizacional, o trabalho, a aprendizagem, a comunicação, a inovação, a negociação, o conflito, suas interpretações e a história estão copresentes na prática. São partes da existência humana, naquele contexto situacional, histórico e social. Sujeito, objeto, conhecimento e contexto são inseparáveis.

Segundo Gherardi (2000), a prática consiste simultaneamente na produção do mundo e no resultado deste processo, ou seja, ela é produto em que condições históricas específicas resultantes de práticas passadas são transformadas em práticas presentes. Esta visão teórica baseada na prática (practice-based theorizing) contribui para compreender a prática como um sistema de atividades no qual conhecer (knowing) é inseparável de fazer. É uma atividade social, e não cognitiva. Participar na prática é o meio de adquirir conhecimento-em-ação e também de modificar e perpetuar este conhecimento, além de produzir e reproduzir a sociedade.

Essa reprodução ocorre em sistemas de atividades, tais como: prática-comotrabalho (practice-as-work), que transforma um determinado processo de trabalho; prática-como-linguagem (practice-as-language), como, por exemplo, a linguagem profissional e as interações que ocorrem em determinado processo de trabalho e que envolvem a criação de sentido e significado; e prática-como-moralidade 
(practice-as-morality), relacionada com a política e o poder dos diferentes grupos envolvidos no processo de trabalho (EHN, 1988, apud GHERARDI, 2000).

Já Orlikowski (2002) sugere três perspectivas do conhecimento. Retomando e endossando a perspectiva taxonômica de Tsoukas (1996), ela apresenta a visão dicotômica, na qual os pesquisadores desenvolvem diversas classificações para examinar as estratégias, rotinas e técnicas por meio das quais os diferentes tipos de conhecimento são criados, codificados, convertidos, transferidos e trocados. Para Orlikowski (2002), a falta de compreensão da distinção feita tanto por Ryle (1949) quanto por Polanyi (1966) entre conhecer tácito e explícito gerou novas dicotomias no ramo do conhecimento: local $\mathrm{x}$ universal, codificado $\mathrm{x}$ não codificado, canônico x não canônico, processual x declarativo e know-how x know-what.

A segunda perspectiva emerge dos pesquisadores críticos a esta visão dicotômica, em defesa de uma visão integrativa. Nela, o conhecimento organizacional é processual, disperso, inerentemente indeterminado (TSOUKAS, 1996), emergente (BROWN e DUGUID, 1998), no qual o know-how é a habilidade de colocar o know-what em prática, uma capacidade incorporada em comunidades de prática específicas (BROWN e DUGUID, 1991). A facilitação da circulação e do compartilhamento do conhecimento pelas comunidades de prática se deve aos seguintes fatores: o desenvolvimento de práticas de fronteira (WENGER, 2008), o uso de knowledge-brokers (BROWN e DUGUID, 1998) e o uso de objetos de fronteira (STAR, 1989; CARLILE, 1998; 2002; 2004).

De acordo com Orlikowski (2002), ambas as visões anteriores são reducionistas, sendo a primeira uma reificação do conhecimento de modo objetivista, como uma entidade separada, uma propriedade estática; enquanto a segunda consiste em uma redução subjetivada do processamento do conhecimento, na forma de uma disposição dos indivíduos. Sua crítica se concentra na visão de que conhecimento e prática são mutuamente constitutivos, inexistindo, assim, qualquer possibilidade de separação entre eles.

A terceira perspectiva, portanto, se concentra na cognoscibilidade (knowledgeability) da ação, ou seja, no conhecer (knowing). Intencionalmente, o verbo conhecer/knowing conota ação, fazer e prática, enquanto o substantivo conhecimento/knowledge conota coisas, elementos, fatos, processos e disposições. A perspectiva do conhecer na prática (knowing in practice) retoma a essência dos 
trabalhos de Polanyi (1966) e Ryle (1949), que incluem a habilidade prática profissional, o conhecer que está inserido na ação. Assim, o conhecimento tácito é uma forma de conhecer, inseparável da ação, pois é constituído por meio desta ação, havendo, assim, uma constituição mútua de conhecer e prática (ORLIKOWSKI, 2002). Orlikowski (2002) baseia-se na Teoria da Estruturação de Giddens (1984) e na autopoiesis de Maturana e Varela (1980). Boa parte dos estudos classificados no enfoque de workplace studies, em que se insere o próprio trabalho da Orlikowski (2002), seguiu esta mesma base teórica.

Patriotta (2003a; 2003b), por sua vez, propõe quatro perspectivas do conhecimento na organização, onde ele procura identificar e apontar a visão do conhecer (knowing) e da prática existentes em cada uma delas.

A abordagem cognitiva [racional] remonta ao trabalho de Simon (1947) sobre a racionalidade da tomada de decisão e a cognição, resultando em consequências comportamentais. Sob esta abordagem cognitiva, surgem os conceitos de mente, intencionalidade e criação de sentido. O conhecimento é um fenômeno associado à imagem do cérebro (MORGAN, 1986) e reside nas estruturas mentais sob a forma de quadros, roteiros, mapas cognitivos e esquemas interpretativos, que permitem que as organizações confiram um sentido às suas atividades e as desempenhem em meio a mudanças ambientais. Toda ação encontra-se dentro da cabeça e há uma distinção clara entre a realidade "lá fora", que precisa ser interpretada, e os processos que ocorrem "aqui dentro" da organização.

O ponto de partida é o indivíduo (e sua cognição) e se estende, em seguida, à organização, que também é vista como sendo dotada de uma mente própria que fragmenta, rotiniza e vincula o processo de tomada de decisões, de modo a tornálo manejável. Patriotta (2003a) atrela a esta perspectiva cognitiva a aprendizagem organizacional, de Argyris e Schön (1978), e também remete à cognição simbólica, que se constrói no processo de criação de sentido (sense making), de Weick (1995).

A abordagem estrutural gira em torno das características estruturais e materiais da organização, sob a forma de recursos e rotinas, e da conceituação do conhecimento como um ativo ou commodity intangível, mas que forma um corpo (de conhecimento). A exemplo da perspectiva da economia e gestão do conhecimento proposta por Gherardi $(2000 ; 2006)$, Patriotta (2003a) propõe o 
conhecimento como um fator de produção ligado ao desempenho da organização, consolidado na visão baseada em conhecimento (KBV) e visão baseada em recursos (RBV). Nestas visões, o conhecimento inclui recursos, rotinas, competências, capacidades e capital intelectual. Os autores foram omitidos, devido à longa lista de estudos e modelos produzidos, fora do escopo direto deste trabalho.

Nonaka e Takeuchi (1997) e Nelson e Winter (1982) apresentam estudos que caracterizam esta abordagem. As organizações são grandes repositórios de conhecimento, sob a forma de objetos explícitos ou tácitos, que, de qualquer modo, precisam ser explicitados e expandidos, por meio de modelos de interação social. Trata-se de uma abordagem funcionalista do conhecimento, com relação direta de causa e efeito do conhecimento-desempenho e com modelos formatados, dispondo o conhecimento em categorias estáticas (Patriotta, 2003a).

De acordo com Patriotta (2003a), a ampla maioria da literatura sobre conhecimento organizacional se enquadra nas duas perspectivas anteriores. Este aspecto pode ser confirmado na revisão de literatura recente (últimos 10 anos), realizada para o presente trabalho.

A abordagem da cognição situada distingue-se pelo foco nas práticas organizacionais, dirigindo sua atenção para a importância dos detalhes da prática (BROWN e DUGUID, 1991), a ação situada (LAVE e WENGER, 1991), os contextos formativos (UNGER, 1987 apud PATRIOTTA, 2003a; BLACKLER, 1992; CIBORRA e LANZARA, 1994) e os sistemas de atividade (ENGESTRÖM, 1987; BLACKLER, 1995). Segundo Patriotta (2003a), ela foi concebida como uma reação à abordagem cognitiva racional. A abordagem situada ofereceu uma definição pragmática do conhecimento, orientada rumo à interpretação do desempenho organizacional por meio da observação das práticas diárias no ambiente de trabalho. Suas raízes repousam na teoria sociológica da prática, de Bourdieu (1977), e na filosofia do pragmatismo, de Dewey (1938) (PATRIOTTA, 2003a), muito embora outras correntes também tenham contribuído para o sua formação, como, por exemplo, a teoria da atividade, de Vygotsky e Leontiev (GHERARDI, 2000).

De um modo geral, a cognição situada ultrapassa as dicotomias tradicionais entre pensamento-ação e individual-organizacional, reconceituando o mundo da atividade social em termos relacionais. Assim, esta perspectiva rejeita a distinção 
ontológica entre a realidade "lá fora" e as representações internas de algo a conhecer. O conhecimento é uma ação de conhecer (knowing), que é situada, distribuída e material. Além disso, a abordagem situada se concentra nas práticas de produção do conhecimento, incluindo questões de identidade, confiança (trust) e compromisso (commitment) (PATRIOTTA, 2003a). Uma visão detalhada desta perspectiva com seus autores será apresentada nos tópicos 2.2.2 e 2.2.3.

A última abordagem, a técnico-científica (LATOUR e WOOLGAR, 1979; KNORR-CETINA, 1981; LATOUR, 1987; BIJKER et al., 1989; apud PATRIOTTA, 2003), possui raízes na sociologia da ciência e em estudos sociológicos da tecnologia. Há uma rejeição da tradicional oposição entre corpo-mente e o reconhecimento da natureza socialmente construída do conhecimento. O laboratório é a metáfora que representa o foco empírico dos trabalhos desta abordagem, enfatizando os processos de produção e transformação do conhecimento. Para tanto, é preciso abrir as caixas pretas das organizações e explorar seu conteúdo, ou seja, o modo pelo qual o processo de conhecer (knowing) gera o produto acabado: conhecimento. Segundo Patriotta (2003a), esta abordagem coloca-se como um braço da sociologia do conhecimento, de Berger e Luckmann (1978), construtivista social. Adotando a postura de uma sociologia da ciência e tecnologia, estuda o trabalho de cientistas, inventores e engenheiros na produção de conhecimento, assim como as organizações por eles integradas.

Patriotta (2003a) destaca o caráter provisório, contestado e controverso do conhecimento [científico] nesta perspectiva e, ainda, a questão do discurso científico (e sua semiótica). A abordagem técnico-científica rejeita a separação entre ciência e tecnologia, e as dicotomias entre sujeito-objeto, mente-corpo, natureza-ciência, tecnologia-sociedade, interno-externo. Os autores que abordam o tema sob essa ótica tomam uma visão holística e sistêmica para o conhecer (knowing), com base em sistemas e redes de interações, associações e traduções. Os trabalhos seminais de Callon $(1980 ; 1991)$, a teoria ator-rede (actor-network theory), de Latour (1999), e os estudos de Law e Hassard (1999), caracterizam esta abordagem. 


\begin{tabular}{|c|c|c|c|c|}
\hline Autor & Perspectivas & $\begin{array}{l}\text { Visão acerca do } \\
\text { Conhecimento }\end{array}$ & Modelos & Metáforas \\
\hline \multirow[t]{2}{*}{$\begin{array}{l}\text { Tsoukas } \\
(1996)\end{array}$} & Taxonômica & $\begin{array}{l}\text { Realidade objetivada, } \\
\text { estável. } \\
\text { Conhecimento objeto, } \\
\text { manipulável e } \\
\text { transferível. }\end{array}$ & $\begin{array}{l}\text { Daft e Weick (1984) } \\
\text { Mitroff (1990) } \\
\text { Spender (1996) } \\
\text { Nonaka e Takeuchi (1997) }\end{array}$ & - \\
\hline & $\begin{array}{l}\text { Distribuído na } \\
\text { ação }\end{array}$ & $\begin{array}{l}\text { Realidade social, fluida. } \\
\text { Conhecimento na ação, } \\
\text { compartilhado, } \\
\text { emergente. }\end{array}$ & $\begin{array}{l}\text { Morgan (1986) } \\
\text { Weick e Roberts (1993) }\end{array}$ & $\begin{array}{l}\text { Cérebro } \\
\text { Mente }\end{array}$ \\
\hline \multirow[t]{3}{*}{$\begin{array}{l}\text { Gherardi } \\
(2000 ; \\
2006)\end{array}$} & Cognitiva & $\begin{array}{l}\text { Conhecimento objeto, } \\
\text { existente } \text { a priori, } \\
\text { independentemente do } \\
\text { conhecedor. }\end{array}$ & $\begin{array}{l}\text { Aprendizagem } \\
\text { organizacional } \\
\text { Modelo cognitivo } \\
\text { Teoria da aprendizagem } \\
\text { cognitiva } \\
\end{array}$ & Mente/Cabeça \\
\hline & Econômica & $\begin{array}{l}\text { Conhecimento como } \\
\text { fator de produção, } \\
\text { reificado nas rotinas, na } \\
\text { forma de capacidades. }\end{array}$ & $\begin{array}{l}\text { Gestão do conhecimento e } \\
\text { Economia do } \\
\text { conhecimento } \\
\text { Escolas RBV e KBV } \\
\text { Davenport e Prusak } \\
(1998) \\
\end{array}$ & Recurso/Objeto \\
\hline & $\begin{array}{l}\text { Conhecer na } \\
\text { Prática }\end{array}$ & $\begin{array}{l}\text { Conhecimento e contexto } \\
\text { são inseparáveis. }\end{array}$ & Practice-based theorizing & Contexto/Prática \\
\hline \multirow[t]{3}{*}{$\begin{array}{l}\text { Orlikowski } \\
(2002)\end{array}$} & $\begin{array}{l}\text { Dicotômica/ } \\
\text { Taxonômica }\end{array}$ & $\begin{array}{l}\text { Reificação objetivista: } \\
\text { uma entidade separada, } \\
\text { estática. }\end{array}$ & \begin{tabular}{|l} 
Nelson e Winter (1982) \\
Leonard-Barton (1992) \\
Nonaka (1994) \\
Nonaka e Takeuchi (1997) \\
\end{tabular} & Uma coisa \\
\hline & Integrativa & Redução subjetivista. & $\begin{array}{l}\text { Brown e Duguid (1998) } \\
\text { Wenger (2008, original } \\
\text { 1998) } \\
\text { Carlile (1998) }\end{array}$ & $\begin{array}{l}\text { Uma disposição } \\
\text { (individual ou } \\
\text { coletiva) }\end{array}$ \\
\hline & \begin{tabular}{|l|} 
Conhecer na \\
ação (knowing \\
in practice)
\end{tabular} & $\begin{array}{l}\text { Conhecer e prática são } \\
\text { inseparáveis. }\end{array}$ & $\begin{array}{l}\text { Lave (1988) } \\
\text { Spender (1996b) } \\
\text { Cook e Yanow (1996) } \\
\text { Weick e Roberts (1993) }\end{array}$ & Uma ação \\
\hline \multirow{4}{*}{$\begin{array}{l}\text { Patriotta } \\
(2003 \mathrm{a} \\
2003 \mathrm{~b})\end{array}$} & $\begin{array}{l}\text { Cognitiva } \\
\text { [racional] }\end{array}$ & $\begin{array}{l}\text { Conhecimento como } \\
\text { representação. }\end{array}$ & $\begin{array}{l}\text { Argyris e Schön (1978) } \\
\text { Weick (1995) }\end{array}$ & Cérebro \\
\hline & Estrutural & $\begin{array}{l}\text { Conhecimento como } \\
\text { objeto comoditizado. }\end{array}$ & $\begin{array}{l}\text { RBV } \\
\text { KBV } \\
\text { Nelson e Winter (1982) } \\
\text { Nonaka e Takeuchi (1997) }\end{array}$ & $\begin{array}{l}\text { Corpo (de } \\
\text { conhecimento), } \\
\text { Ativo econômice }\end{array}$ \\
\hline & $\begin{array}{l}\text { Cognição } \\
\text { Situada }\end{array}$ & $\begin{array}{l}\text { Conhecimento como } \\
\text { prática organizacional, } \\
\text { visão pragmática do } \\
\text { conhecimento. }\end{array}$ & $\begin{array}{l}\text { Engeström (1987) } \\
\text { Unger (1987) } \\
\text { Brown e Duguid (1991) } \\
\text { Lave e Wenger (1991) } \\
\text { Blackler, (1992; 1995) } \\
\text { Ciborra e Lanzara (1994) } \\
\end{array}$ & Prática \\
\hline & $\begin{array}{l}\text { Técnico- } \\
\text { científica }\end{array}$ & $\begin{array}{l}\text { Conhecimento como } \\
\text { heterogêneo, provisório, } \\
\text { contestado e controverso. }\end{array}$ & $\begin{array}{l}\text { Latour e Woolgar (1979) } \\
\text { Callon (1980; 1991) } \\
\text { Knorr-Cetina (1981) } \\
\text { Latour (1987) } \\
\text { Bijker et al. (1989) }\end{array}$ & Laboratório \\
\hline
\end{tabular}

Quadro 1: Perspectivas do Conhecimento Organizacional (elaborado pela autora com base em TSOUKAS, 1996; GHERARDI, 2000; 2006; ORLIKOWSKI, 2002; PATRIOTTA, 2003a; 2003b). 
As classificações apresentadas pelos autores implicam na evolução conceitual e teórica da visão acerca do conhecimento nas organizações. Elas foram consolidadas no Quadro 1, anterior. Pode-se perceber que, a partir de uma visão dual e antagônica inicial, proposta por Tsoukas (1996), as perspectivas do conhecimento organizacional ganharam abordagens mais dotadas de nuances e especificidades em Gherardi (2000; 2006) e Orlikowski (2002), até um resgate do conhecer (knowing) na prática nas diversas correntes, em Patriotta (2003a; 2003b).

Em comum, todos os autores encontraram uma forte corrente de estudos que tende a objetivar e reduzir o conhecimento, tornando-o um meio (recurso) para que a organização atinja o desempenho desejado, estático, estável, rotinizado, reproduzível, estocável e manejável, em uma visão instrumental-funcionalista. Esta corrente comporta os movimentos da aprendizagem organizacional (GHERARDI, 2000), gestão do conhecimento (GHERARDI, 2000; ORLIKOWSKI, 2002; TSOUKAS, 1996), assim como as visões da estratégia baseada em recursos e em conhecimento (GHERARDI, 2000; PATRIOTTA, 2003a).

Entretanto, a visão do conhecer (knowing) na ação e na prática não encontra a mesma unanimidade entre os autores, fato este já identificado por Gherardi (2006). Orlikowski (2002) insere em uma abordagem integrativa, ainda reducionista, estudos que Gherardi $(2000 ; 2006)$ considera como a abordagem do conhecimento na prática e Patriotta (2003a) classifica como da cognição situada. De fato, identificou-se que as diferentes correntes e origens teóricas que originaram a perspectiva do conhecer na ação produziram uma diversidade de enfoques que não são excludentes entre si, mas consistem, isso sim, em diferentes aproximações do mesmo objeto de estudo ou fenômeno: o conhecer em fluxo, constituído e reconstituído nas interações e práticas sociais, imerso na ação e na prática do trabalho, e, portanto, contextualizado e compartilhado pelos membros, sendo, por isso mesmo, sempre provisório e em transformação. Em comum entre os enfoques, Gherardi (2006) e Patriotta (2003) apontam a ideia central da prática.

O tópico seguinte apresenta a perspectiva do conhecer na prática e na ação, enquanto o tópico 2.2.3 detalha os diferentes enfoques existentes sob esta perspectiva. 


\subsection{Perspectiva do Conhecer (Knowing) na Prática e na Ação}

O presente estudo busca investigar os diferentes modos pelos quais os membros organizacionais percebem e experimentam a valoração do conhecimento no contexto do trabalho. Investiga, também, como objetivo secundário, os impactos na incorporação, utilização e compartilhamento do conhecimento pelos membros e pela própria organização na ação, no conhecer (knowing) organizacional, em decorrência das percepções e significações atribuídas.

Deste modo, utilizou-se a perspectiva do conhecer (knowing) na prática e na ação, cujas noções são conceituadas a seguir. Cabe ressaltar que o conceito de prática remonta aos trabalhos de Ryle (1949) e de Polanyi (1966), responsáveis pela articulação da relação entre o knowing how e knowing that (RYLE, 1949) e conhecer tácito e explícito (POLANYI, 1966). A capacidade ou ação habilidosa de "conhecer como" fazer algo encontra-se inseparável da prática que o faz, ou seja, conhecer e prática são mutuamente constitutivos (ORLIKOWSKI, 2002).

Blackler (1995) enfatiza que, ao concentrar-se no conhecer (knowing), e não no conhecimento, a distinção convencional entre conhecimento e aprendizagem desaparece, assim como a dicotomia processo-resultado. Segundo Gherardi e Nicolini (2000), esta perspectiva do conhecer na prática e na ação abandona o pressuposto de que o conhecimento seja um processo precipuamente individual, mental e cognitivo, para adotar o conhecer (knowing) como um fenômeno social e cultural, situado no contexto histórico, sócio-material e cultural em que ele ocorre.

O conhecer (knowing) encontra-se distribuído e situado em um sistema de práticas contínuas (LAVE e WENGER, 1991; ORLIKOWSKI, 2002; TSOUKAS, 1996; WENGER, 2008). É desempenhado na ação de realizar qualquer atividade (ORLIKOWSKI, 2002). É emergente e indutivo, sendo, portanto, indeterminado (ORLIKOWSKI, 2002; TSOUKAS, 1996).

Está sempre enraizado no contexto da interação e é adquirido por meio de alguma forma de participação na comunidade de prática (BROWN e DUGUID, 1991; LAVE e WENGER, 1991; WENGER, 2008). A comunidade de prática pode ser concebida como: a organização (ANAND et al., 2007; JACOBS e COGHLAND, 2005), a rede de subsidiárias (AGTERBERG et al., 2010; HARMAN, 2012), o departamento (NAG et al., 2007) ou o grupo profissional (HSIAO et al. 2006), a equipe de projeto (SOLE e EDMONDSON, 2002), a 
aliança e/ou arranjo em rede interorganizacional (INKPEN, 2008; MULLERSEITZ e GÜTTER, 2012), a rede de comunidades (GHERARDI e NICOLINI, 2002; HILBERT e HUXHAM, 2011) ou rede de práticas (HEIZMANN, 2011; VAAST, 2007).

A perspectiva do conhecer (knowing) na prática e na ação necessita de artefatos e práticas de fronteira para que a interação ocorra e o conhecimento circule (WENGER, 2000; 2008; CARLILE, 2002; 2004). Portanto, são objeto de investigação as fronteiras (CARLILE, 2004; SCARBROUGH et al., 2004), os processos (HARGADON, 2002; HSIAO et al., 2011; MAJCHRZAK et al., 2012; OBORN e DAWSON, 2010), os artefatos (CARLILE, 2002; HSIAO et al., 2011; OBORN e DAWSON, 2010; STURDY e WRIGHT, 2011; SWAN et al., 2007; TSOUKAS, 2009) e a produção de conhecimento de fronteira (CARLILE, 2004; SCARBROUGH et al., 2004; TAGLIAVENTI e MATTARELLI, 2006), que delimitam, expandem ou atravessam a organização em suas comunidades que praticam a ação de trabalhar.

Também presume que o conhecer (knowing) seja relacional e mediado por artefatos, tais como: a linguagem, a tecnologia, os objetos, as pessoas e o dinheiro (CALLON, 1980; 1991; LATOUR, 1999; 2012; LAW, 1992; 1999; LAW e HASSARD, 1999). É continuamente reproduzido e negociado, sendo, portanto, sempre dinâmico e provisório. Como é passível de legitimação para tornar-se durável e temporária e provisoriamente, permanente, é também composto por conflito, tensão e poder, sendo contestável (LATOUR, 1999; 2005; LAW, 1992; 1999; LAW e HASSARD, 1999).

A perspectiva do conhecer (knowing) na prática e na ação pode ser denominada de practice-based theorizing (GHERARDI, 2000; 2006). Patriotta (2003a; 2003b) salienta que, apesar da diversidade dos enfoques inseridos nesta perspectiva, que serão explorados no próximo tópico, eles são complementares, jamais excludentes. Em seus trabalhos, o autor prefere não se enquadrar em qualquer enfoque em particular, pois isto restringiria a própria visão do conhecer na prática e na ação. 


\subsubsection{Enfoques na Perspectiva do Conhecer (Knowing) na Prática e da Ação}

Os diferentes enfoques ou correntes que tratam do conhecer na prática e na ação de realizar alguma atividade serão discutidos nos tópicos a seguir. Procurouse apresentar as origens teóricas de cada enfoque, assim como os trabalhos, modelos ou estudos dos principais autores seminais destes enfoques, de modo a definir os conceitos fundamentais sobre a forma como se processa o conhecer na prática e seus elementos constitutivos, de acordo com cada visão.

É importante reiterar que os diferentes enfoques aqui apresentados, conforme já esclarecido, não são excludentes entre si. Trata-se de diferentes aproximações do mesmo objeto de estudo ou fenômeno: o conhecer na prática, na ação. Em conjunto, compõem a visão do conhecer que ocorre em fluxo, constituído e reconstituído nas interações e práticas sociais, imerso na ação e na prática do trabalho, sendo, portanto, situado, contextualizado e compartilhado pelos membros e, por isso, sempre provisório, contestável e em transformação. Os membros, por sua vez, estão envolvidos em processos de negociação, conflito, poder, transformação, tradução, que envolvem questões de construção de identidade e ontológicas, já que conhecer é inseparável de ser ou tornar-se.

\subsubsection{Teoria da Atividade (Activity Theory)}

Remontando, em sua origem, aos trabalhos da escola de psicologia social russa, de Vygosky (década de 1920) e Leontiev (década de 1930), este enfoque do conhecer na prática enfatiza a natureza histórica, mediada e transformacional dos esforços colaborativos (GHERARDI, 2006). Segundo Blackler (1995), o trabalho de Lave e Wenger (1991) assume uma forma da teoria da atividade concentrada nos processos por meio dos quais as pessoas desenvolvem concepções compartilhadas de suas atividades, desenhando um modelo de aprendizagem como socialização. Já Engeström (1987; 1993, apud BLACKLER et al. 2000) apresenta um modelo das relações existentes entre as concepções de uma comunidade acerca de suas atividades e os recursos materiais, mentais, culturais e sociais empregados no desempenho dessas concepções de atividades.

Segundo Blacker (1995), baseado em Engeström (1987), um sistema de atividade é um sistema de produção de perturbação, constituído por incoerências, 
inconsistências, paradoxos, conflitos e tensões. Esse sistema dinâmico é composto pelas relações entre os agentes, as comunidades por esses integradas e as concepções dos indivíduos acerca de suas atividades (triângulo central da Figura 1). Estas relações são mediadas por uma série de fatores, tais como: a linguagem e a tecnologia, utilizadas pelos participantes dentro do sistema; as regras sociais implícitas e explícitas, que os mantêm conectados à comunidade mais ampla; e o sistema de papéis e divisão do trabalho, adotado pela comunidade. A Figura 1 apresenta o modelo geral de análise, proposto pelo autor.

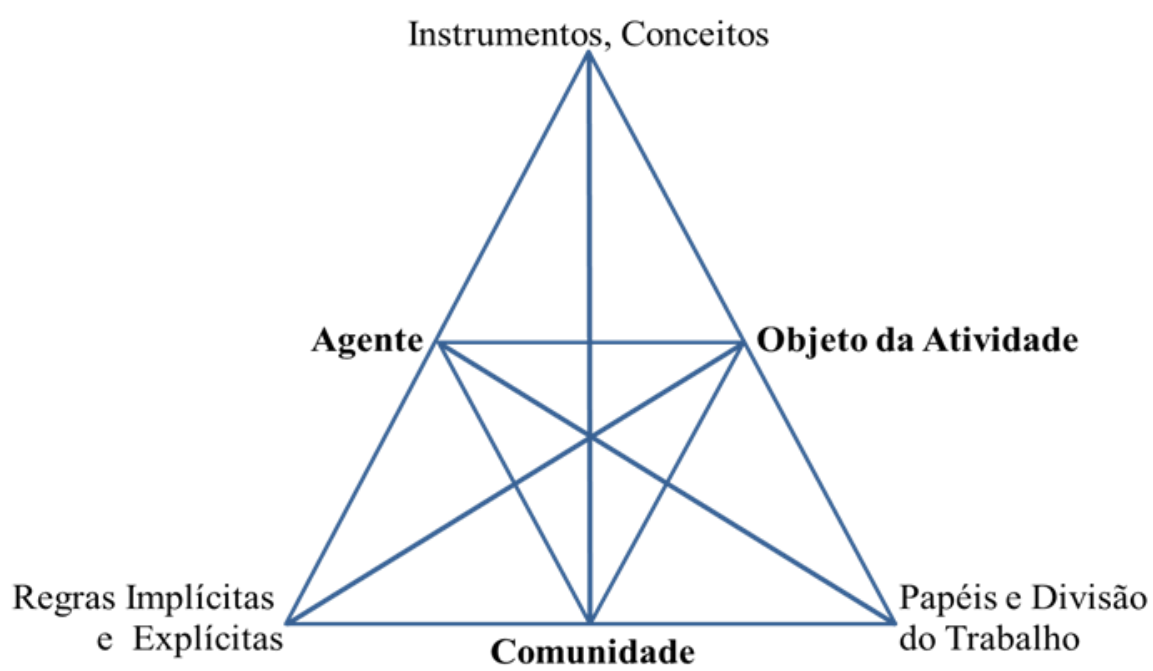

Figura 1: Modelo Geral do Sistema de Atividade Socialmente Distribuído (BLACKLER 1995, baseado em ENGESTRÖM,1987).

Neste enfoque, a prática está posicionada no centro do que o indivíduo conhece (TELL, 2004). Na atividade, se acham inseridos os modos de conhecer (knowing) e fazer (doing), que podem emergir se a comunidade repensar estas tensões em um novo contexto. À medida que os indivíduos transformam as situações, eles modificam suas atividades e, simultaneamente, a si mesmos (BLACKLER, 1995; BLACKLER et al., 2000). De acordo com Gherardi (2006), a característica mais fundamental deste enfoque da prática consiste na noção do objeto de trabalho parcialmente dado e parcialmente emergente, o que revela a natureza tentativa do conhecer (knowing) e desempenhar (acting). 


\subsubsection{Enfoques Cultural e Estético}

A cultura, interpretada como uma ação vivida na organização, mantém coletivamente os significados incorporados nas práticas em um dado contexto específico. $\mathrm{O}$ enfoque interpretativo cultural enfatiza: a coletividade; os seus atos situados em um dado contexto, incluindo as interações; os objetos que são enfocados por estes atos; a linguagem usada nestes atos; os significados específicos destes vários artefatos para os atores na situação; e o campo ou o conjunto de métodos interpretativos desenhados para acessar e analisar este contexto (YANOW, 2000).

Assim, para Gherardi (2006), o enfoque cultural revela o quão dependente se mostra o desempenhar do trabalho do processo social, tanto para sua existência quanto para sua comunicação e produção (COOK e YANOW, 1993; YANOW, 2000). Neste processo, Cook e Yanow (1993) e Yanow (2000) desenvolvem o conceito de maestria, em que a prática é o conhecimento que se reproduz - como aquele que se dá entre mestre e aprendiz - no próprio ato de trabalhar. Além disso, demonstra a forma como os artefatos e interações sustentam ambos os significados e conhecer na prática, sem se concentrar em qualquer averiguação sobre se o ator pensa ou acredita ou age de acordo com alguma ideia específica ou um conjunto de valores e predisposições. Trata-se de uma compreensão cultural e simbólica da organização, da coletividade - de como as coisas se processam naquele lugar.

Esse último ponto, segundo Gherardi (2006), é o alicerce do enfoque do conhecimento estético. Este enfoque baseia-se em Strati (1992; 2003; 2007). Nele, o conhecimento estético é a forma de conhecimento que os indivíduos adquirem ao ativar capacidades específicas de suas faculdades de percepção sensorial, para realizarem um julgamento estético no cotidiano da vida organizacional. A dimensão estética nas organizações não reside apenas no julgamento estético sobre o que é feio, bonito, grotesco ou kitsch, mas principalmente naquilo que os cinco sentidos dão a conhecer (STRATI, 2003). Trata-se de uma avaliação sobre perfeição e imperfeição percebidas por meio de sentimentos e sensações, e não de conceitos e definições, o que se aproxima do conceito de conhecimento tácito e inexprimível de Polanyi (1966). O conhecimento que a estética oferece se baseia em processos contínuos de construção, desconstrução e reconstrução simbólica. A 
contribuição deste enfoque estético se concentra na ideia de compreensão estética (STRATI, 1992; 2007), que ultrapassa a dicotomia mente-corpo, ao introduzir as sensações como forma de conhecer não cognitivo.

Por meio da estética, Gherardi (2009) procurou ampliar a compreensão do modo como a prática é socialmente sustentada, aprendida e constantemente refinada, por abranger muito mais que um conjunto de atividades. Para tanto, a autora incorpora, como base, o enfoque da actor-network theory para fundamentar o enfoque estético. Ela argumenta que a prática, além do julgamento instrumental e ético, envolve gosto e avaliação, que passa por uma rede de objetos, símbolos, avaliações, pessoas, identidades, finalidades, dentre outras categorias.

Gosto é um sentido do que é esteticamente adequado dentro de uma comunidade de praticantes, uma preferência no modo como as coisas são realizadas em conjunto. O gosto é, portanto, baseado no envolvimento subjetivo com o objeto de prática, sendo ensinado e aprendido como parte do processo de engajamento de um praticante àquele grupo, desempenhado coletivamente, e situado na atividade dentro da prática. A elaboração e refinamento do gosto dentro de uma comunidade envolvem três processos: compartilhamento de vocabulário de avaliação, elaboração de identidades dentro das comunidades e refinamento dos desempenhos (GHERARDI, 2009).

\subsubsection{Enfoque dos Contextos Formativos}

O conceito de contextos formativos foi proposto por Ciborra e Lanzara (1994), com base em Unger (1987, apud PATRIOTTA, 2003a). Os autores identificam, mediante o estudo do conhecimento na prática que apoia a ação humana, que ele se estrutura em dois níveis: as rotinas de trabalho que carregam o cotidiano nas organizações e que se utilizam dos estoques de conhecimento incorporados e taken for granted, e o contexto formativo, relacionado ao conhecimento tácito em uma dimensão não declarada, dentro do qual as rotinas são formadas e recebem seu significado e escopo em uma situação de ação.

Os autores definem o contexto formativo como sendo o conjunto preexistente de arranjos institucionais, quadros cognitivos e imaginários que os atores trazem e desempenham rotineiramente em uma situação de ação. Ele possui uma dimensão organizacional e uma dimensão cognitiva, e constitui a condição 
por trás da ação, reforçando barreiras, dando direção e significado, e estabelecendo as possibilidades de ações a serem tomadas. Assim, o contexto formativo dirige a atenção aos fundamentos cognitivos, sociais e materiais do contexto que confere suporte à ação.

Quando desempenhado na ação, o contexto formativo é expressão da cognição social que ultrapassa o individual: a cognição que está incorporada nos artefatos materiais e simbólicos, procedimentos e estruturas organizacionais, ambientes institucionais e, especialmente, nos relacionamentos, nas ligações das ações e suas ferramentas. O resultado do contexto formativo no ambiente de trabalho é a textura das rotinas, papéis e funções que parecem "naturais" (hierarquia, divisão do trabalho, mecanismos de coordenação, poder, esquemas mentais de decisão) para aqueles que executam diariamente as rotinas naquele contexto (CIBORRA e LANZARA, 1994).

O estudo de Ciborra e Lanzara (1994) mostra a forma como o contexto formativo molda o trabalho, determina a aprendizagem e o conhecer na ação, e explica os processos de resistência à mudança e às práticas emergentes no trabalho.

\subsubsection{Teoria da Aprendizagem Situada (Situated Learning Theory $S L T)$}

O enfoque da aprendizagem situada possui suas raízes na sociologia da prática social, de Bourdieu (1977), e na filosofia do pragmatismo americano, de Dewey (1938), muito embora tenha sofrido diversas outras influências teóricas (PATRIOTTA, 2003). Wenger (2008) menciona a teoria da estruturação social de Giddens (1984); as teorias da experiência situada com base na filosofia fenomenológica de Heidegger (1927, apud WENGER, 2008), na abordagem ecológica de Maturana e Varela (1980) e Winograd e Flores (1986); na sociologia do interacionismo simbólico; e nas teorias de identidade de Giddens (2002).

A principal vertente no enfoque da aprendizagem situada encontra-se no conceito de comunidades de prática, introduzido por Lave e Wenger (1991), Brown e Duguid (1991) e Wenger (2000; 2008). Estes autores desenvolveram um modo elaborado de falar sobre aprendizagem e conhecer, baseado na prática na organização (ou comunidade de comunidades, como diriam Brown e Duguid, 
1991). Este conceito de comunidade de prática define um sujeito coletivo, um tipo especial de comunidade estabelecida por um empreendimento conjunto, engajamento mútuo, com um repertório compartilhado de ações, estilos, artefatos, conceitos, discursos, estórias (GHERARDI, 2006).

Assim, aprendizagem e conhecer (knowing) são atividades sociais que ocorrem por meio de participação nesta comunidade que pratica compartilhadamente de um empreendimento (atividade ou trabalho). O conhecer, segundo os autores, é uma questão de participação nos empreendimentos, isto é, o engajamento ativo no mundo. O trabalho, por sua vez, é concebido como uma prática, que implica no pensamento, na ação, e na solução de um problema inserido no seu contexto (DEWEY, 1938). A etnografia de Orr (1996) acerca dos técnicos discorrendo sobre máquinas defeituosas inspirou Brown e Duguid (1991) e ilustrou como o conhecer na ação de trabalhar, não canônico, é muito mais rico e complexo do que se poderia supor a partir dos manuais e documentações das empresas.

Para que o processo de conhecer ocorra, a teoria da aprendizagem social de Lave e Wenger (1991) e Wenger (2008) introduz os componentes de:

- significado, ou o modo de falar sobre as habilidades mutantes para experimentar o mundo como algo significativo;

- prática, como o modo de compartilhar recursos, modelos e perspectivas sociais e históricas que sustentam o engajamento mútuo na ação;

- identidade, ou o meio de falar sobre como a aprendizagem modifica o indivíduo e cria histórias pessoais de tornar-se, no contexto da comunidade.

A comunidade, por fim, é o componente de configuração social, na qual o empreendimento é definido como valioso a ser seguido e a participação é reconhecida como competência.

Cabe fazer uma ressalva ao trabalho de Boland e Tenkasi (1995), que procura redefinir as comunidades de prática em communities of knowing, dadas as múltiplas comunidades existentes na organização intensiva em conhecimento (ALVESSON, 2001). Os autores destacam a relevância dos processos de comunicação e da linguagem que, de acordo com sua proposta, geram o conhecer (knowing). Eles procedem a uma distinção entre conhecimento intracomunidade e intercomunidade, em termos de processos de perspective making, ou seja, a 
comunicação que fortalece o conhecimento único da comunidade, e perspective taking, a comunicação que aprimora a habilidade comunicacional de levar em conta o conhecimento dos demais membros e comunidades.

O modelo proposto por Wenger $(2000 ; 2008)$ reforça que, na estruturação de um sistema de aprendizagem social, alguns componentes devem ser considerados em três dimensões distintas:

1. Na dimensão da comunidade de prática, a competência é definida pela combinação de sentido de empreendimento comum, relações de mutualidade do capital social e repertório compartilhado de autoconsciência como comunidade. Os elementos que a estruturam são os eventos que agregam os membros da comunidade, a liderança, a conectividade, a associação, os projetos de aprendizagem e os artefatos produzidos.

2. No âmbito das fronteiras, que funcionam como uma oportunidade ou barreira à aprendizagem, os processos de construção de pontes estão relacionados com coordenação, transparência e negociação. Os elementos que podem promover coesão são os indivíduos ou knowledge brokers; os objetos de fronteira, como artefatos, discursos e processos; e as interações de fronteira, por meio de encontros de fronteira, práticas de fronteira e periferia (no atendimento à comunidade não membro).

Star (1989) define objetos de fronteira como sendo aqueles que compartilham ou são compartilháveis por meio de diferentes soluções para problemas e que trabalham para estabelecer um contexto comum, sendo classificados em quatro tipos: repositórios, formas e métodos, modelos, mapas. Carlile $(2002 ; 2004)$ estudou as fronteiras e objetos de fronteira, classificando os tipos de conhecimento de fronteira e as categorias de objetos de integração: sintáticos (integrados por repositórios, taxonomias), semânticos (integrados por formas e métodos) e pragmáticos (integrados por objetos, modelos e mapas).

A abordagem pragmática da fronteira presume que as condições de diferença, dependência e novidade estejam presentes no processo de transformação do conhecimento existente, de modo a validar e integrar o novo conhecimento em cada função e coletividade por meio da organização. Ela ajuda a explicar a razão pela qual o conhecimento constitui tanto uma barreira como uma fonte de inovação, já que os objetos de fronteira estabelecem a infraestrutura ou 
processo onde o conhecimento pode ser representado, aprendido e transformado (CARLILE, 2002).

3. A dimensão das identidades é crucial para o sistema de aprendizagem social, pois ela conjuga competência e experiência no conhecer (knowing); ao lidar com as fronteiras, a habilidade de engajar ou suspender a identidade se reflete no resultado de aprender e se transformar; e as identidades são as veias que tornam a comunidade real. Os atributos da identidade social são a conectividade das relações sociais, a expansividade por meio da multiassociação e a efetividade da participação. Os elementos que auxiliam no alcance destas qualidades da identidade são os seguintes: a base onde ela está engajada; as trajetórias, ao longo das quais ela se estende no tempo; a associação, ao longo da qual ela se estende no espaço; e os fractais, por onde ela se estende através dos níveis.

Elkjaer (2003) reitera que a teoria da aprendizagem social torna inseparável o conhecer (knowing) do ser (being) e tornar-se (becoming). O pragmatismo americano e, em especial, a noção de Dewey do questionamento, reflexão e experiência, contribuem para explicar as razões para a impossibilidade de separação entre as dimensões ontológica e epistemológica da aprendizagem. Segundo Dewey (1938), o conhecimento se refere diretamente à experiência humana, enquanto que a origem do conhecimento é a experiência vivida. Não que o pragmatismo rejeite a cognição, mas nele, ideias, teorias e conceitos, ou seja, diferentes formas de cognição e pensamento abstrato funcionam como instrumentos para a ação. O conhecer começa com o questionamento baseado nas experiências de vida, em que, a partir da comparação com outras experiências, os indivíduos fazem avaliações e encontram respostas. Desta forma, os indivíduos ganham experiência como resultado do modo como vivem suas vidas e de como se associam com outras pessoas, e isto depende diretamente de como eles são enquanto indivíduos (ELKJAER, 2003).

De acordo com Elkjaer (2003), a teoria da aprendizagem social se beneficia da visão do pragmatismo de Dewey (1938) em três dimensões distintas. Quanto ao conteúdo da teoria, o foco não se baseia apenas na formação de identidade e na transformação em um praticante no ato de trabalhar, mas também no 
desenvolvimento da experiência humana e no conhecer sobre o mundo e tornar-se parte dele. Quanto ao método de conhecer, que toma por base a participação e a interação na prática diária, o pragmatismo insere o pensamento na ação e a reflexão necessária para a aprendizagem. Quanto à relação entre indivíduos e organização, mais do que um entrelaçamento, trata-se de domínios inseparáveis. O pragmatismo sugere ultrapassar a visão dos contextos individual e organizacional produzidos historicamente para adotar a visão do conhecer humano como parte integrante da própria condição humana, cujos resultados são o indivíduo e o contexto.

Patriotta (2003) enfatiza a importância do enfoque situacional, uma vez que o conhecimento incorporado na prática só pode ser recuperado pelos atores organizacionais em suas ações e negociações diárias; a situação torna-se o nível mais apropriado de análise organizacional, pois as ações dos indivíduos são sempre formatadas, de algum modo, pela situação; o conhecimento, por sua vez, é situado no sentido de ser altamente contingente, mediante a interação entre pessoas, recursos e rotinas presentes em uma dada situação.

Por outro lado, é importante ressaltar que o enfoque da aprendizagem situada é alvo de críticas quanto à forma de tratamento das relações de poder, política, negociação e legitimação. Contu e Willmott (2000) chamam a atenção para aspectos que foram abordados no trabalho original de Lave e Wenger (1991) - tais como as relações de hegemonia sobre pensamento e recursos, e alienação da completa participação na aprendizagem, que influenciam a legitimação dos grupos periféricos da organização, assim como os conhecimentos produzidos -, e que se tornaram temas esquecidos e desaparecidos na visão de comunidade de prática de Wenger (2000, 2008).

Segundo Contu e Willmott (2000), trata-se do enfraquecimento, esquecimento e abandono de aspectos-chave radicais que foram os mais relevantes para a formulação inicial da aprendizagem situada de Lave e Wenger (1991). A visão da participação em uma comunidade analítica, engajada em práticas, que procura alcançar uma compreensão mútua com propósito de emancipação, considerando as questões de hegemonia, alienação e imobilidade (LAVE e WENGER,1991), se desloca para a participação em uma comunidade prioritariamente preocupada com melhorias de predição e controle, com o propósito de incremento de desempenho (WENGER, 2000; 2008). A releitura da etnografia 
de Orr (1996), feita por Contu e Willmott (2003), revela a preocupação em especificar tecnologias de aprendizagem que venham a facilitar uma aparente visão consensual de progresso nos processos de aprendizagem para cumprimento de objetivos corporativos, ignorando que as práticas de aprendizagem são possibilitadas e constrangidas nas relações de poder existentes e institucionalizadas nas organizações (CONTU e WILLMOTT, 2003).

O desaparecimento dos aspectos críticos na SLT trouxe como consequência a subexploração dos temas de poder, política, controle, legitimação, negociação, conflito, dentre outros, no enfoque da aprendizagem situada. Estas questões foram recuperadas posteriormente, após as críticas de Contu e Willmott (2000; 2003) em estudos empíricos (ANAND et al., 2007; HEIZMANN, 2011) e revisitas teóricas ao tema.

\subsubsection{Teoria do Ator-Rede (Actor-Network Theory ANT), Sociologia da Tradução ou Sociologia da Associação}

A teoria do ator-rede (ANT) direciona-se para o desenvolvimento de uma epistemologia da ação, pois o conhecimento em criação é visto como um processo baseado na ação que se desdobra de forma controversa (PATRIOTTA, 2003a). Para a ANT, a questão fundamental reside no fechamento epistemológico, ou seja, no processo pelo qual o conhecimento é socialmente legitimado e torna-se durável, ainda que provisoriamente. Na busca pelo conhecimento, a teoria aborda as questões sobre a forma como as controvérsias são estabelecidas, como os processos e fluxos são transformados em coisas, e como os artefatos são traduzidos em fatos.

Law e Hassard (1999) explicam que o oximoro intencional actornetwork/ator-rede combina e suprime a distinção entre agente e estrutura. Nas palavras de Callon (1991, p. 142), “para um ator, também é a rede”. Neste enfoque, é central a noção de tradução, que captura a tensão existente entre sujeito e objeto, estrutura e agência, ator e sistema, diferença e identidade, ordem e desordem. Esta visão distingue-se pelo enfoque do knowledge making (traduzido doravante como conhecimento em criação) relacionado à controvérsia, 'deslocalização', movimento e tensão. 
Callon (1980) desenvolveu o trabalho que deu origem ao enfoque, ao estudar um grupo de engenheiros em torno do desenvolvimento do veículo elétrico. O termo ator-rede designa uma entidade relacional, sob a forma de uma rede de referências constituída tanto de elementos humanos como não humanos, um nexo de desempenhos desdobrados sob a forma de traduções: elétrons, bateria, acumuladores de energia, usuários, pesquisadores, fornecedores, ministério dos transportes, regulamentação tecnológica, e outras. Nele, atores interagem em redes para criar um mundo coerente. $\mathrm{O}$ enfoque ator-rede coloca a indeterminação do ator, abrindo o mundo do ator para entidades não humanas e permitindo que elas tenham fala.

Callon (1991) conferiu a denominação de rede técnico-econômica a esse conjunto heterogêneo de atores que interagem para produzir algo, que são ligados por intermediários, ou seja, qualquer coisa que, passando entre atores, define o relacionamento entre eles. São definidos quatro tipos principais de intermediários: os textos, na sua mais ampla concepção, incluindo as mídias que os carregam; os artefatos técnicos, geralmente um grupo estável de entidades não humanas para a realização de uma tarefa; os seres humanos, com suas habilidades, conhecimentos e know-how; e o dinheiro, em todas as suas diferentes formas. Todos estes intermediários, segundo Callon (1991), são constituídos em si mesmos como uma rede também, dado que remetem a outros textos, artefatos, homens e recursos que ordenam ideias, papéis, atividades, habilidades, negociações.

A teoria ator-rede aborda o conhecimento em criação, ou seja, no ato performativo, no qual o conhecimento é produzido nas relações entre estes materiais heterogêneos humanos e não humanos. Os agentes do conhecimento estão atados nesta rede de relações, em um fluxo de intermediários, que circulam, conectam, ligam e reconstituem identidades (CALLON, 1999). Portanto, o conhecimento em criação é sempre provisório, contestado e controverso. Assim, sua durabilidade (ou seja, legitimação) é o resultado de uma ligação temporária entre as entidades circulantes, o desfecho das controvérsias da caixa preta técnica ['de Pandora'], segundo Latour (2001). O conhecimento se torna uma unidade coerente, remontagem dos materiais heterogêneos e das relações múltiplas, que alcançou uma configuração estável provisória (LATOUR, 2012).

Na visão de Latour (2012), a Teoria Ator-Rede (ANT) ganha uma dimensão bem mais ampla ao ser apresentada como uma teoria sociológica. Para a 
Sociologia da Tradução, ou Sociologia da Translação, ou Sociologia da Associação, ou Sociologia das Ciências ou Sociologia do Conhecimento Cientifico (denominações dadas por Latour, 2012) não existe dualidade ou dicotomia como nível micro/macro da sociedade, agente/agência, contexto/estrutura, local/global, não há nada abaixo ou acima, nem sequer existe 'sociedade', ou seja, todos estes conceitos são construções produzidas pela ciência da sociologia tradicional para tentar explicar um mundo social que parece sólido, concreto, estruturado, fixo e permanente.

Existem, para a sociologia da associação, os agrupamentos, os grupos ou os agregados sociais (no sentido de associação) de atores humanos (sujeitos) e não humanos (instituições, organização, objetos, tecnologia, natureza, como também 'rotinas organizacionais', 'cultura organizacional', 'liderança', 'planejamento', 'departamento' e qualquer coisa a mais que seja actante) que atuam como mediadores na ação de traduzir comportamentos e produzir uma realidade social (LATOUR, 2012). Latour (2012) considera as associações sociais como interações fluidas com laços frouxos que constituem e reconstituem os grupos sociais; interações estas, baseadas na comunicação e no discurso entre atores; e os sujeitos como atores passíveis de cognoscibilidade e conscientes de suas ações, que produzem e reproduzem os mundos sociais.

Assim, segundo Latour (2012), a constituição do agregado social é composta por uma série de conexões laterais entre atores (não importando seu tamanho: seja um agente que desempenha uma tarefa; seja uma agência, uma organização que estabelece um padrão de trabalho), desde que haja um veículo, um mediador que conecte e transforme as ações e comportamentos de ambos os atores (sendo que o mediador também é um ator, como, por exemplo, uma rotina organizacional). A série de conexões que atua conjuntamente forma a rede que, pela sociologia tradicional, poderia ser mal comparada à estrutura, à 'sociedade'. Latour (2012) prefere denominar de coletivo a esse agrupamento que forma o mundo onde os atores se inserem. O mundo social de Latour (2012) é plano, todos os atores estão agrupados no mesmo nível, lado a lado, formando a rede que o constitui, daí o nome ator-rede (com hífen!, cuja função é juntar as coisas).

Os atores também são rede: utilizam 'panoramas' (cenários, discursos e ideias muito articulados) concebidos e construídos por outros atores (seja adquirido em uma disciplina do MBA de Gestão de Pessoas, seja lido em uma 
revista de negócios, seja conversado em um happy-hour em um bar com colegas de trabalho), que também constituem parte da rede, não importando tempo ou espaço. Assim, apropriam-se de 'padrões estruturantes' circulantes, materializados em técnicas e tecnologias intelectuais deslocadas de outro lugar e de outro tempo (o curso de MBA, por exemplo, realizado há dez anos, ou uma palestra de uma hora realizada na semana passada).

Produzem e fazem uso também de 'escalas' para poder classificar, denominar e comparar as coisas com o objetivo de se inserirem no mundo social, agrupamento ou coletivo (LATOUR, 2012), (podendo ser sua classe social, sua formação, seu cargo, seu status, a empresa onde trabalha; se faz parte das 100 Maiores e Melhores ou das 10 Melhores Empresas para se Trabalhar!). Desse modo, embora todos os atores estejam no mesmo nível plano e tenham o mesmo tamanho, alguns exercerão maior peso no coletivo sobre outros atores, justamente por causa do 'panorama' que constrói o modo de pensar e suas justificações, do 'padrão estruturante' circulante, das 'escalas' produzidas pelo próprio coletivo.

Adicionalmente, só existe tal mundo porque os atores se conectam, se interrelacionam e interagem; caso algum deles deixe de atuar e se torne um mero intermediário (sem vida), a composição do mundo social se modifica ou mesmo deixa de existir. Assim, chega-se ao ponto mais relevante: toda e qualquer definição só possui realidade e sentido porque os atores (humanos e não humanos) estão naquele mundo social, inseridos nele, produzindo aquela rede, agrupados naquele coletivo (LATOUR, 2012). Para encontrar o agrupamento social e compreender seu mundo, deve-se seguir os atores, sejam eles quem for - humanos ou não humanos -, observar seus comportamentos e como eles constroem e produzem seu mundo social, sabendo que os agrupamentos são fluidos, frágeis, inconstantes e provisórios.

Quanto ao indivíduo, ser humano, ele também é fruto de uma produção elaborada. Segundo Latour (2012, p. 299), "para obter atores humanos 'completos', é preciso compô-los com várias camadas sucessivas, cada qual empiricamente distinta da seguinte. $\mathrm{O}$ ator competente vem agora em minúsculos grãos.”. Portanto, ser um ator competente exige do indivíduo a sua própria produção, a fim de ser considerado como tal, no mundo onde 'escolheu viver'. Por fim, Latour (2012), com a ANT, não deseja nada, não quer desconstruir nada, nem fragmentar nada; procura apenas reagregar o social. 
Patriotta (2003a) destaca que a ANT aborda o conhecimento performativo, mas não se trata da performance sócio-organizacional, e sim da natureza relacional da rede de atores. Além disso, o conhecimento em criação evoca dois níveis de análise, a saber: as microinterações que ocorrem nos locais de prática, de trabalho; e as macrointerações geradas pelas noções de sociedade, normas, valores, cultura, estrutura e contexto social. Os dois níveis devem ser reconciliados na atenção a ser dada ao paradeiro do conhecimento, por onde ele flui e se desdobra.

\subsubsection{Workplace Studies}

Gherardi (2006) introduz o termo workplace studies para indicar um corpo de análises que compartilhem o interesse comum em estudar o ambiente de trabalho sob a perspectiva da prática, por meio de métodos geralmente naturalísticos (tais como etnografia, observação-participante e pesquisa-ação). Esses estudos não se definem nem se baseiam em um único enfoque acima e, geralmente, transitam pelos diversos autores de diferentes enfoques ou até mesmo introduzem novas fundamentações.

Eles concebem o ambiente de trabalho como uma construção social por meio das interações entre os participantes e pelos artefatos e tecnologias utilizados. Por meio de análises detalhadas das ações e interações naquele ambiente, os estudos procuram revelar as rotinas, os modos, o taken for granted que os participantes consideram como pertencentes ao conhecimento especializado.

Segundo a colocação de Gherardi (2006), estes estudos estariam interessados na tecnologia como elemento constitutivo do ambiente de trabalho, ou seja, a tecnologia como uma prática social realizada por um trabalhador perito, especializado - o trabalhador do conhecimento (ALVESSON, 2001) - e, portanto, consideram a tecnologia em ação. As análises acerca do conhecimento e práticas para o trabalho especializado (como, por exemplo, consultores, designers, engenheiros e outros trabalhadores do conhecimento), o trabalho cross-border, o trabalho entre grupos virtuais e a implementação de novas tecnologias em grupos de trabalho são temas recorrentes neste enfoque. 


\begin{tabular}{|c|c|c|c|}
\hline $\begin{array}{l}\text { Practice- } \\
\text { Based } \\
\text { Theorizing }\end{array}$ & $\begin{array}{c}\text { Base } \\
\text { Teórica }\end{array}$ & Autores Seminais & Conceito \\
\hline $\begin{array}{l}\text { Teoria da } \\
\text { Atividade } \\
\text { (AT) }\end{array}$ & $\begin{array}{l}\text { Vygostky } \\
(192 \text { 's) } \\
\text { Leontiev } \\
(193 \text { 's }) \\
\text { Escola } \\
\text { Russa de } \\
\text { Psicologia } \\
\text { Social }\end{array}$ & \begin{tabular}{|l|} 
Engeström (1987; \\
1993, apud Blackler et \\
al. 2000) \\
Lave e Wenger (1991) \\
Blackler (1995) \\
Blackler et. al. (2000) \\
\end{tabular} & $\begin{array}{l}\text { A prática está no centro do que o indivíduo conhece: as } \\
\text { relações existentes entre as concepções de uma comunidade } \\
\text { acerca de suas atividades e os recursos materiais, mentais, } \\
\text { culturais e sociais empregados para o desempenho destas } \\
\text { concepções de atividades. } \\
\text { É um sistema de produção de perturbação, constituído por } \\
\text { incoerências, inconsistências, paradoxos, conflitos e tensões. } \\
\text { Os modos de conhecer (knowing) e fazer ( } \text { doing) podem } \\
\text { emergir, se a comunidade repensar estas tensões em um novo } \\
\text { contexto. }\end{array}$ \\
\hline $\begin{array}{l}\text { Enfoques } \\
\text { Cultural }\end{array}$ & $\begin{array}{l}\text { Schein } \\
(1985)\end{array}$ & $\begin{array}{l}\text { Cook e Yanow (1993) } \\
\text { Yanow (2000) }\end{array}$ & $\begin{array}{l}\text { Organizações são entidades culturais; knowing envolve } \\
\text { significados compartilhados transmitidos por artefatos } \\
\text { culturais, únicos para cada organização. } \\
\text { Investiga como o desempenhar do trabalho depende do } \\
\text { processo social, tanto para sua existência quanto para sua } \\
\text { comunicação e produção. } \\
\text { Os artefatos e interações sustentam os significados e o } \\
\text { conhecer na prática. }\end{array}$ \\
\hline Estético & & $\begin{array}{l}\text { Strati (1992; 2007, } \\
\text { original de 1999) }\end{array}$ & $\begin{array}{l}\text { O conhecimento estético se baseia em processos contínuos } \\
\text { de construção, desconstrução e reconstrução simbólica. } \\
\text { A compreensão estética introduz as sensações como forma } \\
\text { de conhecer não cognitivo. }\end{array}$ \\
\hline $\begin{array}{l}\text { Enfoque } \\
\text { dos } \\
\text { Contextos } \\
\text { Formativos }\end{array}$ & $\begin{array}{l}\text { Giddens } \\
(1984) \\
\text { Schein } \\
(1985)\end{array}$ & $\begin{array}{l}\text { Unger (1987) } \\
\text { Ciborra e Lanzara } \\
(1994)\end{array}$ & $\begin{array}{l}\text { O contexto formativo desempenhado na ação é a expressão } \\
\text { da cognição social - incorporada nos artefatos materiais e } \\
\text { simbólicos, procedimentos e estruturas organizacionais, } \\
\text { ambientes institucionais, nos relacionamentos, nas ligações } \\
\text { das ações e suas ferramentas - que ultrapassa a individual. } \\
\text { No ambiente de trabalho, resulta na textura das rotinas, } \\
\text { papéis e funções que parecem "naturais" para aqueles que } \\
\text { executam diariamente as rotinas naquele contexto. }\end{array}$ \\
\hline $\begin{array}{l}\text { Teoria da } \\
\text { Aprendiza- } \\
\text { gem } \\
\text { Situada } \\
\text { (SLT) }\end{array}$ & $\begin{array}{l}\text { Bourdieu } \\
(1977) \\
\text { Giddens } \\
(1984) \\
\text { Dewey } \\
(1938)\end{array}$ & $\begin{array}{l}\text { Star (1989) } \\
\text { Brown e Duguid } \\
(1991) \\
\text { Lave e Wenger (1991) } \\
\text { Orr }(1996) \\
\text { Lave }(2000) \\
\text { Wenger }(2008) \\
\text { Cook e Brown (1999) }\end{array}$ & $\begin{array}{l}\text { A aprendizagem e conhecer (knowing) são atividades sociais } \\
\text { que ocorrem por meio de participação nesta comunidade que } \\
\text { participa compartilhadamente de um empreendimento, com o } \\
\text { engajamento ativo no mundo. } \\
\text { Os componentes da SLT são: significado; prática (modelos } \\
\text { de compartilhar recursos, perspectivas sociais e históricas); } \\
\text { identidade (como a aprendizagem transforma o indivíduo). }\end{array}$ \\
\hline $\begin{array}{l}\text { Teoria } \\
\text { Ator-Rede } \\
\text { ou Actor- } \\
\text { Network } \\
\text { Theory } \\
\text { (ANT) }\end{array}$ & $\begin{array}{l}\text { Berger e } \\
\text { Luckmann } \\
(1978) \\
\text { Foucault } \\
(1980) \\
\text { Latour } \\
(1987)\end{array}$ & $\begin{array}{l}\text { Callon (1980, 1992) } \\
\text { Knorr-Cetina (1981) } \\
\text { Law (1994) } \\
\text { Czarniawska e Jorges } \\
(1995) \\
\text { Star (1995) } \\
\text { Araujo (1998) Law e } \\
\text { Hassard (1999) } \\
\text { Gherardi e Nicolini } \\
(2000)\end{array}$ & $\begin{array}{l}\text { Investiga o processo pelo qual o conhecimento é socialmente } \\
\text { legitimado e torna-se durável, aborda a forma como as } \\
\text { controvérsias são estabelecidas, como os processos e fluxos } \\
\text { são transformados em coisas, como os artefatos são } \\
\text { traduzidos em fatos. } \\
\text { O conhecer, sempre contestado e provisório, é um } \\
\text { empreendimento coletivo por onde materiais e entidades } \\
\text { heterogêneos são mobilizados, traduzidos, usados, ignorados } \\
\text { para cumprir com alguma prática, situada e relacional. }\end{array}$ \\
\hline $\begin{array}{l}\text { Workplace } \\
\text { Studies }\end{array}$ & $\begin{array}{l}\text { Diversa, } \\
\text { Giddens } \\
(1984)\end{array}$ & $\begin{array}{l}\text { Schuman et al. (1999) } \\
\text { Orlikowski (2002) }\end{array}$ & $\begin{array}{l}\text { Um corpo de análise do ambiente de trabalho, como uma } \\
\text { construção social, por meio das interações entre os } \\
\text { participantes e dos artefatos e tecnologias utilizados. }\end{array}$ \\
\hline
\end{tabular}

Quadro 2: Enfoques do Conhecer na Perspectiva da Prática e da Ação (elaborado pela autora) 
O Quadro 2, anterior, sintetiza a base teórica, os autores seminais e os conceitos principais de cada enfoque da perspectiva practice-based theorizing ou do conhecer a ação.

\subsubsection{Enfoque do Conhecer (Knowing) na Prática e na Ação e Método Fenomenográfico}

Cabe destacar o trabalho de Sandberg e Pinnington (2009), que relaciona o Método Fenomenográfico, o mesmo a ser utilizado no presente estudo, àquele que constitui uma competência na prática profissional - a aplicação do conhecimento na ação - em um campo onde há um corpo substancial de conhecimento formalizado, a advocacia. Os autores sugerem que a prática profissional possui aspectos centrais, tais como conhecimento, compreensão e ferramentas que se integram em formas específicas de competência no desempenho do trabalho.

A visão de competência profissional explorada por Sandberg e Pinnington (2009) encontra-se em uma perspectiva relacional, em que, segundo classificação dos autores, se inserem as facetas de: 1) competência como conhecer na ação (COOK e BROWN, 1999); 2) prática como lócus da competência, pelas abordagens practice-based das comunidades de prática (LAVE e WENGER, 1991; WENGER, 2008), teoria da atividade (BLACKLER, 1995; ENGESTRÖM, 1987, apud BLACKLER et al., 2000); teoria ator-rede (LATOUR, 1999; LAW e HASSARD, 1999), e enfoque cultural (COOK e YANOW, 1993; YANOW, 2003); 3) competência como compreensão do trabalho (SANDBERG, 1994; 2000; baseado em MARTON, 1981). Todas estas correntes contribuem para identificar importantes aspectos do conceito de competência profissional no desempenho do trabalho.

Entretanto, os autores argumentam que estas abordagens não explicam de que modo os aspectos da prática profissional tornam-se integrados em uma forma específica de competência no desempenho do trabalho. Os achados sugerem que a competência profissional consista em um modo de ser. Os diferentes modos de praticar a lei distinguem e integram modos específicos de compreender o trabalho, a si mesmo, os outros indivíduos e as ferramentas legais em distintas formas de competência. 


\section{3 \\ Valoração do Conhecimento}

Esse tópico explora três enfoques da valoração do conhecimento, identificados na revisão da literatura: enfoque sobre mensuração ou depreciação do conhecimento; enfoque sobre criação de valor estratégico e desempenho organizacional; e enfoque sobre percepção do indivíduo, com maior ênfase e detalhamento nos estudos relativos ao último enfoque. O valor do conhecimento, segundo o enfoque das percepções dos indivíduos, revela-se um tema relativamente pouco pesquisado na literatura do conhecimento organizacional.

\subsection{Valor: Uma Definição}

Na dimensão do presente estudo, que investiga o modo como os indivíduos percebem a valoração do conhecimento no contexto do trabalho, é preciso conceituar o que é valor. Para tanto, retomamos a perspectiva do conhecer (knowing) na prática e ação, que é dotado de um caráter social, cultural, material e histórico. Conforme já discutido, o conhecer é situado e construído na ação; é relacional e distribuído; é dinâmico e provisório; é praticado e emergente. Portanto, o valor atribuído ao conhecer deveria guardar propriedades similares e não pode ser um número estático, tampouco uma escala mensurável, que tenda a objetivar e reduzir. A revisão da literatura revelou um enfoque sobre a mensuração e depreciação do conhecimento, que se subdivide em correntes de estudo com base em: ativos intangíveis, curvas de aprendizagem, conhecimento especializado passível de depreciação e valorização.

Tampouco pode ser uma predisposição ao considerar um valor futuro. Neste caso, o conhecer seria um recurso prévio, um antecedente e, graças à sua existência, poderia gerar valor. $\mathrm{O}$ valor residiria no sucesso ou desempenho da organização pelo uso deste conhecimento. A revisão da literatura trouxe o enfoque sobre o valor estratégico contido nas visões estratégicas baseadas em recursos (RBV) e em conhecimento (KBV). 
O valor, enquanto ação, deve ser construído social e historicamente, possuindo significado naquele ambiente. Deve ser um critério próprio acerca do que é importante e valorado naquele contexto, para aquelas pessoas, naquela situação. Portanto, é algo cultural e material, ou seja, representa algo para aqueles indivíduos, diz respeito àquelas práticas locais e se reflete nelas. Assim, o estudo contempla a visão antropológica das teorias de valor (GRAEBER, 2001).

Graeber (2001) apresenta uma síntese das teorias de valor presentes na economia (dos custos de produção) e na semiologia (significação da relação social), aparentemente irreconciliáveis. Na visão antropológica do autor, o valor é definido como ação e dela emerge. De uma forma ampla, valor é toda a energia, direção, esforço - ou seja, modos de ação - que o indivíduo dedica para manter, preservar, proteger as coisas concretas (produto) ou abstratas (significados e relações) que fazem sentido para ele, por terem sido incorporadas no amplo contexto social.

Assim, "valor é o modo pelo qual os indivíduos representam a importância de suas próprias ações para eles mesmos" (GRAEBER, 2001, p.45). Esse fato não está isolado do contexto social; pelo contrário, está inserido nas relações sociais e, neste caso, valor também é o poder de criar relações sociais. Valor é o modo como as pessoas acessam a importância do que fazem enquanto estão fazendo, ganhando sentido sobre si mesmas e sobre suas ações (GRAEBER, 2001).

Tendo por base esse conceito, a revisão da literatura revelou um enfoque sobre percepção dos indivíduos, ou seja, sobre a forma como eles interpretam e significam o valor do conhecimento. Nesta linha e na perspectiva do conhecer na prática e na ação, Swart (2011) define valor como um senso coletivo de apreciação mútua. Valor é construído socialmente. O grupo, em um determinado contexto, atribui valor a um mesmo resultado emergente de uma atividade (SWART, 2011). O conhecer na prática é especialmente relevante, pois é por meio da prática, da ação no contexto, que o valor do conhecimento se torna visível para os membros organizacionais (NAG et al., 2007). 


\subsection{Valoração do Conhecimento e os Enfoques da Revisão de Literatura}

Este tópico procura, a partir da revisão da literatura dos últimos onze anos, apresentar uma visão acerca dos estudos produzidos com base no conteúdo, nos modos ou no objetivo de valorar o conhecimento. Foram encontrados e analisados 98 artigos internacionais e apenas três nacionais. O propósito desta revisão consiste em: identificar a produção acadêmica neste campo; compreender e classificar sob quais abordagens a valoração do conhecimento se inseriu; identificar quais os aspectos que se mostram relevantes para os estudos relacionados à valoração do conhecimento, especialmente no âmbito das percepções dos indivíduos; e analisar estudos do tema sob a perspectiva do conhecer na prática.

\subsubsection{Valor do Conhecimento como um Número: Enfoque sobre Mensuração ou Depreciação do Conhecimento}

Uma preocupação inicial dos estudos de valoração do conhecimento foi o enfoque sobre mensuração. Nesta abordagem, o conhecimento é compreendido como um ativo de valor da organização, e que deve ser medido, uma vez que causa impacto no desempenho organizacional ou pode depreciar e perder valor. Nesse enfoque de estudos, o conhecimento é considerado um objeto, concreto, com um valor de utilidade e troca, passível de apropriação e mensuração por um número financeiro-contábil, em boa parte dos casos. Referenciais utilizados nesta mensuração são a curva de aprendizagem, o conceito dos ativos intangíveis e a visão do trabalho especializado. Como não se trata de uma linha cujo enfoque esteja contido no escopo deste trabalho, não será aprofundada na revisão.

A partir da sequência descrita no parágrafo anterior, a primeira corrente segue a linha de estudos dos ativos intangíveis. Nela, encontram-se os trabalhos de Bontis (1998; 2001) e Bontis e Fitz-Enz (2002), dentre outros autores. Estes estudos investigam modelos e medidas financeiras com vistas a apropriar o conhecimento incorporado no capital humano em números concretos de retorno sobre investimento e desempenho. Bontis et al. (2001) procuram consolidar as ferramentas disponíveis para medir e gerenciar recursos intangíveis presentes no capital humano, de modo a encontrar o valor econômico adicionado (Economic 
Value Added - EVA) por meio de uma contabilidade de recursos humanos. Do mesmo modo, Antunes e Martins (2007) exploram a compreensão do conceito de capital intelectual (CI) entre gestores, de forma a verificar a adequação das medidas de desempenho existentes para captar os efeitos dos investimentos nos elementos que compõem o CI.

Massingham (2008), baseando-se nos construtos dos ativos intangíveis, procura identificar o modo como a perda de conhecimento causada pela saída de empregados valiosos afeta a organização e os demais funcionários. O autor argumenta que a perda de: capital humano pode gerar uma diminuição da produção e da produtividade organizacional; capital social pode reduzir a memória organizacional; capital estrutural pode diminuir a aprendizagem organizacional; e capital relacional pode interromper os fluxos de conhecimento externo. O autor apresenta um modelo que mapeia o impacto da perda de conhecimento, a natureza do problema e o nível de risco envolvido.

Maurer et al. (2011) se baseiam no capital social para investigar a relação existente entre o capital social dos membros e os resultados em desempenho intraorganizacional mediado pela transferência de conhecimento.

Uma segunda corrente no enfoque do valor como um número toma por base o conceito e modelo matemático que Epple et al. (1991) descreveram de curvas de aprendizagem cumulativas de experiência, responsáveis por uma redução dos custos. A aprendizagem pela experiência modifica comportamentos e atividades internas na organização, gerando valor. Inversamente, quando há interrupção na transferência de conhecimento e estoques deixam de ser transferidos, ocorre depreciação e perda de valor. Fang (2011), nesta linha, propõe um modelo de curva de aprendizagem organizacional, no qual o mecanismo de aprendizagem é o reconhecimento gradual dos passos para atingir um objetivo. À medida que a organização ganha experiência, reduz o número de passos para o alcance de resultados.

Reagans et al. (2005) argumentam que a experiência acumulada de trabalhar conjuntamente promove coordenação e trabalho de equipe, que podem advir da proficiência dos indivíduos, da habilidade dos membros em alavancar conhecimento acumulado pelos outros e da capacidade de coordenação das atividades. Com base no modelo de curva de aprendizagem, os autores 
examinaram que cada tipo de experiência traz uma contribuição distinta para o desempenho do grupo.

Uma terceira corrente buscou estudar o conhecimento do especialista e sua possível depreciação (ARGOTE e EPPLE, 1990; BOONE et al., 2008; DARR et al. 1995, entre outros autores). Essa linha parte do princípio de que empresas de serviços, firmas intensivas em conhecimento (tais como consultorias, auditorias, escritórios de advocacia) e serviços profissionais (de design, inovação e criatividade, arquitetura, medicina, entre outros) possuem trabalhadores do conhecimento que detêm um ativo de conhecimento passível de crescimento/valorização ou depreciação. Alguns estudos tomam por base as curvas de aprendizagem mencionadas acima.

Quanto aos tipos de conhecimento, Madsen e Desai (2010) identificaram que os conhecimentos advindos do sucesso depreciam mais rapidamente que aqueles aprendidos por intermédio do fracasso. Gaimon et al. (2011) argumentam que determinadas tecnologias e treinamentos respondem à depreciação, de modo a trazer receita e reduzir a obsolescência do conhecimento. O estudo de Groysberg et al. (2008) examina a portabilidade dos funcionários considerados estrelas que, ao mudarem de emprego, vivenciam uma queda de desempenho pelos anos seguintes, em maior ou menor grau, em decorrência das capacidades existentes na nova firma de ingresso. De todo o modo, a firma que contrata estrelas tem suas ações desvalorizadas, devido à destruição de valor representada pelo ingressante.

\subsubsection{Valor do Conhecimento como um Recurso ou Capacidade: Enfoque sobre Criação de Valor Estratégico e Desempenho Organizacional}

Neste enfoque, o conhecimento é um antecedente que gera valor estratégico, sendo responsável por um desempenho organizacional distintivo. Ele é visto como recurso ou como uma capacidade prioritária para a criação de valor da organização, e se incorpora nas visões RBV ou KBV. O enfoque do conhecimento enquanto um ativo, cuja preexistência possibilita a geração de valor estratégico, apresenta uma interseção com a visão do conhecimento como objeto 'comoditizado', já discutida nas classificações de Gherardi (2000; 2006) e Patriotta (2003a; 2003b). 
Tanto este enfoque sobre valor estratégico quanto aquele sobre mensuração tratam do conhecimento como um ativo da organização, mas diferem na medida em que o último tende a objetivar e reduzir o conhecimento a um número, enquanto que o primeiro entende o conhecimento como o antecedente ou o mediador que possibilita certas atividades e resultados da organização, tais como estratégia, inovação, articulação em redes e alianças, desempenho. Assim, a unidade principal de análise dos estudos neste enfoque é a organização. Será apresentada apenas uma visão dos conteúdos identificados na revisão, apenas para fins de exemplificação, por não se enquadrar diretamente no propósito do presente trabalho.

Quanto aos conteúdos abordados nos estudos revisados, eles dizem respeito: à transferência de conhecimento e competências, determinando as capacidades de maior importância e valor para a organização na relação entre matriz e subsidiárias (DENRELL et al., 2004); e às contingências nas quais a transferência de conhecimento beneficia o desempenho, considerando os investimentos realizados em tipos de esforços de transferência e seus custos diretos (LEVINE e PRIETULA, 2011). Watson e Hewett (2006) descobriram que firmas intensivas em conhecimento investem dinheiro e tempo na tentativa de melhor gerir seus recursos de conhecimento, enquanto a efetividade da transferência interna e reutilização do conhecimento são subestimadas.

Ainda com relação às capacidades organizacionais, King e Zeithaml (2003) identificam o conjunto de recursos existentes de conhecimento, a fim de medir as percepções dos gerentes sobre o valor agregado de cada recurso, enquanto Haas (2006) examina o valor da coleta de conhecimento em ambientes ambíguos, políticos e sobrecarregados de informação, no nível da equipe.

Felin e Hesterly (2007) procuram identificar o lócus da criação de valor: o conhecimento cosmopolita e local, o conhecimento coletivo (em alianças, redes, firmas) e individual (através dos gerentes e especialistas). Também são estudados: o uso de recursos de conhecimento codificado por equipes e as implicações no desempenho em função da dependência, da desatualização ou do contexto em que o conhecimento foi gerado (HAAS e HANSEN, 2005); a maximização do valor inserido nas relações sociais, pela perspectiva relacional do conhecimento em fluxo versus estoque, no contexto da estrutura de RH (KANG et al., 2007). Reus et al. (2009) analisam os drivers de investimento em conhecimento através dos 
contextos organizacionais, utilizando o esquema interpretativo de Daft e Weick (1984).

A mudança organizacional, causada pela transformação ambiental, erode o valor do uso do conhecimento existente. Contudo, ambientes mutantes também erodem a geração de novos conhecimentos, razão pela qual Posen e Levinthal (2011) analisam mecanismos que tornam a adaptação organizacional mais (ou menos) valiosa.

Ndofor e Levitas (2004) sugerem modos para sinalizar aos stakeholders o valor do conhecimento contido na organização (em inovação e P\&D), com base nas percepções externas e no ambiente em que a firma opera. Pitelis (2009) apresenta um modelo de como capturar valor junto aos agentes econômicos que percebem possuir um valor apropriável, criando vantagens, capacidades e potenciais de ação, impactando no surgimento de organizações, suas estratégias e ações destinadas a capturar socialmente o valor cocriado.

Os investimentos em capital intelectual emergem como a maior influência determinante da governança em estratégia interorganizacional (SUBRAMANI e VENKATRAMAN, 2003). Os processos de troca de valor de conhecimento ou tipos de conhecimento, em firmas em rede, geram impactos diferentes nas firmas, na forma de valor ou de criação de valor (KARAMANOS, 2003; MOLLER E SVAHN, 2006).

O único estudo nacional neste enfoque é o trabalho teórico-conceitual de Scharf e Soriano-Sierra (2008), que busca interligar os conceitos de gestão do conhecimento (leia-se NONAKA e TAKEUCHI, 1997) e valor percebido, no qual a gestão do conhecimento é considerada um fator diferenciador na entrega de valor [estratégico] ao cliente.

Em síntese, o enfoque sobre valor estratégico aborda os temas centrais que deram origem à linha de conhecimento organizacional, porém sob a ótica do valor, tais como: lócus [da criação de valor] do conhecimento, natureza do conhecimento [de valor], transferência de conhecimento intra e interorganizacional, capacidade de absorção, retenção e vazamento de conhecimento [de valor] em organizações, redes e alianças. 


\subsubsection{Valor do Conhecimento como Interpretação e Significado: Enfoque sobre Percepção do Indivíduo}

O terceiro enfoque identificado recai sobre as percepções dos indivíduos, vertente esta que, a partir da revisão da literatura, se mostra pouco explorada. Esse enfoque apresenta uma linha de pesquisa de abordagem predominantemente qualitativa, embora também abranja estudos quali-quanti ou quantitativos.

De um modo geral, a revisão identificou que a atribuição de importância e o valor do conhecimento estão associados a(os): relacionamentos (MENON e BLOUNT, 2002; WONG, 2008); identidade social (GAO e RILEY, 2010), identidade ou identificação organizacional (ANTONACOPOULOU, 2006; COLMAN e LUNNAN, 2011; NAG et al., 2007; RAVISHANKAR e PAN, 2008); relações de poder (CONTU e WILLMOTT, 2003; HARMAN, 2012; HEIZMANN, 2011; KAMOCHE et al., 2011; NAG et al., 2007; OBORN e DAWSON, 2010; SWART, 2011); conflito (COLMAN e LUNNAN, 2011); política (ANTONACOPOULOU, 2006; SWART, 2011); legitimação (HEUSINKVELD E BENDERS; 2005); e status social (THOMAS-HUNT et al., 2003), gerando impactos na escolha do conhecimento e na sua utilização pelos indivíduos e na organização.

Neste enfoque, o conteúdo encontrado explora a valoração do conhecimento por meio das comparações e percepções dos indivíduos acerca do conhecimento (COLMAN e LUNNAN, 2011; INKPEN, 2008; MENON e PFEFFER, 2003; MENON et al. 2006, THOMAS-HUNT et al., 2003); os tipos de relacionamentos estabelecidos (MENON e BLOUNT, 2002); o papel do referente social no julgamento da importância do conhecimento (WONG, 2008); o reflexo da organização no indivíduo e o isomorfismo institucional (ANTONACOPOULOU, 2006); o poder como forma de estabelecimento da aprendizagem e do conhecimento (HARMAN, 2012; HEIZMANN, 2011); a percepção do papel do consultor (STURDY et al., 2009) e dos grupos na organização (HEIZMANN, 2011; OBORN e DAWSON, 2010; THOMAS-HUNT et al., 2003).

\subsubsection{Relação entre Conhecimento Valorado e Identidade}

Um grupo de estudos investigou a relação entre o conhecimento valorado e a identidade social / identificação entre grupos e indivíduos na organização. Na 
verdade, a relação entre estes construtos conhecimento e identidade já se encontra descrita desde a origem do enfoque da aprendizagem situada (BROWN e DUGUID, 1991; LAVE e WENGER, 1991), e se desenvolveu por toda a perspectiva do conhecer na prática. No contexto do trabalho, o indivíduo não apenas aprende a "ser" naquele ambiente (ELKJAER, 2003), como também o conhecer transforma o indivíduo.

Os artigos fundamentam-se principalmente nas teorias de identidade social e identificação, de Tajfel e Turner, e nos conceitos de associação e referentes sociais, de Festinger e outros. Pode-se identificar que a posição no grupo e a identidade entre os membros influenciam na forma de atribuição de importância e valoração dos conhecimentos circulantes nos grupos ou nas relações. Concorrem, neste ponto, questões de status no grupo, hierarquia, percepção de expertise, conectividade e centralidade nas relações entre os membros, que ativam a questão de identidade dos indivíduos e interferem na atribuição de importância e nos julgamentos acerca do valor do conhecimento existente, proposto ou emergente naqueles contextos. Os principais estudos são descritos a seguir.

Menon e Blount (2002) fundamentaram seu estudo em três aspectos da percepção social, particularmente relevantes para a compreensão da forma como o conhecimento é avaliado: a identificação grupal (TAJFEL e TURNER, 1979, apud MENON E BLOUNT, 2002) baseada em categorias sociais, avaliação pessoal e status. Menon e Blount (2002) apresentam uma perspectiva relacional, em que o relacionamento social entre a fonte e o receptor de conhecimento afeta o modo pelo qual os gerentes avaliam o novo conhecimento recebido. Com base em papéis desempenhados pelos atores organizacionais, Menon e Blount (2002) identificaram seis tipos comuns de relacionamento, denominados de esquemas relacionais.

Os autores analisaram a forma como a percepção relacional entre os agentes influencia na avaliação do novo conhecimento, ou seja, os tipos de relacionamentos e a percepção acerca deles podem moderar o valor do conhecimento atribuído às fontes. Os papéis que ameaçam a identificação entre membros do grupo e o status vigente recebem um valor do conhecimento menor do que aquele cujos papéis reforçam o grupo.

Menon e Pfeffer (2003) se utilizam das teorias de identidade social e favoritismo intragrupo (a partir de ABHRAMS e HOGG, 1990; FESTINGER et 
al., 1950; TAJFEL e TURNER, 1986; apud MENON e PFEFFER, 2003) como referencial de base para comparar o modo como os gerentes valoram o conhecimento advindo de fontes internas e externas à organização e a síndrome do "não inventado aqui" (Not Invented Here - NIH). Nos dois estudos de caso (realizados na Xerox e na fusão entre duas cadeias de restaurantes), o conhecimento externo foi considerado com mais valor que o conhecimento desenvolvido internamente.

Os autores atribuem esse fato ao ambiente externo competitivo, que torna o conhecimento advindo dos competidores e mercado mais atrativo e valioso, motivando a aprendizagem. Em ambos os casos, também o ambiente interno era competitivo, implicando, de certo modo, na preferência por valorar o externo em detrimento do competidor interno. Nesse aspecto, há implicações de status e de diferentes créditos recebidos em função do conhecimento escolhido pelo gerente. Ainda com relação aos achados, a proximidade do conhecimento interno faz decrescer o seu valor atribuído, porque o torna mais visível e frágil, além de mais familiar e comum, enquanto a escassez, a dificuldade e a unicidade valorizam o conhecimento. Como consequência, Menon e Pfeffer (2003) ressaltam a forma como as organizações desperdiçam conhecimento interno tácito, detalhado e disponível, na busca por um conhecimento externo, por vezes menos rico.

Em continuidade a esse estudo, Menon et al. (2006) comparam a forma como as pessoas reagem ao conhecimento de autoria de rivais internos (funcionários da mesma organização) contra rivais externos (funcionários de uma organização concorrente). A premissa dos autores é de que os rivais internos e externos evocam tipos contrastantes de ameaças. Especificamente, é difícil usar o conhecimento de um rival interno, porque este gera uma ameaça ao indivíduo e à sua competência: equivale a ser um seguidor e perder o status em relação a um concorrente direto. Por outro lado, os rivais externos representam uma ameaça menor ao status pessoal. Assim, os indivíduos estão mais dispostos a usar o conhecimento externo.

Nos três casos estudados, os autores observaram os seguintes achados: 1) as rivalidades interna e externa envolvem relações opostas entre ameaça e valorização do conhecimento; quanto maior a ameaça provocada pelos rivais internos, maior será a rejeição das pessoas ao seu conhecimento; e quanto maior a ameaça gerada pelos rivais externos, maior será a avidez das pessoas pelo seu 
conhecimento; 2) os indivíduos acreditavam que iriam perder mais status pessoal se usassem o conhecimento de um rival interno e, portanto, reduziram o valor daquele conhecimento; 3) a autoafirmação atenua ou até mesmo reduz estes padrões.

Os autores consideram as questões de favoritismo intra e extragrupo à luz da teoria de identidade social (de TAJFEL, 1970, apud MENON et al. 2006), onde a valoração do conhecimento externo em detrimento do conhecimento intragrupo ocorre justamente por identidade intragrupo (o conhecimento externo melhora o conhecimento intragrupo e sua coesão), ou por formação de subcategorias no intragrupo, onde valorar o conhecimento do intragrupo rival afeta e ameaça o status do seu próprio subgrupo.

O trabalho de Thomas-Hunt et al. (2003) investiga os efeitos de status social (fundamentado em TAJFEL, 1981 e TURNER et al., 1987; apud THOMASHUNT et al., 2003) e de status de especialista na transmissão do conhecimento, observando a ênfase no conhecimento exclusivo e no conhecimento compartilhado no interior de grupos heterogêneos, assim como a avaliação dos membros do grupo. Os achados dos autores indicam que, em grupos heterogêneos, o grau de ênfase e de importância que os grupos atribuem ao conhecimento exclusivo dos membros afeta o desempenho do grupo. Em comparação com aqueles percebidos como não especialistas, os membros percebidos como especialistas participam mais das discussões e enfatizam tanto o compartilhamento de conhecimento quanto o conhecimento exclusivo dos outros membros. Os autores sugerem que os membros percebidos como especialistas assumem a responsabilidade por gerenciar a informação do grupo, concentrandose em agregar e enfatizar ambos os tipos de conhecimento (exclusivo e compartilhado).

Enquanto as contribuições de conhecimento exclusivo aumentaram a percepção positiva sobre os membros isolados, as contribuições de conhecimento exclusivo diminuíram a percepção positiva dos membros socialmente conectados, sugerindo que os membros socialmente isolados sentem menos desconforto em discordar ou apresentar conhecimento divergente, enquanto o mesmo não ocorre entre membros socialmente conectados, que preferem suprimir opiniões ou conhecimento discordante para não gerar distância do seu grupo social. 
Assim, os autores concluem que o status social no grupo pode promover diferentes ênfases pelo conhecimento compartilhado, exclusivo, próprio ou pertencente a outro membro do grupo, assim como avaliações distorcidas do conhecimento dos membros e suas contribuições. Deste modo, apesar das tentativas dos membros de menor status social no grupo em participar e contribuir, eles continuam sendo alvo de avaliações tendenciosas. Por fim, a inabilidade dos grupos heterogêneos de identificar e incorporar os conhecimentos dos membros se deve ao insucesso dos membros dotados de status social em contribuir com seu conhecimento exclusivo e em reconhecer a validade das contribuições exclusivas dos demais.

Wong (2008) parte da premissa de que as diferentes percepções acerca da importância dos diversos conhecimentos podem impedir a integração destes conhecimentos na solução de problemas em equipe. O autor estudou os referentes sociais tomados pelos membros de grupos de trabalho para o julgamento da importância do conhecimento, assim como a extensão da influência relativa de cada referente nas relações de trabalho em rede. Wong (2008) explora três tipos de referentes e as relações nas quais eles se engajam em grupo e redes de trabalho: referente coesivo (caracterizado por um laço direto, comunicação frequente e que busca trocar julgamentos com o grupo), referente estruturalmente equivalente (que é fonte de influência social, relacionando-se com pessoas idênticas em termos de opinião) e referente central (possuidor de maior expertise e, portanto, mais central na rede de relacionamentos, devido à busca de aconselhamento junto a ele por parte dos demais membros e pares).

Os achados indicam que os membros de grupo com posição de referente coesivo e estruturalmente equivalente compartilham julgamentos similares sobre a importância dos diferentes conhecimentos nos seus grupos de trabalho. Entretanto, os referentes centrais não compartilham dos mesmos julgamentos, pelo fato de possuírem um nível hierárquico superior no grupo, sendo menor a sua relação social com os demais referentes. Assim, o autor sugere que o papel e posição desempenhados na rede social de trabalho influenciam o valor atribuído aos conhecimentos do grupo.

O trabalho teórico-conceitual de Gao e Riley (2010) propõe um modelo para a valoração do conhecimento pelos membros organizacionais a partir da relação entre conhecimento e identidade social profissional, argumentando que a 
identidade ocupa um papel central na atribuição de valor ao conhecimento. Segundo os autores, as noções de prática e eficácia juntam-se em uma forma de conhecimento que aumenta a percepção e a apreciação sobre o valor do conhecimento existente, ou seja, uma conexão com o conceito de competência profissional. Deste modo, valorar o conhecimento é parte de um processo que vincula a prática profissional com a identidade profissional.

O modelo de Gao e Riley (2010) relaciona o conhecimento existente nos processos cognitivos de afiliação indivíduo-grupo (autocategorização do conhecimento; ligação com grupo que copossui o conhecimento; ligação com o grupo por meio de conhecimento como um atributo de valor para o grupo; dependência no contexto do grupo para recuperar o conhecimento; recuperação do conhecimento por meio de ações profissionais sancionadas pelo grupo) à identidade, mediados pelos processos de socialização (na situação atual e adequação ao trabalho em grupo profissional) e filtrados pela competência demonstrada. A propensão em compartilhar um conhecimento possuído pelo indivíduo passa pela intervenção sobre a identidade social ativada (desde a postura individualista à afiliação ao grupo, e sentimento de posse do conhecimento) e o conhecimento internalizado. Por tratar-se de um modelo teórico, seria necessário um estudo empírico para avaliar em quais conceitos os atributos de valor do conhecimento efetivamente são interligados à identidade.

Harman (2011) interliga a questão de identidade, na ótica do conhecer na prática, com o discurso de poder que circula na organização, e que acaba por moldar o indivíduo naquele contexto e por gerar impacto nas escolhas acerca do que é importante e valioso no ambiente de trabalho.

\subsubsection{Relação entre Valoração do Conhecimento e Identificação dos Indivíduos com a Identidade Organizacional}

Um segundo grupo de estudos explorou a forma como a identificação dos indivíduos com a identidade organizacional gera impacto nos modos de valorar o conhecimento na organização. Os artigos tomam por base as teorias de identidade organizacional, presentes nos trabalhos de Corley e Gioia (2001), Corley et al. (2006), Dutton e Dukerich (1991), e de identificação, de Mael e Ashforth (1992). Se a identidade define o que a entidade - seja o indivíduo, o grupo ou a 
organização - é, em uma tentativa de definir a si mesma, no nível organizacional, a identidade diz respeito a capturar o que proporciona significado para além dos membros, isto é, um significado autorreferencial, onde o self é coletivo (CORLEY et al., 2006).

Corley et al. (2006) propõem que identidade organizacional seja o termo usado para descrever a identidade como um coletivo, a cognição no nível individual sobre "o que a organização é” (DUTTON et al., 1994), enquanto o termo organizationally based identity seja empregado para descrever a parte desse autoconceito que define a conexão do indivíduo com a organização, ou seja, a identificação.

Assim, a identidade organizacional é concebida como um fenômeno experimentado pelos membros organizacionais, percebido pelos outsiders e central para os processos sociais, com resultados reais nos contextos organizacionais (CORLEY et al., 2006). Nesta visão, as identidades no nível coletivo podem ser distintas das identidades no nível individual, embora estejam relacionadas, e são capazes de ser modeladas nos processos sociais na organização. Portanto, a IO é uma construção social contínua que tem lugar entre os membros organizacionais; pode ser influenciada e acessada pelos indivíduos, grupos, alta gestão ou outros coletivos; e é geralmente entendida como sendo focada na organização. Os membros organizacionais fazem uso de narrativas e outras abordagens para articular, negociar e substanciar as identidades, operando o sensemaking (WEICK, 1995) de suas identidades na(s) realidade(s) vivida(s) na organização.

A identificação, por sua vez, tem o papel de incorporar os indivíduos nas identidades relevantes para eles (ASHFORTH et al., 2008). Significa que o indivíduo se autodefine ao ver a definição coletiva ou os papéis, ou seja, quando o autoconceito do indivíduo contém os mesmos atributos daqueles percebidos na IO (DUTTON et al., 1994). A identificação é uma relação entre três níveis da identidade: 1) o centro da identidade apresenta os conceitos de autodefinição (eu sou), de atribuição de importância (eu valoro), e de afeto (eu sinto); 2) o conteúdo da identidade - o que significa ser aquele indivíduo - apresenta os valores (eu me importo), metas (eu quero), crenças (eu acredito), traços estereótipos (eu faço), e conhecimentos, habilidades e capacidades (eu posso); e 3) comportamentos da identidade (eu me comporto) (ASHFORTH et al., 2008). 
A identificação é representada por uma linha tênue e maleável entre o centro da identidade (eu sou) e o conteúdo da identidade (eu me importo/quero/ acredito/faço/posso). Ela é o processo pelo qual o indivíduo se define, comunica esta definição aos outros e se utiliza dessa definição para guiar sua vida e trabalho. Contribui para o sentido de pertencimento do indivíduo na organização ou nos grupos, afetando sua autoestima e/ou motivando-o para o autodesenvolvimento (ASHFORTH et al., 2008).

Os estudos apontam que a ameaça à identidade organizacional está relacionada negativamente à criação de valor (BROWN e STARKEY, 2000; COLMAN e LUNNAN, 2011; NAG et al., 2007), pois os indivíduos protegem sua autoestima por meio da continuidade da sua identidade organizacional existente, deixando, assim, de contribuir com a nova organização ou valorando aqueles conhecimentos da organização com que mais se identificam (RAVISHANKAR e PAN, 2008).

Segundo Nag et al. (2007), a relação entre identidade organizacional e conhecimento ainda se encontra subestudada, embora represente um conceito fundamental para a análise da prática organizacional. Uma maior compreensão sobre a forma como a identidade organizacional afeta o conhecimento, e, ainda, sobre a implicação dessa dinâmica sobre poder e controle, é relevante na questão da adaptação organizacional. $\mathrm{O}$ estudo dos autores trata do fracasso da transformação estratégica, sugerindo que as lideranças tenham sido incapazes de gerar uma mudança muito mais basilar no tocante à forma como o conhecimento se aplica nas práticas locais e cotidianas dos membros organizacionais, apesar de terem disseminado com sucesso os novos conhecimentos de orientação estratégica.

De acordo com Nag et al. (2007), os modos por meio dos quais os membros utilizaram o conhecimento nas suas práticas diárias afetaram e foram afetados recursivamente pela noção coletiva de quem eles eram enquanto organização (identidade organizacional), e certas relações de poder e controle se salientaram e evidenciaram quando os gerentes tentaram modificar sua identidade e/ou suas práticas. Emergiram daí questões sobre quem controla o conhecimento, como ele é controlado e ameaças às relações de poder existentes na organização com tentativas de preservação da identidade organizacional corrente. Assim, os 
achados mostram a relevância das relações de identidade com o modo como o conhecimento se manifesta nas práticas organizacionais.

Ravishankar e Pan (2008) estudaram a implantação de um sistema de gestão do conhecimento em duas unidades de negócio de uma empresa de desenvolvimento de projetos. Os profissionais relutaram em seguir as normas de compliance e compartilhar, no sistema da organização, os conhecimentos advindos dos projetos de seus clientes, demonstrando maior identificação organizacional com esses do que com a própria empresa matriz. Assim, atribuíram maior valor ao conhecimento dos clientes do que à contribuição para o conhecimento da organização. Os achados sugerem que a identificação organizacional possua uma importância central nos processos de compartilhamento e valoração de conhecimento.

Colman e Lunnan (2011) analisaram duas aquisições feitas por uma mesma empresa. Enquanto em uma aquisição houve uma identificação imediata dos empregados da adquirida com a adquirente, em um processo de integração sem conflitos e marcados por funcionários satisfeitos, a outra aquisição foi caracterizada por rupturas e conflitos, sem identificação dos funcionários com a nova empresa proprietária. Entretanto, os funcionários da empresa adquirente consideraram que a aquisição que criou mais valor foi justamente a mais conturbada. Os autores sugerem que a ameaça à perda de identidade empurre os funcionários a demonstrarem conhecimento e soluções vindas da empresa adquirida, que eles consideram superiores aos do seu adquirente. A identificação com a empresa anterior estimula a resistência dos funcionários em adotar processos e estruturas que eles julgam como inferiores, além de dar confiança para promoção das velhas capacidades inovadoras para a nova organização.

O estudo de Cherman e Rocha-Pinto (2013) encontrou uma importante relação entre o conhecimento valorado pelos indivíduos no contexto do trabalho e identidade organizacional. A organização apareceu como o referente mais relevante para os indivíduos (em comparação com os pares ou outros membros organizacionais), como aquele que julga, avalia e determina os conhecimentos mais relevantes a serem valorados naquele ambiente. Assim, os indivíduos procuram confirmar, ajustar ou negar suas identidades à organização, por meio de mecanismos de identificação e não identificação, a fim de conferir sentido à sua permanência (ou não) naquela organização. 


\subsubsection{Valoração do Conhecimento como Exercício de Poder, Política e Hierarquia}

Um terceiro conjunto de estudos explorou as relações e implicações existentes entre valoração conhecimento e poder, política e hierarquia nas organizações. Esses estudos geralmente tomam por base os trabalhos de Foucault (1980) acerca do poder e do conhecimento, e abrangem a forma como o poder define o que deve ser aprendido e o modo como deve ser aprendido para ser significativo em determinado contexto. Abordam também a natureza bastante limitada e limitante da visão do que pode ser aprendido (ANTONACOPOULOU, 2006), podendo o conhecimento valorado (privilegiado) estar relacionado com a hierarquia existente e acabar por reafirmá-lo (HEIZMANN, 2011; OBORN e DAWSON, 2010) ou residir nas relações e no discurso (HARMAN, 2012).

Antonacopoulou (2006) explorou a aprendizagem nos âmbitos individual e coletivo. Ao examinar a natureza da aprendizagem individual, verifica-se o quanto esta é limitada, em função da visão restrita da aprendizagem no âmbito organizacional. A aprendizagem individual é significativamente afetada pelas práticas organizacionais, e as práticas de aprendizagem gerencial refletem a orientação da organização para a aprendizagem. Os achados da autora demonstram a influência direta da organização nas percepções individuais do que é aprendizagem, o que deve ser aprendido, como deve ser aprendido e do juízo de significância no momento em que os indivíduos aprendem. Assim, a aprendizagem é moldada pelo contexto organizacional no qual ela se situa. Cherman e Rocha-Pinto (2013) chegaram a conclusões similares acerca do conhecimento que os indivíduos possuem e valoram em relação aos conhecimentos que os indivíduos percebem que a organização valora. Também a concepção em relação ao que é conhecimento por parte da organização, na percepção e fala dos indivíduos, é bastante restrita, limitada e limitante.

O segundo fator que afeta a aprendizagem no trabalho é a política. De acordo com Antonacopoulou (2006), a aprendizagem nas organizações é um fenômeno calculativo e estruturado para o modo como os indivíduos encaram os dilemas internos quando eles têm que equilibrar as prioridades pessoais e organizacionais em relação à aprendizagem. São escolhas limitadas, refletindo a política de aprendizagem que transparece nos desequilíbrios de poder e controle, e 
nas tensões entre prioridades entre aprendizagem individual e organizacional. Segundo a autora, aprendizagem seria apenas outra forma de controle, refletindo modelos mentais, significados considerados importantes no nível organizacional para os indivíduos, e identidades institucionais que os indivíduos devem possuir para permanecer naquele local por meio de comportamentos inconscientes que mantêm o status quo.

O terceiro fator relaciona-se à identidade institucional da aprendizagem individual, ou seja, à condição de funcionário ou gerente naquela organização, adequando-se e mantendo o status quo (ou isomorfismo institucional). Deste modo, a aprendizagem individual é boa na medida do contexto da organização. Além disso, há evidências sobre a reciprocidade entre aprendizagem individual e organizacional: a organização afeta a aprendizagem do indivíduo, mas o inverso é menos verossímil. Dada a complexidade da aprendizagem nas organizações, este processo deveria ser tratado como um processo emergente de negociação (não apenas de conteúdo ou forma, mas de significados e identidades). Antonacopoulou (2006) conclui que a natureza política da aprendizagem é um processo de interpretação de sinais em um contexto particular e que os discursos inerentes conferem à aprendizagem um significado para que indivíduos se engajem.

Oborn e Dawson (2010), com base em Foucault, Polanyi e no enfoque do conhecimento na prática e na ação, examinam o processo de geração e tradução de conhecimento em equipes multidisciplinares, mais especificamente o processo de integrar práticas e construir conhecimento por meio da atuação dos especialistas em colaboração. Os autores demonstram como o significado comum é desenvolvido, comunicado e coconstruído, mas não necessariamente integrado no grupo. O conhecimento passa por discursos concorrentes, situações de incerteza e contestação, quando os membros da equipe estão decidindo, individual ou coletivamente, o que privilegiar. Há processos de conflito e acomodação, e os conhecimentos de determinados membros são sistematicamente preferidos (privilegiados) ou constrangidos (silenciados).

O conhecimento privilegiado é reconstituído como as práticas da equipe, sendo autoritariamente estruturado como multidisciplinar (dignificado pelo consenso). Os achados sugerem que a criação de estruturas multidisciplinares suporte e ampare, mais do que desafie, o conhecimento privilegiado já existente e 
apenas reforça as hierarquias de poder. Oborn e Dawson (2010) concluem que o conhecimento formal de disciplinas profissionais molda a forma como as instituições humanas são organizadas e sugere que esse tipo de normalização seja um instrumento central de poder profissional.

Heizmann (2011) analisa, com base em Foucault e sob a perspectiva de poder e do discurso organizacional, uma rede dispersa de práticas de recursos humanos. O estudo demonstra a forma como a luta pelo poder/conhecimento organizacional (inseparáveis e mutuamente constitutivos na forma do discurso, na visão de Foucault, 1980) afeta a dinâmica do compartilhamento de conhecimento e a participação em redes de prática. A autora encontrou três achados específicos: a contestação dos conhecimentos pelos grupos, a dinâmica de participação e o papel das relações de poder.

Foram encontrados discursos de poder/conhecimento concorrentes, distantes da visão de engajamento e mútuo entendimento proposta no enfoque da aprendizagem situada (BROWN e DUGUID, 2001), e que direcionaram os grupos regionais (periféricos) para práticas próprias e exclusivistas, e não colaborativas. Ao mesmo tempo, os membros do grupo da matriz posicionaram-se como membros privilegiados, com esfera de influência sobre as decisões. A dinâmica em torno de duas comunidades separadas formata as relações de poder no interior das comunidades e da rede de prática. Dado o poder regional mais fraco em relação à matriz, cabe o papel reduzido de implantar o conhecimento da matriz na subsidiária, e não há qualquer encorajamento para compartilhar o conhecimento local, regional. Heizmann (2011) conclui que as práticas de compartilhamento de conhecimento possuem um papel de reproduzir e reforçar as relações desiguais de poder, que marginaliza grupos e favorece determinados conhecimentos.

O trabalho de Harman (2012) adota a mesma perspectiva baseada em Foucault, com achados paralelos aos de Heizmann (2011), embora em outro contexto. Harman (2012) argumenta que a aprendizagem no contexto do trabalho pode ser compreendida como o processo durante o qual os funcionários aprendem a 'ser' no trabalho. A aprendizagem diária é um trabalho de construção de identidade contínuo, que tem lugar na, e por meio da, participação nas práticas do trabalho. Os mecanismos discursivos existentes nas organizações, que o indivíduo toma para identificação e negociação/renegociação de identidades, permitem este processo de construção identitária. 
O discurso, portanto, consiste na combinação de práticas social e de linguagem, que contribuem para a construção do conhecimento, identidades e experiências. Os diversos discursos concorrentes e seus significados e valores correlatos se tornam incorporados, proporcionando os modos de pensar e representando a aprendizagem diária no contexto do trabalho. $\mathrm{O}$ autor reitera que o processo de poder não é necessariamente hierárquico e top-down; trata-se da autorregulação dos próprios indivíduos em busca de progressão na carreira ou aumento de salário, por exemplo.

\subsubsection{Valoração do Conhecimento pela Legitimação}

Um quarto conjunto de estudos aborda o processo de legitimação do conhecimento pelos indivíduos, visando a que ele se estabeleça na organização, entre organizações, no grupo, ou entre grupos. Nestes artigos, os indivíduos, geralmente trabalhadores do conhecimento (ALVESSON, 2001), assumem o papel de legitimadores, encarregados de endossar o conhecimento que deve ser aceito e incorporado.

Heusinkveld e Benders (2005) procuram compreender o processo de comoditização do conhecimento dentro do sistema de suprimento de conhecimento, ou seja, em firmas de consultorias em gestão. Geralmente, a transformação de novos modelos de gestão em produtos é vista como linear e não problemática. O estudo dos autores, entretanto, revela que o processo de comoditização do conhecimento é problemático e contestado dentro das consultorias. Heusinkveld e Benders (2005) analisam o estabelecimento interno de novos produtos de conhecimento, identificando os elementos que inibem ou encorajam este processo, assim como as bases que impedem a ligação de novos produtos de conhecimento com a organização: falta de alinhamento com os negócios existentes; falta de envolvimento da alta gestão e colaboração dos pares; e, especialmente, a importância dos esforços internos de legitimação. Os achados indicam que o desenvolvimento de novas ideias não necessariamente se adéqua às práticas estabelecidas e não obtém suporte nem colaboração automática por parte dos membros internos das consultorias. Torna-se um processo extensivamente legitimado em âmbito interno, até ganhar valor percebido, antes de aparecer como produto ao mercado. 
Sturdy et al. (2009) discutem a percepção do papel dos consultores de gestão na perspectiva do cliente. Consultores, na qualidade de inovadores, levam à adoção de novos conhecimentos pelo cliente e são vistos como outsiders da organização e de conhecimento, agindo como objetos de fronteira, que geram fluxo de novo conhecimento not invented here (NIH). Por outro lado, consultores, na função de legitimadores, reforçam os conhecimentos existentes no cliente, sendo a sua tarefa vista como um papel de fronteira organizacional. Os autores reforçam e modelam o papel dos consultores como inovadores, em termos de status de especialista e identidade (outsider).

Embora não trate a questão especificamente sob a ótica da legitimação, o estudo de Inkpen (2008) discute que a transferência de conhecimento entre gerentes envolvidos em uma aliança do tipo joint-venture somente começa a ocorrer quando se forma um consenso sobre o valor do conhecimento acessível do parceiro, reduzindo a ambiguidade. Primeiramente, portanto, o valor do novo conhecimento precisa ser reconhecido e aceito pelos indivíduos, para que, em seguida, as práticas e os investimentos em aprendizagem sejam estabelecidos (INKPEN, 2008).

O consenso em torno do valor do conhecimento foi necessário para que se formasse uma rede social e uma linguagem comum, de modo a que os investimentos em aprendizagem pudessem trazer resultados. Inkpen (2008) ainda sugere que o consenso acerca do valor do conhecimento e uma linguagem comum associada a esse valor são antecedentes que suportam a transição entre padrões de aprendizagem desordenada para uma transferência de conhecimento sistemática, incorporada nas rotinas organizacionais.

\subsubsection{Valoração do Conhecimento pela Confiança (Trust)}

O quinto grupo de estudos trata da confiança (trust) interpessoal (RENZL, 2008) ou membros-rede interorganizacional (MULLER-SEITZ e GÜTTEL, 2012), como elemento que determina se o conhecimento valorado deve ser compartilhado ou qual o conhecimento que deve ser valorado.

Renzl (2008) aponta da influência da confiança (trust) interpessoal, em particular na gestão, sobre o compartilhamento de conhecimento. A autora demonstra que o medo de o indivíduo perder seu valor único e exclusivo e a 
documentação do conhecimento exercem um efeito mediador no relacionamento entre confiança e compartilhamento do conhecimento, pois a confiança na gestão aumenta o compartilhamento de conhecimento por meio da redução do medo de perder o valor único do conhecimento e aumento da propensão a documentá-lo.

O estudo de Muller-Seitz e Güttel (2012) procura identificar a forma como as organizações podem estabelecer práticas para governar a absorção de conhecimento em redes interorganizacionais. Com base na perspectiva do conhecimento na prática e no enfoque da aprendizagem situada, Muller-Seitz e Güttel (2012) analisam o modo como a Intel e a rede que congrega a indústria de tecnologia colaboram entre si para alcançar uma vanguarda tecnológica, assim como para adquirir e disseminar conhecimento entre vários membros e parceiros. Os autores sugerem que a congregação em torno da rede seja valiosa devido à circulação de conhecimento e do valor do conhecimento externo, que podem gerar direcionamento estratégico, sendo certo que os membros da rede tentam influenciar na atribuição de valor ao novo conhecimento. Questões de confiança (trust), identidade e influência sobre a rede (em promover ou abandonar uma tecnologia) emergiram no estudo. Além disso, entre as atividades dos membros da rede como provedores e recebedores de conhecimento, também consta a de modificar o conhecimento existente pela interpretação e avaliação contínua da rede de parceiros.

\subsection{Valoração do Conhecimento e o Enfoque do Conhecer (Knowing) na Prática e na Ação}

Cabe ressaltar os estudos que trabalharam a percepção dos indivíduos acerca de valor com base no enfoque do conhecer (knowing) na prática e na ação: Antonacopoulou (2006), Harman (2012), Heizmann (2011), Muller-Seitz e Güttel (2012), Nag et al (2007), Oborn e Dawson (2010). Os trabalhos de Swart (2011) e Thompson e Walsham (2004) foram destacados, pois abordam especificamente a relação entre os conceitos de conhecer na prática e na ação e o valor do conhecimento.

Thompson e Walsham (2004) ilustram, com base na teoria da atividade de Blackler (1995), que o contexto organizacional é inseparável do conhecer, e 
demonstram a interação relacional entre os componentes pessoais do contexto, profundos e compartilhados. Com base nesses achados, os autores argumentam que a organização pode obter maior valor dos seus investimentos em iniciativas internas, ao aumentar sua capacidade de em suportar o conhecer na prática, assim como a criação de um significado comum entre seus funcionários.

O trabalho de Swart (2011) aborda especificamente a forma como o conhecer na ação ou knowing cria valor. $\mathrm{O}$ autor argumenta que o conhecimento só possui valor quando é desempenhado (enacted). Para tanto, Swart (2011) considera a rotina na prática, constituída de ações, pessoas, espaço e tempo específicos, onde o valor é criado pelas interações entre know-how, relacionamentos e histórico, ou seja, inter-relações entre conhecer e artefatos. Criação de valor é o resultado que emerge de uma atividade, razão pela qual o foco se desloca do conhecer sobre algo para conhecer sobre fazer atividades. O modelo proposto pelo autor considera as relações de poder negociadas na ação e no tocante aos recursos percebidos pelos indivíduos em um dado contexto (SWART, 2011).

Em síntese, a revisão da literatura dos artigos publicados em matéria de conhecimento organizacional revelou três enfoques relacionados ao valor do conhecimento: o valor do conhecimento como um número mensurável, o valor do conhecimento estratégico, o valor do conhecimento como percepção e significado.

Quanto a este último enfoque, a valoração do conhecimento pela percepção do indivíduo demonstra ser um fenômeno multidimensional e complexo. Cinco mecanismos parecem atuar sobre os modos de percepção de valor do conhecimento e exercer influência sobre as escolhas dos indivíduos acerca dos conhecimentos a serem adotados no contexto organizacional: identidade social e profissional; identificação e identidade organizacional; poder, política e hierarquia; legitimação; e confiança, sendo certo que algumas questões de status, expertise, negociação, dentre outros fatores se inserem em alguns destes aspectos. A análise desses mecanismos sugere que a valoração do conhecimento pelos indivíduos ocorre em diversos níveis de interação: o indivíduo busca alinhamento com os grupos (times, equipes ou departamentos), com a organização, com a rede de relacionamentos interorganizacionais (clientes, parceiros ou rede de colaboração), e também entre grupos com a organização. 
A Figura 2 esquematiza a relação entre os mecanismos com as dimensões de interação sugeridas. O esquema revela o jogo de forças que influencia as escolhas individuais, ou que parecem ser individuais. Os estudos expõem indiretamente que, longe de ser um processo isento, a atribuição de importância ao conhecimento circulante, no contexto da organização, apresenta vieses e filtros que moldam e distorcem as escolhas. Eles sugerem que os indivíduos atribuem valor de importância em função dos grupos aos quais pertencem (MENON e BLOUNT, 2002; THOMAS-HUNT et al., 2003; WONG, 2008) e do poder exercido pelos vários grupos (ANTONACOPOULOU, 2006; HARMAN, 2012; HEIZMANN, 2011). Porém, também a organização (por intermédio do grupo da alta gestão e das estratégias, rotinas, cultura e estrutura) gera influência por meio dos mecanismos de identidade organizacional, poder, legitimação e confiança.

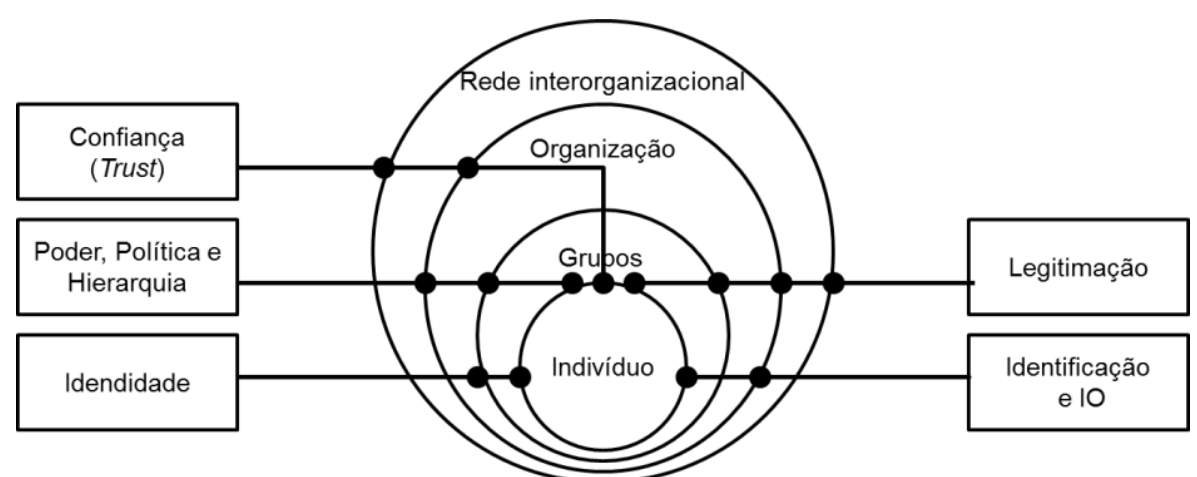

Figura 2: Relação entre os mecanismos de valoração do conhecimento com as dimensões de interações (elaborado pela autora)

Os contextos organizacionais, portanto, parecem favorecer determinados conhecimentos, aqueles percebidos como os mais relevantes e reconhecidos do ponto de vista da organização (do seu modelo mental), mas não necessariamente os mais necessários para ela (ANTONACOPOULOU, 2006; COLMAN e LUNNAN, 2011; HEUSINKVELD e BENDERS, 2005; INKPEN, 2008; MENON e PFEFFER, 2003; MULLER-SEITZ e GÜTTEL, 2012; NAG et al., 2007; OBORN e DAWSON, 2010; RAVISHANKAR e PAN, 2008; RENZL, 2008; STURDY et al., 2009).

Por conseguinte, a revisão dos estudos sugere que a incorporação dos conhecimentos individuais no conhecimento coletivo, organizacional sofre os impactos dos mecanismos e dimensões mencionados. Parece implicar, também, 
que a relação inversa, a internalização do conhecimento organizacional, no portfólio de conhecimentos individuais, ocorre com maior intensidade, dados os mecanismos existentes e os contextos organizacionais, que agem como modeladores das escolhas individuais. 


\section{4 \\ Rotinas Organizacionais}

Esse capítulo trata da origem e evolução do conceito e dos aspectos principais que dizem respeito às rotinas organizacionais, um dos meios pelos quais o conhecimento se incorpora nas práticas organizacionais e se institucionaliza na organização. A seguir, são abordadas, comparativamente, as duas correntes de estudos que abordam o tema de rotinas organizacionais: a corrente das capacidades, derivada da economia organizacional; e a corrente da prática, derivada da teoria das organizações. Maior atenção é dada ao último enfoque, das rotinas organizacionais como prática, uma vez que se alinha com a perspectiva do conhecer (knowing) na ação e na prática e o enfoque do valor do conhecimento como significado e interpretação na percepção dos indivíduos, ou seja, practice-based.

\subsection{Origens das Rotinas}

Segundo o trabalho de Parmigiani e Howard-Grenville (2011), as origens das rotinas organizacionais remontam ao trabalho de Dewey (1922, apud PARMIGIANI e HOWARD-GRENVILLE, 2011) sobre hábito e ação reflexiva como os primeiros guias para o comportamento individual e coletivo. Posteriormente, Cyert e March (1963), March e Simon (1958) e Simon (1947) escreveram acerca dos aspectos comportamentais da tomada de decisão nas organizações. Estes autores concebiam as rotinas organizacionais como regras simples, uma programação fracamente aglutinada visando desempenho, que permitiria a reação da organização ao ambiente (MARCH e SIMON, 1958). Assim, as rotinas organizacionais seriam desenvolvidas para ganhar tempo e atenção a determinados aspectos durante a análise e a tomada de decisão (SIMON, 1947). Os procedimentos-padrão, as regras e os padrões de comportamento facilitam o processo de tomada de decisão mais efetivo, uma vez que suportam a resolução de conflitos e a adaptação ao ambiente (CYERT e MARCH, 1963). 
Entretanto, ainda de acordo com Parmigiani e Howard-Grenville (2011), foi a publicação de Nelson e Winter (1982) que definitivamente disseminou as rotinas organizacionais, definidas como padrões de comportamento regular e previsível das organizações. Metaforicamente, são genes que dão a herança e a marca seletiva pelas quais a organização tomará por base para sua mudança evolucionária. As rotinas foram categorizadas pelos autores como aquelas relacionadas em saber como fazer e aquelas relacionadas a saber como escolher, ou seja, produção e implementação em contrapartida à deliberação, seleção e modificação, respectivamente. As rotinas são vistas ainda como: metas de desempenho, promovendo mecanismos de controle e base para replicação; repositórios de memória organizacional, onde a organização recorda-se ao fazer rotinas específicas por determinados indivíduos diante de determinados estímulos. Nelson e Winter (1982) ainda reforçam o caráter contextual das rotinas, no qual habilidades, organização e tecnologia estão intimamente interligadas em uma rotina funcional.

Segundo Parmigiani e Howard-Grenville (2011), Pentland (1995) lança as bases para uma perspectiva da prática sobre as rotinas organizacionais, ao reforçar as ações diárias associadas com rotinas específicas. Ele propôs a ideia de que as rotinas performativas demandam que os indivíduos selecionem de um amplo repertório de ação já existente, enquanto que o desempenho resultante é melhor concebido como um esforço realizado. A corrente das rotinas organizacionais como prática será detalhada no tópico 4.3.

Com o objetivo de criar um entendimento comum e conduzir as futuras pesquisas nesse campo de estudo, Cohen et al. (1996) apresentam um conceito para rotinas organizacionais. Com base no pressuposto de que as organizações são sistemas políticos, sociais e econômicos, os autores reiteram que as rotinas são padrões de ação recorrentes e elegíveis, definindo-as como a "capacidade executável para o desempenho repetido, em algum contexto que foi aprendido por uma organização, em resposta a pressões seletivas" (1996; p. 683). O contexto específico é responsável por projetar ambientes e artefatos em que os trabalhadores podem aprender comportamentos coordenados, daí sua relevância. Assim, as rotinas consistem em uma mistura de elementos tácitos e automáticos com atividades deliberativas, de solução de problemas, que são difíceis de serem 
compreendidos em sua intenção quando apenas o comportamento pode ser observado.

Assim, embora os conceitos iniciais associem a ideia de rotinas organizacionais a regras e procedimentos fixos, estáticos, repetitivos, que controlam atividades e comportamentos, o conceito evoluiu e, com a contribuição de Feldman (2000), já se sabe que as rotinas incorporam na ação, na prática de sua execução, adaptações e mudanças contínuas, em função do contexto da situação.

Como será explorado a seguir, o conceito ganha nuances diferenciadas em acordo com as duas perspectivas de estudos em rotinas organizacionais: corrente de capacidades e corrente de prática.

\subsection{Correntes no Campo das Rotinas Organizacionais}

Parmigiani e Howard-Grenville (2011) descrevem duas correntes constitutivas do que seria uma visão completa de rotinas organizacionais. Elas devem ser compreendidas como duas perspectivas acerca do mesmo fenômeno, uma evolução natural dos estudos em rotinas organizacionais.

A primeira corrente, oriunda da economia organizacional, ganhou o rótulo de Capacidades. Ela trata as rotinas como uma caixa preta, analisando-as como uma entidade completa, única. Está interessada no propósito e motivação das rotinas e seu impacto no desempenho organizacional. Neste enfoque, os indivíduos são considerados limitadamente racionais, agindo potencialmente em interesse próprio, porém operando conforme esperado e desempenhando as rotinas do modo como foram desenhadas.

Uma definição prototípica na corrente de capacidades é a de que as rotinas são blocos constitutivos das capacidades, com natureza repetitiva e dependente do contexto (DOSI et al., 2008; apud PARMIGIANI e HOWARD-GRENVILLE, 2011). Três ramificações de estudos derivam desta corrente: rotinas como microfundações de capacidades (FELIN et al. 2012; HODGSON, 2012; TEECE, 2007); rotinas como repositórios de conhecimento organizacional, que possibilita aprendizagem e mudança (ARGOTE e REN, 2012; DARR et al., 1995; GRANT, 1996; NELSON e WINTER, 1982); e rotinas como genes que promovem estabilidade ou inércia (SZULANSKI, 1996). 
A fusão das ideias de aprendizagem organizacional e as mudanças nas rotinas organizacionais geraram o conceito de capacidades dinâmicas (EISENHARDT e MARTIN, 2000; TEECE et al., 1997: ZOLLO e WINTER, 2002), ou seja, o padrão sistemático de atividade organizacional visando a geração e adaptação de rotinas operacionais (ZOLLO e WINTER, 2002). Os fundamentos das mudanças nas rotinas, segundo Zollo e Winter (2002), advêm dos mecanismos de: aprendizagem da experiência acumulada, articulação do conhecimento e codificação do conhecimento nas organizações.

A segunda corrente, proveniente da teoria organizacional, recebeu o rótulo de Prática. Ela tem sua base fundamentada nos trabalhos de Bourdieu (1977) e Giddens (1984). As rotinas, nesta visão, são analisadas em suas partes e como estas se interligam, ou seja, uma preocupação com sua dinâmica interna. Ela interessa-se pelas práticas das rotinas, como elas operam e como são reproduzidas ou mudadas de acordo com o modo como as pessoas atuam elas no dia a dia organizacional. Neste caso, a ação humana é situada em um conjunto específico de circunstâncias, o qual pode ou não conduzir os indivíduos a desempenharem as rotinas conforme foram desenhadas.

No presente estudo, foi priorizada a visão advinda da corrente das rotinas organizacionais como prática, em linha com os enfoques do conhecer na prática e na ação e do valor do conhecimento como interpretação e significado pelo enfoque sobre a percepção do indivíduo. Portanto, ela é mais detidamente explorada no tópico a seguir.

Cabe ressaltar que, em comum, ambas as perspectivas reconhecem a atenção aos indivíduos, o papel relevante do conhecimento tácito, o entendimento de que as rotinas são tanto estáveis como evolutivas, a importância do contexto para a compreensão de como as rotinas operam. O quadro 3, baseado em Parmigiani e Howard-Grenville (2011), apresenta uma síntese dos pressupostos existentes em cada uma das correntes mencionadas, além de incluir as definições de rotinas respectivas a cada corrente, com fins de comparação. 


\begin{tabular}{|c|c|c|}
\hline & Corrente das Capacidades & Corrente da Prática \\
\hline $\begin{array}{l}\text { Definição de } \\
\text { rotinas } \\
\text { organizacionais }\end{array}$ & $\begin{array}{l}\text { São blocos constitutivos das } \\
\text { capacidades, com natureza repetitiva e } \\
\text { dependente do contexto. }\end{array}$ & $\begin{array}{l}\text { São padrões de ação interdependentes, } \\
\text { repetitivos e reconhecíveis, conduzidos } \\
\text { por múltiplos atores. }\end{array}$ \\
\hline $\begin{array}{l}\text { Interesses } \\
\text { principais }\end{array}$ & $\begin{array}{l}\text { O que as rotinas fazem (coordenam, } \\
\text { criam, mudam); } \\
\text { Como elas guiam o desempenho da } \\
\text { firma. }\end{array}$ & $\begin{array}{l}\text { Como as rotinas operam; } \\
\text { Quais são as dinâmicas internas. }\end{array}$ \\
\hline $\begin{array}{l}\text { Nível focal de } \\
\text { análise }\end{array}$ & $\begin{array}{l}\text { A organização: a estrutura para } \\
\text { governar, coletar, criar e manter as } \\
\text { rotinas. }\end{array}$ & A rotina. \\
\hline $\begin{array}{l}\text { Unidade de } \\
\text { análise }\end{array}$ & $\begin{array}{l}\text { Rotinas como "entidades": rotinas } \\
\text { completas, "caixas pretas". }\end{array}$ & $\begin{array}{l}\text { Rotinas como "partes": estrutura } \\
\text { interna da rotina, o que está dentro da } \\
\text { "caixa preta". }\end{array}$ \\
\hline Foco empírico & $\begin{array}{l}\text { Especificidade das rotinas por } \\
\text { organização; } \\
\text { Como elas criam valor e levam a } \\
\text { desempenhos diferentes; } \\
\text { Como são criadas para formar } \\
\text { capacidades; } \\
\text { Complementaridade entre rotinas; } \\
\text { Transferência intra e entre } \\
\text { organizações. }\end{array}$ & $\begin{array}{l}\text { Influência do ator no desempenho da } \\
\text { rotina; } \\
\text { Influência de artefatos no desempenho } \\
\text { da rotina; } \\
\text { Como as rotinas são criadas ou } \\
\text { mudadas; } \\
\text { Como as rotinas mudam e permanecem } \\
\text { estáveis no tempo, e o papel da } \\
\text { organização e seus artefatos sobre isso; } \\
\text { Como e quando as rotinas deixam de } \\
\text { funcionar. }\end{array}$ \\
\hline $\begin{array}{l}\text { Pressupostos } \\
\text { comportamentais }\end{array}$ & $\begin{array}{l}\text { Baseado na racionalidade; } \\
\text { Especificidade da visão por } \\
\text { organização; } \\
\text { Interesse próprio potencial; } \\
\text { Agentes agem conforme esperado. }\end{array}$ & $\begin{array}{l}\text { Ação humana é baseada em esforços; } \\
\text { Agente humano e atividade diária } \\
\text { constituem a vida social; } \\
\text { Agentes não são substituíveis, têm } \\
\text { diferentes intenções, motivações e } \\
\text { entendimentos. }\end{array}$ \\
\hline Metáforas & $\begin{array}{l}\text { Gene } \\
\text { Repositório da memória } \\
\text { (organizacional) } \\
\text { Microfundações das capacidades }\end{array}$ & $\begin{array}{l}\text { Gramática } \\
\text { Repertório } \\
\text { Sistemas generativos }\end{array}$ \\
\hline $\begin{array}{l}\text { Estabilidade e } \\
\text { mudança }\end{array}$ & $\begin{array}{l}\text { Compreensão que as rotinas podem } \\
\text { mudar, mas interesse principal na } \\
\text { estabilidade; } \\
\text { O que as rotinas oferecem para } \\
\text { estabilidade ou mudança. }\end{array}$ & $\begin{array}{l}\text { Mudança e estabilidade são sempre } \\
\text { possíveis; } \\
\text { Os mesmos mecanismos (agência, } \\
\text { artefatos) sublinham a mudança ou a } \\
\text { estabilidade. }\end{array}$ \\
\hline
\end{tabular}

Quadro 3: Pressupostos das Correntes das Capacidades e da Prática (adaptado de PARMIGIANI e HOWARD-GRENVILLE, 2011, p.418).

\subsection{Corrente das Rotinas Organizacionais como Prática}

Segundo Feldman e Orlikowski (2011), a corrente da prática estuda a atividade cotidiana de organizar (organizing), descrevendo como as práticas diárias são realizadas, reforçadas ou alteradas no curso da ação. A ênfase se encontra no trabalho interno de rotinas específicas em contextos organizacionais específicos. Nesta perspectiva, as rotinas organizacionais são definidas como padrões de ação interdependentes, repetitivos e reconhecíveis, conduzidos por 
múltiplos atores (FELDMAN e PENTLAND, 2003). O foco, entretanto, é como os padrões são produzidos e reproduzidos e em que medida os padrões se mantêm estáveis ou mudam no decorrer do tempo.

Baseando-se em Feldman e Orlikowski (2011), que descrevem o campo emergente da teoria da prática em relação aos fenômenos organizacionais, Parmigiani e Howard-Grenville (2011) apresentam os pressupostos que sublinham a visão da teoria da prática e suas implicações para os trabalhos em rotinas organizacionais. Primeiro, a ação situada é consequência na produção do mundo social, ou seja, as ações diárias são resultantes na produção dos contornos estruturais da vida social (FELDMAN e ORLIKOWSKI, 2011). Portanto, buscase acessar o comportamento situado do indivíduo, ações específicas no tempo e espaço, para generalizar como a ação se desdobra em outros contextos.

Segundo, os dualismos que distinguem o ator humano da agência são rejeitados, reconhecendo-se a inerente relação entre os elementos que antes eram considerados dicotômicos ou opostos, tais como: mente-corpo, cognição-ação, objeto-sujeito, estrutura-agência, individual-institucional (FELDMAN e ORLIKOWSKI, 2011; LATOUR, 1986; 2012). Terceiro, as relações são mutuamente constitutivas, ou seja, nenhum fenômeno pode ser visto de modo independente ou isolado. Os fenômenos sempre existem em relação um ao outro, produzidos por um processo de mútua constituição (FELDMAN e ORLIKOWSKI, 2011), implicando que estruturas (rotinas, instituições e qualquer ordem social) são produtos da ação humana, ainda que a ação humana seja constrangida e possibilitada por estas mesmas estruturas.

As implicações destes pressupostos para as rotinas organizacionais dizem respeito ao fato de que as rotinas possuem uma dinâmica interna própria para sua reprodução, onde rotinas aparentemente estáveis, que não mudam no tempo, são consideradas como as realizações do esforço dos atores (PARMIGIANI e HOWARD-GRENVILLE, 2011). Dada a visão da mútua constituição, estabilidade e mudança são diferentes resultados da mesma dinâmica, e não resultado de dinâmicas distintas.

A perspectiva da prática considera as rotinas tanto como emergentes, uma vez que elas acontecem através do desempenho feito pelos atores (FELDMAN, 2000), quanto como generativas, já que elas possuem sua própria dinâmica interna para sua continuidade e mudança (FELDMAN e PENTLAND, 2003). Os 
indivíduos, ao desempenharem as rotinas, se utilizam de um repertório mutuamente compreendido de ações possíveis, em uma analogia com a gramática. Deste modo, as rotinas são sempre esforços realizados pelos indivíduos e as mudanças nelas são constrangidas pelas estruturas que as cercam no seu uso, na sua aplicação. Feldman (2000), por sua vez, argumenta que as rotinas mudam continuamente, a cada vez que são desempenhadas pelos indivíduos.

Feldman (2000) propõe que as rotinas devem ser encaradas como um fluxo que abarca uma ampla gama de pensamentos, sentimentos e ações que os indivíduos experimentam quando trabalham. Assim, em seu modelo, a autora procura esquematizar e conceituar as rotinas performativas como um ciclo (interminável) de planos, ações, resultados e ideais. A interação entre os elementos no ciclo suportam as ações de reparar, expandir e lutar, que mudam as rotinas estabelecidas.

Em estudo posterior, Feldman e Pentland (2003) apresentaram as rotinas como performativas ou ostensivas, com base em seus aspectos. A rotina performativa pode ser considerada a rotina na prática, onde o aspecto performativo consiste em ações específicas, desempenhadas por pessoas específicas, em um lugar e tempo específicos. Já a rotina ostensiva é a rotina, em princípio, já internalizada como uma norma, sendo seu aspecto ostensivo à ideia abstrata e generalizada de rotina. Ambos os aspectos ostensivo e performativo constituem mutuamente a rotina, porém o aspecto ostensivo invoca os recursos para conduzir à ação e, ao mesmo tempo, inibe e constrange mudanças às rotinas; enquanto o aspecto performativo gera, recria, mantém e modifica o aspecto ostensivo (os recursos) (FELDMAN, 2000; FELDMAN e PENTLAND, 2003; PENTLAND e FELDMAN, 2008).

O trabalho de Feldman e Pentland (2003), de entender as rotinas como possuindo duplo caráter, é muito relevante, pois viabilizou o estudo das rotinas na perspectiva da prática. Possibilitou integrar o aspecto cognitivo (ostensivo) com o aspecto comportamental (performativo). Além disso, permitiu observar que as rotinas podem ser diferentes a cada vez que são realizadas, enquanto retêm as mesmas características rotineiras que as fazem ser identificadas como o mesmo padrão de ação. Friesl e Larty (2013) agregam à lista, sugerindo que a visão de Feldman e Pentland (2003) possibilitou entender a replicação da rotina como um processo político nas organizações, uma vez que a noção de agência englobando 
os indivíduos e suas influências nas práticas (com base na ANT e em Latour, 1986), e não apenas as instituições, implica nos múltiplos interesses dos diversos atores envolvidos na rotina.

\subsubsection{Estudos Empíricos na Corrente das Rotinas Organizacionais como Prática}

A revisão dos estudos empíricos conduzida por Parmigiani e HowardGrenville (2011) sintetiza que o corpo de conhecimento consistente em rotinas organizacionais se concentrou em torno de três grandes áreas: 1) muitos estudos buscando construção de teoria em torno do papel dos atores e agência na formatação das rotinas; 2) poucos estudos analisando o papel dos artefatos não humanos nas rotinas; e 3) poucos estudos focando a incorporação das rotinas organizacionais em outras facetas da vida organizacional, ou seja, os contextos. O presente estudo, em seu objetivo secundário, se encaixa nas primeira e terceira áreas, ao buscar identificar as relações entre a valoração do conhecimento e a incorporação do conhecimento nas rotinas organizacionais.

\subsubsection{1. Área de Estudos Ator-Agência}

Esse campo foca em como os indivíduos moldam as rotinas no decorrer do tempo. Feldman (2000) descobriu que as pessoas nem sempre conduzem as rotinas conforme pretendido e alteram a atuação das rotinas no cotidiano, porque a rotina não está alcançando o resultado esperado, está gerando resultados indesejáveis não pretendidos ou os resultados revelam novas possibilidades de ação. Mais do que aprendizagem tentativa-e-erro ou ajustamento, as mudanças sugerem um processo contínuo e permanente de mudança em como a rotina é usada através da organização. Os indivíduos não operam com um repertório fixo quando desempenham uma rotina, mas sim expandem o repertório pelo empréstimo de outros contextos ou por meio de invenção.

A persistência da rotina, apesar do seu uso flexível pelos indivíduos, foi estudada por Feldman (2003) e Howard-Grenville (2005). Determinadas rotinas são difíceis e demoradas para mudar, porque a mudança desejada é inconsistente com o entendimento dos indivíduos de como a organização, como um todo, funciona. Também, por vezes, os indivíduos pensam em novos usos para a rotina, 
propondo mudança. Porém, outras vezes, seguem um entendimento ostensivo da atuação da rotina, por razões políticas. Esses fatos sugerem que a agência pode promover mudança ou estabilidade sobre a atuação da rotina.

Outros estudos consideraram como os atores moldam a adoção ou atuação de rotinas particulares, focando em questões motivacionais e dinâmica de poder, que revelam as diferenças entre grupos (LAZARIC e DENIS, 2005; REYNAUD, 2005; ZBARACKI e BERGEN, 2010). Reynaud (2005) argumenta que as rotinas devem ser vistas como um esforço individual, demandando que os indivíduos façam sentido das regras disponíveis para eles. A autora conclui que as regras são arranjos esperando interpretação, enquanto as rotinas são regras já interpretadas (que fazem parte do repertório).

O grupo de estudos com foco no ator e agência na rotina revela que os indivíduos contribuem para a flexibilidade e persistência das rotinas, que eles trazem entendimentos e motivações particulares ao desempenhar as rotinas, e que as interações e dinâmica de poder entre grupos podem formatar a adoção, mudança ou persistência das rotinas (PARMIGIANI e HOWARD-GRENVILLE, 2011).

\subsubsection{2. Área de Estudo dos Artefatos}

O papel dos artefatos no desempenho das rotinas explorou, nos trabalhos iniciais, os objetos como representação (regras, procedimento operacional padrão) ou entidades materiais (computadores, espaço físico) que permitiam a atuação da rotina e sua replicação (NELSON e WINTER, 1982). Os trabalhos mais recentes, da perspectiva da prática, analisam os artefatos e sua influência em como as rotinas são realizadas.

D’Adderio (2003) observou as implicações do conhecimento organizacional codificado e práticas incorporados em software, que se tornam invisíveis e privilegiam certas funções, atores ou conhecimentos. Em achado oposto, Hales e Tidd (2009) exploraram como representações formais de rotinas incorporadas em software pouco formatam o desempenho, ressaltando que procedimentos operacionais padrão ou outros artefatos de uma rotina não devem ser confundidos com a rotina em si. 
Parmigiani e Howard-Grenville (2011) ressaltam que o papel dos artefatos é relevante para o estudo das rotinas, porém ainda ambíguo. D’Adderio (2008) e Pentland e Feldman (2008) utilizam a teoria ator-rede (ANT) para explorar a interação entre elementos humanos e não humanos nas rotinas, entretanto os achados são mistos. Trata-se de uma linha de estudos a ser desenvolvida.

\subsubsection{3. Área de Estudo em Incorporação das Rotinas}

Este grupo de estudos abarca o contexto no qual as rotinas estão incorporadas, moldando seu uso e como elas mudam no tempo. Feldman (2003) foi a primeira autora a ressaltar a relevância do contexto no desempenho das rotinas, argumentando que o desempenho tanto interno como externo à rotina moldam a dinâmica da rotina. Como já mencionado, a falta de mudança em uma rotina pode advir da inconsistência entre a mudança pretendida e os entendimentos dos membros organizacionais acerca da organização e como ela funciona.

Howard-Grenville (2005) aborda a incorporação das rotinas em estruturas tecnológicas, culturais e coordenadoras, internas da organização. A autora propõe que as rotinas que estão mais fortemente incorporadas seriam mais resistentes à mudança no tempo, mesmo se os atores as desempenhem com flexibilidade. Rerup e Feldman (2011) demonstram como uma rotina (de recrutamento) coevolui e se altera, com o esquema interpretativo da organização.

Pode-se concluir que as rotinas são mutuamente constituídas com outras estruturas (PARMIGIANI e HOWARD-GRENVILLE, 2011), tais como cultura (HOWARD-GRENVILLE, 2005), padrões de coordenação ou relacionamentos entre grupos (FELDMAN, 2000; ZBARACKI e BERGEN, 2010), regras (REYNAUD, 2005) e artefatos (D'ADDERIO, 2003; HALES e TIDD, 2009). 


\section{5 \\ Metodologia de Pesquisa}

O estudo apresentado nesta tese tem como objetivo identificar as percepções dos indivíduos com relação à valoração do conhecimento no contexto do trabalho. No presente capítulo, foi desenvolvido o percurso metodológico e as escolhas adotadas na realização da pesquisa. Quanto aos meios ou procedimentos de pesquisa e coleta de dados, o design do estudo adotará um conjunto de métodos, a saber: pesquisa bibliográfica em duas fases, pesquisa empírica de campo com o uso do Método Fenomenográfico, utilizando entrevistas semiestruturadas e posterior consolidação com grupo de foco.

A pesquisa bibliográfica e os métodos utilizados na revisão sistemática da literatura inicial são apresentados no próximo tópico 5.1, enquanto a pesquisa empírica, de campo, de natureza qualitativa é abordada a partir do tópico 5.2. O Método Fenomenográfico (BOWDEN e GREEN, 2005; BOWDEN e WALSH, 2000; MARTON, 1981; 2005; MARTON e BOOTH, 1997), e seu modo de aplicação, é descrito, caracterizado, justificado e detalhado no tópico 5.4. Os procedimentos relativos ao grupo de foco, também denominado entrevista em grupo (GOLDMAN e MCDONALD, 1987), são apresentados no tópico 5.5.

\subsection{Etapa 1: Pesquisa Bibliográfica para Revisão Sistemática da Literatura}

Devido à sua natureza qualitativa, a pesquisa bibliográfica foi realizada em dois momentos. Uma primeira pesquisa abrange a revisão da literatura acerca das perspectivas e enfoques nos temas de conhecimento organizacional na perspectiva da ação (knowing, knowledge-in-action, knowledge-in-practice ou knowledge-aspractice) e valoração de conhecimento. Essa revisão objetivou analisar as questões e linhas de pesquisa já abordadas no tema, assim como buscar lacunas e vertentes de relevância ainda pouco exploradas ou não satisfatórias do ponto de vista do objeto de estudo (valoração do conhecimento a partir da percepção dos 
indivíduos no contexto do trabalho). Visou, também, situar e contextualizar a área de estudo em que se insere a presente pesquisa, pois, assim como nos demais métodos qualitativos indutivos, não são estabelecidos hipóteses e modelos a priori antes da realização da pesquisa empírica de campo. Portanto, a segunda pesquisa bibliográfica, para articulação do referencial teórico, foi realizada após a análise dos dados empíricos, com base nos temas emergentes da pesquisa de campo.

Os critérios norteadores para a revisão da literatura inicial foram a amplitude (dada pelo número de periódicos investigados e quantidade de anos de revisão) e a profundidade (dada pela qualidade, relevância e pertinência das publicações). Desse modo, a revisão da literatura comportou três esferas, com o objetivo de buscar exaustividade e abrangência: 1) revisão da literatura seminal; 2) revisão da literatura relevante; 3) revisão da literatura recente, nacional e internacional sobre os temas apontados, compreendida no período dos últimos dez anos. Nos casos abaixo, contou-se com o suporte da ferramenta de pesquisa integrada das principais bases de dados nacionais e internacionais, disponibilizada pelo Portal de Biblioteca da PUC-Rio integrado ao Portal CAPES, para busca e acesso às publicações e artigos.

\subsubsection{Revisão da Literatura Seminal}

Os autores pesquisados na revisão da literatura seminal foram definidos por meio de dois mecanismos:

i. Artigos de revisão de literatura, especialmente, Easterby-Smith e Lyles (2003), Gherardi (2006), Gherardi e Nicolini (2000, 2001), KaratasÖzkan e Murphy (2010); e fontes de referência mencionadas em The Oxford Handbook of Organizational Learning e Knowledge (DIERKES et al., 2001) e The Blackwell Handbook of Organizational Learning and Knowledge Management (EASTERBY-SMITH e LYLES, 2003).

ii. Metarreferência no próprio processo de estudo, onde os artigos remetem e apontam para os autores seminais dedicados ao tema Conhecimento Organizacional e aos subtemas Valoração do Conhecimento e Conhecimento na Ação / Knowing / Knowledge-in-Practice. 


\subsubsection{Revisão da Literatura Relevante}

A revisão da literatura relevante sobre os temas foi determinada pelo uso dos instrumentos a seguir especificados:

i. Utilização de dois handbooks de aprendizagem e conhecimento organizacional, abrangentes e recentes, que reúnem o estado da arte e os tópicos expoentes no campo de estudos, a saber:

- The Oxford Handbook of Organizational Learning e Knowledge (DIERKES et al., 2001) e

- The Blackwell Handbook of Organizational Learning and Knowledge Management (EASTERBY-SMITH e LYLES, 2003; 2011).

\subsubsection{Revisão da Literatura Recente (Últimos Onze Anos)}

A revisão da literatura recente buscou amplitude e profundidade. Conforme a proposta de Villas, Macedo-Soares e Russo (2008), a utilização de rankings e ratings classificatórios dos periódicos por área de estudo busca assegurar a leitura em fontes relevantes e compatíveis com o tema em pesquisa, tendo sido utilizada na revisão de literatura da presente tese. Deste modo, a revisão realizada considerou três rankings e ratings:

i. Journal of Citation Report (JCR, 2010), para a categoria Management. Foram selecionados, inicialmente, 28 periódicos internacionais, dentre os 100 primeiros ranqueados pelo fator de impacto dos últimos cinco anos, considerando-se também o critério de publicação e interesse editorial nos temas de Conhecimento Organizacional e seus subtemas Valoração do Conhecimento e Conhecimento na Ação / Knowing / Knowledge-inPractice.

Foram excluídos da lista os periódicos Harvard Business Review, Sloan Management Review e California Management Review, dado o seu caráter de revista executiva e de cunho não propriamente científico. Além disso, foram excluídos dois periódicos, por impossibilidade de acesso à sua base de dados: International Journal of Human Resource Management e Journal of Organizational Behavior Management.

Tendo em vista que o tema Conhecimento Organizacional foi reconhecido como campo de estudo há cerca de 30 anos, realizou-se a 
revisão da literatura no tocante aos últimos onze anos, ou seja, desde janeiro de 2002.

Após proceder a essa revisão, ainda foram eliminados os periódicos

Administrative Science Quarterly, Leadership Quarterly, Journal of Management Information, Information and Management, Organizational Behavior and Human Decision por não trazerem artigos nos subtemas, donde terem restado 21 publicações. A lista final dos periódicos incluídos na revisão de literatura se encontra no Quadro 4.

\begin{tabular}{|c|c|c|c|c|c|c|}
\hline & Periódico & Ranking & $\begin{array}{l}5 \text { Years } \\
\text { Impact } \\
\text { Factor }\end{array}$ & $\begin{array}{l}\text { Artigos } \\
\text { em CO }\end{array}$ & $\begin{array}{c}\text { Artigos } \\
\text { em } \\
\text { K-i-P }\end{array}$ & $\begin{array}{c}\text { Antigos } \\
\text { em Valor }\end{array}$ \\
\hline 1 & Academy of Management Review & 2 & 11.657 & 9 & 0 & 4 \\
\hline 2 & Academy of Management Journal & 3 & 10.779 & 20 & 2 & 6 \\
\hline 3 & Strategic Management Journal & 6 & 6.818 & 19 & 1 & 4 \\
\hline 4 & Journal of Management & 8 & 6.210 & 14 & 0 & 2 \\
\hline 5 & Organization Science & 10 & 5.838 & 34 & 10 & 7 \\
\hline 6 & Organizational Research Methods & 13 & 5.350 & 1 & 0 & 1 \\
\hline 7 & Research in Organizational Behavior & 15 & 5.167 & 3 & 2 & 1 \\
\hline 8 & Journal of Management Studies & 17 & 4.684 & 36 & 14 & 3 \\
\hline 9 & Journal of Organizational Behavior & 18 & 4.411 & 8 & 1 & 0 \\
\hline 10 & International Journal of Management Reviews & 20 & 4.304 & 9 & 1 & 2 \\
\hline 11 & Management Science & 23 & 3.966 & 42 & 0 & 16 \\
\hline 12 & International Journal of Management Science & 26 & 3.733 & 10 & 0 & 4 \\
\hline 13 & Organization Studies & 29 & 3.590 & 43 & 18 & 5 \\
\hline 14 & Group Organization Management & 41 & 2.710 & 6 & 2 & 1 \\
\hline 15 & British Journal of Management & 45 & 2.631 & 10 & 2 & 1 \\
\hline 16 & Human Relations & 46 & 2.595 & 21 & 9 & 4 \\
\hline 17 & Organization & 55 & 2.152 & 18 & 7 & 3 \\
\hline 18 & Management Learning & 60 & 1.887 & 70 & 44 & 16 \\
\hline 19 & Human Resource Management & 61 & 1.825 & 20 & 0 & 6 \\
\hline 20 & Journal of Management Inquiry & 66 & 1.600 & 11 & 2 & 2 \\
\hline 21 & Organizational Dynamics & 85 & 0.979 & 11 & 0 & 3 \\
\hline 22 & European Management Journal & & Rate 2 & 15 & 1 & 3 \\
\hline 23 & European Management Review & & Rate 2 & 11 & 0 & 4 \\
\hline \multirow[t]{2}{*}{24} & Intl. Studies of Management and Organization & & Rate 2 & 7 & 1 & 0 \\
\hline & Total & & & 447 & 117 & 98 \\
\hline
\end{tabular}

Quadro 4: Listagem de Posição dos Periódicos Internacionais no Ranking JCR (2010) para Management e Rating ABS (2010) para General Management (elaborado pela autora) 
ii. Rating de classificação da Association of Business Schools, Academic Journal Quality (ABS, 2010), nas categorias General Management e Organization Studies. Foram selecionados, inicialmente, 12 e 10 periódicos internacionais, respectivamente, classificados de 4 a 2 , considerando-se o critério de publicação e interesse editorial nos temas de Conhecimento Organizacional e seus subtemas Valoração do Conhecimento e Conhecimento na Ação / Knowing / Knowledge-inPractice.

Na categoria General Management, houve a repetição de 9 periódicos do ranking JCR, tendo sido agregados 3 periódicos à revisão de literatura, enquanto que, na categoria Organization Studies, não surgiu qualquer nova publicação.

Os periódicos incluídos foram os seguintes: European Management Journal; European Management Review; International Studies of Management and Organization. Eles encontram-se sombreados no Quadro 5.

Realizou-se a revisão da literatura no tocante aos últimos 10 anos, ou seja, desde janeiro de 2002.

iii. Rating de classificação Qualis, da CAPES (2011), para os periódicos brasileiros, na classificação em Administração. Foram selecionadas 13 publicações entre A2 e B2, que foram revisadas ao longo dos últimos 11 anos, ou seja, desde janeiro de 2002, ilustrados no Quadro 5. A escolha baseou-se nos periódicos cuja área de interesse editorial enfoca o tema de conhecimento organizacional, seus subtemas valoração de conhecimento e conhecimento-em-prática.

Duas publicações foram excluídas: Latin America Business Review (A2) e Brazilian Business Review (B2), devido à impossibilidade de acesso à base de dados e à ausência de publicação dos temas e subtemas em sua linha editorial respectivamente. 


\begin{tabular}{|l|l|c|c|c|c|}
\hline & Periódico & Rating & $\begin{array}{c}\text { Artigos } \\
\text { em Co }\end{array}$ & $\begin{array}{c}\text { Artigos } \\
\text { em } \\
\text { K-i-P }\end{array}$ & $\begin{array}{c}\text { Antigos } \\
\text { em } \\
\text { Valor }\end{array}$ \\
\hline 1 & Brazilian Administration Review BAR & $\mathrm{A} 2$ & 4 & 0 & 0 \\
\hline 2 & Revista de Administração Pública RAP & $\mathrm{A} 2$ & 2 & 0 & 0 \\
\hline 3 & Revista de Administração Contemporânea RAC & $\mathrm{B} 1$ & 8 & 1 & 1 \\
\hline 4 & Revista de Administração de Empresas RAE & $\mathrm{B} 1$ & 1 & 0 & 1 \\
\hline 5 & RAE Eletrônica & $\mathrm{B} 1$ & 5 & 1 & 0 \\
\hline 6 & Cadernos EBAPE & $\mathrm{B} 1$ & 3 & 2 & 0 \\
\hline 7 & Revista de Administração Mackenzie RAM & $\mathrm{B} 1$ & 3 & 0 & 0 \\
\hline 8 & Revista de Administração USP RAUSP-e & $\mathrm{B} 2$ & 3 & 0 & 0 \\
\hline 9 & Revista Eletrônica de Administração REAd & $\mathrm{B} 2$ & 4 & 0 & 0 \\
\hline 10 & Revista de Administração FEA-USP & $\mathrm{B} 2$ & 3 & 1 & 1 \\
\hline 11 & Base Revista de Administração e Contabilidade UNISINOS & $\mathrm{B} 2$ & 2 & 0 & 1 \\
\hline & Total & & $\mathbf{3 8}$ & $\mathbf{5}$ & $\mathbf{3}$ \\
\hline
\end{tabular}

Quadro 5: Classificação dos Periódicos no Rating Qualis CAPES (2011) para Administração (elaborado pela autora)

\subsection{Abordagem Qualitativa}

Denzin e Lincoln (1994) definem a pesquisa qualitativa como sendo dotada de um foco multimétodo, envolvendo uma abordagem interpretativa e naturalística para com o assunto abordado. Assim, o objeto de pesquisa é estudado em seu ambiente natural, no cenário onde ocorre o fenômeno e encontram-se os sujeitos envolvidos. Cabe ao pesquisador construir sentido ou interpretar o fenômeno em termos dos significados que os sujeitos trazem acerca deste fenômeno (DENZIN e LINCOLN, 1994). A pesquisa qualitativa envolve uma coleção variada de materiais empíricos e, no caso do presente estudo, encontramse, por exemplo, as experiências pessoais retomadas pelos entrevistados, por meio de entrevistas, gerando narrativas que descrevem a rotina, os momentos problemáticos e os significados nas vidas individuais.

Na definição de Creswell (1998), a pesquisa qualitativa é um processo de compreensão baseado em distintas tradições metodológicas de questionamento, que exploram um problema social ou humano. O pesquisador, por sua vez, constrói um quadro complexo e holístico, analisa palavras, reporta visões detalhadas dos informantes e conduz o estudo em seu cenário natural. Quanto às características da pesquisa qualitativa, além das já mencionadas acima, há uma 
concordância entre os diversos autores acerca dos seguintes aspectos (CRESWELL, 1998):

- O pesquisador é instrumento principal de coleta de dados;

- O resultado é o processo, mais do que o produto da pesquisa;

- A análise é indutiva, com atenção às particularidades;

- O foco encontra-se nas perspectivas dos participantes, no seu significado;

- Uso da linguagem expressiva e persuasiva.

Deve-se ter em mente que uma pesquisa qualitativa não é uma opção em oposição à pesquisa quantitativa. Segundo Creswell (1998), há razões e motivações específicas para a condução de uma pesquisa qualitativa. No caso do presente estudo, a primeira delas consiste na natureza da pergunta de pesquisa. A questão de pesquisa Como os indivíduos percebem e experimentam a valoração do conhecimento no contexto do trabalho e a incorporação desses conhecimentos nas práticas organizacionais? conduz a tópicos que descrevem o que se passa em situações e experiências de vida dos sujeitos.

O segundo motivo para adoção de uma abordagem qualitativa refere-se à existência de um tópico que precisa ser explorado, pois os aspectos relacionados ao fenômeno não são facilmente identificados de outra forma e há espaço para uma proposição teórica (CRESWELL, 1998). O modo pelos quais os indivíduos experimentam e percebem a valoração do conhecimento e quais são os seus impactos na incorporação do conhecimento nas práticas organizacionais só podem ser detalhados e compreendidos por meio dos relatos das vivências dos próprios indivíduos no contexto do trabalho. Em decorrência desse ponto, surge a terceira motivação: há necessidade de uma visão ampla e detalhada do tópico, já que perspectivas parciais ou pouco profundas não ajudam a entendê-lo (CRESWELL, 1998).

O quarto motivo encontra-se no estilo narrativo, no qual o pesquisador engaja-se nas histórias de vida ou relatos (CRESWELL, 1998). O presente estudo envolve a valoração do conhecimento sob a ótica dos indivíduos, profissionais de recursos humanos, no contexto do trabalho, no ambiente organizacional. O Método Fenomenográfico, que será apresentado nos próximos tópicos, preconiza especialmente o uso dos relatos narrados por esses indivíduos, por meio de entrevistas. Daí, decorre o quinto aspecto: deve-se adotar a pesquisa qualitativa para estudar os indivíduos em seus ambientes naturais (o contexto do trabalho nas 
organizações), o que envolve ir ao cenário ou campo de estudo, ou seja, obter acesso aos indivíduos e ambientes, a fim de coletar material.

O sexto aspecto a ser considerado consiste nos fatores tempo e recurso, já que, segundo Creswell (1998), pesquisas qualitativas demandam tempo para coleta extensiva e profunda de dados, o que, por sua vez, implica em tempo disponível para análise. Esse aspecto é relevante, uma vez que, no Método Fenomenográfico, a manipulação conjunta de 20 a 30 relatos é bastante trabalhosa. Akerlind (2005) menciona um período de 3 a 6 meses para a análise, dependendo da complexidade do objeto de estudo.

Em sétimo, deve-se considerar a receptividade da audiência ao tipo de abordagem. No campo de estudo de conhecimento organizacional, encontramos pesquisas com abordagens de natureza tanto quantitativa como qualitativa. Entretanto, o enfoque na perspectiva do conhecimento enquanto prática tem um caráter fortemente discursivo, com predominância de trabalhos de natureza qualitativa.

A oitava razão reside no emprego da pesquisa qualitativa para enfatizar o papel do pesquisador como um aprendiz ativo, que apresenta a história sob o ponto de vista dos participantes, em vez de posicionar-se como um perito que avalia e julga os participantes a partir do seu próprio ponto de vista, estabelecido $a$ priori.

\subsection{Etapa 2: A Escolha do Método de Pesquisa}

Inseridos na abordagem de pesquisa qualitativa, foram considerados quatro métodos de pesquisa para o estudo: as perspectivas da Fenomenologia Descritiva, de Husserl e a Fenomenologia Interpretativa, de Heidegger (em MOUSTAKAS, 1994); a Fenomenografia (BOWDEN e GREEN, 2005; BOWDEN e WALSH, 2000; MARTON, 1981; 2005; MARTON e BOOTH, 1997); e o Grounded Theory Method (BRYANT e CHARMAZ, 2007; CHARMAZ, 2006; CORBIN e STRAUSS, 2008; GLASER e STRAUSS, 2006).

Cada uma das abordagens acima explora uma determinada questão de pesquisa, conduzindo a diferentes enfoques de resposta, conforme abaixo explicitado: 
1. A pesquisa da Fenomenologia Descritiva está interessada em saber mais sobre os conhecimentos valorados, acerca de quais e como são os conhecimentos valorados no contexto do trabalho; busca a descrição do fenômeno no seu significado em comum, atribuído a um aspecto da realidade pelos indivíduos. O foco encontra-se no fenômeno.

2. A pesquisa da Fenomenologia Interpretativa está interessada nos $\underline{\text { significados atribuídos pelo indivíduo à valoração dos }}$ seus conhecimentos no trabalho; busca interpretar o que significa o fenômeno para os indivíduos, o que significa ter seus conhecimentos valorados no contexto do trabalho. $\mathrm{O}$ foco encontra-se no indivíduo.

3. A pesquisa Fenomenográfica está interessada em saber mais sobre a experiência do indivíduo na valoração dos seus conhecimentos, nos seus mais diversos modos; assim, a Fenomenografia estaria interessada em saber como os indivíduos experimentam a valoração do conhecimento. Como um fenômeno pode ser experimentado de formas qualitativamente diferentes; busca qualquer coisa (anything) que possa ser dita acerca de como os indivíduos percebem, conceituam (pensam) e agem em relação ao fenômeno. O foco encontra-se na experiência vivida do fenômeno pelo indivíduo, na percepção do fenômeno pelo indivíduo.

4. A pesquisa Grounded Theory Method está interessada em saber quais processos levam os indivíduos a valorarem (determinado) conhecimento; busca interpretar as ligações entre as experiências, ações e eventos vividos pelos indivíduos, ou seja, o processo construído pelos indivíduos. O foco encontra-se no processo utilizado pelo indivíduo para lidar com o fenômeno.

Em função da questão central e dos objetivos de pesquisa, os dois métodos mais detidamente considerados e avaliados para emprego nesse estudo foram o Grounded Theory Method (GTM) e a Fenomenografia. Um estudo exploratório sobre o tema de valoração do conhecimento foi conduzido com o emprego do GTM, utilizando a questão de pesquisa pertinente acerca dos processos de valoração do conhecimento no contexto do trabalho (ver CHERMAN e ROCHAPINTO, 2013), o que possibilitou a inserção no tema de pesquisa e experimentação do referido método. 
A realização do estudo exploratório trouxe à luz algumas considerações importantes. Devido à apreciável lacuna de estudos em matéria de valoração do conhecimento sob o enfoque das percepções dos indivíduos, o estudo dos processos pelos quais os indivíduos valoram o conhecimento pareceu dar um passo além, enquanto ainda falta uma compreensão maior de como os indivíduos percebem a valoração do conhecimento, e até mesmo a compreensão do que é conhecimento, para os indivíduos, no contexto do trabalho. Assim, optou-se pelo método de pesquisa Fenomenográfico.

A escolha do Método Fenomenográfico se alinha com a conceituação do conhecimento pela perspectiva do conhecer (knowing) na prática e na ação organizacional a ser utilizada, pelas razões expostas a seguir. Primeiro, na concepção do método, a proposta consiste no alinhamento e na redução da distância entre teoria e prática, ou seja, practice-based (MARTON, 1981; MARTON e BOOTH, 1997), em consonância com a perspectiva de conhecimento practice-based aqui adotada. Segundo, a questão de pesquisa, para o Método Fenomenográfico, já é formulada com base no problema de ordem prática que visa responder (BOWDEN e GREEN, 2005), tendo uma preocupação com o caráter prático no que diz respeito aos resultados. Terceiro, na coleta de dados, a visão do que é conhecimento emerge dos sujeitos entrevistados, e não é um conceito pré-definido, pré-classificado ou objetivado. Além disso, o Método Fenomenográfico parte das diferentes concepções dos indivíduos acerca de um fenômeno, com base na experiência vivida pelo indivíduo em um determinado contexto. Parte-se, portanto, da percepção acerca da experiência prática, que é retomada e revivida no momento das entrevistas.

\subsection{Etapa 3: A Pesquisa Empírica com o Método Fenomenográfico}

A Fenomenografia foi criada na década de 70, na Suécia, pelo Grupo de Gothenburg. O método, desenvolvido por Marton e Säljö (MARTON, 1981, MARTON e BOOTH, 1997; MARTON e SÄLJÖ, 1976; SÄLJÖ, 1979), propunha-se a analisar a aprendizagem em estudantes em fase escolar a partir do conteúdo aprendido (e não da usual avaliação de quanto é aprendido) em suas diferentes concepções (MARTON e SÄLJÖ, 1976), das concepções dos 
indivíduos sobre o que é aprendizagem (SÄLJÖ, 1979), o que leva alguém a aprender (MARTON e BOOTH, 1997). Contudo, os aspectos relacionados à ontologia e epistemologia do método não foram descritos até 1997 , no trabalho de Marton e Booth.

A ideia básica dos autores, e do método, consiste no princípio de que os indivíduos possuem diferentes concepções sobre algo, baseados nas suas experiências e vivências no mundo ou em alguns aspectos do mundo. A conscientização (awareness) sobre os diferentes conceitos, fruto das diversas percepções dos modos de experimentar algo, permite a sistematização das formas de pensamento em uma estrutura. $\mathrm{O}$ entendimento da estrutura, ou formas de pensamento por onde os indivíduos transitam, possui o objetivo principal de compreender como os indivíduos interpretam significantes aspectos da realidade (MARTON, 1981; MARTON e BOOTH, 1997). No caso dos autores em suas pesquisas sobre aprendizagem, como decorrência dessa compreensão, seria mais fácil lidar com as questões advindas dos indivíduos sobre a aprendizagem e aquisição de conhecimentos.

Nos tópicos seguintes serão detalhados os principais conceitos e características do Método Fenomenográfico; as bases paradigmática, ontológica e epistemológica; a aplicação do método para a presente pesquisa; e o uso do método em Estudos Organizacionais.

\subsubsection{Definição e Características do Método}

Segundo Marton (1981, p. 180), “o objetivo do método de pesquisa [fenomenográfica] é o de descobrir e sistematizar formas de pensamento, em termos dos quais as pessoas interpretam aspectos da realidade - aspectos que são significativos socialmente e supostamente compartilhados pelos membros de um tipo de sociedade". E, segue o autor, "o propósito é a descrição, análise e o entendimento de experiências; isto é, pesquisa que é direcionada para a descrição da experiência” (MARTON, 1981, p.180).

Desse modo, o propósito da pesquisa fenomenográfica é descrever e mapear as formas qualitativamente diferentes de experimentar e vivenciar os fenômenos (MARTON, 1997). O foco reside na descrição da variação de percepções, e não na explicação desta variedade (MARTON, 1981; MARTON e BOOTH, 1997). 
Com relação à variação de percepções, há um número limitado de modos qualitativamente diferentes de experimentar e conceituar o fenômeno ou aspectos da realidade, dentre três a sete concepções (MARTON, 1981).

A Fenomenografia lida tanto com o que é experimentado (através de exemplos de situações) quanto com a conceituação (dos indivíduos sobre o aspecto da realidade experimentada), assim como sobre o que é pensado sobre o que é vivido. Portanto, o método trabalha tanto com o que é culturalmente aprendido quanto com o que é desenvolvido individualmente na relação do indivíduo com o mundo à sua volta. Além disso, ela se refere a qualquer coisa (anything) que pode ser dita sobre como os indivíduos percebem, conceituam (pensam) e experimentam (agem) o fenômeno (MARTON, 1981).

\subsubsection{Perspectiva de Segunda Ordem}

Uma característica importante do método é a utilização da perspectiva de segunda ordem, em detrimento de uma perspectiva de primeira ordem, para a investigação da relação entre os sujeitos pesquisados e o fenômeno abordado (MARTON, 1981). Marton (1981) exemplifica com duas questões de pesquisa em educação: 1) Por que algumas crianças são mais bem-sucedidas na escola do que outras? e 2) O que as pessoas pensam sobre por que algumas crianças são mais bem-sucedidas na escola do que outras?

A primeira questão apresenta a perspectiva de primeira ordem: qualquer resposta a ela traz, em sua formulação, uma declaração sobre a realidade, incorporando um processo mental que embute uma crença já teorizada pelos indivíduos. No segundo caso, a perspectiva de segunda ordem orienta a resposta para diferentes ideias dos indivíduos acerca da realidade ou sua experiência nela, ou seja, apresenta uma declaração sobre as ideias dos indivíduos acerca de sua experiência da realidade - uma faceta da realidade, e não da realidade em si. Desta forma, a perspectiva de segunda ordem carrega a distinção entre declaração acerca da realidade e percepções de realidade (múltiplas experiências sobre o mundo) (MARTON, 1981; MARTON e BOOTH, 1997).

A perspectiva de segunda ordem, segundo Marton e Booth (1997), coloca em suspenso os julgamentos e conceitos acerca do mundo. Essa perspectiva direciona o olhar para as declarações, ações e artefatos a fim de descobrir quais os 
modos de experimentar aspectos particulares do mundo que eles refletem, independentemente da sua validade, funcionalidade ou habilidade.

Esse ponto de separação e isolamento entre a perspectiva de segunda ordem e aquela de primeira ordem foi alvo de críticas ao método, especialmente de Richardson (1999), em função das implicações ontológicas e epistemológicas. Estas críticas serão apresentadas e discutidas no tópico referente à epistemologia e ontologia do método.

Marton (1981, p.178) argumenta duas razões em torno da perspectiva de segunda ordem: "Explorar diferentes modos pelos quais os indivíduos experimentam, interpretam, compreendem, apreendem percebem ou conceituam diversos aspectos da realidade é suficientemente mais interessante.”. Ademais, as descrições de segunda ordem são independentes daquelas de primeira ordem e levam à investigação do fenômeno sob um novo ponto de vista, onde o que é sabido (declarado) sobre a realidade não possui utilidade para a compreensão do fenômeno.

\subsubsection{A Experiência com o Fenômeno: Concepções}

Em Fenomenografia, diversas expressões são utilizadas de forma alternada para referir-se à experiência com relação a um fenômeno: concepções, experiência, modo de experimentar, entendimento, percepção, apreensão (MARTON E BOOTH, 1997), pois estes conceitos estão interligados. Marton e Booth (1997) deixam claro que a experiência tem relação com a vivência direta e com o aspecto experimental, e não possui relação com o sentido psicológico ou cognitivo do termo.

Central na abordagem fenomenográfica é a busca pela compreensão de como o indivíduo apreende (percepção), faz sentido (significação e pensamento) e atua (ação) um aspecto específico do seu mundo. Ao trinômio percepçãopensamento-ação atribui-se o termo concepção (SANDBERG, 2000; PELLEGRINELLI et al., 2003). Segundo Sandberg (2000), concepção (conception) refere-se às diferentes maneiras como as pessoas vivenciam e dão sentido ao seu mundo. Buscar as concepções emergentes acerca do fenômeno é o resultado procurado no decorrer da pesquisa fenomenográfica. 
Com a análise dos aspectos estruturantes da consciência e dos fatores que constituem a experiência, Marton e Booth (1997) introduzem os elementos interligados presentes na experiência com o fenômeno: o aspecto how ('como') e $\mathrm{o}$ aspecto what ('o que'). O 'como' da experiência descreve a ação, o 'ato' realizado; enquanto o 'o que' da experiência descreve o objeto no qual a ação é focada, o ‘objeto’ da ação.

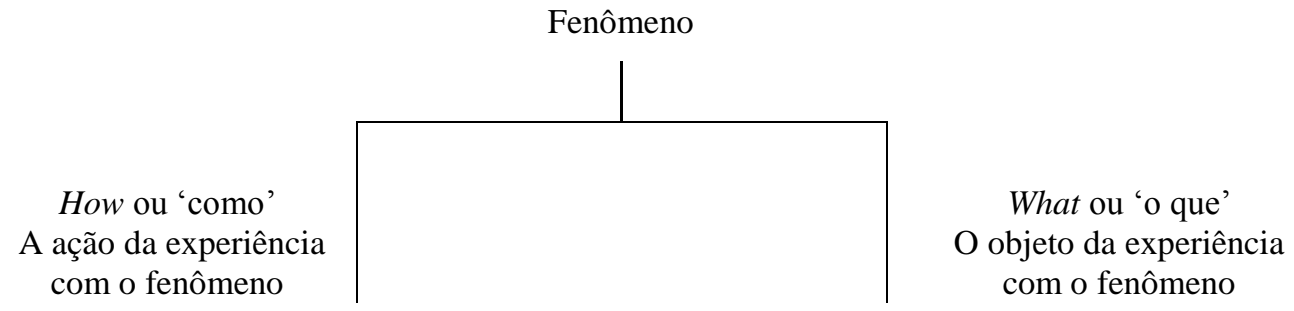

Figura 3: 'O que' e ‘Como' (adaptado de MARTON e BOOTH, 1997, p. 84)

Ainda com relação à 'ação', ela possuiria duas facetas: a do ato tomado e a da intenção (ou objetivo) por trás da ação ou seu objeto indireto.

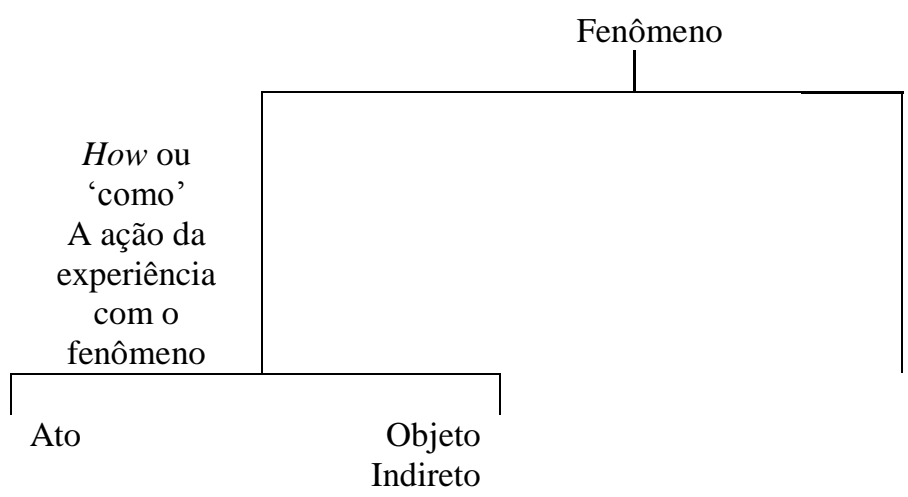

What ou 'o que'

O objeto da

experiência

com o fenômeno

Figura 4: 'Como' e as facetas 'ato' e 'objeto indireto' (adaptado de MARTON e BOOTH, 1997, p. 85)

Os autores reforçam que esta estrutura aborda a forma de interpretar os significados trazidos pelo fenômeno, importante para o tratamento dos dados. No exemplo de Marton e Booth (1997) sobre aprendizagem, o 'fenômeno aprender' pode significar 'aquisição', 'conhecer', 'fazer uso' ou outro significado. O ‘o que' da 'aquisição' pode tratar do aprendiz focado no conteúdo a ser aprendido ou da relação professor-aprendiz, entre outros. O 'como' é o modo como ele apreende 
('ato') e os resultados que ele espera ou como ele aplica o que aprendeu, seu 'objeto indireto'.

Traçando um paralelo meramente ilustrativo, ao considerar a questão da valoração do conhecimento no contexto do trabalho, o fenômeno "valoração do conhecimento" pode significar "atribuição de importância"; ou "reconhecimento" social, monetário, profissional hierárquico, pessoal; ou "poder" político, social; ou "aplicação no trabalho"; ou outro. O 'que' refere-se ao objeto no qual a prática da valoração estaria focada, como, por exemplo, o conhecimento, o conhecedor, os pares, o superior, a organização, as relações, o status, posição no grupo. Por sua vez, o 'como' diz respeito às ações que colocam a valoração em prática. Assim, no exemplo, poderia ser: subir de posição na hierarquia, ter status ou aceitação no grupo (construir identidade e afiliação, fazer política), participar de projetos relevantes, ter seu projeto escolhido dentre vários.

\subsubsection{Modos de Experimentar Algo: Significado e Estrutura}

Segundo Marton e Booth (1997), na Fenomenografia, a unidade de pesquisa é 'um modo de vivenciar (experimentar) algo'. 'Um modo de experimentar algo' é uma forma de discernir algo do contexto e em relação ao contexto. Experimentar algo como algo relevante é experimentar um significado, que está dialeticamente interligado com a estrutura: estrutura pressupõe significado e, ao mesmo tempo, significado pressupõe estrutura. Assim, a experiência possui um aspecto estrutural e um aspecto referencial (ou significado).

O aspecto estrutural de 'um modo de experimentar algo' possui dois lados: discernir o todo do contexto onde ele ocorre e discernir as partes e seus relacionamentos de dentro do todo. Por contexto, entende-se a localização sócioespaço-temporal que forma a situação. Os autores destacam que não é possível experimentar algo independentemente de um contexto. Os contornos e tudo que circunda o fenômeno são denominados horizonte externo. As partes e seus relacionamentos, juntamente com os contornos do fenômeno, são denominados horizonte interno. Intimamente interligado com o aspecto estrutural da experiência, encontra-se o aspecto referencial ou significado. Ao discernir o todo e as partes, é possível discernir graus de significado (MARTON e BOOTH, 1997). A figura 5 esquematiza 'um modo de experimentar algo'. 


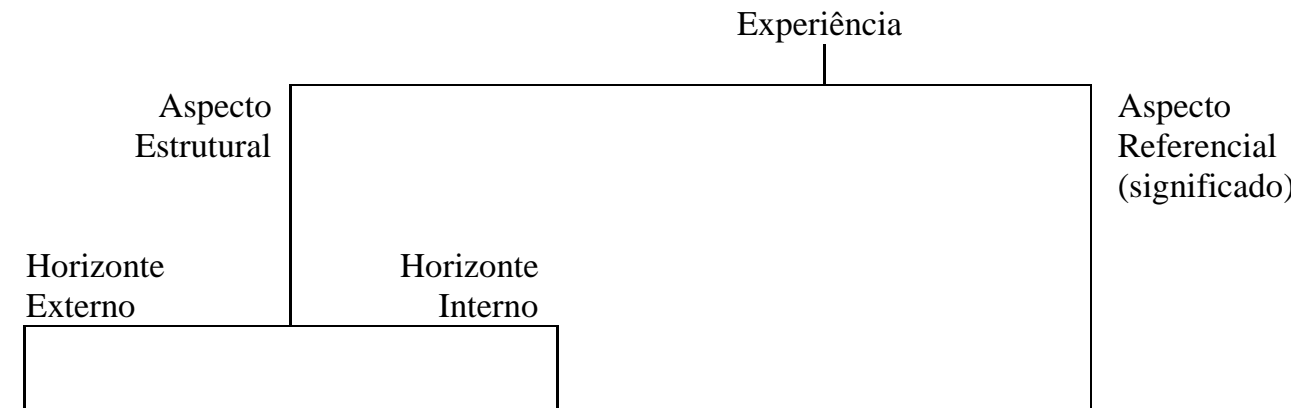

Figura 5: 'Um modo de experimentar algo' (MARTON e BOOTH, 1997, p. 88)

Uma forma de compreender a consciência (awareness) do indivíduo sobre a experiência dá-se pela ideia dos desenhos de figura-fundo: certos fenômenos ou aspectos particulares de certos fenômenos são figurativos e chamam a atenção central, enquanto outros aspectos são não figurativos e constituem o campo circundante. Quando um aspecto sobressai e toma a consciência focal, outros aspectos saem do campo de visão. 'Um modo de experimentar algo' pode ser descrito em termos de estrutura ou organização da consciência em um determinado momento (MARTON e BOOTH, 1997).

Além disso, uma mudança no aspecto referencial da experiência também altera o aspecto estrutural, ou seja, o significado existente na experiência contribui na formatação da estrutura, pois ambos estão interligados. $\mathrm{O}$ significado de algo para alguém em um ponto em particular no tempo corresponde ao padrão das partes ou aspectos que são discernidos e são, simultaneamente, objeto da consciência focal (MARTON e BOOTH, 1997).

\subsubsection{Variação nos Modos de Experimentar Algo: Descrição e Experiência}

O objeto de pesquisa fenomenográfica é a 'variação nos modos de se vivenciar/experimentar um fenômeno' (MARTON e BOOTH, 1997). Conforme apresentam Marton e Booth (1997), como regra, nem todos os aspectos de um fenômeno e da situação no qual ele está incorporado são discernidos e estão presentes simultaneamente na consciência focal. Geralmente, alguns deles são abstraídos, separados, isolados e experimentados um após ou outro, em sequência.

Esse movimento dá origem aos 'modos qualitativamente diferentes de experimentar algo'. Também revela que certos modos de experimentar algo são 
mais complexos que outros, pois trazem mais partes ou aspectos do todo, simultaneamente, à consciência focal e, ainda, que existe uma hierarquia de níveis de complexidade entre os 'modos qualitativamente diferentes de experimentar algo', que promove uma interligação lógica entre as variações nos modos de experimentar o fenômeno (MARTON e BOOTH, 1997).

Os autores destacam que 'modos de experimentar algo' é completamente distinto de descrever representações mentais ou qualquer outro processo cognitivo, no qual os pensamentos são conceitos localizados nas cabeças dos indivíduos e que guiam seus atos, ou seja, estão teorizados e pré-concebidos. No caso da Fenomenografia, certo tipo de experiência pode ser chamado de pensamento. O pensamento, na Fenomenografia, ocorre quando a experiência do que foi feito é acessada e retomada, tanto na situação em que ela ocorreu quanto com quem ou como a experiência foi atuada. Desse modo, ela deve ser interpretada no sentido experiencial, nunca no sentido psicológico. Também não se trata de descrever a experiência física, ou o que (what) se passa (MARTON e BOOTH, 1997).

Para Marton e Booth (1997), descrever a experiência é um nível de descrição autônomo, mais elementar, que não pode ser reduzido a outros níveis de descrição, e retrata como o mundo aparece aos indivíduos. Na Fenomenografia, os indivíduos são vistos como portadores de diferentes modos de experimentar um fenômeno e como portadores de fragmentos de diferentes modos de experimentar aquele fenômeno. Portanto, a descrição à qual se chega é a descrição da variação, a descrição no nível coletivo, onde as vozes individuais não são ouvidas. Marton (1981, p. 198) denomina de 'intelecto coletivo (ou mente coletiva)' à organização das descrições dos diferentes modos de experimentar determinado fenômeno. Não existe uma descrição final, completa, terminada de algo, tampouco será possível descrever uma experiência na sua totalidade, dada a restrição de procurar descrever diferenças críticas na capacidade dos indivíduos em experimentar o fenômeno.

\subsubsection{Categorias Descritivas e Outcome Space}

As diferentes percepções acerca do fenômeno são agrupadas em categorias descritivas, reflexo das diferentes experiências com o fenômeno. 'Os modos de 
experimentar', ou categorias descritivas, constituem um complexo denominado Outcome Space ou 'espaço de resultado', ou seja, o conjunto de categorias descritivas contendo distintos agrupamentos de aspectos do fenômeno (dimensões) e o relacionamento entre eles (BOWDEN, 2005; MARTON e BOOTH, 1997).

Segundo Marton e Booth (1997), 'os modos qualitativamente diferentes de experimentar um determinado fenômeno' formam uma hierarquia, cuja estrutura pode ser definida em termos de complexidade crescente. Os diferentes modos de experimentar o fenômeno são definidos como subconjuntos das partes componentes e relacionamentos dentro de modos mais complexos e completos de perceber o fenômeno. Eles podem ser compreendidos também como diferentes camadas de experiências individuais.

Marton e Booth (1997) definem certos critérios de qualidade para o conjunto de categorias descritivas ou espaço de resultado (Outcome Space), metodologicamente fundamentados no aspecto de consciência (awareness) exposto anteriormente:

1. Cada uma das categorias individuais deve permanecer em clara relação com o fenômeno investigado, de modo a que cada categoria diga algo distinto sobre um modo particular de experimentar o fenômeno.

2. As categorias têm de permanecer em uma relação lógica entre si, um relacionamento que frequentemente é hierárquico. Baseia-se na noção da complexidade crescente entre as categorias descritivas/'modos de experimentar o fenômeno'.

3. O conjunto deve ser parcimonioso, ou seja, com poucas categorias descritivas viáveis e razoáveis, para capturar a variação crítica nos dados.

Os autores fazem uma distinção entre o aquilo que é descrito ('modos de experimentar algo') e o modo no qual é descrito (categoria descritiva), embora estejam eles inseparavelmente interligados.

O mapeamento da estrutura ou espaço de resultado (Outcome Space) é um dos produtos de Método Fenomenográfico. Os indivíduos transitam de uma categoria descritiva para outra, à medida que experimentam repetidamente o fenômeno e aprendem a experimentá-lo de diferentes maneiras, ou seja, os indivíduos transitam pela estrutura (BOWDEN, 2005). Este Espaço de Resultado 
representa o intelecto ou mente coletiva de determinado grupo acerca de um fenômeno, mencionada por Marton (1981).

De uma maneira esquemática, o modelo constitutivo do Outcome Space pode ser visto na figura 6 .

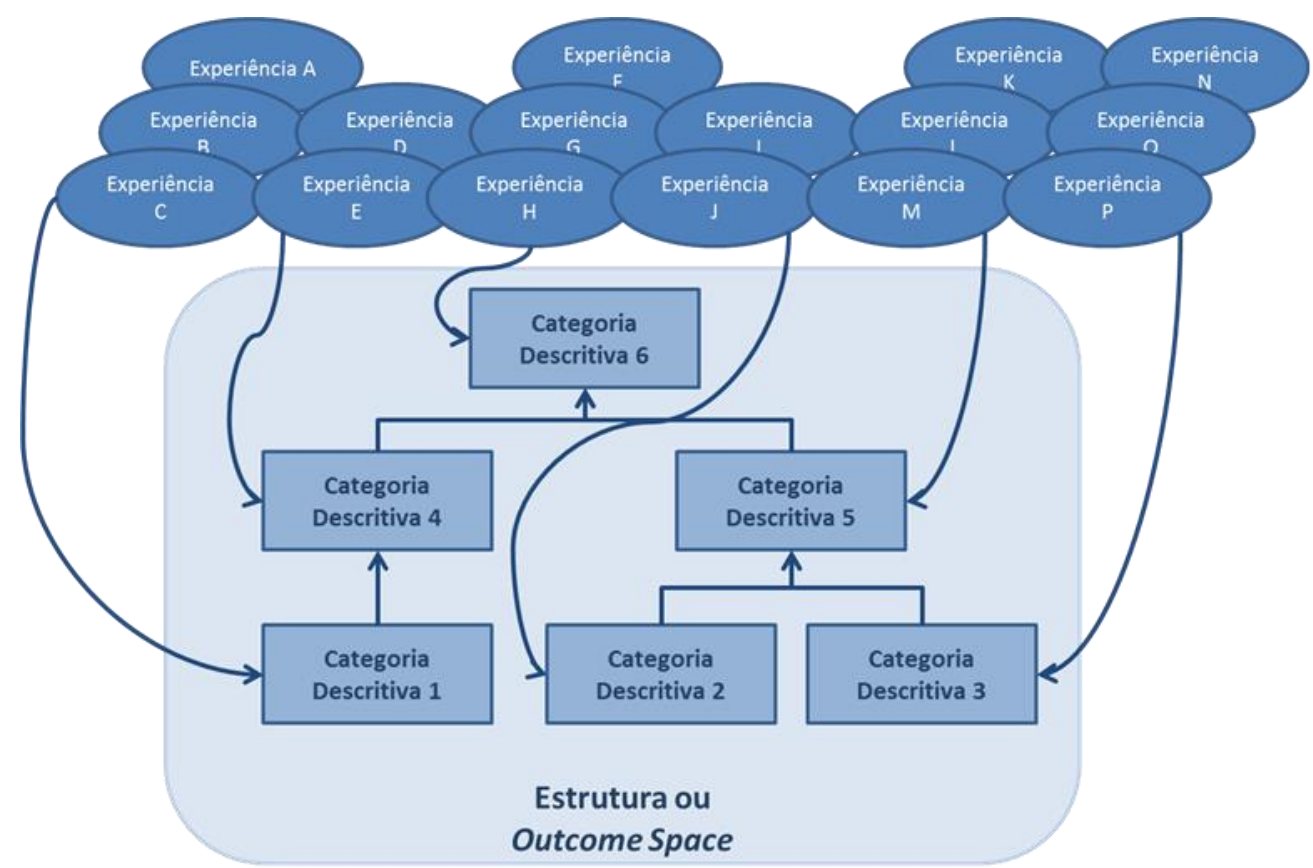

Figura 6: Exemplo de Modelo Constitutivo do Outcome Space (elaborado pela autora com base em BOWDEN, 2005; MARTON e BOOTH, 1997)

\subsubsection{Característica Relacional}

Marton e Booth (1997) destacam um ponto importante do método e da unidade de pesquisa: a relação interna entre a experiência e o sujeito. Nem a experiência nem o sujeito seriam os mesmos sem a relação entre eles. O mesmo se aplica à relação do indivíduo com o mundo: o mundo, ou pelo menos parte dele, está presente no indivíduo, pois o mundo é experimentado pelo indivíduo. O indivíduo não seria a mesma pessoa sem o mundo que ele está experimentando, assim como o mundo não seria exatamente o mesmo mundo sem o indivíduo o experimentando (MARTON e BOOTH, 1997). O mundo é constituído da relação entre o indivíduo e sua experiência no mundo. Esta visão relacional do mundo serve de base para a Fenomenografia, que possui como característica uma visão não dualista do mundo (AKERLIND, 2005; BOWDEN, 2005). 
Bowden (2005) destaca que a perspectiva construtivista individual e a construtivista social adotam uma visão dualista concentrada seja no mundo interno (aqui dentro/in here) ou no mundo externo (lá fora/out there), como uma sendo a explicação para a outra. A Fenomenografia, por sua vez, não foca sobre estruturas mentais hipotéticas separadas do mundo. Na concepção do método, não há uma linha divisória entre o mundo interno e o mundo externo, nem há dois mundos com um tentando explicar o outro. $\mathrm{O}$ mundo não é construído pelo indivíduo, nem é imposto sobre ele de fora, "é constituído como uma relação interna entre eles. Há apenas um mundo, mas é o mundo que nós experimentamos, um mundo no qual nós vivemos, um mundo que é nosso" (MARTON e BOOTH, 1997, p. 13).

Essa visão não dualista e o aspecto relacional e dialógico da Fenomenografia trazem uma consequência importante: são fundamentais para a compreensão da ontologia e epistemologia inerentes ao método (AKERLIND, 2005; GREEN, 2005), que serão abordadas no próximo tópico.

Bowden (2005), na Figura 7, ilustra esquematicamente os conceitos expostos nos tópicos anteriores acerca do Método Fenomenográfico. O objeto de estudo ou 'variação nos modos de se vivenciar/experimentar um fenômeno' concentra-se no aspecto relacional, dialógico e não dualista entre o sujeito e sua experiência com o fenômeno.

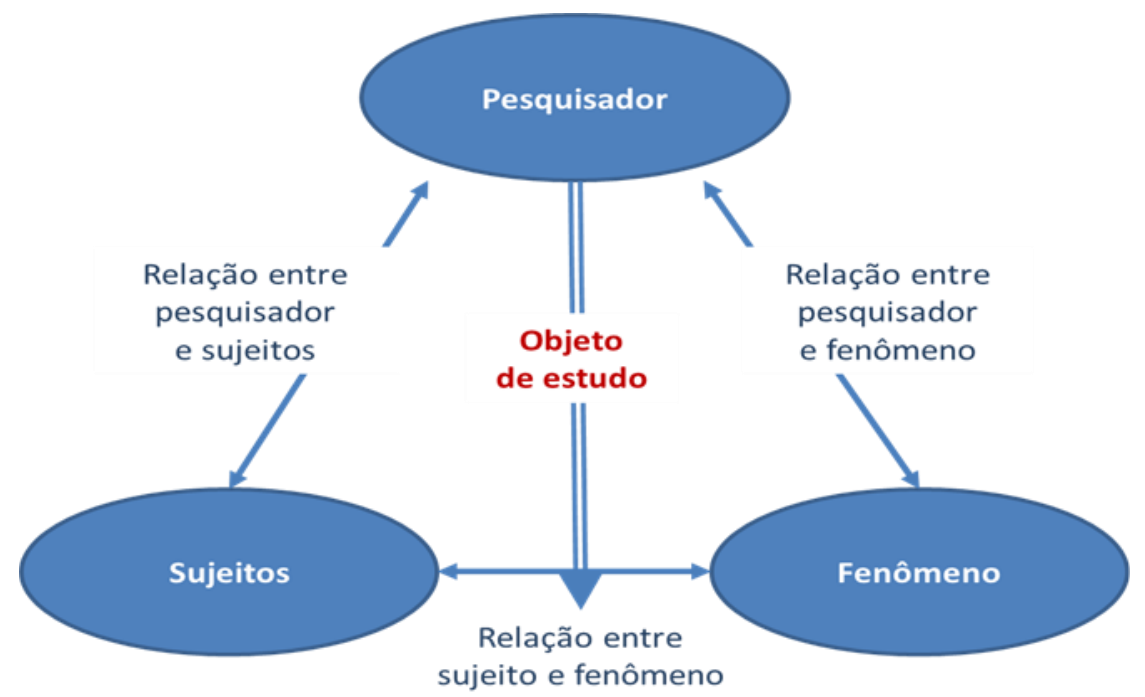

Figura 7: Aspecto Relacional da Fenomenografia (BOWDEN, 2005, p. 13) 


\subsubsection{Sobre Paradigma de Pesquisa, Epistemologia e Ontologia}

Segundo Green (2005), o paradigma de pesquisa fenomenográfica se subscreve na postura interpretativa. Esta postura é baseada na noção de múltiplas realidades, isto é, a realidade não é nem singular nem fixa, mas sim construída a partir das interpretações feitas como consequência das interações no mundo. A visão interpretativa assume uma epistemologia em que as transações entre o pesquisador e os participantes criam entendimentos mútuos subjetivos ou mediados por valores. A distinção entre a epistemologia e ontologia é fluida e embaçada.

Quanto à ontologia, conforme já mencionado no tópico anterior, a Fenomenografia adota uma perspectiva ontológica não dualista (AKERLIND, 2005a; BOWDEN, 2005; MARTON e BOOTH, 1997). Não existe um mundo real "lá fora (out there)" nem um mundo subjetivo "aqui dentro (in here)". O mundo, como uma experiência, não é construído pelo ator nem é imposto sobre ele: é constituído na relação indissociável entre esses aspectos, na relação entre o ator e o fenômeno, em uma perspectiva dialógica e relacional (AKERLIND, 2005a).

Conforme argumentam Marton e Booth (1997), a proposição da Fenomenografia de que 'os modos de experimentar algo' representam a relação entre o sujeito e o fenômeno conduz à ideia de que 'os diferentes modos de experimentar algo' estão logicamente relacionados através do fenômeno em comum. Desse modo, a premissa central da fenomenografia é o pressuposto de que diferentes categorias descritivas (modos de experimentar um fenômeno) são logicamente relacionadas uma a outra. Estes relacionamentos formam uma hierarquia estrutural ou Espaço de Resultado (Outcome Space), onde alguns modos de experimentar são mais complexos e mais completos que outros (AKERLIND, 2005a).

Cabe destacar pontos importantes subjacentes aos aspectos paradigmático, ontológico e epistemológico mencionados acima, que geram impactos no método. Há uma descontextualização dos indivíduos: vozes individuais não são trazidas e toda a análise ocorre atravessando os indivíduos. Há uma descontextualização do contexto da situação: o contexto é relevante para a experiência do fenômeno destacada pelo indivíduo, porém irrelevante na análise dos dados (BOWDEN, 
2005; GREEN, 2005). O método trabalha prioritariamente com as entrevistas, ou seja, discursos e narrativas que são parte integrante da realidade.

$\mathrm{O}$ método sofreu críticas relacionadas à ontologia não dualista, à epistemologia da separação das perspectivas de primeira e segunda ordem, entre outros aspectos que fundamentam o método. As críticas de Webb (1997) ao Método Fenomenográfico tratam especificamente da questão da aplicação do método a respeito da natureza do que é ensino, educação e aprendizagem. Sob o prisma pós-moderno e filosófico, as críticas do autor abordam os aspectos de observação e postura de neutralidade interpretativa do pesquisador, apontando para a importância dos entendimentos dos pesquisadores na construção dos resultados. Sua crítica também se estende à base hermenêutica do método, enfatizando o papel do pesquisador na situação de pesquisa e a intensidade do elemento humano contido no desenvolvimento de empatia nos métodos qualitativos.

Segundo Webb (1997), a base fenomenológica do método de que a percepção é sempre uma representação de parte da realidade traz um problema à Fenomenografia, no tocante à forma como considerar a construção histórica e social do pensamento. Sob o paradigma pós-moderno, é difícil sustentar a ideia de que observações possam ser simplesmente reportadas em categorias ou que categorias estejam simplesmente ali, de algum modo fora da experiência histórica e social do participante.

Richardson (1999, p.65), por sua vez, aponta que "Marton e Booth (1997, p.6-12) rejeitam tanto o construtivismo individual como o construtivismo social; em vez disso, eles propõem que as concepções de realidade são aspectos de uma consciência individual que existe de alguma forma latente a qual só pode ser trazida a um estado de reflexão pela intervenção do pesquisador no curso da entrevista”. Cabe ressaltar que Richardson (1999) critica a partir de uma interpretação dele sobre o que Marton e Booth (1997) escreveram, pois estes autores não rejeitaram o construtivismo e nem escreveram isso; eles sugerem que seja adotada uma visão integrativa e relacional, em que o mundo individual e o mundo social estão "em relação" um com o outro, atuando sobre o indivíduo e sendo, portanto, um só.

Richardson (1999) considera, ainda, que essa intervenção do pesquisador seria o acesso direto às 'concepções de realidade' dos entrevistados como 
entidades objetivas, ou seja, uma interpretação realista da descrição dos indivíduos da realidade. Esta visão, segundo o autor, seria problemática, pois os fenomenógrafos não possuem base para caracterizar as concepções de outras pessoas acerca do mundo, porque eles mesmos só possuem acesso aos relatos das pessoas, e não das mesmas experiências do mundo. Por si só, os relatos não traduzem a experiência fiel do indivíduo acerca da realidade, uma vez que as narrativas já incorporam uma interpretação da experiência com o fenômeno.

O autor dá continuidade à argumentação, afirmando que não estaria clara a forma como duas pessoas diferentes poderiam compartilhar da mesma concepção de algum aspecto da realidade, visto que elas presumidamente permaneceriam em diferentes relações com o objeto ou evento. Para Richardson (1999), a Fenomenografia parece ser incapaz de lidar com identidades interindividuais, já que foca em diferenças interindividuais nas concepções de realidade, ou seja, para ele seria inviável o entendimento da concepção de realidade do outro, sem troca de entendimentos (construção social).

Como decorrência, surge o problema epistemológico de como seria possível saber sobre a concepção de mundo de uma pessoa meramente a partir de seus relatos, dado que a Fenomenografia acaba por assumir uma epistemologia dualista ao acentuar a distinção entre experiência de primeira-ordem dos objetos e eventos e o conhecimento de segunda ordem da experiência dos indivíduos acerca destes objetos e eventos. Esta crítica também está presente em Webb (1997).

Richardson (1999) propõe que uma revisão construtivista na Fenomenografia proporcionaria uma fundamentação apropriada para a pesquisa Fenomenográfica, tanto filosófica quanto heuristicamente. Segundo ele, toda pesquisa social sempre envolve a construção dos objetos em investigação, ou seja, é por meio da interação social que os objetos e eventos são constituídos nos relatos. O autor menciona os trabalhos de Säljö (1994; 1997; apud RICHARDSON, 1999) referentes a essa revisão, onde a possibilidade de interpretar a realidade diferentemente (pelos pesquisadores) se aplica à atividade de descrever concepções de realidade.

Os estudos de Sandberg (2000), Partington e Young (2002), Pellegrinelli, Partington e Young (2003), dentre outros, ao utilizar o método na área de administração, ultrapassam as críticas acima mencionadas. Os autores reafirmam o caráter não dualístico da realidade e a inseparabilidade do sujeito da ação, da sua 
experiência prática no mundo, embora incorporando a visão construtivista da realidade presente em Berger e Luckmann (1979) ou interacional de Giddens (1984). Lopes (2012) propôs um redesenho do modelo de Bowden (2005), incluindo o aspecto construtivista no referido modelo, ilustrado na Figura 8.

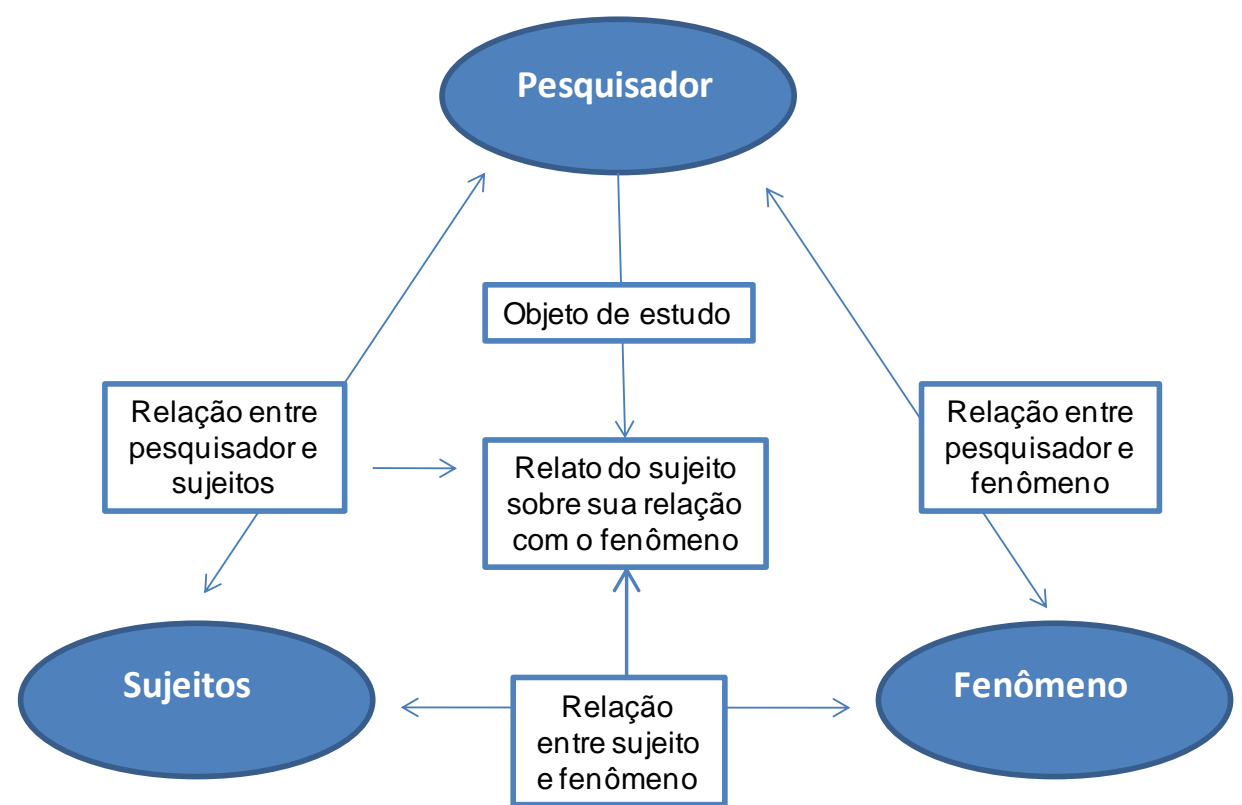

Figura 8: Objeto de estudo em Fenomenografia, abordagem construtivista (LOPES, 2012).

É importante mencionar que, no presente estudo, foram ponderadas as considerações críticas feitas ao Método Fenomenográfico, sobretudo no que diz respeito aos aspectos construtivista, de coleta e de tratamento dos dados em relação ao papel e postura do pesquisador.

\subsection{3. "Contextos" de Fenomenografia}

Säljö (1997) apresentou três tipos de Fenomenografia, com base no conteúdo das pesquisas realizadas. Assim foram identificadas as pesquisas que: 1) buscam compreender a aprendizagem em geral; 2) exploram conceitos acadêmicos; e 3) procuram descrever aspectos diversos da realidade das pessoas. A este último, Marton (1986) denominou de Fenomenografia Pura.

Hasselgren e Beach (1997), ao analisar a Fenomenografia de Gothenburg, preocuparam-se não com o conteúdo no qual a Fenomenografia é aplicada, mas com o contexto discursivo no qual os dados estão ancorados. Eles argumentam 
que, à medida que o contexto de produção dos dados varia, as concepções são expressas em diferentes contextos discursivos. Com base nesse ponto, Hasselgren e Beach (1997) reconheceram cinco contextos-tipos de Fenomenografia, que correspondem a modos de fazer Fenomenografia: experimental, discursiva, naturalística, hermenêutica e fenomenológica.

A Fenomenografia Experimental encontra-se relacionada às primeiras aplicações pelos pesquisadores que desenvolveram o método. Sob condições controladas, do tipo experimento, os pesquisadores analisavam o entendimento dos estudantes acerca do texto lido ou conteúdo ensinado, para compreender como o entendimento havia sido construído. Os principais achados destas pesquisas foram: o limitado número de categorias de experimentar algo, entre 3 e 7 (MARTON, 1981) e a hierarquia de profundidade entre estas categorias, isto é, da compreensão do fenômeno, a que se denominou outcome space. $\mathrm{O}$ trabalho de Marton (1975) enquadra-se nesse tipo.

A Fenomenografia Discursiva refere-se à Fenomenografia Pura, de Marton (1986) e Säljö (1994). O estudo de formação de preço, realizado por Dahlgren (1979), deu origem a este tipo. Nele, o modo de realizar a Fenomenografia não era direcionado (experimentalmente) à avaliação de resultados pré-direcionados (em aprendizagem). Ele trata de respostas práticas às demandas de investigação de um tipo particular de objeto de pesquisa, sob diferentes condições, com o objetivo de mapear as concepções dos indivíduos acerca dos diferentes aspectos da realidade. Para Hasselgren e Beach (1997), esse é o modo menos sofisticado de fazer Fenomenografia, baseado apenas nos relatos transcritos das entrevistas semiestruturadas, sem considerar as regras de produção do discurso e sem análise das expressões das concepções produzidas. Os autores citam, como exemplos deste modo, os trabalhos de Säljö (1979), Marton, Beaty e Dall'Alba (1993), Giorgi (1986, apud HASSELGREN e BEACH, 1997) e Larsson (1982, apud HASSELGREN e BEACH, 1997).

A Fenomenografia Naturalística possibilita a coleta de material empírico para análise fenomenográfica de situações reais, tais como a análise de vídeos ou gravações feitas em situações autênticas, com observação presencial ou não do pesquisador. Ela parte do princípio segundo o qual o que é registrado como dado é passível de ser observado naturalmente e de que as rotinas de interação em um contexto específico podem ser analisadas com outro contexto similar. Hasselgren 
e Beach (1997) citam o trabalho de Lybeck (1981, apud HASSELGREN e BEACH, 1997), onde o que ocorria em sala de aula, assistida e gravada pelo pesquisador, serviu de dado para análise.

A Fenomenografia Hermenêutica, por sua vez, busca compreender as coisas em seu próprio contexto e nos seus próprios termos, procurando fazer uma ponte entre os significados do intérprete e do objeto interpretado. Ela utiliza-se de interpretação de textos e declarações não originalmente gerados para a análise fenomenográfica, característica que a distingue de outros três tipos de Fenomenografia. Os autores ressaltam o trabalho de Lindblad (1995, apud HASSELGREN e BEACH, 1997) sobre as descrições pedagógicas feitas pela Comissão Escolar em fins dos anos 40, de onde emergiram categorias descritivas apontando mudanças.

A Fenomenografia Fenomenológica representa o esforço de alguns pesquisadores em identificar uma qualidade fenomenológica em seus trabalhos. Hasselgren e Beach (1997) não deixam muito claras as características desse tipo, embora o diferenciem dos outros tipos de Fenomenografia, ao mencionar que os pesquisadores perguntam por descrições do que o sujeito está pensando no momento da entrevista, ou seja, uma perspectiva de primeira ordem. Além disso, estaria buscando a essência das experiências. Os trabalhos de Theman (1983) e Neuman (1987) são mencionados para exemplificar este tipo.

Hasselgren e Beach $(1997$, p.) concluem afirmando que a Fenomenografia é "uma pesquisa produtiva que pode ser desenvolvida de inúmeras formas". A análise dos estudos empíricos com o uso do método em Administração confirma essa afirmação. A Fenomenografia, nos diversos estudos, foi utilizada em conjunto com dados documentais, com observação e com workshop de retorno aos participantes (PELLEGRINELLI et al., 2003), em contextos diversos (PELLEGRINELLI et al., 2003; CHEN e PARTINGTON, 2006; CHEN et al., 2008) ou em contexto único, tipo estudo de caso (SANDBERG, 2000), a partir de dados já coletados, recategorizados para novas análises (CHEN e PARTINGTON, 2004; GERBER e VELDE, 1997).

Nos anos 2000, foi introduzido na literatura outro tipo de Fenomenografia, denominada Developmental Phenomenography ou 'Fenomenografia do Desenvolvimento', desenvolvida pelo prof. Bowden. Segundo ele, este tipo de pesquisa busca descobrir o modo como as pessoas vivenciam alguns aspectos de 
seus mundos, mas, diferentemente do que ocorre com a 'Fenomenografia Pura', não se limitaria à descrição destas experiências. $\mathrm{O}$ resultado da Fenomenografia do Desenvolvimento deve ser usado como uma ferramenta de mudança na forma como as pessoas lidam com suas realidades, servindo para influenciá-las e tendo, portanto, um sentido prático (BOWDEN, 2000).

Bowden descreveu minuciosamente as características e procedimentos deste tipo de pesquisa em dois livros: Bowden e Walsh (2000) e Bowden e Green (2005). Na comparação entre a Fenomenografia de Marton (descrita por MARTON e BOOTH, 1997, na obra Awareness and Learning) e de Bowden, pode-se observar que os métodos diferenciam-se mais nos procedimentos de realização da pesquisa do que no seu propósito. Quanto ao propósito, os trabalhos empíricos realizados na área de Administração, com a Fenomenografia de Marton, também apresentam a preocupação constante com uma pesquisa teórica que sirva para auxiliar na realidade prática. Trata-se do mesmo objetivo de Bowden. O diálogo teoria-e-prática parece, assim, apresentar-se como inerente ao Método Fenomenográfico, e não como uma característica particular de um tipo de Fenomenografia.

Entretanto, quanto aos meios para a realização da pesquisa, especialmente na coleta e tratamento dos dados, pode-se observar que a Fenomenografia do Desenvolvimento, de Bowden, é mais rígida e rigorosamente estruturada. Há uma preocupação intensa com os procedimentos para evitar a contaminação da entrevista, única forma possível de coleta de dados, e com o 'espancamento' constante das categorias resultantes na análise dos dados, visando a assegurar a confiabilidade e a validade dos resultados. A Fenomenografia de Marton, conforme já mencionado, apresenta-se mais flexível, pois permite o uso de outras formas de coleta de dados e o uso do método associado a outros métodos, sem perder o rigor e a confiabilidade na forma de interpretar os dados e expor os resultados. Quanto à apresentação dos resultados, por sua vez, ambos os métodos os expõem do mesmo modo: por meio de uma tabela de categorias (concepções) e atributos, organizados por hierarquia de abrangência dessas concepções (dimensões encontradas).

O presente trabalho adotou por base a Fenomenografia de Marton, descrita em Marton e Booth (1997), em Marton $(1981,1986)$ e nos trabalhos empíricos aplicados à Administração de Sandberg (2000), Partington e Young (2002), 
Pellegrinelli et al. (2003), sem deixar de considerar aspectos relevantes relacionados à coleta, ao tratamento de dados e aos critérios de rigor, quando pertinentes e cabíveis, mencionados em Bowden e Green (2005). Esses pontos são discutidos em mais detalhes no tópico referente às fases do método.

Tal escolha foi motivada, primeiramente, pela aplicação do método em Estudos Organizacionais, onde a Fenomenografia de Marton foi utilizada em todas as pesquisas empíricas (com exceção de um estudo internacional e uma tese nacional), apresentando riqueza e profundidade nos resultados. Em segundo lugar, diz respeito à comprovação, por meio destes estudos empíricos, da proximidade entre resultado teórico e utilização prática do Espaço de Resultado nas realidades dos indivíduos participantes e organizações (PELLEGRINELLI et al., 2003; PELLEGRINELLI e GARAGNA, 2010; SANDBERG, 2000). Em terceiro lugar, demonstra a possibilidade de construir, a partir do estudo inicial, análises comparadas em outros contextos (CHEN e PARTINGTON, 2006, 2004; CHEN et al., 2008; CHEN et al., 2009), fato este que interessa à autora do presente estudo, para a continuidade da linha de pesquisa.

\subsubsection{Aplicação do Método em Estudos Organizacionais}

Conforme já mencionado, o Método Fenomenográfico surgiu para analisar a educação e a aprendizagem de estudantes em fase escolar, passando a abranger as diversas formas de ensino, educação e aprendizagem nos diferentes níveis e sobre os mais diversos temas. O método foi rapidamente apropriado nas pesquisas sobre cuidados de pacientes em enfermagem e medicina.

Mais especificamente em estudos organizacionais, o método ainda não possui uma utilização expressiva. Na busca por artigos usando as palavras-chave Fenomenografia e Fenomenográfico, surgem poucos retornos de estudos com o método nessa área. Não é possível avaliar se o pequeno número de artigos decorre da reduzida utilização efetiva do método ou da omissão do nome do método empregado no texto dos artigos. Os Quadros 6 e 7 apresentam as listagens de todos os artigos internacionais e nacionais encontrados na área de estudos organizacionais, classificados por temas de estudo.

A entrada da Fenomenografia na Administração, e especificamente em Estudos Organizacionais, parece ter se dado pela linha de estudos em 
competências profissionais, gerenciais e organizacionais, onde o método encontrou terreno fértil. Pode-se pressupor que essa trajetória tenha ocorrido graças à fronteira entre a educação profissional e de nível superior com a expectativa sobre o desenvolvimento de competências profissionais e gerenciais das organizações, considerando as implicações nos aspectos práticos de treinamento para formação destas competências. Os trabalhos de Sandberg e Dall'Alba (1996), Velde e Gerber (1996, 1997) e Sandberg (2000) foram os primeiros a abordar essa linha, redefinindo, inclusive, o conceito tradicional de competência e a forma como ela se estabelece no contexto do trabalho.

Com relação aos trabalhos de Sandberg (2000) e Sandberg e Dall'Alba (1996), os autores empregaram o método na questão das competências para a prática profissional e o desenvolvimento profissional, sendo certo que Dall'Alba também adotou a Fenomenografia para os estudos sobre a prática profissional na enfermagem (2002) e medicina (1998; 2004).

De forma consistente com essa vertente, seguiram-se os estudos de Partington (2002, 2004, 2005, 2006, 2008, 2009) com seus coautores (Chen, Pellegrinelli, Qiang, Wang, Young), buscando os modos de conceber competências gerenciais em programas complexos de gestão estratégica, assim como as concepções de gerência de programas de gestão estratégica em diferentes culturas (uma vez que os autores replicaram o estudo da Inglaterra na China), a seleção e o desenvolvimento de competências para gerentes de programas de gestão estratégica, dentre outros temas relacionados.

Em outros campos dos estudos organizacionais, a Fenomenografia aparece para abordar temas relativos à mudança organizacional (DUNKIN, 2000), à autonomia no trabalho em projetos na indústria da construção civil (POLESIE, FRÖDELL e JOSEPHSON, 2009) e à gestão da internacionalização de empresas (LAMB, SANDBERG e LIESCH, 2011). Na área de aprendizagem e conhecimento organizacionais, há um estudo realizado de acordo com o método para conceituar Organização de Aprendizagem (ORTENBLAD, 2002), competência informacional (BRUCE, 1999) e aprendizagem em organizações intensivas em conhecimento (SVENSSON, 2009). 


\begin{tabular}{|c|c|c|c|}
\hline \begin{tabular}{c|} 
Tema em \\
Estudos \\
Organizacionais
\end{tabular} & Autor & Título do Artigo e Tipo & Fenômeno Investigado \\
\hline \begin{tabular}{l|} 
Competências \\
Individuais \\
(Profissionais) e
\end{tabular} & Sandberg (1991) & $\begin{array}{l}\text { Competence as Intentional } \\
\text { Achievement: A Phenomenographic } \\
\text { Study - Anais Congresso }\end{array}$ & Não disponível \\
\hline \multirow[t]{9}{*}{ Organizacionais } & $\begin{array}{l}\text { Dall'Alba e } \\
\text { Sandberg (1996) }\end{array}$ & $\begin{array}{l}\text { Educating for Competence in } \\
\text { Professional Practice - Artigo }\end{array}$ & $\begin{array}{l}\text { Como é desenvolvida competência na prática profissional, na visão da experiência vivida. } \\
\text { Desenvolvimento de competência é visto como envolvendo mudanças na estrutura do } \\
\text { significado para prática, que diz respeito tanto a mudanças de significado no modo de } \\
\text { experimentar a prática entre indivíduos quanto ao refinamento no modo de experimentá-la, } \\
\text { gerando implicações nos programas educacionais. }\end{array}$ \\
\hline & $\begin{array}{l}\text { Gerber e Velde } \\
\text { (1996) }\end{array}$ & $\begin{array}{l}\text { Clerical-Administrative Workers' } \\
\text { Conceptions of Competence in their } \\
\text { Jobs - Artigo }\end{array}$ & $\begin{array}{l}\text { Como o conceito de competência é explicado em termos das experiências dos trabalhadores } \\
\text { administrativos acerca da competência nos seus ambientes de trabalho. } 5 \text { diferentes } \\
\text { concepçôes de competência foram encontradas. }\end{array}$ \\
\hline & $\begin{array}{l}\text { Gerber e Velde } \\
\text { (1997) }\end{array}$ & $\begin{array}{l}\text { A Competence Model for Professional } \\
\text { Practice in the Clerical-Administrative } \\
\text { Occupations - Artigo }\end{array}$ & $\begin{array}{l}\text { Derivado da amostra do artigo anterior (1996), são refinadas } 4 \text { concepções de competência } \\
\text { para trabalhadores administrativos em posição gerencial e não-gerencial, quanto à natureza do } \\
\text { seu trabalho. }\end{array}$ \\
\hline & Sandberg (2000) & $\begin{array}{l}\text { Understanding Human Competence at } \\
\text { Work: An Interpretative Approach - } \\
\text { Artigo }\end{array}$ & $\begin{array}{l}\text { O que constitui competência no trabalho de otimização de motores em uma indústria } \\
\text { automotiva. Como achado: A estrutura de significado básica das concepções dos indivíduos } \\
\text { acerca do seu trabalho constitui o que é a sua competência no trabalho. }\end{array}$ \\
\hline & Sandberg (2001) & $\begin{array}{l}\text { Understanding the Basis for } \\
\text { Competence Development - Artigo }\end{array}$ & $\begin{array}{l}\text { O que constitui desenvolvimento de competência no trabalho, ou seja, qual a base necessária } \\
\text { para desenvolver competência. }\end{array}$ \\
\hline & $\begin{array}{l}\text { Partington e } \\
\text { Young (2002) }\end{array}$ & $\begin{array}{l}\text { Configuring Knowledge in Practice- } \\
\text { Grounded Research Networks: A } \\
\text { Contemporary Example - Anais }\end{array}$ & $\begin{array}{l}\text { Estudo das competências de gestão na implementação da estratégia em contextos } \\
\text { competitivos/ambíguos. }\end{array}$ \\
\hline & $\begin{array}{l}\text { Pellegrinelli, } \\
\text { Partington e } \\
\text { Young (2003) }\end{array}$ & $\begin{array}{l}\text { Understanding and Assessing } \\
\text { Programme Management Competence } \\
\text { - Anais }\end{array}$ & $\begin{array}{l}\text { Quais são as competências necessárias aos gerentes de projetos para administrar programas } \\
\text { corporativos de natureza estratégica e complexa. São identificados } 17 \text { atributos e } 4 \text { níveis em } \\
\text { uma hierarquia de competências do indivíduo. }\end{array}$ \\
\hline & $\begin{array}{l}\text { Partington, } \\
\text { Pellegrinelli e } \\
\text { Young (2005) }\end{array}$ & $\begin{array}{l}\text { Attributes and Levels of Programme } \\
\text { Management Competence: An } \\
\text { Interpretative Study - Artigo }\end{array}$ & $\begin{array}{l}\text { O que é ser um gerente de projeto, e quais as competências que o distinguem para ocupar um } \\
\text { papel em programas gerenciais corporativos, de natureza estratégica, em termos de } \\
\text { competências. São identificados } 17 \text { atributos e } 4 \text { níveis em uma hierarquia de competências. }\end{array}$ \\
\hline & $\begin{array}{l}\text { Chen e Partington } \\
\text { (2006) }\end{array}$ & $\begin{array}{l}\text { Three Conceptual Levels of } \\
\text { Construction Project Management } \\
\text { Work - Artigo }\end{array}$ & $\begin{array}{l}\text { Baseia-se na concepção de competência em Sandberg (2000). Foram identificadas } 3 \text { diferentes } \\
\text { concepções básicas de trabalho de gestão de projetos, com diferentes atributos de experiência } \\
\text { e realização do trabalho, refletindo-se em um arranjo hierarquizado de distintas formas de } \\
\text { competências. }\end{array}$ \\
\hline
\end{tabular}




\begin{tabular}{|c|c|c|c|}
\hline & $\begin{array}{l}\text { Chen, Partington e } \\
\text { Wang (2008) }\end{array}$ & $\begin{array}{l}\text { Conceptual Determinants of } \\
\text { Construction Project Management } \\
\text { Competence: A Chinese Perspective - } \\
\text { Artigo }\end{array}$ & $\begin{array}{l}\text { Como são as competências dos gerentes de projeto na indústria de construção chinesa nos } \\
\text { modos de conceber e realizar o trabalho. Replicação do estudo britânico (Chen e Partington, } \\
\text { 2006) sobre competências para gestão de projetos na indústria de construção. }\end{array}$ \\
\hline & Sandberg (2009) & $\begin{array}{l}\text { Understanding of Work: The Basis for } \\
\text { Competence Development - Artigo em } \\
\text { livro }\end{array}$ & $\begin{array}{l}\text { O que constitui desenvolvimento de competência no trabalho e o que torna o desenvolvimento } \\
\text { de competências possível. A compreensão do que é o trabalho forma a base para o } \\
\text { desenvolvimento de competência. }\end{array}$ \\
\hline & \begin{tabular}{|l|} 
Lupson e \\
Partington (2005)
\end{tabular} & $\begin{array}{l}\text { Accountability for Public Sector IT } \\
\text { Projects and the Senior Responsible } \\
\text { Owner: A Theoretical Background } \\
\text { and Research Agenda - Working Series } \\
\end{array}$ & $\begin{array}{l}\text { Compara as limitações de } 5 \text { métodos para estudar o papel do SRO e as vantagens do Método } \\
\text { Fenomenográfico para abordar a questão. }\end{array}$ \\
\hline \multirow[t]{2}{*}{$\begin{array}{l}\text { Administração } \\
\text { Intercultural }\end{array}$} & $\begin{array}{l}\text { Chen e Partington } \\
(2004)\end{array}$ & $\begin{array}{l}\text { An Interpretive Comparison of Chinese } \\
\text { and Western Conceptions of } \\
\text { Relationships in Construction Project } \\
\text { Management Work - Artigo }\end{array}$ & \begin{tabular}{|l} 
Comparação empírica das amostras de gerentes de projetos da indústria de construção chineses \\
e ocidentais quanto à concepção do seu trabalho.
\end{tabular} \\
\hline & $\begin{array}{l}\text { Chen, Partington e } \\
\text { Qiang (2009) }\end{array}$ & $\begin{array}{l}\text { Cross-Cultural Understanding of } \\
\text { Construction Project Managers' } \\
\text { Conceptions of Their Work - Artigo }\end{array}$ & $\begin{array}{l}\text { Comparação dos gerentes de projeto chineses e britânicos, da indústria de construção, acerca } \\
\text { das concepções do seu trabalho. }\end{array}$ \\
\hline Autonomia & \begin{tabular}{|l|} 
Polesie, Frödell e \\
Josephson (2009)
\end{tabular} & \begin{tabular}{|l|} 
Implementing Standardisation in \\
Medium-Sized Construction Firms: \\
Facilitating Site Managers' Feeling of \\
Freedom through a Bottom-Up \\
Approach - Anais \\
\end{tabular} & $\begin{array}{l}\text { Como são vistos os desafios das firmas de construção pela necessidade de padronização das } \\
\text { atividades para redução de perdas e incremento de eficiência, e, simultaneamente, pela } \\
\text { emancipação dos gerentes de obra, de modo a que estes continuem a encontrar liberdade, valor } \\
\text { e motivação no seu trabalho. }\end{array}$ \\
\hline $\begin{array}{l}\text { Mudança } \\
\text { Organizacional }\end{array}$ & Dunkin (2000) & $\begin{array}{l}\text { Using Phenomenography to } \\
\text { Study Organisational Change - artigo } \\
\text { em livro }\end{array}$ & $\begin{array}{l}\text { Compreender a mudança organizacional, apresentando a perspectiva dos agentes de mudança, } \\
\text { a forma como eles conceituam seu papel, como eles escolhem estratégias para fazer a } \\
\text { mudança, o que define um agente de mudança bem-sucedido. }\end{array}$ \\
\hline $\begin{array}{l}\text { Conhecimento e } \\
\text { Aprendizagem } \\
\text { Organizacionais }\end{array}$ & Bruce (1999) & $\begin{array}{l}\text { Workplace Experiences of Information } \\
\text { Literacy - Artigo }\end{array}$ & $\begin{array}{l}\text { Experiência de competência informacional entre os vários tipos de profissionais, explorando } \\
\text { as possíveis diferenças e inter-relações entre a competência informacional individual e } \\
\text { organizacional. }\end{array}$ \\
\hline
\end{tabular}




\begin{tabular}{|l|l|l|l|}
\hline & Ortenblad (2002) & $\begin{array}{l}\text { A Typology of the Idea of Learning } \\
\text { Organization - Artigo }\end{array}$ & $\begin{array}{l}\text { O que é a ideia de Organização de Aprendizagem. Criar uma tipologia advinda dos } \\
\text { profissionais, e não da academia. }\end{array}$ \\
\hline Svensson (2009) & $\begin{array}{l}\text { Learning Environments of Employees } \\
\text { in Knowledge-Intensive Company } \\
\text { Units - Artigo em livro }\end{array}$ & $\begin{array}{l}\text { Baseado em pesquisas anteriores sobre aprendizagem em educação superior e no trabalho. } \\
\text { Concepção sobre os ambientes de aprendizagem de funcionários nas organizações intensivas } \\
\text { em conhecimento. }\end{array}$ \\
\hline $\begin{array}{l}\text { Gestão da } \\
\begin{array}{l}\text { Internacionaliza- } \\
\text { ção de Pequenas } \\
\text { Empresas }\end{array}\end{array}$ & $\begin{array}{l}\text { Lamb, Sandberg e e } \\
\text { Liesch (2011) }\end{array}$ & $\begin{array}{l}\text { Small Firm Internationalisation } \\
\text { Unveiled Through Phenomenography } \\
\text { Artigo }\end{array}$ & $\begin{array}{l}\text { Como gerentes-proprietários de pequenas empresas (indústria de vinhos) praticam } \\
\text { internacionalização. Os diferentes modos de conceber internacionalização resultam em } \\
\text { ifferentes ciclos de atividades. }\end{array}$ \\
\hline
\end{tabular}

Quadro 6: Relação de Artigos em Estudos Organizacionais com Aplicação do Método Fenomenográfico (elaborado pela autora)

\begin{tabular}{|c|c|c|c|}
\hline $\begin{array}{l}\text { Competência } \\
\text { Empreendedora }\end{array}$ & $\begin{array}{l}\text { Rocha-Pinto, } \\
\text { Silva e Soares } \\
(2010)\end{array}$ & $\begin{array}{l}\text { A Experiência de Ter Sido Empregado } \\
\text { e a Visão do Empreendedor }\end{array}$ & $\begin{array}{l}\text { De que forma a experiência de ter sido empregado influencia a decisão individual em realizar } \\
\text { a mudança quanto à formação de competências para a condição de empreendedor }\end{array}$ \\
\hline $\begin{array}{l}\text { Mudança } \\
\text { Organizacional }\end{array}$ & Silva (2001) & $\begin{array}{l}\text { Comunicação e Mudança em } \\
\text { Organizações Brasileiras: Desvendando } \\
\text { um Quadro de Referência sob a Ótica } \\
\text { do Sujeito e da Reconstrução de } \\
\text { Identidades - Tese }\end{array}$ & Como os indivíduos percebem a mudança organizacional. \\
\hline $\begin{array}{l}\text { Implementação de } \\
\text { Ferramentas de } \\
\text { Gestão }\end{array}$ & $\begin{array}{l}\text { Rocha-Pinto e } \\
\text { Carpio (2011) }\end{array}$ & \begin{tabular}{|l|} 
Fatores Críticos para a Implantação \\
do Balanced Scorecard: A Visão de \\
Consultores Organizacionais - Artigo
\end{tabular} & $\begin{array}{l}\text { Identificação, a partir da percepção dos profissionais que participaram da construção e } \\
\text { implantação de projetos de BSC, de quais seriam os fatores críticos para a implantação desta } \\
\text { ferramenta de gestão. }\end{array}$ \\
\hline Programa de TQM & $\begin{array}{l}\text { Mainardes, E.W., } \\
\text { Lourenço, L. e } \\
\text { Tontin, G. (2010) }\end{array}$ & $\begin{array}{l}\text { Percepções dos Conceitos de Qualidade } \\
\text { e Gestão pela Qualidade Total: Estudo } \\
\text { de Caso na Universidade }\end{array}$ & $\begin{array}{l}\text { Revelar o entendimento dos alunos acerca dos principais cursos de uma Universidade quanto } \\
\text { ao significado, para eles, dos fenômenos qualidade e gestão pela qualidade total. }\end{array}$ \\
\hline $\begin{array}{l}\text { Autonomia no } \\
\text { Trabalho }\end{array}$ & Lopes (2012) & $\begin{array}{l}\text { Autonomia no Trabalho: Um estudo } \\
\text { Fenomenográfico - Tese }\end{array}$ & Como os indivíduos percebem a autonomia no trabalho. \\
\hline
\end{tabular}

Quadro 7: Relação de Artigos Nacionais em Estudos Organizacionais com Aplicação do Método Fenomenográfico (elaborado pela autora) 
No Brasil, o uso da Fenomenografia também se encontra difundido na área de ensino e educação, enquanto que, na área de estudos organizacionais, foram encontrados poucos artigos utilizando este método: Silva (2001) analisou a mudança organizacional em sua tese de doutorado, de 'viés Fenomenográfico', Rocha-Pinto et al. (2010) trabalharam a relação entre competências como empregado e empreendedor, e Rocha-Pinto e Carpio (2011) analisaram a implantação da ferramenta de Balanced Scorecard. Recentemente, Lopes (2012) apresentou sua tese de doutorado em Autonomia do Trabalhador, utilizando o método da Fenomenografia do Desenvolvimento.

\subsubsection{Fases do Método Fenomenográfico}

A seguir são detalhadas as fases do método. Conforme já mencionado, a presente pesquisa utilizou a Fenomenografia de Marton, cujos aspectos e procedimentos são descritos nos trabalhos de Marton (1981, 1986), Marton e Booth (1997), e estudos empíricos de Sandberg (2000), Partington e Young (2002), Pellegrinelli et al. (2003), que detalham o Método Fenomenográfico.

Também foram considerados os procedimentos do Método Fenomenográfico descritos por Akerlind (2005a; 2005b), Akerlind et al. (2005), Barnacle (2005), Bowden (2005) e Green (2005), quando pertinentes e adequados ao contexto do presente estudo.

\subsubsection{Seleção dos Sujeitos e Definição da Amostra Intencional}

No Método Fenomenográfico, o tamanho da amostra varia entre 20 a 30 participantes, ou seja, o suficiente para assegurar uma variação nos modos de ver o objeto do estudo e, ao mesmo tempo, para tornar viável o manejo do volume de dados (BOWDEN, 2005). Entretanto, a maioria dos estudos empíricos com aplicação do método em estudos organizacionais apresenta amostras com o número mínimo de 20 participantes, havendo estudos com apenas 14 participantes (em GERBER e VELDE, 1997).

Como a Fenomenografia busca maximizar a variação de modos de ver o fenômeno, a escolha dos participantes deve ter esse objetivo da variedade. Deste modo, Green (2005) sugere o uso de amostragem intencional, ou seja, a seleção dos entrevistados deve ser intencionalmente feita com esse propósito. Akerlind 
(2005b) utiliza um planejamento prévio da variação demográfica da amostra intencional, de modo a que seja contemplada antecipadamente a variedade possível na escolha dos sujeitos. O objetivo não é engessar a seleção dos entrevistados de modo rígido e inflexível, mas considerar os grupos e tipos de participantes que devem ser incluídos na pesquisa para assegurar a variação demográfica da amostra. A flexibilidade, portanto, é assegurada graças ao número de entrevistas por subgrupos, dentro de um intervalo de participantes (entre x e y entrevistados).

A presente pesquisa foi conduzida em uma categoria de atuação profissional, com a escolha pelos profissionais de Recursos Humanos, especialmente aqueles relacionados ao RH estratégico das organizações. Considerou-se que os profissionais de RH são aqueles por quem, em princípio, passam rotinas, cultura, estrutura, estratégias, competências organizacionais e individuais, treinamento, desenvolvimento e educação (TDE), ou seja, o fluxo e a aplicação de conhecimento formal e informal das organizações. Além disso, a categoria de recursos humanos tem o papel de tradutor e disseminador das demandas da alta gestão da organização para os demais funcionários, bem como o papel de interlocutor no sentido inverso. Os conhecimentos valorados entre indivíduos e através da organização perpassam as atividades diárias destes profissionais.

O planejamento da variação demográfica da amostra intencional deste estudo encontra-se no Quadro 8, onde foi comparado o número de entrevistados desejados para a variação proposta e o número de entrevistados obtidos. Buscouse variação com base em: tempo de experiência profissional dos indivíduos, com quatro subgrupos de faixa de tempo de atuação; posição/cargo hierárquico, com três subgrupos de nível; tipo de empresa, com dois subgrupos por porte de faturamento e dois subgrupos por origem da empresa; e formação do profissional, com três subgrupos de formação acadêmica de graduação. 


\begin{tabular}{|c|c|c|}
\hline Grupos & $\begin{array}{l}\text { Variação Proposta no Número de } \\
\text { Sujeitos Entrevistados }\end{array}$ & $\begin{array}{l}\text { Variação Obtida de Sujeitos } \\
\text { Entrevistados e Número de } \\
\text { Entrevistados }\end{array}$ \\
\hline $\begin{array}{l}\text { Tempo de } \\
\text { Atuação } \\
\text { Profissional }\end{array}$ & $\begin{array}{l}4 \text { subgrupos, com } 5 \text { a } 8 \text { entrevistados: } \\
\text { - até } 5 \text { anos; } \\
\text { - de } 6 \text { a } 15 \text { anos; } \\
\text { - de } 16 \text { a } 25 \text { anos; } \\
\text { - acima de } 26 \text { anos. }\end{array}$ & $\begin{array}{l}\text { - até } 5 \text { anos: } 4 \\
\text { - de } 6 \text { a } 15 \text { anos: } 8 \\
\text { - } 16 \text { a } 25 \text { anos: } 7 \\
\text { acima de } 26 \text { anos: } 3\end{array}$ \\
\hline $\begin{array}{l}\text { Posição / } \\
\text { Cargo }\end{array}$ & $\begin{array}{l}3 \text { subgrupos: } \\
\text { - } \text { analista/coordenação: } 6 \text { a } 8 \\
\text { - gerência intermediária: } 8 \text { a } 12 \\
\text { - alta gerência/diretoria: } 6 \text { a } 8\end{array}$ & $\begin{array}{l}\text { - } \text { analista/coordenação/especialista: } 9 \\
\text { - gerência intermediária: } 8 \\
\text { - alta gerência/diretoria: } 5\end{array}$ \\
\hline $\begin{array}{l}\text { Tipo de } \\
\text { Empresa }\end{array}$ & $\begin{array}{l}\text { Indústrias de setores econômicos diversos } \\
\text { Nacional e multinacional privadas } \\
2 \text { subgrupos: } \\
\text { - pequeno e médio porte: } 6 \text { a } 10 \\
\text { - grande porte: } 10 \text { a } 14\end{array}$ & $\begin{array}{ll}\text { - } & 18 \text { indústrias } \\
\text { - } & \text { Nacional: } 12 \\
\text { - } & \text { Multinacional: } 10 \\
\text { - } & \text { Grandio porte: } 8 \\
\end{array}$ \\
\hline Formação & $\begin{array}{l}3 \text { subgrupos: } \\
\text { - Administração: } 6 \text { a } 8 \\
\text { - Psicologia: } 6 \text { a } 8 \\
\text { - Economia, Engenharia, outros: } 8 \text { a } 12\end{array}$ & $\begin{array}{l}3 \text { subgrupos: } \\
\text { - Administração: } 6 \\
\text { - Psicologia: } 9 \\
\text { - Economia, Engenharia, outros: } 7\end{array}$ \\
\hline
\end{tabular}

Quadro 8: Quadro de Variação Demográfica da Amostra Intencional (elaborado pela autora)

\section{A Experiência da Pesquisadora com a Formação da Amostra Intencional}

Para atingir o número de 20 a 30 entrevistas requeridas, foram acionados 30 contatos da rede de networking da pesquisadora, a fim de alcançar 60 empresas distintas. Inserido neste número, contou-se também com a colaboração institucional da Área de Desenvolvimento de Carreira do IAG/PUC-Rio, no convite às empresas parceiras e relacionadas à instituição. No total, foram enviados, apenas pela pesquisadora, 312 e-mails diretos para solicitar indicação para o profissional de $\mathrm{RH}$ da organização, apresentar o escopo genérico do trabalho e convidar à participação, confirmar a participação e agendar as entrevistas. Ao final, obteve-se 32 entrevistas aceitas, 25 realizadas e 22 consideradas válidas para análise. O período entre o convite e a realização das entrevistas foi de 13 de dezembro de 2012 a 17 de abril de 2013, ou seja, quatro meses.

Pode-se considerar como alto o grau de assertividade entre empresas contatadas e entrevistas aceitas e realizadas (quase 50\%). Tal fato se deve à qualidade dos contatos profissionais existentes e história de relacionamento com a pesquisadora e/ou profissionais que a indicavam e endossavam. De outro modo, cabe ressaltar o quanto é difícil conduzir pesquisas de natureza qualitativa no país. Entre as dificuldades encontradas, destacam-se: as empresas não contribuem para 
permitir a pesquisa com seus profissionais e torna-se um problema o prazo indeterminado para aprovação da mesma se o trâmite necessita passar pela esfera institucional; os profissionais participam da pesquisa por iniciativa e interesse próprios, procurando contornar horários na sua agenda de trabalho e as atribulações e imprevistos do dia; cerca de cinco entrevistados aceitaram participar e desapareceram em meio à dura realidade de abrir uma hora na agenda, se expor ao desconhecido e vencer a ansiedade de responder sobre algo que não sabiam exatamente o que seria; por fim, há uma desvinculação (inicial), na maioria dos casos, entre o objeto da pesquisa e a realidade prática, muito embora os entrevistados se surpreendam ao final da entrevista em descobrir que ela os fez refletir sobre si mesmos, suas práticas e o uso de seus conhecimentos no trabalho.

A pesquisa empírica foi conduzida com 25 sujeitos, sendo que três entrevistas foram descartadas. Um entrevistado teve acesso ao roteiro semiestruturado, preparando o discurso da entrevista e foi imediatamente excluído da amostra - tratou-se do único caso em que o trâmite para a entrevista passou pela esfera de aprovação institucional de uma empresa. Ressalva-se que os profissionais envolvidos na aprovação foram esclarecidos e informados inúmeras vezes, em todas as trocas de comunicações com a empresa, de que os entrevistados não poderiam ter acesso ao roteiro semiestruturado.

Duas duplas de entrevistados pertenciam à mesma empresa e foram entrevistados em sequência. Embora as experiências acessadas pelos entrevistados fossem diferentes, nos dois casos, ambos os entrevistados apresentaram percepções acerca da experiência muito similares, quase miméticas, que tornaram as entrevistas replicadas. Uma possível explicação para tal situação venha do fato que os profissionais tenham trabalhado juntos por muito tempo em uma relação superior-subordinado, inclusive um acompanhando ao outro por diferentes empresas durante a trajetória de carreira. Apesar desse aspecto também ser relevante no contexto de uma pesquisa qualitativa, decidiu-se manter a proposta inicial de um entrevistado por empresa, excluindo a entrevista menos rica em termos de conteúdo. Entendeu-se, também, que a manutenção de ambas as entrevistas não agregaria aos modos qualitativamente distintos de conceber o fenômeno, apenas seria mais um entrevistado dentro de uma categoria já presente.

O Quadro 9 apresenta a amostra final de perfil dos 22 sujeitos entrevistados, todos brasileiros de nascimento, considerados para análise. 


\begin{tabular}{|c|c|c|c|c|c|}
\hline Sujeito & Gênero & \begin{tabular}{|c|} 
Tempo de \\
atuação \\
profissional
\end{tabular} & $\begin{array}{l}\text { Posição e } \\
\text { cargo atual }\end{array}$ & Tipo de Empresa & Formação \\
\hline 1 & Feminino & 20 anos & Acadêmica & $\begin{array}{l}\text { Nacional. } \\
\text { Médio porte. } \\
\text { Confecção e varejo de moda. }\end{array}$ & $\begin{array}{l}\text { Economia, } \\
\text { Mestrado em } \\
\text { Administração. }\end{array}$ \\
\hline 2 & Feminino & 12 anos & $\begin{array}{l}\text { Gerente de } \\
\text { Talentos } \\
\text { Humanos }\end{array}$ & $\begin{array}{l}\text { Multinacional americana. } \\
\text { Grande porte. } \\
\text { Alimentos e bebidas. }\end{array}$ & $\begin{array}{l}\text { Fonoaudiologia, } \\
\text { Mestrado em } \\
\text { Administração. }\end{array}$ \\
\hline 3 & Masculino & 28 anos & \begin{tabular}{|l|} 
Diretor de \\
Recursos \\
Humanos \\
\end{tabular} & $\begin{array}{l}\text { Multinacional americana. } \\
\text { Grande porte. } \\
\text { Energia. }\end{array}$ & Economia. \\
\hline 4 & Feminino & 16 anos & $\begin{array}{l}\text { Coordenadora } \\
\text { Desenvolvi- } \\
\text { mento RH }\end{array}$ & $\begin{array}{l}\text { Nacional. Familiar. } \\
\text { Médio-grande porte. } \\
\text { Comércio varejista. }\end{array}$ & $\begin{array}{l}\text { Enfermagem, } \\
\text { Administração, } \\
\text { MBA em Gestão }\end{array}$ \\
\hline 5 & Feminino & 4 anos & $\begin{array}{l}\text { Coordenadora } \\
\text { de Gestão }\end{array}$ & $\begin{array}{l}\text { Nacional. Familiar. } \\
\text { Grande porte. } \\
\text { Administração shopping center. }\end{array}$ & $\begin{array}{l}\text { Engenheira de } \\
\text { Produção, MBA } \\
\text { em RH }\end{array}$ \\
\hline 6 & Feminino & 13 anos & $\begin{array}{l}\text { Especialista } \\
\text { de Recursos } \\
\text { Humanos }\end{array}$ & $\begin{array}{l}\text { Nacional. } \\
\text { Grande porte. } \\
\text { Energia. }\end{array}$ & $\begin{array}{l}\text { Psicologia, } \\
\text { MBA em RH, } \\
\text { MBA Gestão } \\
\text { Empresarial } \\
\end{array}$ \\
\hline 7 & Feminino & 25 anos & $\begin{array}{l}\text { Diretora de } \\
\text { Recursos } \\
\text { Humanos } \\
\end{array}$ & $\begin{array}{l}\text { Nacional. } \\
\text { Médio porte. } \\
\text { Educação superior. }\end{array}$ & Psicologia \\
\hline 8 & Feminino & 24 anos & $\begin{array}{l}\text { Leadership \& } \\
\text { Development } \\
\text { Director, L.A. }\end{array}$ & $\begin{array}{l}\text { Multinacional britânica. } \\
\text { Grande porte. } \\
\text { Farmacêutica. }\end{array}$ & $\begin{array}{l}\text { Administração, } \\
\text { Mestrado em } \\
\text { Administração }\end{array}$ \\
\hline 9 & Feminino & 13 anos & Gerente & $\begin{array}{l}\text { Nacional. } \\
\text { Grande porte. } \\
\text { Varejo online. } \\
\end{array}$ & $\begin{array}{l}\text { Psicologia, } \\
\text { MBA Recursos } \\
\text { Humanos }\end{array}$ \\
\hline 10 & Feminino & 15 anos & \begin{tabular}{|l|} 
Especialista \\
Desenvolvi- \\
mento Gestão \\
\end{tabular} & $\begin{array}{l}\text { Nacional. } \\
\text { Grande porte. } \\
\text { Seguro e previdência. }\end{array}$ & Psicologia \\
\hline 11 & Feminino & 9 anos & Analista & $\begin{array}{l}\text { Multinacional americana. } \\
\text { Grande porte. } \\
\text { Perfumaria e higiene pessoal. }\end{array}$ & Psicologia \\
\hline 12 & Feminino & 11 anos & Gerente RH & $\begin{array}{l}\text { Nacional. } \\
\text { Grande porte. } \\
\text { Construção civil. } \\
\end{array}$ & Psicologia \\
\hline 13 & Masculino & 3 anos & Coordenador & $\begin{array}{l}\text { Multinacional. } \\
\text { Médio porte. } \\
\text { Franquia de fast-food. }\end{array}$ & Administração \\
\hline 14 & Masculino & 32 anos & $\begin{array}{l}\text { Diretor } \\
\text { Administrati- } \\
\text { vo }\end{array}$ & \begin{tabular}{|l|} 
Nacional. Familiar. \\
Médio porte. \\
Administradora de condomínios. \\
\end{tabular} & $\begin{array}{l}\text { Administração, } \\
\text { Mestrado em } \\
\text { Psicologia } \\
\end{array}$ \\
\hline 15 & Feminino & 5 anos & \begin{tabular}{|l} 
Analista de \\
Recursos \\
Humanos \\
\end{tabular} & $\begin{array}{l}\text { Multinacional americana. } \\
\text { Médio porte. } \\
\text { Farmacêutica. }\end{array}$ & Administração \\
\hline 16 & Feminino & 10 anos & Coordenadora & $\begin{array}{l}\text { Multinacional francesa. } \\
\text { Grande porte. } \\
\text { Cimentos e agregados. } \\
\end{array}$ & Psicologia \\
\hline 17 & Feminino & 20 anos & $\begin{array}{l}\text { Gerente de } \\
\text { DHO }\end{array}$ & $\begin{array}{l}\text { Nacional. Familiar. } \\
\text { Médio-Grande porte. } \\
\text { Perfumaria e higiene pessoal. }\end{array}$ & $\begin{array}{l}\text { Psicologia, } \\
\text { MBA em RH }\end{array}$ \\
\hline 18 & Feminino & 24 anos & $\begin{array}{l}\text { Diretora de } \\
\text { Recursos } \\
\text { Humanos }\end{array}$ & $\begin{array}{l}\text { Multinacional americana. } \\
\text { Grande porte. } \\
\text { Tecnologia da informação. }\end{array}$ & Administração \\
\hline
\end{tabular}




\begin{tabular}{|l|l|l|l|l|l|}
\hline 19 & Feminino & 30 anos & $\begin{array}{l}\text { Gerente de } \\
\text { RH }\end{array}$ & $\begin{array}{l}\text { Nacional. Familiar. } \\
\text { Médio-Grande porte. } \\
\text { Comércio varejista. }\end{array}$ & Psicologia \\
\hline 20 & Feminino 15 anos & $\begin{array}{l}\text { Gerente de } \\
\text { DHO }\end{array}$ & $\begin{array}{l}\text { Nacional. Familiar. } \\
\text { Grande porte. } \\
\text { Infraestrutura construção } \\
\text { pesada. }\end{array}$ & $\begin{array}{l}\text { Psicologia, } \\
\text { MBA em RH }\end{array}$ \\
\hline 21 & Feminino & 20 anos & Gerente RH & $\begin{array}{l}\text { Multinacional mexicana. } \\
\text { Grande porte. } \\
\text { Telecomunicações. }\end{array}$ & $\begin{array}{l}\text { Comunicação } \\
\text { Social }\end{array}$ \\
\hline 22 & Feminino & 14 anos & $\begin{array}{l}\text { Coordenadora } \\
\text { de RH }\end{array}$ & $\begin{array}{l}\text { Multinacional americana. } \\
\text { Grande porte. } \\
\text { Serviços consultoria e auditoria. }\end{array}$ & Biblioteconomia \\
\hline
\end{tabular}

Quadro 9: Quadro Final de Perfis dos Sujeitos Entrevistados (elaborado pela autora)

\subsubsection{Coleta de Dados e a Entrevista Fenomenográfica}

Quanto à coleta de dados, conforme já abordado, não parece haver uma direção única postulada pelo método, e sim correntes distintas com procedimentos diferentes. Os estudos empíricos baseados em Marton $(1981,1986)$ e Marton e Booth (1997) apresentam uma variedade de meios de coleta de dados aliados à entrevista semiestruturada. Foram utilizados: um questionário escrito (GERBER e VELDE, 1996) e, ainda, a observação direta (PELEGRINELLI et al., 2003). Também foram apresentados interações recursivas ou workshops de discussão com os entrevistados, visando a refinar e consolidar os achados emergentes das análises. A esse respeito, tem-se que Pelegrinelli et al. (2003) realizaram a análise em paralelo à coleta de dados, pelo período de um ano de trabalho.

Já a Fenomenografia do Desenvolvimento, de Bowden e Green (2005) e Bowden e Walsh (2000), postula que a entrevista é o único meio de coleta de dados no Método Fenomenográfico. Nesta corrente, o Método Fenomenográfico não é complementado por qualquer outra fonte ou material comumente utilizado em pesquisas de abordagem qualitativa como, por exemplo, observação, fonte documental, fontes secundárias ou outros meios (GREEN, 2005). Não foi esta a vertente utilizada na presente pesquisa.

No caso da entrevista fenomenográfica, trata-se de uma entrevista em profundidade baseada em roteiro semiestruturado, com algumas características particulares na elaboração do roteiro e na fase da coleta de dados. Os procedimentos de entrevista fenomenográfica foram compilados a seguir: 
- O cenário (contexto) selecionado da conversa é pré-estabelecido e restrito ao objeto de pesquisa (BOWDEN, 2005; GREEN, 2005), visando a contextualizar e delimitar o conteúdo da entrevista. Deve ser idêntico para todos os entrevistados, de modo que seja explorado o mesmo fenômeno (BOWDEN, 2005). O cenário apresentado deve funcionar para produzir o tipo de dado necessário para o objetivo da pesquisa. Por isso, o piloto de entrevista é essencial (GREEN, 2005). Sandberg (2000) e Pellegrinelli et al. (2003) mencionam duas questões centrais em torno das quais toda a entrevista é realizada, sendo elas exploradas pelas demais questões de apoio.

- O entrevistador precisa evitar introduzir novos materiais e temas que não façam parte do planejamento da estrutura de entrevista (GREEN, 2005). A introdução de novos materiais e temas fora do cenário planejado deveria ser descartada da transcrição e, se muito extensa, poderia chegar a invalidar toda a entrevista (BOWDEN, 2005; GREEN, 2005). Deve-se evitar o ingresso de novos materiais na entrevista por meio dos tipos de questões feitas e comentários feitos pelo entrevistador, limitados a requisitar mais informações ou encorajar explicações sobre as ideias suscitadas pelo participante (BOWDEN, 2005). Essas solicitações devem encorajar os participantes a revelar todo o possível em relação ao fenômeno (BOWDEN, 2005).

- Além disso, o entrevistador deve tomar um cuidado extremo para evitar reportar seus próprios conceitos ou ideias ao participante (BOWDEN, 2005; GREEN, 2005). O entrevistador não emite observações ou constrói ideias com o entrevistado, mas deve estimular que o entrevistado traga suas próprias reflexões, do modo mais completo e detalhado possível (BOWDEN, 2005). Esse aspecto não é especificado na Fenomenografia de Marton, e parece ser um rigor introduzido pela Fenomenografia do Desenvolvimento, até porque, no trabalho de Pellegrinelli et al. (2003), há interação e retorno aos entrevistados na coleta de dados.

- Akerlind (2005b, p.115) reconhece as críticas feitas ao método quanto à "ideia da entrevista fenomenográfica [do desenvolvimento] ser desconfortável", uma vez que o entrevistador não compartilha comentários com o entrevistado, diferentemente a outros métodos 
interpretativistas, e de explorar as causas e motivações (why questions), e não somente o que foi feito ou como foi feito algo. Para tanto, ela sugere um envolvimento dos participantes por meio do contexto da entrevista, de modo a criar uma 'atmosfera empática' e possibilitar o entendimento da experiência do participante acerca do fenômeno.

- De um modo geral, a ideia, na entrevista fenomenográfica, é limitar os temas (inputs) e planejar a sequência que introduza o fenômeno ao entrevistado, procedendo, então, na entrevista, à definição do que é relevante. Cabe ao entrevistador buscar completude e explicitação (BOWDEN, 2005).

- No caso da Fenomenografia do Desenvolvimento, todas as entrevistas devem ocorrer dentro de um período determinado, uma fatia de tempo (time frame), que varia de 2 a 3 meses (GREEN, 2005). Não há possibilidade de retornar ao entrevistado para esclarecer ideias ou estender os dados (BOWDEN, 2005; GREEN, 2005). Na Fenomenografia de Marton, isso não se aplica, vide o exemplo de Pellegrinelli et al. (2003), já mencionado.

Quanto ao conteúdo explorado na entrevista, parece que as diferentes correntes fenomenográficas convergem. Após a apresentação do cenário da entrevista, o roteiro de questões deve ser iniciado a partir da experiência vivida pelo participante, por meio da descrição detalhada de uma experiência recente relacionada ao tema em consideração, seja ela bem ou malsucedida (BOWDEN, 2005).

Marton e Booth (1997) e os estudos empíricos de Gerber e Velde (1996, 1997), Sandberg (2000), Pellegrinelli et al. (2003) recomendam uma etapa inicial com o uso de questões sobre what/o que e how/como, a fim de capturar o que é concebido sobre o fenômeno (pensamento acerca do significado da realidade) e

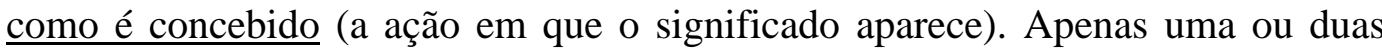
perguntas centrais são feitas aos participantes e todas as demais giram em torno de compreender a relação entre o que é pensado e como é a ação do indivíduo sobre o fenômeno. Assim, se dá a utilização intensa de "why questions / por quê?", que procura justamente compreender o modo como o participante reflete sobre as práticas e exemplos (que ilustram o fenômeno investigado), (AKERLIND, 2005a; 2005b). 


\section{A Experiência da Pesquisadora com a Coleta de Dados}

O roteiro da entrevista semiestruturada encontra-se no Apêndice 1. Ele foi composto de duas perguntas de introdução ao tema e duas perguntas centrais. As perguntas de introdução versaram sobre uma breve trajetória profissional do entrevistado até a empresa e cargo atuais e o que é conhecimento na concepção dele. O roteiro apresentado no Apêndice 1 trata-se da segunda versão de roteiro, pois foi adaptado após uma entrevista piloto. Essa adaptação foi justamente a inclusão das perguntas introdutórias. Elas foram necessárias para ajudar ao entrevistado a organizar e articular suas ideias, uma vez que falar diretamente de valoração do conhecimento é muito difícil: dois conceitos intangíveis. Na segunda entrevista piloto, com a nova versão do roteiro, a entrevista se desenrolou com fluidez, tendo sido inclusive aproveitada na amostra.

As perguntas centrais versaram sobre o conteúdo principal do estudo: um exemplo de experiência em que o entrevistado considerou que teve seus conhecimentos mais valorados no contexto do trabalho e, posteriormente, um exemplo de experiência em que o entrevistado considerou que não teve seus conhecimentos valorados no contexto do trabalho, e como o entrevistado percebeu que os conhecimentos valorados foram ou não incorporados nas suas rotinas e práticas de trabalho. Todas as demais perguntas foram acessórias para explorar: o porquê de o entrevistado considerar o exemplo como representação do fenômeno; o como/how e o que/what do fenômeno; as condições facilitadoras e barreiras à valoração do conhecimento; os indivíduos responsáveis por valorar o conhecimento na organização, ou seja, abordam acerca dos fatores de contexto, a fim de identificar e explorar a significação da valoração do conhecimento para o indivíduo e seu impacto nas rotinas organizacionais.

A forma como é concebida a entrevista para o Método Fenomenográfico gera um grande exercício mental por parte dos entrevistados. Pode-se sugerir que eles precisam conceber, no momento da entrevista, os aspectos e as relações acerca do fenômeno, o que torna a entrevista mais difícil de conduzir. Ela inquire sobre elementos que os entrevistados nunca ou raramente pensam a respeito.

Com exceção de três entrevistas (sujeitos 1, 6 e 9), todas foram realizadas no ambiente de trabalho dos sujeitos entrevistados. Tal fato se deve à conveniência para o entrevistado, que precisa conjugar suas atividades diárias profissionais com a entrevista, uma atividade de interesse particular e, 
inicialmente, de aparente desvinculação com o trabalho. Não pareceu haver diferença de comportamento dos entrevistados nas entrevistas realizadas dentro e fora do ambiente de trabalho, mas cabe ressalvar que no ambiente de trabalho há sempre uma prontidão maior do profissional com a agenda de trabalho da empresa: atraso para atender ao pesquisador, pois uma reunião atrasou, um superior chamou, uma ligação telefônica entrou; há uma reunião ou trabalho importante a entregar após a entrevista, entre outros. Porém, esses fatos não pareceram influenciar no tempo que os participantes dedicaram no momento da entrevista, ou seja, todos tomaram o tempo necessário para responder às perguntas com calma, refletir sobre as questões colocadas sem pressa e, ao final, mesmo com o término da mesma, ainda queriam conversar sobre as reflexões pessoais que o conteúdo da entrevista gerou neles.

As 22 entrevistas válidas transcorreram em reuniões de cinquenta a noventa minutos com os sujeitos, correspondendo a $21 \mathrm{~h} 09 \mathrm{~m}$ de gravação de material de análise. Assim, as entrevistas tiveram uma duração média de 57 minutos, excluídos os tempos de informe esclarecido e a descrição do cenário de entrevista. A transcrição gerou o total de 352 páginas.

O Método Fenomenográfico preconiza a realização de 20 a 30 entrevistas (BOWDEN, 2005), o que, por um lado, resolve a discussão acerca do alcance de saturação teórica em relação aos dados qualitativos coletados. Entretanto, cabe observar que, por outro lado, no presente estudo, a saturação teórica foi sentida na $17^{\text {a }}$ entrevista e, para satisfazer aos requisitos do método, prosseguiu-se até a obtenção de, no mínimo, as 20 entrevistas válidas. Dado o compromisso e agendamento já feito com alguns participantes, foram realizadas as 25 entrevistas.

\subsubsection{Tratamento e Análise dos Dados: Outcome Space e Categorias Descritivas}

Quanto ao tratamento e análise dos dados, primeiramente, cumpre ressaltar que o Método Fenomenográfico é indutivo e que todos os resultados e proposições são principal (no caso da corrente de Marton, 1981; 1997) ou unicamente (no caso da corrente da Fenomenografia do Desenvolvimento) emergentes dos dados transcritos (BARNACLE, 2005; GREEN, 2005). Os dados devem ser repetidamente lidos na íntegra, de modo a formar ideias e permitir o 
surgimento de achados pelo processo indutivo, ou seja, a análise é derivada de um conjunto de significados, de onde são colhidos os modos de conceituá-los (GREEN, 2005; SANDBERG, 2000).

Em ambos os tipos de Fenomenografia, a análise de todas as entrevistas é simultânea, ou seja, não é observada a transcrição de uma entrevista em particular, mas a relação das entrevistas entre si: quais delas agrupam concepções similares ou dissimilares, quais delas apresentam maior proximidade ou distanciamento entre si (AKERLIND, 2005a; BARNACLE, 2005; SANDBERG, 2000). Assim, a análise é tomada através dos indivíduos, isto é, o método promove a descontextualização do indivíduo e vozes individuais não são levantadas (BOWDEN, 2005). Entretanto, a citação de elocuções retiradas das transcrições é bem-vinda para exemplificar um modo comum de pensamento contido em uma categoria descritiva (AKERLIND, 2005a; BARNACLE, 2005).

Entretanto, cabe ressalvar que a Fenomenografia de Marton é mais flexível, na medida em que Pellegrinelli, Partington e Young (2003) realizaram a coleta e o tratamento de dados simultaneamente, e não em fases separadas, como defende a Fenomenografia do Desenvolvimento, e foram feitos no decorrer de um ano de pesquisa.

As transcrições são a evidência-base e todas as categorias descritivas desenvolvidas devem estar nelas contidas (AKERLIND et al., 2005; BARNACLE, 2005; GREEN, 2005). O desenvolvimento de categorias descritivas é feito, portanto, por meio do processo de interação com os dados e entre os dados (GREEN, 2005). Segundo Barnacle (2005), as categorias descritivas não são determinadas a priori na análise textual, nem são representações das percepções individuais. Elas se localizam entre estas duas dimensões.

O processo de análise busca diferentes modos de experimentar a realidade, contidos nas categorias descritivas, e, especialmente, o mapeamento da estrutura, ou espaço de resultado, que delineia a relação hierárquica e lógica entre elas (BOWDEN, 2005). As categorias descritivas possuem um foco no significado ou aspecto referencial, enquanto o esclarecimento da relação lógica entre elas (em seus significados) foca na estrutura ou aspecto estrutural (AKERLIND et al., 2005; AKERLIND, 2005a; 2005b). Bowden (2005) enfatiza a questão de mapeamento da estrutura desde o início da fase de análise, buscando os principais significados holísticos em um menor número de categorias. Deve-se tomar 
cuidado para evitar a catalogação de muitos padrões detalhados que promovam uma menor compreensão do todo, pois não é este o objetivo da Fenomenografia.

O processo de geração de categorias descritivas e mapeamento da estrutura são revisitados e mutáveis no decorrer do processo de análise, à medida que as categorias vão sendo refinadas, na busca pela maximização das diferenças entre elas e a coerência interna delas (BOWDEN, 2005; GREEN, 2005). Bowden (2005) sugere que elas somente sejam rotuladas ao final, para evitar que os rótulos limitem o desenvolvimento mais profundo da categorização.

Para a Fenomenografia do Desenvolvimento, um dos critérios de rigor do método reside no processo de debriefing com pares. Em projetos realizados em times, o processo de questionamento é contínuo (AKERLIND et al., 2005; BOWDEN, 2005). Para os autores, projetos individuais, como o presente estudo, necessitam, em determinado momento da etapa da geração de categorias descritivas, ser submetidos ao questionamento de pares, com o objetivo de confirmar, refinar e repensar o trabalho desenvolvido: 1) a coerência das descrições feitas até então; 2) a lógica da estrutura entre categorias descritivas; e 3) a conformidade das categorias com as transcrições (AKERLIND et al., 2005; BOWDEN, 2005). Este ponto não é necessário na Fenomenografia de Marton (1981, 1997).

O produto final do Método Fenomenográfico consiste em um quadro representativo do espaço de resultado. Ele apresenta as categorias descritivas (ou concepções) e dimensões relacionadas encontradas, sendo que, a cada concepção do fenômeno (da mais simples à mais abrangente) as mesmas dimensões variarão em conteúdo.

No caso do presente estudo, a análise dos dados contou com auxílio do software Atlas $\mathrm{T} i$ para análise heurística das transcrições, visando ao desenvolvimento e refinamento sucessivo das dimensões relacionadas às categorias descritivas (concepções), bem como auxiliou no mapeamento das interrelações lógicas entre categorias.

\section{A Experiência da Pesquisadora com o Tratamento dos Dados}

O Método Fenomenográfico traz alguns desafios específicos para os pesquisadores. O principal deles diz respeito ao modo de pensar inerente ao próprio pesquisador e à forma de analisar e tratar os dados. A Fenomenografia 
trata os dados com base no conjunto total de entrevistas (O que elas dizem em seu conjunto?) em relação a cada entrevista individual (O que esse sujeito quis dizer? Como ele concebe o fenômeno? E onde ele se encaixa no todo, no conjunto total de entrevistas?), ou seja, uma análise com base em pensamento sintético.

Esse aspecto é importante, pois o método parte da categoria, que é uma concepção do fenômeno, para o detalhamento do que compõe a categoria (ou seja, suas dimensões). Esse procedimento é necessário para dar origem ao Espaço de Resultado (outcome space). Assim, somente após o pensamento sintético ter dado origem a categorias que se inter-relacionam, os dados são tratados por partes, ou seja, as entrevistas são desmembradas de modo analítico.

Quando o pesquisador possui pensamento sintético, o método apresenta certa facilidade de análise. Durante as entrevistas, a pesquisadora já encontrava naturalmente relações iniciais com conteúdos de outras entrevistas realizadas previamente (essa entrevista Y se parece com, está dizendo a mesma coisa que, a entrevista X). Mas, para aquele que possui pensamento analítico, que precisa ir aos detalhes para fazer emergir uma síntese, o método pode trazer bastante dificuldade ao pesquisador. Deve-se considerar, também, a dificuldade de manipular simultaneamente 352 páginas de entrevistas, até se definir as categorias definitivas.

O estudo tratou de uma pergunta de pesquisa com duas questões: a questão principal (valoração do conhecimento no contexto do trabalho) e a questão subsidiária (o impacto nas práticas e rotinas organizacionais). A exemplo da pesquisa de tese de Akerlind (2005), as questões foram contempladas em duas perguntas centrais do roteiro da entrevista Fenomenográfica. Quanto ao tratamento, elas foram abarcadas no mesmo Espaço de Resultado, pois a questão subsidiária das rotinas organizacionais encontrava-se relacionada e complementar à questão central.

Assim, a leitura conjunta de todas as entrevistas (descontextualização dos sujeitos) originou a separação das entrevistas em categorias descritivas iniciais, que variavam entre quatro e cinco conjuntos de entrevistas (concepções) para valoração do conhecimento. Entretanto, também foram encontradas, no conjunto das entrevistas, quatro conceituações distintas para rotinas organizacionais, que apenas foram mencionadas no decorrer da descrição das categorias. 
Após a separação em categorias iniciais, a pesquisadora passou a abordar cada entrevista em separado, com auxílio do software Atlas-ti. Neste momento, cada entrevista foi tratada de modo analítico, classificando os trechos das narrativas nos elementos seguintes, em acordo com a estrutura do método:

- Experiência do sujeito com o fenômeno;

- O que/what do fenômeno;

- O como/how do fenômeno;

- Ação/ato;

- Contexto espacial da situação;

- Contexto temporal da situação;

- Contexto social da situação: relacionamentos;

- Aspecto referencial da situação: significado

- Fatores, positivos e negativos, influenciadores do fenômeno;

- Pessoas que influenciam no fenômeno;

- Natureza do conhecimento;

- Estrutura da atividade/tarefa: o quanto é inédita ou rotinizada, processos existentes ou não;

- Influenciadores das rotinas;

- Flexibilidade nas rotinas.

O tratamento individual das entrevistas confirmou cinco concepções para valoração do conhecimento. A análise detalhada, que se encontra no capítulo 6 , foi realizada de 20 de abril a 17 de julho, ou seja, três meses para desenvolver e consolidar as análises. Esse período é compatível com o informado por Akerlind (2005) quanto ao tratamento dos dados.

Cumpre reiterar uma vantagem que o Método Fenomenográfico traz: a abordagem ampla nas diversas formas de concepção do fenômeno, uma vez que mapeia o entendimento dos indivíduos, possibilita uma plataforma para o desenvolvimento de uma linha de pesquisa. A Fenomenografia parece ser especialmente adequada e indicada para temas complexos, recentes e/ou pouco pesquisados, capturando, a um só tempo, uma ampla visão do todo. 


\subsubsection{Critérios de Confiabilidade e Rigor}

Quanto aos critérios de confiabilidade e rigor do método, Marton (1981, 1997) não aborda esse aspecto. Já na Fenomenografia do Desenvolvimento, eles foram tratados por Green (2005), em comparação com outros métodos de natureza qualitativa. As estratégias relacionadas à credibilidade dos resultados são listadas a seguir, apenas para fins de completude de informação:

1. Fatia de Tempo (versus envolvimento prolongado no campo):

- A Coleta de dados é confinada em um período de tempo, sendo mais flexível pela abordagem de Marton (1981, 1997).

- O contexto não é relevante, exceto para a seleção da amostra intencional.

2. A observação persistente não é relevante:

- A entrevista é o método primordial de coleta de dados.

3. A triangulação de dados e fontes ocorre por meio de conformidade com os dados transcritos.

4. Debriefing com pares é crítico:

- Discussão por pares desinteressados (no caso de pesquisa individual).

- Na abordagem de Marton $(1981,1997)$, este aspecto não é tratado.

5. A análise de caso negativo:

- Ocorre por meio do item 4, por processo de advogado do diabo.

6. A checagem pelos participantes é inadequada e inexistente:

- Vozes individuais não são apresentadas, os achados, na forma de Categorias Descritivas, vão através dos indivíduos.

- Pelegrinelli et al. (2003), ao adotar a Fenomenografia de Marton (1981, 1997), voltam aos indivíduos entrevistados por meio de workshops, a fim de discutir os resultados encontrados.

Quanto ao rigor da pesquisa fenomenográfica, Green (2005) lista os seguintes pontos:

1. Preparação para entrevista.

2. Técnica de entrevista aberta, porém focada.

3. Estratégia para evitar ao máximo qualquer impacto não planejado sobre o entrevistado durante a entrevista: cenário estabelecido, não acréscimo 
de novos conceitos; paráfrase da resposta do entrevistado sem alteração de sentido, entre outros.

4. Estratégia para consistência da entrevista.

5. Estrita aderência aos dados.

6. Admissão de inconsistências entre as transcrições, em vez de tentar refrear os dados, de modo a aparentar consistência.

7. Volta aos dados, releitura do contexto, da exata frase.

8. Processo de releitura constante dos dados como um todo.

9. Natureza interativa no desenvolvimento das categorias.

10. Processo de debate crítico, debriefing com pares.

11. Apresentação dos dados em categorias de descrição, considerando a relação entre elas quando relevante, e uso de citações ilustrativas extraídas das transcrições.

Pode-se identificar que, quanto aos aspectos de confiabilidade e rigor, a Fenomenografia do Desenvolvimento trouxe um enrijecimento ao método. Inferese, assim, que se trata de um pensamento tradicional que retoma a antiga discussão de que 'se o método qualitativo não possuir critérios rígidos, inflexíveis, não conseguirá demonstrar validade e valor científico do estudo realizado'. Entretanto, o rigor excessivo proposto acaba por reduzir o papel do pesquisador qualitativo em sua análise interpretativa e por retirar uma das partes mais ricas da essência da pesquisa qualitativa. É inerente à pesquisa qualitativa a subjetividade do pesquisador e dos pesquisados no momento da entrevista - e sua plena aceitação como parte constituinte dos métodos qualitativos. Pode-se pôr em dúvida, desse modo, o excessivo controle e rigor como modo de tentar controlar e contornar a subjetividade - como se ela não estivesse ali.

Conforme já mencionado, a presente pesquisa seguiu a Fenomenografia de Marton (1981; 1997), mais flexível e aberta ao entendimento do fenômeno (conjugada com outros métodos, baseada na capacidade interpretativa do pesquisador), por entender que de forma alguma o rigor na realização do estudo compromete os resultados encontrados. A subjetividade está presente, pois é uma pesquisa de natureza qualitativa com método interpretativo, porém também está presente a plena consciência desse aspecto por parte da pesquisadora, que busca a 
compreensão isenta do fenômeno com uma tentativa de suspensão dos julgamentos de valor.

\subsection{Etapa 4: Grupo de Foco com Profissionais Participantes da Pesquisa Empírica para Validação Interna do Mapa do Espaço de Resultado}

Com o objetivo de validação interna do Mapa do Espaço de Resultado, Figura 9 disponível no capítulo 6 de análise dos dados, foi realizada uma reunião com cinco participantes dos 22 entrevistados da pesquisa. Utilizou-se a técnica de entrevista em grupo em profundidade (GOLDMAN e MCDONALD, 1987), mais conhecida como grupo de foco. O grupo de foco foi realizado em 08 de agosto de 2013, no IAG PUC-Rio, reunindo sujeitos de quatro categorias distintas, sendo um sujeito em trânsito entre categorias e um sujeito que pareceu voltar atrás na hierarquia de categorias. Participaram os entrevistados 2, 4, 5, 6 e 10, considerados indivíduos mais prototípicos e representativos das categorias e de tais movimentos de trânsito. A reunião durou 141 minutos e foi gravada para posterior resgate dos dados.

O grupo de foco conteve a seguinte agenda: primeiramente, a pesquisadora detalhou aos profissionais as concepções encontradas na pesquisa e, posteriormente conduziu a primeira rodada de perguntas acerca da percepção dos participantes da coexistência de indivíduos das diversas categorias na organização onde trabalham; quais delas; se havia predominância evidente de alguma categoria sobre as demais; o que ocorria com os indivíduos que possuíam concepções distintas da concepção dominante da organização (caso ela fosse percebida como existente).

No segundo momento, a pesquisadora apresentou o Mapa de Espaço de Resultado e sua hierarquia. Nova rodada de perguntas foi conduzida acerca da percepção dos profissionais da hierarquia lógica do Mapa; da confirmação de trânsito entre as categorias no decorrer da trajetória de carreira; a direção do trânsito entre categorias no decorrer da carreira. O Apêndice 2 apresenta o roteiro com as perguntas feitas nas duas rodadas de debate.

A validade interna do Mapa do Espaço de Resultado foi confirmada por todos os participantes, em ambas as questões de lógica hierárquica e de 
bidirecionalidade de trânsito entre categorias. Os resultados do grupo de foco foram incorporados no capítulo 6 , de análise de dados, e no capítulo 7 , de discussão e proposição.

Cumpre ressaltar que a realização do grupo de foco foi riquíssima para a pesquisadora:

- Primeiro, pôde confrontar os resultados da análise com os próprios entrevistados participantes, e verificar que os resultados fizeram sentido para eles, do ponto de vista deles.

- Segundo, permitiu validar os achados relativos ao Método Fenomenográfico (dinâmica de trânsito dos sujeitos pelas categorias; visão do mapa do espaço de resultado como um continuum, e não como categorias estanques; bidirecionalidade nesse continuиm).

- Terceiro, possibilitou debater as concepções relacionadas à valoração do conhecimento, onde os participantes procuram se encontrar dentre elas, confirmando o quanto os contextos moldam as percepções.

- Quarto, muitas das questões levantadas no resultado da análise foram debatidas e confirmadas: quanto à coexistência de múltiplas concepções nas organizações; dominância de uma concepção advinda da organização em sua estrutura, forma e modelo; o aspecto relacional e da construção social da concepção pelos indivíduos e a organização, dependente do contexto.

Por fim, cabe ressaltar que os próprios participantes expressaram que gostaram demais de participar da reunião. Para eles, foi importante entender o resultado daquela entrevista que foi difícil, onde eles não sabiam ao certo se estavam respondendo aquilo que a pesquisadora perguntava, nem se estavam sendo claros em falar de um assunto que pouco tinham tempo de pensar no dia a dia do trabalho. Ao ver o resultado, expressaram como as concepções deles a respeito do conhecimento de valor se expandiram, e como tiveram oportunidade de pensar e refletir sobre a utilização do conhecimento individual e organizacional no trabalho. Expressaram, também, como gostariam que mais iniciativas desse tipo fizesse parte da realidade deles nas organizações, por meio do estreitamento entre organizações e universidades. 


\subsection{Limitações do Método}

O Método Fenomenográfico, assim como qualquer método, apresenta suas limitações. Bowden (2005) destaca que a entrevista Fenomenográfica préestabelece o cenário em torno do qual se desenvolverão as narrativas (contexto), razão pela qual novas questões emergentes no processo de entrevista não podem ser exploradas e inseridas na conversa, nem nas entrevistas seguintes. Essa limitação mostrou-se necessária, dado que o método busca acessar qualquer coisa (anything) que o sujeito perceba, pense e atue como relacionado ao fenômeno, trazendo a complexidade da diversidade de assuntos. Embora seja uma limitação de fato, percebe-se que o estudo ganha em abrangência e profundidade ao mesmo tempo.

Outra limitação relevante, suscitada por Akerlind (2005b), reside na análise simultânea dos dados, que é complexa e consome tempo, restringindo a abordagem de mais de dois tópicos entre o objeto de pesquisa em um mesmo estudo. Segundo a autora, dependendo da complexidade do tópico, dedica-se um período entre 3 a 6 meses de análise para chegar-se às categorias descritivas e outcome space finais. Desse modo, o método pressupõe um foco restritivo quanto ao objeto de estudo. Perde-se a oportunidade de explorar mais tópicos relativos ao objeto de estudo, em detrimento de um aprofundamento na análise. A experiência com o método demonstrou que ao explorar um único tópico, está-se concebendo de 3 a 7 concepções diferentes daquele tópico, que devem estar lógica e hierarquicamente interligadas e diferenciadas umas das outras.

Embora não se trate de limitações, mas de aspetos inerentes ao método, é importante reafirmar que o resultado da pesquisa Fenomenográfica não busca tratar dos indivíduos em particular (como o GTM) (BOWDEN, 2005), não procura explicar o que os indivíduos fazem na prática (AKERLIND, 2005a), nem tenta apresentar descrições e explicações do fenômeno (como a Fenomenologia Descritiva e Interpretativa) (MARTON, 1981). O método perpassa através dos indivíduos e objetiva gerar o mapeamento de uma estrutura de pensamento. 


\section{6 \\ Análise dos Dados Emergentes do Campo}

O presente capítulo apresenta a análise dos dados coletados por meio das entrevistas Fenomenográficas e do grupo de foco realizado com fins de validação interna do Mapa do Espaço de Resultado. Cabe ressaltar que as categorias descritivas emergentes dos dados empíricos se tratam de concepções dos indivíduos acerca da sua experiência com a valoração do conhecimento no contexto do trabalho e os impactos nas práticas e rotinas organizacionais, também percebidos e expressos pelos entrevistados. Desse modo, essas concepções são fruto da forma de pensar, agir e significar o fenômeno, não estando certas ou erradas: elas são a 'realidade' para os indivíduos entrevistados; e partes da(s) realidade(s) no contexto desse estudo. Portanto, as análises apresentadas a seguir, na forma de categorias descritivas, ou concepções do fenômeno, devem ser lidas tendo em mente esses aspectos.

O capítulo apresenta as categorias descritivas, que se encontram no tópico das Concepções dos Indivíduos acerca da Valoração do Conhecimento no Contexto do Trabalho; proposições relevantes nas Considerações acerca do Método Fenomenográfico e a Valoração do Conhecimento no Contexto do Trabalho; e os Resultados do Grupo de Foco para Validação Interna do Mapa do Espaço de Resultado, conduzido com os participantes.

\subsection{As Concepções dos Indivíduos acerca da Valoração do Conhecimento no Contexto do Trabalho}

A análise dos dados advindos das entrevistas de campo ressaltou cinco categorias descritivas, ou seja, concepções dos indivíduos acerca da valoração do conhecimento no contexto do trabalho. São elas: Aplicação no Trabalho; Consideração (aqui utilizada como sinônimo de Reconhecimento) do TrabalhoIndivíduo; Realização do Indivíduo no Trabalho; Transformação do Indivíduo e do Trabalho e Criação Emergente para a Vida. 
Elas são apresentadas da concepção mais estreita e restrita à mais ampla, seguindo um encadeamento lógico, hierárquico e inclusivo (ou seja, a categoria imediatamente anterior está contida na categoria seguinte), preconizado pelo Método Fenomenográfico para o espaço de resultado. A análise sugeriu que, mais do que se mover de uma a outra concepção no decorrer da repetida experiência com o fenômeno, a relação entre concepções é dinâmica e em movimento: os indivíduos transitam de uma a outra categoria contígua em alguns casos e, em outros, encontram-se no meio do caminho entre concepções. Propõe-se também, portanto, que as categorias descritivas formam um continuum, e não são apenas categorias isoladas ligadas por uma hierarquia lógica. O estudo sugere e propõe que de forma alguma as categorias têm o objetivo de aprisionar os sujeitos em classificações fixas. Esses aspectos são discutidos mais a frente, no capítulo 7, tópico 7.1.

É sempre extremamente relevante frisar que todas as concepções apresentadas nas categorias descritivas fazem parte de um fenômeno único, são parte de um conjunto só, como peças de um quebra-cabeça. Daí, outros dois pontos importantes decorrem. Primeiro: não existem concepções melhores, mais corretas ou preferíveis às outras: são apenas diferentes concepções, formas diversas de ver e entender o mundo. Segundo: as concepções coexistem e estão presentes sempre em todos os momentos, conforme confirmado no grupo de foco, tanto as encontradas nesse estudo quanto provavelmente outras que não emergiram na pesquisa ou que se encontram fora da consciência focal da própria autora dessa tese. Os sujeitos, entretanto, em função de suas experiências e vivências, só conseguem divisar partes do quebra-cabeça, alguns com mais peças, outros com menos. Sendo possível incluir um terceiro ponto, o estudo sugere (pelo parágrafo acima e o continuum fluido) que os sujeitos às vezes veem mais peças, às vezes se esquecem de algumas peças, às vezes parecem preferir ficar só com algumas peças e com elas permanecer.

Com relação ao segundo ponto mencionado acima, pela análise dos dados, inferiu-se que as várias concepções acerca da valoração do conhecimento estavam presentes em uma mesma organização ao mesmo tempo, agrupadas pelas diferentes consciências focais dos diversos membros organizacionais; posteriormente confirmado no grupo de foco. Entretanto, é sugerido pelo estudo, que determinadas concepções prevalecem como modo correto de compreender e 
viver naquele ambiente/mundo, ou seja, os indivíduos que possuem sua concepção alinhada com a construção compartilhada do que é conhecimento de valor para aquela organização tenderá a permanecer nela com mais facilidade; aqueles com concepções menos alinhadas tenderão a tentar se adaptar, conflitar ou sair. Esse aspecto também foi confirmado junto aos participantes do grupo de foco. Portanto, é absolutamente relevante manter em mente a construção social da(s) realidade(s) e o mecanismo de identificação com a identidade organizacional, utilizados pelos sujeitos.

Ao fim do presente tópico, são apresentados a Figura 9, ilustrativa do Mapa do Espaço de Resultado para as concepções acerca da valoração do conhecimento no contexto do trabalho, representando a hierarquia lógica de ordenação das categorias, e o Quadro 10, com o espaço de resultado para as cinco concepções acerca da Valoração do Conhecimento (VdC) no contexto do trabalho e dimensões associadas.

\subsubsection{Valoração do Conhecimento é Aplicação no Trabalho}

"[o conhecimento valorado está] exatamente na organização desse processo, ou seja, o meu conhecimento de gestão propiciou que a gente pudesse colocar equipes multidisciplinares, todas elas integradas, ou seja, fazendo planejamento de datas e de matérias e tudo isso alinhado com a estratégia da empresa, com a visão de negócios da empresa, com deadlines estabelecidos para que uma planta... A gente tá falando assim de investimentos de trezentos, quatrocentos milhões de dólares, pudesse acontecer. E isso é que eu acho que efetivamente coloca a gestão de RH efetivamente alinhada com a estratégia da empresa, ou seja, efetivamente o negócio tem o RH como parceiro estratégico para que as coisas possam efetivamente acontecer." (Entrevistado 3)

Essa categoria comporta uma visão do conhecimento na organização que se enquadra na metáfora da máquina (MORGAN, 1986), inserida na perspectiva econômica (GHERARDI, 2000) ou estrutural (PATRIOTTA, 2003a; 2003b), onde o conhecimento de valor é um objeto para auxiliar na eficiência e na eficácia dos processos organizacionais. O conhecimento valorado é expresso pelos entrevistados como algo fundamentalmente individual, técnico e formal, originário da educação formal dos indivíduos e dos treinamentos formais recebidos durante o trabalho nas organizações, muito enfatizados pelos entrevistados. Ele tem a utilidade de ser aplicado e gerar os resultados desejados para a organização. 
Quando perguntados acerca dos exemplos de situações em que tiveram seus conhecimentos mais e menos valorados, os sujeitos narraram ocorrências vividas pela organização relacionadas ao mercado (fusão, aquisição, fechamento de fábricas, abertura de planta) e ao ambiente de negócios (“o setor na época do presidente Fernando Henrique tinha escassez de mão de obra"), mas não se ativeram à vivência deles nessas situações. Foi necessário insistir para os entrevistados mencionarem exemplos concretos relacionados a eles, ou seja, não falam diretamente de si mesmos, mas evocam a organização para falarem de si, o que aponta para forte identificação com a identidade organizacional como mecanismo de base (CORLEY et al., 2006). Nesse caso, a forte identificação com a IO sugere que os indivíduos tendem a valorar os conhecimentos que entendem como sendo importantes da perspectiva da organização, com quem se identificam (CHERMAN e ROCHA-PINTO, 2013; RAVISHANKAR e PAN, 2008).

A valoração do conhecimento apresenta-se como um fenômeno despersonalizado, sem gente (elemento humano), onde quem atribui valor ao conhecimento é: "a cultura", "os valores" e o "planejamento" (Entrevistada 8); "é a cadeia, são as estratégias que dizem o que é importante" e o "planejamento" (Entrevistado 3); "as rotinas da organização" (Entrevistada 22).

$\mathrm{Na}$ visão da sociologia da associação ou ANT (LATOUR, 2012), a organização, a cultura, o departamento de RH, o planejamento e as rotinas organizacionais são alguns dos atores não humanos que mediam ações para os quais os entrevistados respondem com novas ações. Ou seja, essas entidades não são meros intermediários sem vida; elas são atores capazes de transformar, gerar ou desencadear ações nos atores humanos e, portanto, possuem vida própria (LATOUR, 2012). Reagregando o agrupamento social, na perspectiva de Latour (2012), o contexto social seria redefinido para incluir esses atores não humanos mencionados nos parágrafos acima, que demonstram ser mais importantes para os sujeitos inseridos nesta concepção do que os colegas e pares humanos. Os elementos não humanos, tais como organização, departamento, cultura, rotinas, planejamento, a política do Fernando Henrique, ocupam a consciência focal dos sujeitos.

A perspectiva dimensional do fenômeno centra-se na organização. Sugerese que os entrevistados respondem com a voz dela. Pode-se perceber também o quanto a organização é reificada, corporificada. Os entrevistados pouco se 
colocam na ação, preferindo tratar suas ações na $3^{\mathrm{a}}$. pessoa (o RH fez..., a organização entende que..., a cultura valoriza...) ou na $1^{\mathrm{a}}$. pessoa do plural [nós (eu com o departamento, com as áreas, com a organização) fizemos...].

Desse modo, com relação ao contexto social do fenômeno pela concepção da Aplicação no Trabalho, ele é quase inexistente na percepção dos entrevistados. Há pouca relação de conhecimento de valor com equipes ou pares, o conhecimento não é construído com eles ou por meio deles, pois, de acordo com essa concepção, o conhecimento é individual. Nesse ponto, cabe ressalvar que há interação social na construção do trabalho diário (e é necessário que haja!). Entretanto, ou ela não assume importância e valor para os entrevistados ou realmente ela não é objeto da consciência focal (MARTON e BOOTH, 1997) por parte deles.

As pessoas são apenas recursos que contêm conhecimentos técnicos e especializados (repositórios) para aplicar o conhecimento quando necessário a fim de se chegar ao resultado esperado. Nesse caso, o entrevistado é o gestor, o orquestrador responsável para que os conhecimentos técnicos necessários estejam no lugar e no momento certo. O contexto social está centrado no indivíduoresultado para a organização.

"Você tem a sensação de um trabalho de gestão de recursos humanos efetivamente funcionando, ou seja, você vê todo mundo no dia se sentindo não cem por cento seguro, mas efetivamente se sentindo apto para efetivar esse dia um. O conhecimento de segurança, todos eles estão uniformizados... o conhecimento de operação, o conhecimento de manutenção... Ou seja, com o modelo de recursos humanos estabelecido, as pessoas se sentindo engajadas dentro desse contexto todo... eu acho que... do ponto de vista de $\mathrm{RH}$, que é uma vitória muito expressiva, muito expressiva." (Entrevistado 3)

Já o contexto espaço-temporal apresenta-se no planejamento das atividades, detalhadas e alinhadas em sequência, por meio das quais o resultado eficaz é obtido e o conhecimento se torna presente e visível. Ao fim do ciclo das atividades planejadas, estando os recursos (humanos) colocados no seu lugar, o resultado do trabalho acontece. As organizações com estruturas definidas e processos formais instaurados, com cultura organizacional e valores disseminados, parecem favorecer esse tipo de valoração.

Ao mesmo tempo, é como os indivíduos concebem o espaço onde o conhecimento de valor (resultado) ocorre e onde se sentem confortáveis para trabalhar. Como características adicionais, é sugerido que o conhecimento de 
valor opera na certeza, na pouca (ou quase nenhuma) assunção de risco de errar, talvez também inferindo que o especialista, o profissional, não erre.

Quanto às rotinas organizacionais, elas estruturam a tarefa (fator de influência para a valoração do conhecimento) e ordenam a vida organizacional. Para a área de recursos humanos, as rotinas relacionadas estabelecem os padrões de trabalho (Entrevistado 3), dão transparência às regras (Entrevistada 22), criando um senso de justiça e de justificação das demandas e respostas da organização, na percepção dos entrevistados. De um modo amplo, elas possuem um significado ordenatório, delimitador e padronizador, correspondendo, principalmente, à classificação de rotina mais fortemente ostensiva, de Feldman e Pentland (2003).

As rotinas são dadas e encontram-se pré-definidas pela matriz da organização, sendo de natureza de conformidade $^{1}$ (normas regulatórias e procedimentos operacionais padrão, a fim de cumprir com agências reguladoras e certificações do tipo ISO e Boas Práticas) e de certeza (políticas, regras e processos de trabalho). No máximo, as rotinas da certeza podem ser tropicalizadas, ou seja, ajustadas e adequadas a fim de fazer cumprir com demandas e exigências legais, operacionais ou negociais locais.

Dado que o conhecimento valorado é individual, técnico e formal, a incorporação desse conhecimento nas rotinas somente reforça o processo existente ou auxilia na tropicalização das mesmas. Na verdade, nessa categoria, a questão é subvertida, isto é, as rotinas estabelecidas definem o trabalho e, por consequência, estabelecem o conhecimento de valor a ser recrutado, treinado e alinhado em cada parte do processo. De acordo com a visão da sociologia da associação (LATOUR, 2012), a própria rotina desempenha o papel de ator que media como os sujeitos devem desempenhar suas atividades, traduzindo como eles devem se comportar e o que eles devem valorizar.

Pode-se sugerir que a incorporação do conhecimento individual no conhecimento organizacional (nas práticas e rotinas) é muito limitada; é utilitária; com objetivo adaptativo, pouco inovador. Propõe-se ainda que os indivíduos

\footnotetext{
1 A classificação mencionada, a saber: rotina da conformidade, rotina da certeza, rotina tropicalizada e rotina da inovação (que será citada em outra categoria); foi criada pela pesquisadora a partir da leitura dos dados, com base nas expressões e descrições feitas pelos entrevistados em suas narrativas.
} 
reproduzem continuamente a organização, de forma mimética, sem grandes questionamentos ou riscos (pessoais/profissionais). Friels e Larty (2013) chamam a atenção para a dominação política que a rotina pode desempenhar, impedindo desvios, replicando e disseminando os valores e crenças dos grupos dominantes.

Ao recontextualizar os indivíduos pertencentes a essa categoria (cargo, tempo de trabalho, tipo de empresa), encontrou-se sujeitos com muitos anos de trabalho na mesma empresa $(9,14,15$ anos), todas multinacionais de setores diferentes, com gestão centralizada na matriz, com cultura, práticas e processos muito estruturados e fortemente disseminados. Dois deles ocupam cargos na alta gestão (um homem e uma mulher) e um na média gerência (uma mulher), fruto dos anos de trajetória de carreira na organização.

\title{
6.1.2.Valoração do Conhecimento é Consideração (Reconhecimento) do Trabalho-Indivíduo
}

\begin{abstract}
"Essa trajetória, essa minha formação em graduação, pós-graduação e mestrado me deu toda a base para eu ser hoje um profissional muito mais completo da [nome da empresa] e hoje eu consigo perceber o quanto as pessoas valoram esse profissional... o quanto é importante ter um profissional mais completo, mais robusto. [...] Eu percebo o seguinte: toda vez que tem um projeto novo, pensam no meu nome... isso é interessante: "Poxa, vamos botar a [entrevistada 4] porque ela tá fazendo sistema de qualidade, ela tem muito conhecimento em qualidade, em clientes, atendimento a clientes, em conceitos de CRM... vamos colocar a [entrevistada 4] porque ela tem já essa bagagem"." (Entrevistada 4)
\end{abstract}

Nessa categoria, a concepção do conhecimento valorado é principalmente individual, fortemente baseada em conhecimento formal, técnico e em experiência prática, com o principal objetivo de ser aplicado e gerar resultado no trabalho. O que difere essa concepção da categoria anterior, da Aplicação no Trabalho, é a necessidade dos entrevistados em receber reconhecimento por parte dos demais membros organizacionais. A consideração/reconhecimento retorna em forma de recompensa, podendo assumir diversas configurações, tais como: desde a menção do nome do indivíduo relacionado à atividade bem-sucedida ou indicação/lembrança do sujeito para participar ou conduzir algum trabalho até promoção salarial ou promoção de cargo.

Desse modo, o conhecimento de valor ocorre na medida em que os indivíduos são reconhecidos pelo líder da organização, liderança, pares e equipe, ou seja: o conhecimento valorado é significado como consideração do indivíduo 
e/ou de seu trabalho e/ou de seu conhecimento, elementos quase indissociáveis. Parece ocorrer uma ação circular: o indivíduo precisa ser considerado pelos membros organizacionais, ter seu trabalho-conhecimento reconhecido, para poder valorar a si mesmo, e reflexivamente age para ter/ser o conhecimento que a organização valora. Nessa reflexividade, à medida que a organização reconhece os conhecimentos do indivíduo aplicados ao trabalho, eles são entendidos como aqueles que são os de valor para a empresa.

Enquanto na categoria da Aplicação no Trabalho o indivíduo é a organização, narra com a fala dela, demonstrando total identificação com a identidade organizacional, na presente categoria o sujeito precisa de aprovação para sentir pertencimento à organização, realizando um trabalho de construção de identidade. Analisada sob esse prisma, a construção de identidade é um processo elaborado pelo indivíduo de modo predominantemente inconsciente, a partir da interpretação, entendimento e racionalização do que é valorizado naquele ambiente/contexto, na percepção dele, passando a ser reproduzido e aplicado pelo próprio sujeito (ASHFORTH et al, 2008; CORLEY et al., 2006). Há um esforço de encaixe na identidade organizacional, intrínseco ao processo.

Quando perguntados acerca dos exemplos de situações em que tiveram seus conhecimentos mais valorados, os sujeitos narraram os eventos nos quais desenvolveram processos, políticas, práticas, projetos para a organização, obtendo endosso de tais trabalhos pelo líder ou alta gestão e passando a ser guardiões daquela atividade. Nas narrativas há uma transparente conotação de prestígio, status e respeito adquiridos, que, de algum modo, geram uma ascensão 'social' no espaço organizacional e certo poder relativo àquela área de atividade. Sugere-se que a ameaça à identidade organizacional seria uma ameaça ao indivíduo, uma vez que ele se construiu em torno dela: conhecimentos de valor, status e prestígio, posição segura no espaço organizacional, tendendo a preservá-la ou superestimála (NAG et al., 2007; RAVISHANKAR e PAN, 2008). Os entrevistados dão uma relevância excessiva a processos relativamente simples ou básicos, desenvolvidos e implantados por eles, uma vez que, no contexto onde trabalham, esses foram os conhecimentos valorados.

"Essa questão mesmo do DHO de trazer implementação de avaliação de desempenho, implementação de cargos de salários, é... checar essa questão até do coaching, apesar de eu não ter formação de coaching - eu fiz algumas formações, mas não tenho uma formação completa de coaching - é estar fazendo coaching 
com os gestores o tempo todo, [...] criar alguns processos que não existiam antes... Até mesmo quando você fala em recrutamento e seleção, normalmente, as pessoas acham que isso é menos, né... E existe uma ideia de mercado de que "Ah, isso aí é menos...". Não é menos, é muito importante... Se você seleciona errado, se você recruta e seleciona errado, se você coloca alguém em um lugar errado, você tem grandes problemas... O MBA veio trazer, não só com a formação tradicional, mas especificamente mais essa troca que o MBA traz... eu acho que isso é muito importante." (Entrevistada 17)

Quanto à perspectiva dimensional do fenômeno, ela se inicia em torno da organização, por meio do líder ou da alta gestão, de quem os indivíduos buscam consideração e reconhecimento inicial. Pode-se sugerir que quem estabelece qual é o conhecimento de valor é a liderança da organização. Porém, os indivíduos, nessa concepção, necessitam de aprovação constante, que é reforçada pelos demais grupos, tais como pares, equipe, demais funcionários e áreas. Desse modo, o contexto social do fenômeno é fundamental, já que é por meio da equipe que os resultados são obtidos, concorrendo para a consideração da competência do sujeito pelos demais grupos.

"[quem influencia na valoração do conhecimento é a] Diretoria, né... o meu gerente direto [...] e a própria equipe... Eu tenho aqui um feedback que eu recebi ontem da equipe. A gente tá em momento de avaliação de desempenho e que é bacana... que você consegue resultado através das pessoas, né...Como fazer isso que é o mais difícil. [...] Isso me dá bastante indicadores dizendo 'bacana, eu tô numa linha certa e acho que a gente consegue resultado por aí.' Então assim... a diretoria percebe e a minha gestão imediata percebe, porque eu consigo ver ela me olhando mais, com maior senioridade e valorando o meu salário... Acho que isso também te da aí um indicador interessante para dizer 'caramba, né...eu tenho valor nessa organização... o meu conhecimento, a minha bagagem tem valor nessa organização'." (Entrevistada 4)

O contexto social é tão relevante nessa concepção, que a liderança e a confiança (trust) no líder ou gestor também emergem como os fatores organizacionais de influência na valoração do conhecimento, mencionados por alguns entrevistados. Conforme Renzl (2008) aborda, há uma relação estreita entre a confiança na gestão e a propensão dos sujeitos em compartilhar seus conhecimentos únicos e exclusivos, considerados de maior relevância.

Os sujeitos apontaram como barreira ao conhecimento valorado justamente a autonomia de trabalho dos demais grupos ou membros da organização, considerando que a autonomia poderia significar descumprimento das práticas e processos instaurados por eles e endossados pela liderança. Pode-se inferir que essa situação representaria perda de status, respeito, posição social, certo poder 
inerente à atividade, e consequente perda de consideração, reconhecimento e valor.

Já o contexto espacial apresenta-se na relação da estrutura organizacional centralizada e tradicional com a estruturação das atividades e processos, dado o baixo grau de formalização existente. Os processos e práticas em estruturação por meio das rotinas organizacionais (endossadas pelo líder) objetivam medir e controlar as tarefas, as pessoas e o desempenho, a fim de reproduzir o sistema de reconhecimento; e não tanto gerar resultado em termos de qualidade do produto final da atividade. As organizações de estrutura tradicional (hierárquica, rígida) e/ou familiar, com alto grau de centralização das decisões e do poder, com poucos processos formais instaurados parecem favorecer a esse tipo de concepção.

O contexto temporal encontra-se fora da consciência focal (MARTON e BOOTH, 1997) dos sujeitos. Sugere-se que o tempo é dado pela liderança ou alta gestão em sua demanda pelas atividades e tarefas, e não pelo ciclo das atividades (que são pouco estruturadas) ou do ambiente de negócios.

As rotinas organizacionais, portanto, são de caráter de estruturação e formalização do trabalho, para controle das tarefas, pessoas e desempenho. Configuram-se em rotina da certeza, de natureza mais fortemente ostensiva (PENTLAND e FELDMAN, 2003). Dado o alinhamento, o ato reflexivo, entre sujeito e organização, o conhecimento do indivíduo está a serviço da criação das rotinas organizacionais (ressalva-se, aprovadas pelo líder ou alta gestão), que geram controles para avaliar o desempenho e recompensar os demais funcionários, ou seja, um novo ciclo/círculo reflexivo, no qual o sujeito usa da sua concepção para aplicar nos demais funcionários.

Ao mesmo tempo, a rotina organizacional cria/assegura a posição (social, de status) e o reconhecimento do sujeito. Pode-se sugerir que a incorporação do conhecimento individual no conhecimento organizacional (nas práticas e rotinas) é mediada pela liderança ou alta gestão.

Recontextualizando os indivíduos pertencentes a essa categoria, foram encontrados sujeitos com tempo variado de trabalho na empresa mencionada $(3,5$, 20 anos) todas de setores diferentes. Duas organizações são nacionais familiares. A terceira foi adquirida, há cerca de um ano, por um grupo multinacional e passava por uma nova aquisição na época da entrevista, mas ainda possuía fortes traços estruturais de empresa nacional. Duas entrevistadas ocupam cargos de 
analista/coordenação, enquanto a entrevistada com 20 anos de empresa ocupa cargo de gerência, tendo feito quase toda sua trajetória de carreira na organização. As empresas encontradas nessa categoria são de médio porte, com estruturas tradicionais hierarquizadas, com centralização das decisões e baixo grau de estruturação e formalização das atividades.

\subsubsection{Valoração do Conhecimento é Realização do Indivíduo no Trabalho}

"Toda vez que eu tive oportunidade de me sentar com uma área, ouvir aquela área, entender qual era a demanda daquela área, de desenvolvimento, entender a dor, as fragilidades..., mas assim... onde o bicho tava pegando... onde eles não tinham conhecimento e eu podia, de alguma forma, com a minha experiência e com o meu conhecimento com eles, criar alguma coisa que fosse ajudá-los a alavancar aquilo que nos entendemos que estava faltando, eu vi o conhecimento ser valorizado." (Entrevistada 10)

Essa categoria é suportada pela visão de que o conhecimento emerge das práticas sociais no contexto do trabalho, isto é, a perspectiva do conhecer na prática ou practice-based (GHERARDI, 2000; 2006) e conhecer na ação (ORLIKOWSKI, 2002), posicionando-se no domínio da cognição situada (PATRIOTTA, 2003a; 2003b). O conhecimento valorado é fruto do compartilhamento, da construção na ação de trabalhar coletivamente, e emergente da situação onde se faz necessário. Ele é uma reunião de conhecimentos individuais, de diversas ordens e naturezas, todos considerados igualmente importantes, a saber: técnico de diversas áreas, operacional e gerencial, experiência prática, vivência, relacional.

A troca social permite a síntese dos conhecimentos individuais em uma solução maior que as propostas iniciais individuais, portanto, de maior valor. $\mathrm{O}$ conhecimento só tem sentido, só ganha significado para o indivíduo quando é compartilhado: "não faz o menor sentido eu conhecer para mim mesma. (Entrevistada 10)". Nesse momento do compartilhamento o conhecimento ganha sentido e torna-se valorado (SWART, 2011). A concepção de valor nessa categoria parece explicitar a definição exposta por Graeber (2001), na qual o valor emerge da ação e encontra respaldo e significado coletivo comum naquele grupo (embora o significado comum advindo da ação ocorra em todas as categorias).

Quando perguntados acerca dos exemplos de situações onde tiveram seus conhecimentos mais e menos valorados no contexto do trabalho, os sujeitos 
narraram eventos onde a atividade, tarefa ou trabalho permitia estruturação, criação e soluções emergentes a partir da participação dos envolvidos. Não raro, o trabalho é estruturar a atividade, ou seja, não existiam processos formais estabelecidos. Os entrevistados se sentem participando da construção da organização, onde, portanto, há uma percepção de alinhamento dos conhecimentos individuais e o conhecimento organizacional.

"Valorizado, eu acredito, pelo fato da gente estar trocando... pelo fato de estar ouvindo o outro... eu acho que isso, o ouvir o outro já é uma forma de valorizar o conhecimento do outro, na minha visão. E ter uma entrega que é conjunta, assim... não, não foi o RH que fez, é uma entrega da área... é uma entrega da [nome da empresa]... não é uma entrega de alguém...é uma entrega da organização, é conhecimento que fica para a organização." (Entrevistada 10)

Ao mesmo tempo em que o conhecimento de valor emergente da construção compartilhada deve trazer resultados para o trabalho, soma-se o trabalho coletivo, participativo e com autonomia, que geram realização pessoal do indivíduo no contexto do trabalho. Os sujeitos dão grande importância a realizar projetos e se realizar no trabalho: "Eu fui muito feliz, fui muito feliz na [nome da empresa]. Eu brilho quando eu falo assim... eu sinto assim..." (Entrevistada 10).

"Eu lembro perfeitamente de quando a gente fechou o programa de excelência... que com certeza foi o que fez meu bônus ter sido muito bom naquele ano mas...é muito mais um senso de realização do que qualquer coisa. Eu acho que as pessoas que tem isso vão realizar cada vez melhores as coisas, sabe...se você faz pelos outros...[...] se você faz as coisas com esse senso de realização pessoal e vendo como um crescimento, eu acho que naturalmente as outras coisas são consequência." (Entrevistada 05)

Deste modo, a perspectiva dimensional do fenômeno encontra-se no indivíduo: é ele quem valora o conhecimento. Mas, para isso, ele precisa relacionar-se com o grupo com o qual interage, cujo ato de trabalhar e conhecer reflete a organização, ou seja, o modo como o conhecimento de valor é estabelecido. Há identificação com a identidade organizacional, entretanto, diferentemente da concepção da Aplicação no Trabalho onde o indivíduo é a organização e se expressa pela fala dela, na presente categoria, o indivíduo apresenta-se como sendo um com a organização, ele é parte constitutiva dela, interage nela, está engajado nela. O indivíduo se vê autônomo e independente da organização, com ideias e capacidade de julgamento de valor próprias, mas integrante partícipe dela. Pode-se sugerir que as ideias de aprendizagem situada de Brown e Duguid (1991) e de Lave e Wenger (1991), onde a organização é uma comunidade que se reúne para praticar o trabalho e aprender a partir do 
engajamento na atividade e na sua realização conjunta, encontram 'realidade' nessa categoria.

O contexto social da valoração do conhecimento pela concepção da Realização do Indivíduo no Trabalho é, portanto, o pressuposto para o conhecimento de valor acontecer, na percepção dos entrevistados. Conforme já mencionado, é por meio dele que o trabalho é praticado, desempenhado, e o conhecimento de valor emerge.

Quanto ao contexto espaço-temporal, ele apresenta-se fluido e flexível, uma vez que as estruturas organizacionais são descentralizadas, com alto grau de autonomia, gestão participativa e grande possibilidade de intervenção nas tarefas e processos (ou mesmo criação destes). Desse modo, os sujeitos não estão confinados em estruturas hierárquicas ou processos rígidos, que são aspectos apontados como barreiras ao conhecimento de valor. $\mathrm{O}$ aspecto temporal parece ser inerente ao trabalho, já que a necessidade de solução para um problema ou desenvolvimento de uma atividade surge na sua realização.

Os fatores relevantes relacionados à valoração do conhecimento, apontados pelos entrevistados, foram a autonomia no trabalho e a cultura organizacional, que suporta o ambiente propício à construção coletiva. A liderança exerce um papel fundamental, não no sentido de reforçar o indivíduo (como na concepção anterior, da Consideração do Trabalho-Indivíduo), mas para assegurar a cultura e manter o suporte ao ambiente de autonomia e participação.

Quanto às rotinas organizacionais, são a consequência, o produto do trabalho. São constituídas a partir da prática, sendo depois formalizadas e institucionalizadas na organização e sofrem alterações a partir de nova necessidade identificada no desempenhar da atividade. Desse modo, as rotinas são criadas do modo como as coisas são feitas, considerando as regras implícitas da cultura. Encaixam-se nas concepções da rotina da inovação, uma vez que são flexíveis e situacionalmente adaptadas, ou seja, classificam-se na natureza mais fortemente performativa (FELDMAN e PENTLAND, 2003).

"Rotinas [eram] criadas quando havia mudanças... [...] então eu atuava de uma forma e tinha um conhecimento associado àquela atuação, que agora eu vou mudar. Agora eu vou fazer diferente, eu tenho que mudar a minha forma de fazer conhecer... Eu documento aquilo, mas também, ao mesmo tempo em que estou documentando para que aquilo fique registrado em algum lugar, as pessoas já estão praticando daquela forma diferente.” (Entrevistada 10) 
As rotinas objetivam mais o registro para conservação e disseminação de uma prática já comprovada, resultado de algo conhecido e valorado pelos indivíduos coletivamente, do que o mero ordenamento do trabalho. Entretanto, cabe ressalvar que alguns processos assim estabelecidos também servem para avaliação do desempenho individual, constituem-se em metas. Sugere-se que a incorporação do conhecimento individual no conhecimento organizacional por meio das práticas e rotinas é um processo fluido e retroalimentado.

Ao recontextualizar os sujeitos pertencentes a essa categoria, foram encontrados profissionais de nível de coordenação, atuantes em organizações nacionais de médio à grande porte, com gestão profissional, com alto grau de descentralização das decisões e autonomia $O$ tempo de permanência na organização foi muito variável, de 3 a 14 anos na mesma empresa. As organizações possuíam médio grau de estruturação/formalização das tarefas e processos.

\subsubsection{Valoração do Conhecimento é Transformação do Trabalho e do Indivíduo}

"O [nome da empresa] é uma empresa muito hierarquizada...muito hierarquizada...se você não é gerente, se você não é gerente executivo, você não ganha o respeito por esse seu conhecimento, a não ser que você venha do mercado por causa do conhecimento, que são os grandes especialistas. Houve, na implementação do projeto de planos de cargos e remuneração, o famoso PGCR que todo mundo fala na empresa, a empresa definiu que haveriam visitas a cada localidade para explicar o impacto e eu apoiei muito, na área, o desenho do PGCR, de fazer cargos por contas e tudo mais... e nunca que um analista seria convidado para viajar nas áreas para fazer essa exposição... e eu fui convidada, não pela minha gerente, mas pelo gerente executivo. [...]. Ficou até uma situação meio assim complicada por causa da cultura da empresa, [...] porque a empresa privilegia o gerente porque ele tem o conhecimento que o cargo diz que ele tem... E eu fui. E eu me senti muito valorizada nesse sentido porque eu tava ali...apesar de ser analista sênior, apesar da hierarquia, eu tava ali representando conhecimento naquele assunto". (Entrevistada 6).

Essa categoria aborda o desafio e o antagonismo entre o conhecimento valorado, estabelecido pelo indivíduo - que possibilita a transformação da organização, mas que questiona o status quo - e o exercício de controle, baseado no poder e/ou hierarquia organizacional formal, estrutural, geralmente realizado pelo líder, gestor ou "caixa hierárquica" que comporta tal poder. 
A natureza do conhecimento valorado é uma construção coletiva, compartilhada entre membros e equipes na ação de trabalhar, mas trata-se de algo que não se processava desta forma (coletiva, compartilhada) na organização. Portanto, o modo de fazer emergir o conhecimento é disputado e conflituoso entre grupos ou membros, é questionador das regras, políticas, normas e cultura da organização, e tem estreita relação com poder e política. O conhecimento valorado precisa da transformação das estruturas organizacionais para se estabelecer.

Do mesmo modo que na categoria anterior (sua coirmã), da Realização do Indivíduo no Trabalho, o sujeito é autônomo e independente na sua forma de julgar e valorar o conhecimento relevante, e busca a realização pessoal através da construção de trabalhos compartilhados com os demais membros. Porém, a diferença encontra-se nas estruturas de poder e hierarquia, com suporte da cultura organizacional, apresentarem barreiras aos indivíduos, que passam a questionar a organização em si: a gestão e liderança, os mecanismos de poder, a estrutura hierárquica, a cultura organizacional. Sugere-se que os indivíduos buscam a transformação da organização, derrubar o status quo e as estruturas que os impedem de colocar seu conhecimento (do seu modo de ver) em prática. Como Heizmann (2011) apresenta, há contestação dos conhecimentos estabelecidos, que encontra resposta em uma dinâmica de reforço das relações de poder.

Quando perguntados acerca dos exemplos de situações em que tiveram seus conhecimentos mais e menos valorados no contexto do trabalho, os sujeitos expuseram situações em que, para realizar projetos e atividades construídas com participação de equipes, pares, grupos da organização, tiveram de enfrentar conflitos e contestação advindos das estruturas hierárquicas formais ou das relações de poder instituídas no líder, alta gestão, gestores e/ou pares. Estes aspectos aparecem: no questionamento do conhecimento técnico presente na entrevistada 6 versus o conhecimento dado pelo cargo da caixa hierárquica; nos jogos de poder vivenciados pelo entrevistado 14 , onde conhecimento deve-não-deve ser participativo ("só que os donos, eles brincam com essa história de poder... eles me dão poder e me tiram poder"); e nas disputas pelo controle do conhecimento:

"Eu estou vivendo isso... é uma área de produção de conteúdo. Ela não deixa a gente mandar o material de treinamento, por exemplo, para a área cliente. Então a força de vendas vai ser treinada e antes de entrar em sala de aula, eu gosto de ir no meu cliente interno, na minha força de vendas, ir lá no meu diretor e mostrar... 
porque aí eles vão dizer se isso tem a ver com a realidade das pessoas... Então, a área que é a produtora de conteúdo não quer enviar, porque não quer que eles deem palpite. Tipo assim: "Isso é o que eu tenho para passar, então vamos entrar em sala de aula com isso e acabou. Eles não têm nada que dar palpite, não tem nada que avaliar o meu trabalho." Isso, hoje na [nome da empresa] é muito controlado, é um poder... isso é uma situação que eu acho que eu nunca vivi, do cara querer segurar a sua caneta porque não quer que o outro dê palpite. [...] Então tem uma coisa de feio... porque eu acho que a gente tem uma coisa que é até da presidência que.. de uma certa maneira incentiva isso... de cada um cuidar do seu quadrado." (Entrevistada 21)

"Era uma transformação da cultura da organização. [...] Eu tinha muita dificuldade que ela mudasse aqui no topo, eu tentei que ela viesse da base para cima... É um equívoco... A empresa foi mudando, o cliente passou a ser uma peça importante, os funcionários começaram a perceber que o resultado... ele é decorrente do cliente. O cliente que gera resultado, clientes satisfeitos, acionistas satisfeitos... e... só que em determinado momento eu vi que começou a ficar claro, assim, que existia uma disputa de poder. Eu tava disputando poder. Só que os donos, eles brincam com essa história de poder... eles me dão poder e me tiram poder... [...] E os funcionários, por mais que eles admirassem tudo que eu falasse, concordassem em tudo, eles olhavam para os pés dos donos da empresa... para aonde eles caminham... Os donos da empresa, eles concordavam que os valores da organização, identidade da organização era a XPTO, mas a prática era diferente... onde na verdade isso foi construído muito mais dentro dos valores, na missão, na visão e dos valores do [entrevistado 14] do que da organização... não eram deles..." (Entrevistado 14)

"Eu percebi que toda a minha capacidade de influência, que eu acho que tenho, toda minha capacidade de inovação, a minha capacidade relacionamento, de propor coisas novas era literalmente vetada. No nível assim: "cala a boca". Um dia [o gestor] me mandou calar a boca... numa reunião de diretoria ele pisou no meu pé e falou "cala a boca". [...] Ligar e falar: "Quando foi isso? Você já fez aquilo?" Eu falei "gente, eu não suporto esse controle... eu sou uma pessoa que gosta de autonomia para fazer as coisas, eu gosto de liberdade em todos os relacionamentos da minha vida." Então... eu acho que não foi aproveitada efetivamente a minha capacidade de... de... transformar, de propor coisas... eu até implantei projetos e fizemos coisas, mas não foi valorizado...não era valorizado.[...] Isso foi na [nome da empresa] e as coisas não eram valorizadas... Era, é uma empresa evidentemente masculina... uma empresa de engenheiros, setenta por cento de homens num nível médio... técnicos e engenheiros... uma coisa extremamente masculina e extremamente pesada do ponto de vista de clima, um clima horroroso." (Entrevistada 7)

A perspectiva dimensional do fenômeno é iniciada no indivíduo, pois é ele quem valora o conhecimento, que, porém, esbarra na própria organização (por meio do líder, da alta gestão e/ou da cultura), onde sofre confrontação. Dados os fatores estruturais da organização, centralizada, hierarquizada e com relações de poder instaladas, o conhecimento de valor mistura-se à transformação da própria organização, do ponto de vista dos entrevistados (para modelos participativos, descentralizados, delegados com autonomia). Eles parecem trabalhar em uma 
organização que eles projetam como gostariam que ela fosse. Trata-se da primeira categoria de onde emerge alteridade organizacional, na qual os sujeitos não se veem como a organização é, e não possuem identificação com a identidade organizacional (ASHFORTH et al., 2008), não aderindo a ela, mas desejando transformá-la (CHERMAN e ROCHA-PINTO, 2013; NAG et al., 2007).

Deste modo, o contexto social do fenômeno é por onde a transformação ocorreria - do controle e poder em direção à participação - ou não, por intermédio da rede de relacionamento (político) que facilita ou impede as ações. Assim, podem ser também organizações bastante personalistas, onde quem o indivíduo é ou quem ele conhece influencia na aplicação do seu conhecimento.

Intimamente relacionado e intrincado ao aspecto social, apresenta-se o contexto espaço-temporal, pressuposto para o conhecimento que transforma ou não a organização e o indivíduo. A posição ocupada e a hierarquia estabelecida, ou seja, a caixa hierárquica no organograma define/contém as competências que autorizam os sujeitos; o poder de reter/requerer/tomar conhecimento e informação; e o tempo de execução de determinado evento - características do modelo burocrático. Há centralização das decisões, baixíssimo grau de autonomia dos indivíduos e de possibilidade de intervenção nas atividades da empresa fora do escopo do cargo/função/caixa hierárquica destinado a eles.

Para trabalhar nesse contexto conflituoso, os indivíduos expressam as estratégias políticas articuladas para realizar as atividades e/ou fazer seu conhecimento ser escutado, isto é, estratégias de sobrevivência. São mencionadas: fingir que não é conhecedor do tema em discussão e se passar por aprendiz (Entrevistada 6), criar amizade e relacionamento com pessoas de outras áreas (Entrevistada 21), articular com a gestão imediata a condução e o discurso acerca de uma atividade (Entrevistada 21), ocupar um espaço no ouvido do líder que detém o poder (Entrevistado 14), entre outras. Em decorrência da elaboração dessas estratégias, criação de personagens e atuação de papéis, que os entrevistados julgam necessárias para se fazer presentes no ambiente, eles também se transformam.

"Você vai criando estratégias, né... [...] como o ambiente não te dá esse carimbo de perita no assunto, muito bem... eu tenho que me fazer passar por aprendiz pra eles, pra ser ouvida, porque ai eu entro num personagem que faz sentido ali naquele ambiente. Aí eu começo a fazer perguntas: "Mas vocês acham que se colocar eles juntos, eles vão entender que o papel deles é diferente?" Eles respondem "é...é...pode ser que não." Quem está perguntando é a aprendiz. Mas isso são as 
sacadas que você vai aprendendo ao longo tempo, sabendo fazer a análise do ambiente. Mas eles só vão ouvir se eu entrar no papel de aprendiz, de querer saber "me responde se isso faz sentido?" Ai eles refletem naturalmente, e vão perceber que não." (Entrevistada 6)

"E outra coisa: é uma empresa muito de relacionamento. Então a gente tem, no final, uma estratégia de se tornar amigo das pessoas para que elas tenham mais boa vontade de resolver um negócio para a gente...” (Entrevistada 21)

"Eu acho mesmo que não adianta só você falar, mostrar o seu saber... tem toda uma estratégia para provar o negócio que você quer. Você tem que fazer uma estratégia lenta... combinar com o chefe... tem que pedir para o chefe falar de um jeito... primeiro tem coisas que eu não falo em reunião, que eu falo individualmente, até chegar na reunião para falar... Aí e-mail... como é que você estrutura um e-mail: "não, então vamos fazer isso e depois vamos fazer isso..." Mas é um suor para fazer as coisas acontecerem, né? E muitas vezes o que eu acho que é o momento que é menos valorado é quando [o trabalho] só sai se a chefe pedir... E aí assim... às vezes eu tenho que escrever um e-mail, mandar para ela e pedir para ela mandar como se ela que tivesse escrito, porque senão não sai, e ela sabe disso. [...] Aí a [nome da empresa] tem isso, tem uma coisa meio "Só se o chefe falar" entendeu? [...] Mas é uma coisa da cultura mexicana mesmo. Você chega e o presidente é assim... Aí a estratégia: tudo é ele que aprova, tudo ele tem que ver... Então assim: é só se ele mandar. Isso as pessoas tem aqui: "Eu só faço se o meu chefe mandar." (Entrevistada 21)

Dentre os fatores que propiciam a valoração do conhecimento (e a possível transformação da organização), são apresentadas a autonomia no trabalho e a cultura organizacional transformada. As barreiras ao fenômeno estão presentes no desalinhamento entre discurso e prática, e nas relações de poder e hierarquia, geralmente relacionados.

Com relação às rotinas organizacionais, elas são fortemente estruturadas, pela formalização dos processos ou pela internalização das práticas na cultura organizacional. De um ou de outro modo, a forma de trabalhar já existe, já é dada. São rotinas da certeza. A flexibilidade nas práticas e rotinas só ocorre por determinação de quem possui poder ou pela posição avalizada pelo cargo (estrutura organizacional), não necessariamente para alterar a rotina, mas sim para atender a alguma necessidade específica de alguém ou porque o líder "disse para fazer".

A contribuição do conhecimento individual ao conhecimento organizacional por meio das práticas e rotinas é muito baixa, a menos que seja requisito da função/cargo ou advenha de uma demanda do líder, o que gera muita frustração e questionamento por parte dos sujeitos. Projetos inovadores não são valorizados e 
novas formas de fazer algo que já existe não são bem-vindas, muito menos incorporadas nas práticas ou rotinas de trabalho.

Ao recontextualizar os indivíduos pertencentes a essa categoria (cargo, tempo de trabalho, tipo de empresa), encontramos sujeitos com muitos anos de experiência de trabalho $(13,25,32$ e 20 anos), mas não necessariamente nas empresas mencionadas, fato que os empurrava a querer provar seus conhecimentos e competências. As organizações mencionadas caracterizam-se por serem empresas privatizadas do setor público (em dois casos), ou formada em decorrência da reestruturação do setor público (um caso) e em empresas nacionais familiares de médio porte com a presença do dono (várias menções de exemplos vivenciados pelos entrevistados).

Pôde-se perceber que os sujeitos repetiam, ao longo do tempo, seus embates com as empresas, frequentemente com características similares. Três entrevistados já haviam transitado pela concepção da Realização do Indivíduo no Trabalho na sua trajetória de carreira, e pareciam tentar reproduzir aquela organização no contexto da presente concepção, como se seu conhecimento de vivência daquela experiência possibilitasse essa transformação.

\title{
6.1.5.Valoração do Conhecimento é Criação Emergente para a Vida
}

\begin{abstract}
"Então... [a valoração do conhecimento no trabalho] é o intangível do tangível porque assim eu vejo valorização no trabalho dos resultados, das suas entregas, mas não necessariamente do conhecimento nas organizações. Eu vejo que as companhias valorizam o resultado que você traz... não necessariamente o conhecimento que está por trás disso ou o conhecimento que você tem... Então isso te formata, assim, num quadrado. Você começa a enxergar que fazer daquele jeito dá resultado e o resultado é valorizado... então você perde muito a questão do questionar, do fazer diferente, do entender o novo, do trazer o novo... porque infelizmente o valor não está nisso... O valor está no resultado... e o resultado esperado é muito concreto, ele é uma meta." (Entrevistada 9)
\end{abstract}

Esta categoria apresenta a desvinculação entre o conhecimento valorado e o conhecimento que a organização valora: são esferas separadas e, de certo modo, independentes. O conhecimento valorado, na concepção dos entrevistados, é aquele que questiona o modo como as coisas são feitas, indaga o trabalho em si e os objetivos, desconstrói a ordem e traz inovação, sendo uma construção de longo prazo, enquanto o conhecimento valorado pelo líder, chefia ou alta gestão, é 
aquele que traz resultado de curto prazo no cumprimento da meta organizacional e reproduz a organização.

Nessa concepção, o conhecimento também emerge da prática e da ação, na perspectiva practice-based (GHERARDI, 2000; 2006; ORLIKOWSKI, 2002), sendo generativo, compartilhado e coletivo na ação de trabalhar. Está localizado nas pessoas, nas pequenas às grandes atividades do dia a dia no trabalho. Entretanto, ele questiona a organização. Os indivíduos parecem perceber que há novas formas e diferentes modelos para fazer o convencional. Contudo, para desenvolvê-los, precisam quebrar paradigmas e empenhar um risco pessoal na ação, sendo também independentes nessa decisão (de se expor ao risco ou não).

O que difere esta categoria das concepções anteriores, especialmente das concepções da Transformação do Indivíduo e do Trabalho e da Realização do Indivíduo no Trabalho, é o fato dos sujeitos conceberem a si mesmos como diferentes da organização, com alteridade organizacional, mas sem embates. Eles questionam a organização, mas não almejam transformar a organização nem a si mesmos, pois são muito cônscios de ambos. A realização no trabalho é apenas parte da vida, não é a vida. O conhecimento valorado é algo que o sujeito carrega na/para a vida; é maior que o conhecimento utilizado na organização. Todos esses aspectos estão presentes na consciência focal dos indivíduos (MARTON e BOOTH, 1997), tratando-se, portanto, da mais ampla concepção do fenômeno encontrada na pesquisa empírica.

Quando perguntados acerca dos exemplos de situações em que tiveram seus conhecimentos mais e menos valorados, os sujeitos narraram eventos marcantes para eles e para a organização, "que viraram lenda" (Entrevistada 2), "caso único" (Entrevistada 19), ou seja, são projetos ou situações ad hoc, com baixíssima ou nenhuma estruturação prévia, nunca ocorridos antes na organização ou na vida profissional, onde os sujeitos precisaram utilizar muito mais de suas capacidades (criatividade, inovação), habilidades e valores pessoais do que de conhecimentos técnicos, experiências prévias ou vivências profissionais. Para seu desenvolvimento e execução, os sujeitos tiveram autonomia, tempo (como um recurso) e nenhuma cobrança de resultados com base em metas pré-definidas, até porque as situações eram novas, decorrentes do ambiente dinâmico. Foram quase experimentos, de onde se tinha expectativa de que a organização tirasse 
aprendizagens, fato que não ocorreu em nenhum dos casos mencionados. Por isso, "ficaram para a história".

"Era um grupo de trinta pessoas e a partir do momento que eles foram comunicados que eles seriam demitidos ou que não haveria mais o emprego que eles estavam fazendo, eles também foram apresentados a mim e disseram: "Essa é a [entrevistada 2], a sua representante do $\mathrm{RH}$ e ela vai cuidar de vocês até que vocês não existam mais nessa capacidade em que vocês estão." E eu construí todo um plano para tentar minimizar o impacto que isso ia ter na vida das pessoas de duas maneiras: ou ajudando-as a achar outra posição dentro da empresa, uma vez a comunidade era muito pequena, então não tinham muitas oportunidades fora [da empresa]... ou ajudando-as a reconhecer que aquilo ali era uma oportunidade que elas podiam ter para mudar de vida completamente. Tinha gente que já podia se aposentar ou que podia ser criativa a partir do momento em que elas pensassem diferente do modo como elas estavam levando a vida... E é interessante porque nem eu sabia que eu tinha esse conhecimento, ou esse poder, ou essa capacidade de ajudá-los a pensar nisso.” (Entrevistada 2)

"Eu aprendi muitas coisas e várias delas de nível pessoal... Acho que uma delas foi ser humilde... no sentido de que eu poderia ser qualquer uma daquelas pessoas e poderia estar naquela situação em qualquer momento. Elas tinham um cargo muito menor do que o meu, trabalharam vinte anos atendendo telefone e respondendo perguntas, então, a priori, acho que eu cheguei dizendo "Ah... esse pessoalzinho, vai ser fichinha trabalhar com eles, porque é um pessoal de nível mais baixo". E como eu aprendi que isso não significa nada [...] Esse foi um grande aprendizado. $\mathrm{O}$ segundo foi de buscar alternativas pra ajudar as pessoas a procurar uma ocupação diferente. [...] Alguns colegas disseram: "Nossa, mas isso vai ser impossível! Você não vai conseguir nunca porque esse pessoal não tem uma formação boa. Como você vai arranjar vaga pra esse pessoal?" E eu consegui junto com eles! Acho que essa força do trabalho coletivo foi muito boa, de procurar alternativas juntos do que seria viável. [...] Eu aprendi a procurar alternativas onde a gente primeiro não vê. $\mathrm{O}$ terceiro, realmente, é que foi muito bom para eu aprender a ouvir. [...] Ouvir foi muito importante nesse processo. E, também mais uma vez, assim que eu comecei eu queria uma solução que servisse para todo mundo: "todo mundo vai fazer assim, vai ter uma capacitação para todo mundo usar todos Microsoft's muito bem". E para algumas pessoas isso não servia, e ouvir isso e conseguir entender isso e pensar junto foi fundamental... [...] Em termos de $\mathrm{RH}$ eu aprendi algumas coisas... alguns processos... mas foram aprendizados muito maiores do que isso. Foram aprendizados que levei para minha vida." (Entrevistada 2)

A perspectiva dimensional do fenômeno centra-se fundamentalmente no indivíduo, muito embora a natureza do trabalho seja coletiva e a interação social seja importante. É o indivíduo quem avalia o conhecimento de valor e o modo de obtê-lo, pois é de cunho eminentemente pessoal. Inclusive, é o sujeito quem julga e valora o conhecimento que organização requisita. Ele se posiciona como o ator (e não objeto) diante do fenômeno.

Cabe ressaltar que quem valora o conhecimento que traz o resultado, na concepção dos indivíduos, ainda é o líder, chefia ou alta gestão; mas não se trata do conhecimento de "valor real", o qual o indivíduo valora. São conhecimentos 
diferentes. É o sujeito quem atribui importância ao conhecimento, baseado na sua concepção de vida, e não restrito ao que a organização atribui valor, geralmente limitado ao que dá resultado. Assim, alteridade para com a organização (CORLEY et al., 2006) é o mecanismo de base nessa concepção.

O contexto social do fenômeno, conforme já abordado, é pressuposto para a criação de conhecimento de valor, uma vez que o conhecimento encontra-se nos indivíduos e emerge nas pequenas coisas do dia a dia durante a interação social no ato de trabalhar. Assim, a participação coletiva no trabalho sobre um problema ou uma atividade é o que possibilita a geração de visões criativas e propostas inovadoras, sob um ângulo diferente das soluções e atividades convencionais.

O contexto temporal, na concepção da Criação Emergente para a Vida, é elástico e flexível, pois é dado pelo desenvolvimento da atividade em si, por sua complexidade, pelos recursos materiais disponíveis, já que a solução é uma criação generativa emergente do trabalho, questiona intrinsecamente a ordem convencional de como as coisas são feitas. Por consequência, o contexto espacial é caracterizado por descentralização com alto grau de autonomia e pouca hierarquia, em situações ad-hoc de baixa estruturação/formalização das atividades. Dada a complexidade e a relevância das situações, há o patrocínio direto do líder e/ou alta gestão. Outro aspecto característico é o alto grau de envolvimento dos indivíduos no trabalho em curso, em função dos contextos mencionados.

Após estas "experiência(s) única(s)", torna-se difícil para os entrevistados deixar de enxergar todo o contexto existente, na consciência focal, em novas situações, similares ou não, e de perceber a impossibilidade de acessar o mesmo contexto sócio-espaço-temporal da experiência marcante. Daí a clareza acerca da dissociação entre o conhecimento de valor e o conhecimento para resultado. Os indivíduos também estão conscientes do risco pessoal e profissional ao tentar questionar os paradigmas da organização e propor ou aplicar modelos inovadores em contextos organizacionais não propícios. Essa se constitui na maior barreira ao conhecimento de valor: a própria avaliação do risco a ser empenhado pelo sujeito naquela organização. De novo, o indivíduo parece se posicionar como ator diante do fenômeno.

"São os nãos em alguns momentos, e em alguns momentos batalhas travadas para implementar um projeto e assumir riscos.... Então assim: "por mim não, porque eu 
acho que isso não vai dar certo e aí se você quiser você vai lá e faz...” Aí é um nãopatrocínio que eu te falei... A pressão é muito maior porque o ter que dar certo vira uma condição única. Exclusivamente porque a consequência do não dar certo pode ser uma consequência crítica para você... Hoje tudo é vinculado: o teu bônus, a tua performance do teu resultado, sem implicação direta para a organização". (Entrevistada 9)

Quanto às rotinas organizacionais, elas se mostram pouco estruturadas, inadequadas ou inexistentes para aquele determinado processo, questão ou situação. Assim, a pouca experiência com a conjuntura e dinâmica do ambiente pedem um experimento, aceito pela alta gestão, o que possibilita ao indivíduo gerar algo diferente do convencional com alto grau de autonomia. Há, portanto, espaço para experimentação, erro e seu resultado não é mensurado da mesma forma que os processos tradicionais. São rotinas de natureza performativa (PENTLAND e FELDMAN, 2003), generativas de inovação. Porém, estranhamente, as experiências, mesmo sendo bem sucedidas, não se repetem nem são adotas em conjunturas similares.

Portanto, parece que a incorporação do conhecimento individual no conhecimento organizacional, advindas dessas novas experiências e com base nessas práticas e rotinas inovadoras, é muito pequena. Sugere-se que há baixa capacidade das organizações, por meio dos indivíduos e gestores, de integrá-las nos processos organizacionais estabelecidos, podendo-se apontar a dificuldade das organizações em extrair aprendizado a partir de novas formas de fazer processos convencionais e a dificuldade de incorporar inovação e novos processos em função do foco em resultados de curto prazo, falta de visão (de longo prazo, empreendedora) e medo de assumir riscos.

"No final das contas, eu desconstruí todo o meu conceito de recrutamento e seleção, porque tudo que eu já tinha feito na minha carreira, nesse processo, foi totalmente diferente e [o novo] me trouxe resultados muito mais efetivos. [...] E esse projeto trouxe algo muito novo, até pra mim... por isso que mexeu tanto comigo, quebrou paradigmas. [...] Não sei se ele entraria na rotina, o conhecimento em si. Talvez se eu continuasse ali, eu poderia incentivar um pouco mais, mas não sei se o conhecimento pura e simplesmente, ele por si só, tenha gerado o impacto suficiente para ser contínuo e independente de quem o execute. E eu não sei se as organizações estão prontas para o novo o tempo todo, para transformar em padrão, mesmo quando elas reconhecem o benefício... porque o novo desconforta, o desconhecido é um risco... [...] Que tentar diferente é aprender, é gerar conhecimento e isso exige um processo para acontecer. E as empresas não têm estruturalmente tempo, paciência nem empreendimento, talvez hoje... de entender exatamente o valor que é isso." (Entrevistada 9)

Os entrevistados apontam a visão imediatista da alta gestão e a incompatibilidade de adotar inovações sujeitas a risco, erro-aprendizado, de tempo 
incerto de adoção, frente à pressão por resultados e metas objetivas. Pode-se observar que os processos inovadores emergentes lidam com aspectos subjetivos das tarefas, que são colaterais, intangíveis e difíceis de serem mensurados nas práticas convencionais de RH, tais como: qualidade, imagem, valores, envolvimento. Para os entrevistados, entretanto, eles são necessários em casos específicos e contingenciais (terminação de uma área com profissionais de muitos anos de empresa, seleção de jovens profissionais para uma empresa de nome pouco conhecido no país, ou retenção de profissionais muito especializados). Quando possível, a alta gestão prefere adotar a rotina da certeza e o conforto do resultado mensurável, reproduzindo o estabelecido.

Ao recontextualizar os indivíduos pertencentes a essa categoria (cargo, tempo de trabalho, tipo de empresa), encontramos sujeitos no nível de gerência em dois grupos de tempo de trabalho (12/13 anos e mais de 30 de experiência). As experiências mencionadas dizem respeito à atuação em empresas multinacionais ou nacionais de grande porte com gestão profissional e descentralizada. Nelas, havia alto grau de formalização das tarefas e processos já existentes, em um ambiente de gestão participativa que proporcionava autonomia aos indivíduos em suas atividades.

O Quadro 10 apresenta o Espaço de Resultado para as Concepções acerca da Valoração do Conhecimento (VdC) no Contexto do Trabalho, sintetizando as dimensões características das cinco categorias descritivas discutidas anteriormente. A Figura 9 ilustra o Mapa do Espaço de Resultado, representando a hierarquia de inter-relação entre as Concepções acerca da Valoração do Conhecimento ( $\mathrm{VdC}$ ) no Contexto do Trabalho, por onde transitam os sujeitos. Esse mapa será explicado mais detalhadamente no tópico 7.1., do próximo capítulo. 


\begin{tabular}{|c|c|c|c|c|c|}
\hline Dimensão & $\begin{array}{c}\text { Aplicação } \\
\text { no Trabalho }\end{array}$ & $\begin{array}{c}\text { Consideração } \\
\text { (Reconhecimento) do } \\
\text { Trabalho-Indivíduo } \\
\end{array}$ & $\begin{array}{c}\text { Realização } \\
\text { do Indivíduo no Trabalho }\end{array}$ & $\begin{array}{c}\text { Transformação } \\
\text { do Indivíduo e do Trabalho }\end{array}$ & $\begin{array}{c}\text { Criação Emergente } \\
\text { para a vida }\end{array}$ \\
\hline Conceito & $\begin{array}{l}\text { Alinhamento entre o } \\
\text { conhecimento valorado do } \\
\text { indivíduo - fundamentalmente } \\
\text { técnico, objetivado e estocável } \\
\text { e a necessidade estratégica } \\
\text { da organização, visando um } \\
\text { "funcionamento perfeito", } \\
\text { "eficiência e eficácia". }\end{array}$ & $\begin{array}{l}\text { Ajustamento entre } \\
\text { conhecimento valorado e } \\
\text { consideração do indivíduo para } \\
\text { atividades da organização. } \\
\text { Ação reflexiva: o indivíduo } \\
\text { precisa ser reconhecido para } \\
\text { poder valorar a si mesmo, } \\
\text { assim age para ter/ser o } \\
\text { conhecimento que a } \\
\text { organização valora. }\end{array}$ & $\begin{array}{l}\text { Associação entre } \\
\text { conhecimento valorado - que é } \\
\text { avaliado pelo indivíduo e que } \\
\text { desempenha a organização - e } \\
\text { conhecimento organizacional. } \\
\text { Ação conjunta de trabalhar e } \\
\text { solucionar problemas } \\
\text { (emergentes do trabalho) } \\
\text { movem o indivíduo para os } \\
\text { resultados organizacionais. }\end{array}$ & $\begin{array}{l}\text { Antagonismo entre } \\
\text { conhecimento valorado - que } \\
\text { questiona o status quo, } \\
\text { transforma a organização - e o } \\
\text { exercício de controle (pelo } \\
\text { poder e/ou hierarquia), } \\
\text { geralmente realizado pelo líder } \\
\text { ou gestor. }\end{array}$ & $\begin{array}{l}\text { Dissociação entre } \\
\text { conhecimento valorado - que } \\
\text { questiona o paradigma vigente, } \\
\text { traz inovação, de longo prazo - } \\
\text { e o conhecimento que traz } \\
\text { resultado, de curto prazo - } \\
\text { geralmente valorado pelo líder, } \\
\text { chefia, ou alta gestão. }\end{array}$ \\
\hline $\begin{array}{l}\text { Natureza do } \\
\text { Conhecimento }\end{array}$ & $\begin{array}{l}\text { Individual, fundamentalmente } \\
\text { baseado em conhecimento } \\
\text { técnico, com aplicação direta } \\
\text { no trabalho e na geração de } \\
\text { resultados. } \\
\text { Objeto estocável, deve ser } \\
\text { planejado, na dimensão } \\
\text { individual e organizacional. }\end{array}$ & $\begin{array}{l}\text { Individual, fortemente baseado } \\
\text { em conhecimento técnico e } \\
\text { também em experiência } \\
\text { prática, para aplicação e } \\
\text { resultado no trabalho, a fim de } \\
\text { ser considerado pela } \\
\text { organização. }\end{array}$ & $\begin{array}{l}\text { Compartilhado, coletivo na } \\
\text { ação de trabalhar, } \\
\text { uma junção de conhecimentos } \\
\text { individuais, processual. } \\
\text { Insere-se na prática e na ação } \\
\text { de trabalhar, practice-based. } \\
\text { CdV alinha conhecimento } \\
\text { individual e organizacional. }\end{array}$ & $\begin{array}{l}\text { Compartilhado, coletivo na } \\
\text { ação de trabalhar, } \\
\text { questionador, disputado e } \\
\text { conflituoso. }\end{array}$ & $\begin{array}{l}\text { Compartilhado, coletivo na } \\
\text { ação de trabalhar, } \\
\text { questionador, emergente da } \\
\text { ação. Envolve assunção de } \\
\text { risco e aprendizagem com o } \\
\text { erro. } \\
\text { CdV é para a vida, é maior que } \\
\text { a organização. }\end{array}$ \\
\hline $\begin{array}{l}\text { Perspectiva } \\
\text { Dimensional }\end{array}$ & Organização & $\begin{array}{l}\text { Organização > Grupo > } \\
\text { Indivíduo }\end{array}$ & $\begin{array}{l}\text { Indivíduo > Grupo > } \\
\text { Organização }\end{array}$ & Indivíduo > Organização & Indivíduo \\
\hline $\begin{array}{l}\text { Mecanismos } \\
\text { de base }\end{array}$ & $\begin{array}{l}\text { Identificação com a } \\
\text { Identidade Organizacional }\end{array}$ & $\begin{array}{l}\text { Identificação com a IO } \\
\text { com esforço de encaixe }\end{array}$ & Identificação com a IO & $\begin{array}{l}\text { Alteridade Organizacional } \\
\text { com dificuldade de encaixe }\end{array}$ & Alteridade Organizacional \\
\hline
\end{tabular}




\begin{tabular}{|c|c|c|c|c|c|}
\hline Dimensão & $\begin{array}{l}\text { Aplicação } \\
\text { no Trabalho }\end{array}$ & $\begin{array}{c}\text { Consideração } \\
\text { (Reconhecimento) do } \\
\text { Trabalho-Indivíduo } \\
\end{array}$ & $\begin{array}{c}\text { Realização } \\
\text { do Indivíduo no Trabalho }\end{array}$ & $\begin{array}{c}\text { Transformação } \\
\text { do Indivíduo e do } \\
\text { Trabalho } \\
\end{array}$ & $\begin{array}{l}\text { Criação Emergente } \\
\text { para a vida }\end{array}$ \\
\hline $\begin{array}{l}\text { Contexto } \\
\text { Social }\end{array}$ & $\begin{array}{l}\text { Quase inexistente. } \\
\text { Relação centrada no eu- } \\
\text { resultado para a organização. } \\
\text { Pessoas são meios/recursos } \\
\text { para aplicar o conhecimento e } \\
\text { chegar ao resultado. }\end{array}$ & $\begin{array}{l}\text { É por meio da equipe que os } \\
\text { resultados são obtidos, } \\
\text { concorrendo para a } \\
\text { consideração da competência } \\
\text { do sujeito. }\end{array}$ & \begin{tabular}{|l|} 
É primordial e pressuposto: é \\
por onde o conhecimento se \\
constrói e o indivíduo se \\
realiza na entrega conjunta. A \\
interação entre as pessoas \\
conjuga conhecimentos que \\
praticam a organização.
\end{tabular} & $\begin{array}{l}\text { É por onde a transformação } \\
\text { ocorre - do controle e poder } \\
\text { para a participação (ou não) } \\
\text { da rede de relacionamento } \\
\text { que impede ou facilita as } \\
\text { ações. }\end{array}$ & $\begin{array}{l}\text { É pressuposto para a criação } \\
\text { de CdV. O conhecimento está } \\
\text { nos indivíduos, nas pequenas } \\
\text { coisas do dia-a-dia, e emerge } \\
\text { da/na interação social. }\end{array}$ \\
\hline $\begin{array}{l}\text { Contexto } \\
\text { Espacial }\end{array}$ & $\begin{array}{l}\text { É pressuposto para que o } \\
\text { conhecimento de valor se faça } \\
\text { visível (resultado eficaz): as } \\
\text { estruturas definidas e } \\
\text { processos formais instaurados, } \\
\text { cultura organizacional e } \\
\text { valores disseminados são } \\
\text { ordenamentos necessários para } \\
\text { aplicação do conhecimento. } \\
\end{array}$ & $\begin{array}{l}\text { É por meio da relação da } \\
\text { estrutura centralizada e } \\
\text { tradicional com a estruturação } \\
\text { das atividades e processos, que } \\
\text { o CdV (reconhecimento) } \\
\text { ocorre: os processos e práticas } \\
\text { em estruturação visam medir e } \\
\text { controlar as pessoas, as tarefas } \\
\text { e o desempenho, reproduzindo } \\
\text { o sistema de reconhecimento. }\end{array}$ & $\begin{array}{l}\text { É condição para a interação } \\
\text { social ocorrer. É fluido e } \\
\text { flexível, com estruturas } \\
\text { descentralizadas, com alto grau } \\
\text { de autonomia, gestão } \\
\text { participativa e grande } \\
\text { possibilidade de intervenção } \\
\text { nas tarefas e processos ou } \\
\text { criação destes. }\end{array}$ & $\begin{array}{l}\text { É o pressuposto para o } \\
\text { conhecimento que transforma a } \\
\text { organização: a posição } \\
\text { ocupada, a hierarquia } \\
\text { estabelecida. A caixa } \\
\text { hierárquica define/ contém as } \\
\text { competências que autorizam os } \\
\text { sujeitos. }\end{array}$ & $\begin{array}{l}\text { É condição para o CdV } \\
\text { emergir: descentralização com } \\
\text { alto grau de autonomia e pouca } \\
\text { hierarquia, em situações de } \\
\text { baixa estruturação das } \\
\text { atividades em situaçõoes } \\
\text { complexas e únicas. }\end{array}$ \\
\hline $\begin{array}{l}\text { Contexto } \\
\text { Temporal }\end{array}$ & $\begin{array}{l}\text { É por meio do planejamento, } \\
\text { das atividades detalhadas e } \\
\text { alinhadas, em sequência, que o } \\
\text { resultado eficaz é obtido e o } \\
\text { conhecimento se torna } \\
\text { presente. }\end{array}$ & $\begin{array}{l}\text { É inexistente para os sujeitos. } \\
\text { O tempo é dado pela liderança } \\
\text { na demanda pelas atividades e } \\
\text { tarefas, e não pelo ciclo das } \\
\text { atividades (pouco estruturadas) } \\
\text { ou do ambiente de negócios. }\end{array}$ & $\begin{array}{l}\text { É inerente ao trabalho, já que a } \\
\text { necessidade de solução para } \\
\text { um problema ou } \\
\text { desenvolvimento de uma } \\
\text { atividade surge na sua } \\
\text { realização. }\end{array}$ & $\begin{array}{l}\text { É inerente ao trabalho, para } \\
\text { cumprir com as demandas } \\
\text { estabelecidas pela liderança ou } \\
\text { pela hierarquia. }\end{array}$ & $\begin{array}{l}\text { É por onde a criação do CdV } \\
\text { ocorre, no tempo indefinido de } \\
\text { fazer algo novo emergir para } \\
\text { resolver um problema ou } \\
\text { desenvolver uma atividade no } \\
\text { trabalho }\end{array}$ \\
\hline $\begin{array}{l}\text { Pessoas de } \\
\text { Influência na } \\
\text { VdC }\end{array}$ & $\begin{array}{l}\text { A estratégia; a alta gestão; uma } \\
\text { cadeia despersonalizada. } \\
\text { Reificação da organização e } \\
\text { não corporificação do Quem, } \\
\text { reprodução mimética da } \\
\text { Organização. }\end{array}$ & $\begin{array}{l}\text { A consideração das pessoas é } \\
\text { fundamental para o indivíduo: } \\
\text { o diretor, gerente direto, } \\
\text { equipe, pares exercem } \\
\text { influência e reforçam o CdV. } \\
\text { O líder suporta/endossa o } \\
\text { indivíduo. }\end{array}$ & $\begin{array}{l}\text { O líder, chefia e alta gestão } \\
\text { estabelecem o "ambiente } \\
\text { propício", a cultura } \\
\text { organizacional. } \\
\text { O indivíduo e seus pares e } \\
\text { equipe constroem o CdV. }\end{array}$ & $\begin{array}{l}\text { O líder, chefia ou alta gestão, } \\
\text { através do poder (ou da } \\
\text { posição) e das escolhas } \\
\text { definidas para a organização. }\end{array}$ & $\begin{array}{l}\text { Geralmente o líder, chefia ou } \\
\text { alta gestão, mas não do } \\
\text { conhecimento de valor; e sim } \\
\text { aquele que traz o resultado. } \\
\text { O indivíduo valora o } \\
\text { conhecimento de valor 'real'. }\end{array}$ \\
\hline
\end{tabular}




\begin{tabular}{|c|c|c|c|c|c|}
\hline Dimensão & $\begin{array}{c}\text { Aplicação } \\
\text { no Trabalho }\end{array}$ & $\begin{array}{c}\text { Consideração } \\
\text { (Reconhecimento) do } \\
\text { Trabalho-Indivíduo }\end{array}$ & $\begin{array}{c}\text { Realização } \\
\text { do Indivíduo no Trabalho }\end{array}$ & $\begin{array}{c}\text { Transformação } \\
\text { do Indivíduo e do Trabalho }\end{array}$ & $\begin{array}{c}\text { Criação Emergente } \\
\text { para a vida }\end{array}$ \\
\hline $\begin{array}{l}\text { Característi- } \\
\text { cas das } \\
\text { Rotinas } \\
\text { Organizacio- } \\
\text { nais (RO) }\end{array}$ & $\begin{array}{l}\text { Pré-definidas pela organização } \\
\text { da conformidade, da certeza, } \\
\text { podendo ser tropicalizadas. } \\
\text { Rotinas ostensivas. }\end{array}$ & $\begin{array}{l}\text { Em estruturação, em } \\
\text { formalização. Busca da rotina } \\
\text { da certeza. } \\
\text { Rotinas ostensivas. } \\
\end{array}$ & $\begin{array}{l}\text { Processos básicos já } \\
\text { estruturados e formalizados, } \\
\text { aliados a novos processos e } \\
\text { rotinas em construção: Rotinas } \\
\text { da inovação, emergentes da } \\
\text { situação. } \\
\text { Rotinas performativas. }\end{array}$ & $\begin{array}{l}\text { Muito estruturadas, } \\
\text { formalizadas, } \\
\text { Flexibilidade se dá por quem } \\
\text { possui poder, pela posição ou } \\
\text { avalizado pelo cargo (estrutura } \\
\text { organizacional). } \\
\text { Rotinas ostensivas } \\
\end{array}$ & $\begin{array}{l}\text { Pouco estruturadas, } \\
\text { inadequadas ou inexistentes } \\
\text { (para aquele processo, questão, } \\
\text { situação). Em recriação. } \\
\text { Pode ser um experimento } \\
\text { (fazer diferente). } \\
\text { Rotinas performativas }\end{array}$ \\
\hline $\begin{array}{l}\text { VdC e } \\
\text { Rotinas } \\
\text { Organizacio- } \\
\text { nais (RO) }\end{array}$ & $\begin{array}{l}\text { É o modo de controle da vida } \\
\text { organizacional. Tem um } \\
\text { significado ordenatório, } \\
\text { delimitador e padronizador do } \\
\text { comportamento dos } \\
\text { indivíduos. } \\
\end{array}$ & $\begin{array}{l}\text { É a forma de medir as pessoas, } \\
\text { as tarefas, o desempenho e } \\
\text { reproduzir o sistema de } \\
\text { reconhecimento. }\end{array}$ & $\begin{array}{l}\text { É o meio de praticar, de } \\
\text { desempenhar o trabalho. O } \\
\text { sujeito constrói ou intervém } \\
\text { coletivamente na RO. }\end{array}$ & $\begin{array}{l}\text { Poder, hierarquia ou } \\
\text { cargo/posição ocupada avaliza } \\
\text { ou não a intromissão do sujeito } \\
\text { na RO. }\end{array}$ & $\begin{array}{l}\text { Baixa capacidade das ROs } \\
\text { criadas se integrarem nos } \\
\text { processos organizacionais } \\
\text { estabelecidos. Dificuldade de } \\
\text { incorporar inovação em novos } \\
\text { processos. }\end{array}$ \\
\hline \begin{tabular}{|l|} 
Recontextua- \\
lização da \\
Estrutura \\
\end{tabular} & $\begin{array}{l}\text { Estrutura multinacional, com } \\
\text { alto grau de estruturação/ } \\
\text { formalização das atividades e } \\
\text { processos. }\end{array}$ & $\begin{array}{l}\text { Estrutura tradicional e/ou } \\
\text { familiar, com baixo grau de } \\
\text { estruturação/formalização das } \\
\text { atividades e processos. } \\
\text { Centralização das decisões e } \\
\text { do poder. }\end{array}$ & $\begin{array}{l}\text { Estrutura nacional de grande } \\
\text { porte, com gestão profissional. } \\
\text { Médio grau de estruturação/ } \\
\text { formalização das tarefas e } \\
\text { processo. Descentralização das } \\
\text { decisões com autonomia }\end{array}$ & $\begin{array}{l}\text { Estrutura multinacional ou } \\
\text { nacional de grande porte, } \\
\text { derivadas de empresas públicas } \\
\text { privatizadas. Alto grau de } \\
\text { estruturação/formalização das } \\
\text { atividades e processos. Alta } \\
\text { centralização das decisões, } \\
\text { baixo grau de autonomia, } \\
\text { hierarquizada. }\end{array}$ & $\begin{array}{l}\text { Estrutura multinacional e/ou } \\
\text { estrutura nacional de grande } \\
\text { porte com gestão profissional. } \\
\text { Alto grau de formalização das } \\
\text { tarefas e processos existentes, } \\
\text { mas sujeita a novos processos } \\
\text { ad hoc, pela dinâmica do } \\
\text { ambiente. Descentralização das } \\
\text { decisões com autonomia. }\end{array}$ \\
\hline Sujeitos & $3,8,18$ & $4,11,15,17$ & $1,5,10,13$ & $6,7,21$ & $2,9,19$ \\
\hline em Trânsito & & & & $\mathbb{Z}+-----1$ & 14. - - - - - - - \\
\hline
\end{tabular}

Quadro 10: Espaço de Resultado para as Concepções acerca da Valoração do Conhecimento (VdC) no Contexto do Trabalho (elaborado pela autora) 


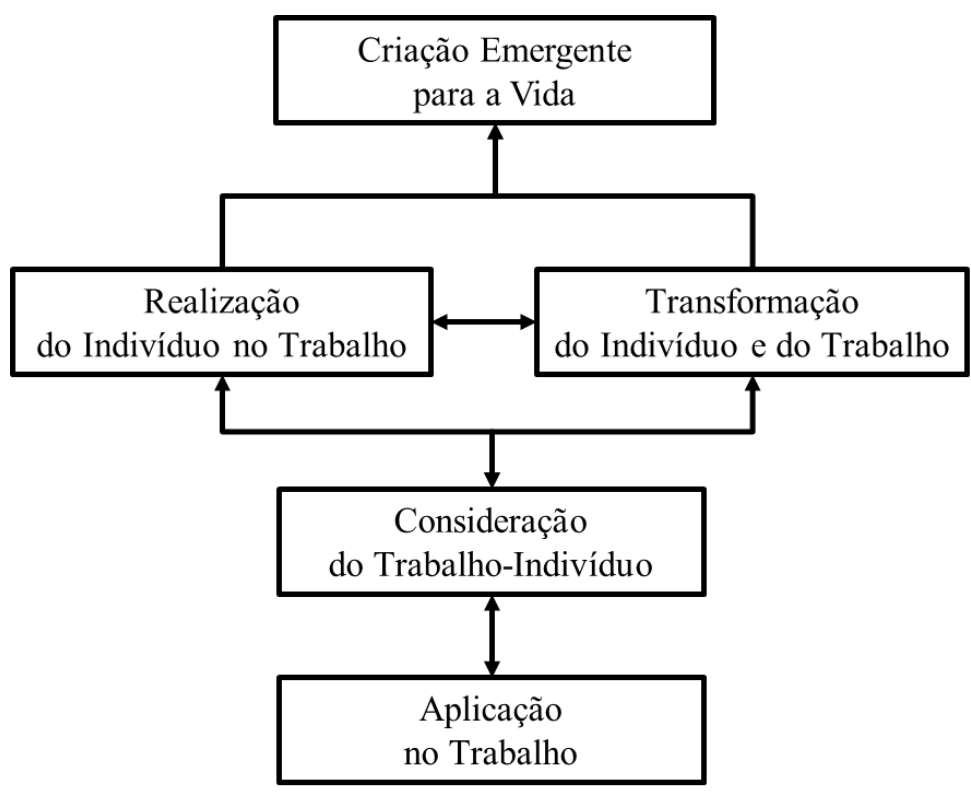

Figura 9: Mapa do Espaço de Resultado para as Concepções acerca da Valoração do Conhecimento (VdC) no Contexto do Trabalho (elaborado pela autora)

\subsection{Resultados do Grupo de Foco para Validação Interna do Mapa do Espaço de Resultado}

Conforme apresentado no tópico 5.5, referente ao Grupo de Foco para Validação Interna do Mapa do Espaço de Resultado, no capítulo de Metodologia de Pesquisa, foi realizada uma reunião para discutir os achados e proposições encontrados junto a um grupo de participantes do estudo. A reunião teve o objetivo primeiro de buscar validade interna do Mapa do Espaço de Resultado.

Os principais resultados do grupo de foco se consolidam a seguir, sendo discutidos e apresentados em forma de proposições teóricas no capítulo seguinte, no tópico 7.1.:

1. Os participantes, naturalmente, procuraram se encontrar (e se encaixar) dentre as concepções apresentadas; e expressaram a dificuldade de fazê-lo (se autoclassificar). Esse fato ocorreu porque, curiosamente, além de perceber o trânsito nas concepções no decorrer da carreira (“eu já pensei assim...”), os participantes expressaram que se sentem inseridos em diferentes categorias ao mesmo tempo, dependendo das diferentes situações (grupos e contextos) a que são submetidos no trabalho. Eles analisaram que, por um lado, trata-se do fato das concepções serem inclusivas e, assim, estarem presentes, onde cada uma delas parece se acentuar em diferentes situações. Por outro lado, também foi analisado 
que o trânsito de uma a outra categoria, hierarquia acima, também gera essa dificuldade, onde o indivíduo ganha mais consciência focal na medida em que é exposto repetidas vezes ao fenômeno.

Essa discussão se coaduna com o método, uma vez que propõe que os sujeitos transitam pelo Espaço de Resultado no decorrer da vida. Assim, também sugere confirmar o achado de que as categorias, de forma alguma, isolam ou amarram os sujeitos em categorias estanques. Ao contrário, os sujeitos parecem se utilizar das concepções de forma ainda mais fluida e transitória do que o encontrado pela própria pesquisadora: mudam de concepção, e agem em acordo a ela, diante de diferentes grupos e situações no mesmo ambiente de trabalho. Por exemplo, essa mudança ocorre ao lidar com as diferentes áreas e departamentos da empresa ou pela novidade de um projeto, onde ambos exigem diferentes concepções do conhecimento de valor. Esse aspecto sugere que a visão do continuum entre categorias, que será discutido no tópico 7.1., parece fazer sentido junto ao método.

2. Quatro participantes reconheceram situações na carreira em que já estiveram em uma concepção e decidiram mudar de organização, voltando para uma concepção anterior (hierarquia abaixo) e/ou movendo-se para a busca de uma concepção mais alinhada com suas crenças, valores, personalidade a fim de ter algum 'conforto' no trabalho (hierarquia acima ou abaixo). Essa discussão sugere que o Mapa do Espaço de Resultado poderia ser realmente representado de modo bidirecional, conforme proposto no tópico 7.1. Não necessariamente os sujeitos caminham apenas hierarquia acima em suas concepções, podem preferir ficar com um tipo de concepção e repeti-lo no decorrer da carreira. Novamente, a visão do continuum entre categorias parece demonstrar melhor o movimento realizado pelos participantes no trânsito pelas concepções do fenômeno.

3. Os participantes concluíram que assumir uma concepção de conhecimento de valor, e comportamentos (ação) relacionados, está intimamente interligado com o contexto onde o indivíduo se encontra, principalmente os contextos profissional e organizacional, mas também pessoal (momento de vida). Concordaram fortemente com a inferência proposta pelo método, de que as concepções mudam durante a trajetória na vida (e na carreira). Foi informado, pelos participantes, que essas mudanças são mais intensamente dirigidas pelo ambiente/contexto organizacional e a necessidade de nele se encaixar. 
Mencionaram, para esse processo, a identificação com a organização por parte do indivíduo e a busca da aceitação pelos grupos da organização.

4. Os participantes afirmaram encontrar várias concepções distintas coexistindo na organização, ou seja, percebem diferentes indivíduos e grupos que pensam de modo similar às diferentes concepções apresentadas, convivendo na mesma organização. Sugeriram que as diferentes concepções coexistem, pois os grupos sociais na organização percebem o contexto e constroem, juntos, uma visão de como devem utilizar seus conhecimentos de valor no trabalho, a partir de uma percepção do que a organização valoriza.

5. Os participantes confirmaram a existência de uma concepção dominante no ambiente organizacional, que se sobrepõe às demais. Chegaram a discutir que essa concepção de valoração do conhecimento dominante poderia estar ligada à cultura dominante da organização ou aos valores do grupo da alta gestão e/ou do indivíduo dominante (presidente, um vice-presidente ou diretor) que exerce o poder de fato. Após uma intensa discussão, a explicação foi rearticulada entre os participantes, ou seja, determinados indivíduos ou grupos (da alta gestão) parecem exercer maior influência na concepção dominante de conhecimento de valor, devido à posição de poder, representando o modelo de conhecimento de valor da organização, influenciando mais fortemente e servindo de referência para concepção a ser adotada pelos membros organizacionais.

6. De acordo com os participantes, os indivíduos que não possuem concepções de valoração do conhecimento alinhadas com a concepção dominante da organização vivem as seguintes situações: a) permanecem na organização quando conseguem adequar sua concepção com aquela da empresa, fazendo uso do processo de identificação e, nesse caso, mudam de concepção (transitam no Mapa); b) conflitam com a organização, como no caso da Transformação do Trabalho-Indivíduo, permanecendo na medida em que a organização permite o conflito (ou as reclamações, em menor escala); c) são expurgados da organização (demitidos ou pressionados a sair) ou saem por vontade própria (como alguns participantes fizeram, conforme exposto no tópico 7.1.). Essas declarações indicam e reforçam que, em maior ou menor grau, há um controle por parte de grupos ou indivíduos da organização sobre o conhecimento de valor a ser estabelecido e, principalmente, comportamentos decorrentes dele, no contexto do trabalho. 
7. Os participantes validaram o Mapa do Espaço de Resultado em suas concepções inclusivas, hierárquicas e bidirecionais. Entretanto, ficaram muito incomodados com a figura na forma de um 'organograma', sugerindo que um caminho fluido e contínuo, que permite o trânsito de uma a outra categoria, deveria ser representado de outro modo. A figura dos círculos inclusivos das categorias descritivas pareceu representar melhor, do ponto de vista deles, o Mapa do Espaço de Resultado. Tal representação se encontra na Figura 10.

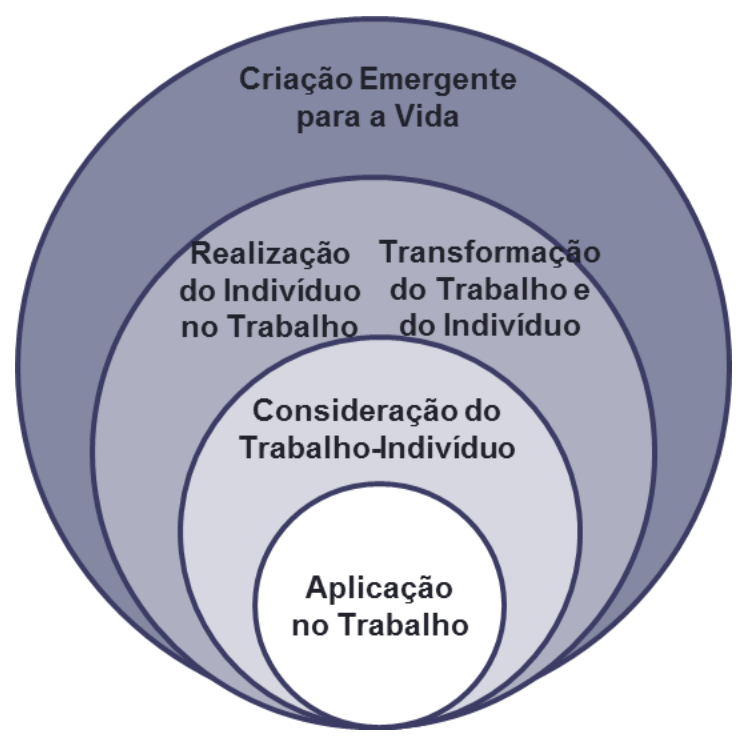

Figura 10. Mapa do Espaço de Resultado conforme proposto pelos participantes do grupo de foco (elaborado pelos participantes do grupo de foco)

Em suma, os achados relacionados ao método e apresentados em forma de proposição no próximo capítulo, tópico 7.1, foram confirmados pelos participantes do grupo de foco, assim como a validade interna do Mapa do Espaço de Resultado. Entretanto, deve-se ter consciência de que as categorias ora propostas são fruto dos arranjos existentes naquele momento da realização das entrevistas.

Passados cerca de cinco a sete meses da realização das entrevistas, os participantes expressaram o quanto houve mudanças no seu ambiente de trabalho, que os induzem a pensar e agir com relação ao conhecimento valorado de modo diferente do narrado previamente. Assim, os arranjos do contexto, e suas mudanças, fazem parte da construção das concepções, uma vez que é o mundo onde os indivíduos estão inseridos, sendo essa construção relacional. Esse aspecto 
será discutido no próximo capítulo, de Discussão e Proposições Teóricas acerca da Valoração do Conhecimento no Contexto do Trabalho. 

Conhecimento no Contexto do Trabalho e os Impactos nas Práticas Organizacionais

Este estudo se propôs a apresentar os diferentes modos pelos quais os membros organizacionais percebem e experimentam a valoração do conhecimento no contexto do trabalho e seus impactos nas práticas organizacionais. O Método Fenomenográfico empregado na pesquisa, conforme já foi discutido no capítulo de metodologia, objetiva representar um mapeamento da estrutura de pensamento acerca do fenômeno (BOWDEN e WALSH, 2000; MARTON e BOTH, 1997; SANDBERG, 2000). O Mapa (Figuras 9 e 10) e o quadro de Espaço de Resultado (Quadro 10) encontrados para a Valoração do Conhecimento no Contexto do Trabalho foram apresentados no capítulo 6, de análise dos dados emergentes do campo.

Compete lembrar, portanto, que o resultado da pesquisa Fenomenográfica não procura apresentar explicações acerca do fenômeno (MARTON, 1981). Entretanto, cabe, para a presente tese, o exercício de propor explicações que auxiliem no seu entendimento mais profundo. Assim, este capítulo tem a finalidade de expor uma dimensão explicativa e proposições teóricas relacionadas aos principais achados do estudo.

\subsection{Proposições Teóricas acerca do Método Fenomenográfico Aplicado ao Fenômeno da Valoração do Conhecimento}

Entende-se que, conforme preconiza o Método Fenomenográfico (MARTON, 1981; BOWDEN e WALSH, 2000), não é objetivo abrir um grande número de categorias descritivas pouco inclusivas, mas sim concentrar em um número adequado de categorias descritivas relevantes que ajudem a compreender a valoração do conhecimento no contexto do trabalho (o fenômeno) como um todo articulado. Por esse motivo, o Espaço de Resultado (Quadro 10) e o 
respectivo Mapa do Espaço de Resultado (Figura 9) foram consolidados em cinco categorias descritivas.

Segundo Marton (1981), Marton e Booth (1997) e Bowden e Walsh (2000), o uso do Método Fenomenográfico busca o encadeamento lógico e inclusivo entre categorias descritivas. Esse aspecto fica bastante evidente na leitura da trajetória de carreira dos indivíduos à luz das categorias descritivas emergentes das narrativas (concepções). Pôde-se perceber com clareza os movimentos feitos pelos sujeitos nas suas concepções acerca da valoração do conhecimento durante sua vida profissional (trânsito pela estrutura do Espaço de Resultado).

Entretanto, também há uma dinâmica de movimento de transição dos sujeitos entre categorias, capturada pelo método, relacionando concepção e momento profissional (contexto sócio-espaço-temporal) - muito interessante de se observar. Pode-se inclusive propor, mais apropriadamente, que as categorias descritivas caminham em um continuum, e que elas não possuem, de forma alguma, um caráter estático e aprisionador dos sujeitos. Pode-se também, propor que, em função da experiência em determinado contexto sócio-espaço-temporal, determinados aspectos do fenômeno ganham maior atenção na consciência focal dos indivíduos, fazendo com que eles percebam o fenômeno de determinada maneira e que transitem dinamicamente pelas categorias de acordo com o contexto.

Por esse motivo, optou-se por adotar setas bidirecionais no mapa do Espaço de Resultado (Figura 9), algo que não é utilizado, ou ao menos mencionado, pelos autores e pesquisadores do método (BOWDEN e GREEN, 2005; BOWDEN e WALSH, 2000; MARTON, 1981; MARTON e BOOTH, 1997; SANDBERG, 2001). Os autores do método dão a entender que os indivíduos, à medida que ganham consciência focal na repetida experiência com o fenômeno, avançam hierarquia acima nas concepções, e que este movimento seria sempre nesse sentido. No presente estudo, no entanto, foi observado que os sujeitos também podem recuar em suas concepções, mesmo tendo expandido sua consciência focal.

Desse modo, quanto ao Método Fenomenográfico, é proposto:

Proposição 1: As concepções do Mapa do Espaço de Resultado são posicionadas em um continuum ininterrupto, por onde os sujeitos transitam, de uma a outra categoria, dinâmica e bidirecionalmente. 
Assim, ao se analisar a trajetória de carreira dos indivíduos em relação às concepções do fenômeno, percebeu-se que o trânsito entre categorias não é unidirecional, sempre hierarquia acima. $\mathrm{O}$ indivíduo pode preferir retroceder na hierarquia, deixando uma empresa onde a concepção acerca da valoração do conhecimento está mudando para a concepção seguinte (e ele consegue distinguir esse fato), indo para outra organização onde ele retorna à concepção em que se sente mais confortável, como no caso da entrevistada 10.

Alguns outros exemplos desse movimento entre categorias foram expressos nas trajetórias dos entrevistados 3 e 7 . No caso do entrevistado 3, ao começar a trabalhar em uma empresa multinacional de origem nórdica, onde as decisões são muito discutidas entre os pares e gestores na busca de consenso, tornando a tomada de decisão mais lenta, porém mais sólida e com conhecimento compartilhado, o profissional relata sua passagem curta por essa empresa devido a não adaptação ("meu conhecimento não era aproveitado, tudo era discutido, muito discutido") e retorna a um contexto onde seu conhecimento voltava a ser direcionado para aplicação no trabalho e medido por resultado.

Também se notam indivíduos em transição, movendo-se de uma a outra categoria descritiva, no meio do caminho, nesse continuum proposto. Nesse caso, o sujeito possui uma concepção composta por dimensões referentes a uma categoria, mas também apresenta alguns conceitos (pensamento ou ação) relacionados à categoria seguinte do Espaço de Resultado. Assim, propõe-se:

Proposição 2: No movimento entre concepções do Mapa do Espaço de Resultado, os sujeitos podem se posicionar em trânsito entre categorias, fruto de se encontrar em uma concepção e começar a perceber aspectos da concepção seguinte, em processo de ampliar sua consciência focal.

Um exemplo ilustrativo encontra-se na entrevistada 22, que transita entre duas concepções, dado seu histórico de 14 anos na mesma organização onde ela ingressou como secretária e percorreu uma trajetória de carreira até a muito recente promoção à coordenação de RH (abaixo apenas da Diretora de RH, sediada em São Paulo), após ter sido preterida uma vez para essa posição.

Desse modo, a entrevistada possui a concepção de que o conhecimento de valor é aquele responsável por resultados efetivos; útil para o bom andamento do 
ambiente organizacional; representado pela aplicação do seu conhecimento da própria organização após tantos anos de trabalho no mesmo lugar; que possui rotinas organizacionais muito estruturadas e definidas (rotinas da certeza) as quais a entrevistada é guardiã.

Entretanto, em vários momentos a entrevistada transita pelo reconhecimento dado a ela por razão do conhecimento (de valor) que ela detém (dos processos e rotinas organizacionais); a confiança na liderança e chefias ao considerarem o conhecimento dela, cuja concretização se deu com a promoção de cargo. São aspectos inerentes à concepção da Consideração do Trabalho-Indivíduo.

Outro exemplo ilustrativo é o do entrevistado 14, que também demonstra transitar entre categorias. Depois de repetidas experiências similares na concepção da Transformação do Trabalho e do Indivíduo, começava a vislumbrar aspectos da concepção seguinte, da Criação Emergente para a Vida. Em seus questionamentos demonstrava começar a conceber que seus conhecimentos de valor, aqueles que poderiam transformar a organização, não necessariamente seriam aqueles que a organização onde se encontrava desejava, e se questionava se estaria disposto a empenhar novo risco pessoal e profissional nesta ação. Ele evidenciava discernir novos elementos à sua consciência focal com relação ao fenômeno.

A visão do continuum fluido entre concepções, bidirecional, adicional à lógica hierárquica e inclusiva, se não é um novo achado relacionado especificamente ao método, parece tratar-se de um aspecto inter-relacionado ao fenômeno. Tal achado merece um destaque de importância por um motivo simples: ao se perceber a dinâmica de trânsito dos sujeitos pelas categorias durante sua trajetória de carreira (ou vida, dependendo do objeto de estudo) encontra-se apoio para a validade interna do Mapa do Espaço de Resultado, ou seja, é possível discernir quais concepções acerca do fenômeno vem antes ou depois em hierarquia inclusiva, quais já estão presentes na consciência focal do indivíduo, quais já não possuem tanto valor, e para quais concepções os sujeitos caminham, sempre lembrando que os atores são livres para voltar atrás, se arrepender e esquecer. 


\subsection{Proposições Teóricas acerca da Valoração do Conhecimento no Contexto do Trabalho}

Pela perspectiva adotada no presente estudo, practice-based (GHERARDI, 2000; 2002; LATOUR, 2012; PATRIOTTA, 2003a; 2003b), a valoração do conhecimento seria uma construção coletiva de significado, compartilhada por um agrupamento de atores em um determinado contexto social (das interações ocorridas e conectadas em diversos níveis), espacial (nas estruturas produzidas pelos indivíduos a partir da conexão de diversos nexos de como é aquele ambiente) e temporal (no intervalo fluido, elástico, que mantém os atores conectados e as ações ocorrendo), acerca de quais conhecimentos são importantes valorar, significar, reproduzir e atuar para o indivíduo viver naquele mundo, e que se traduzem nas concepções (percepção-pensamento-ação dos indivíduos) (SANDBERG, 2000) narradas acerca desse ambiente/mundo/realidade. Essa perspectiva será utilizada como 'panorama' (de acordo com a nomenclatura de Latour (2012) para as proposições explicativas apresentadas nesse capítulo.

Ainda que, por diversas vezes, tenha-se a impressão de que as concepções, percepções, ideias expressas pelos entrevistados sejam individuais e próprias, não se deve perder de vista que são produções que os indivíduos construíram imersos em uma rede de relações, interações, mediações com atores, situados, mesmo que provisoriamente (ou em um arranjo provisório), em algum ponto, em algum momento (LATOUR, 2012). Assim, a concepção é resultado de uma construção social dos atores imersos em um arranjo composto por um coletivo.

É sugerido, com base em Latour (2012), que uma mudança na configuração do arranjo, desse coletivo que o compõe, do ponto ou do momento, poderá gerar uma mudança na concepção do indivíduo, ou seja, diferentes arranjos sociais, dentro do mesmo ambiente, podem construir diferentes concepções. Decorre daí um possível entendimento de por que há as diferentes concepções; por que há o trânsito fluido e contínuo na estrutura do espaço de resultado; por que para diferentes estruturas percebidas pelos atores correspondem diferentes concepções; por que coexistem diferentes concepções dentro do mesmo espaço organizacional.

A busca por compreender as concepções da valoração do conhecimento no contexto do trabalho pela perspectiva dos indivíduos revelou, também, que o 
fenômeno é multidimensional. Evitou-se a palavra nível no presente capítulo (e utilizou-se a palavra dimensão), sempre que possível, para tentar manter os diferentes atores no mesmo plano (LATOUR, 2012), muito embora alguns atores (especificamente a organização e seus mediadores) tenham mais peso e influenciem mais na valoração do conhecimento do que outros. Esse aspecto foi mencionado no capítulo 6 e será retomado mais à frente, no presente tópico.

A multidimensionalidade encontra-se na relação do indivíduo com os diversos níveis de interação social descobertos na análise, os quais influenciam na sua forma de conceber o conhecimento de valor, tais como: os grupos, equipes e pares; a organização (por meio da liderança, alta gestão ou ela mesma, enquanto entidade não humana que mantém outros atores não humanos na cultura, na estrutura e hierarquia, nas práticas e rotinas, entre outros); e o mundo exterior à organização (onde se insere a vida mais ampla do sujeito).

Desse modo, o estudo sugere que:

Proposição 3: Para as diferentes concepções acerca da valoração do conhecimento, as diversas dimensões de interação social exercem influências distintas, fruto da consciência focal do indivíduo e da consequente importância atribuída pelos sujeitos a estes níveis/grupos para a construção social do fenômeno.

Portanto, para a cada concepção, determinados níveis/grupos são priorizados na consciência focal, a saber:

- Aplicação no Trabalho: a dimensão social de interação do sujeito encontra-se na organização; onde o indivíduo se dilui nela, sem fronteiras entre ambos. O indivíduo é a organização.

- Consideração do Trabalho-Indivíduo: as dimensões sociais encontram-se na organização em grupos e pares; onde o indivíduo busca aceitação constante de ambos os níveis, para diluir as fronteiras visíveis e delimitadas, a fim de adequar-se e encaixar-se.

- Realização do Indivíduo no Trabalho: as dimensões sociais encontram-se no indivíduo em interação com os grupos e pares e com a organização; onde as fronteiras são fluidas, possibilitando o indivíduo com seu grupo realizar para a organização. 
- Transformação do Trabalho e do Indivíduo: a dimensão social volta a se estreitar e encontra-se no indivíduo e a organização, em lados conflitantes, separados por fronteiras bem delimitadas, que o indivíduo busca diluir na transformação. O indivíduo não é a organização.

- Criação Emergente para a Vida: as dimensões sociais de grupos e pares, organização e da vida mais ampla se diluem no indivíduo, que é o centro e o ator da ação. Todas as dimensões são partes constitutivas do indivíduo, sendo que a organização ocupa uma parte separada dessa relação, com fronteira bem delimitada. O indivíduo é diferente da organização.

A Figura 11, na página seguinte, esquematiza as relações sugeridas em cada categoria.

Em comum e presente em todas as concepções de valoração do conhecimento, observa-se a relação entre o indivíduo e a organização. Conforme já foi inicialmente exposto, os atores, de diferentes dimensões, encontram-se envolvidos na interação social, sendo responsáveis por produzir em conjunto com o indivíduo a concepção de conhecimento valorado, em cada contexto (ou arranjo ou coletivo). Latour (2012) preconiza que não existe 'estrutura' concreta, maior que outra (como uma organização versus um indivíduo). Nos agrupamentos sociais, todos os atores do arranjo ator-rede encontram-se no mesmo nível, no mesmo plano bidimensional, procurando representar que todos os atores, independentemente de seu tamanho, exercem igual influência nos demais atores.

Entretanto, devido aos 'panoramas', 'escalas' e, especialmente, 'padrões estruturantes' - produzidos e interpretados pelos próprios atores - circulando, materializados por técnicas e tecnologias intelectuais disseminadas, determinados atores, particularmente a entidade organização e mediadores relacionados (liderança, alta gestão, entre outros), possuem mais peso ou influência do que outros, como membros de equipes e pares, sobre as ações e comportamentos (e concepções) dos indivíduos. 


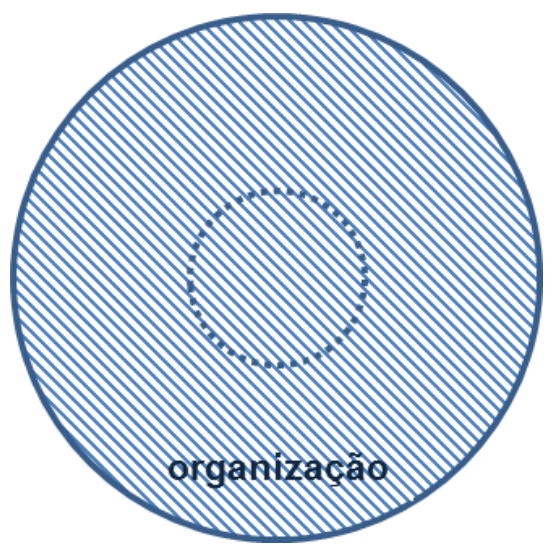

Aplicação no Trabalho

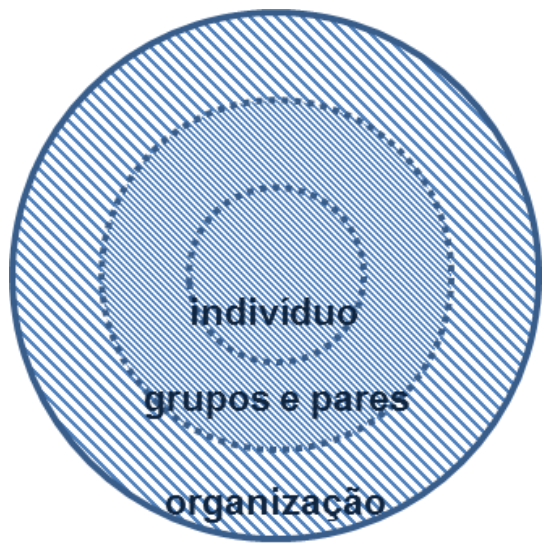

Realização do Indivíduo no Trabalho

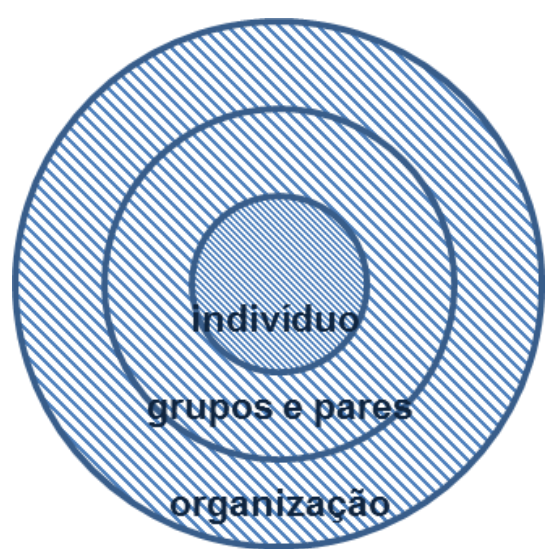

Consideração do Trabalho-Indivíduo

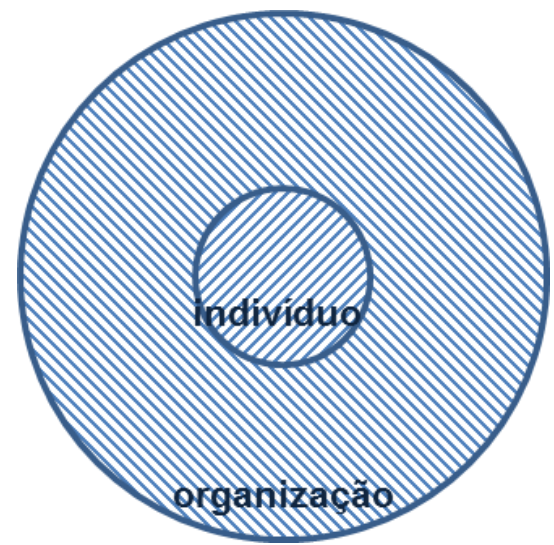

Transformação do Trabalho e do Indivíduo

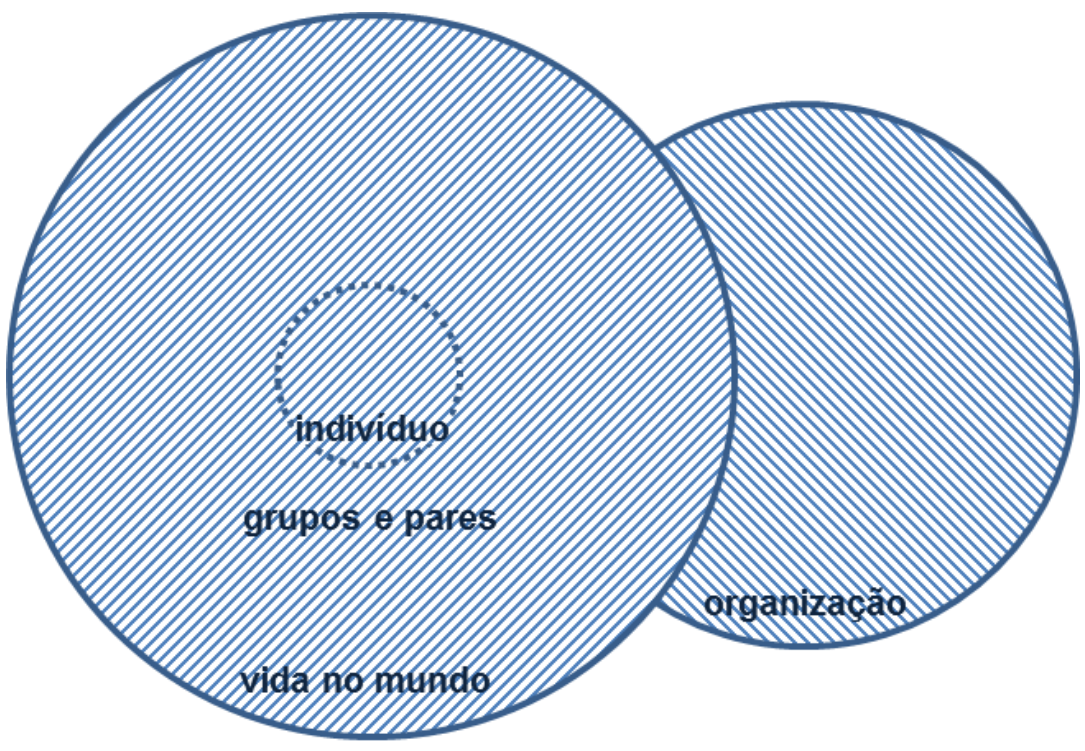

Criação Emergente para a Vida

Figura 11: Esquema ilustrativo das dimensões de interação social envolvidas nas concepções de valoração do conhecimento no contexto do trabalho (elaborado pela autora) 
Dessa forma, sugere-se que os indivíduos utilizam-se mais fortemente da organização e seus mediadores relacionados, tais como a liderança, a alta gestão, a cultura, as rotinas, entre outros, como modelo de referência (ou padrões estruturantes) para construir suas concepções de conhecimento de valor para aquela organização, ou seja, outro padrão estruturante. A organização e seus mediadores diretos são, inclusive, apontados por entrevistados, em diversas categorias, como "quem valora o conhecimento". No caso do grupo de foco, por sua vez, esses atores foram apontados como quem estabelece a concepção dominante do conhecimento de valor.

Sugere-se, também, que a identificação com a identidade organizacional seja um mecanismo importante na expressão do alinhamento da relação entre sujeito e organização para a construção da valoração do conhecimento. A identidade no nível coletivo pode ser distinta da identidade no nível individual, mas ambas estão relacionadas e são modeladas nos processos sociais na organização (CORLEY et al., 2006). A identificação incorpora os indivíduos nas identidades que são relevantes para eles (ASHFORTH et al., 2008), onde o indivíduo produz seu autoconceito que contém os mesmos atributos daqueles percebidos na identidade organizacional (DUTTON et al., 1994); comunica essa definição aos outros e se utiliza dessa definição para guiar sua vida e trabalho (ASHFORTH et al., 2008). Entre estes atributos, está o centro da identidade: o que é ser, valorar e sentir, que resulta no comportamento da identidade (ASHFORTH et al., 2008).

A pesquisa indica que o indivíduo se comporta (resultado do processo de identificação) atribuindo ou não valor a algo, ao tomar, por base e orientação, o conhecimento que ele compreende como aquele que a organização valora, por meio dos processos sociais de construção coletiva da identidade organizacional (CORLEY et al., 2006).

Desse modo, propõe-se que:

Proposição 4: A identificação com a identidade organizacional é um mecanismo por meio do qual os indivíduos expressam o alinhamento entre a sua concepção de conhecimento de valor e o conhecimento valorado pela organização. 
Cabe ressalvar que para cada categoria esse mecanismo cumpre um papel diferente no ajustamento do indivíduo para com a organização.

- Aplicação no Trabalho: O indivíduo é a organização. Há alinhamento entre o conhecimento valorado pelo indivíduo e pela organização aquele que está estabelecido e traz resultado para a organização - com total encaixe e identificação do indivíduo com a IO.

- Consideração do Trabalho-Indivíduo: O indivíduo busca ajustamento com a organização/IO, a fim de ser aceito, sem questionamento. Há trabalho de identidade, no qual o indivíduo faz um esforço ativo para compreender (interpretar), valorar e se comportar de acordo com o que ele entende que a organização atribui importância. Desse modo, ele busca interpretar o conhecimento valorado pela organização - aquele que traz controle sobre as atividades, mensura e recompensa os indivíduos - e procura ativamente ter e demonstrar que o possui, a fim de ser reconhecido e considerado pela organização.

- Realização do Indivíduo no Trabalho: O indivíduo é um com a organização. Há identificação com a identidade organizacional, uma vez que o conhecimento valorado pela organização - aquele que é compartilhado, emergente e contribui para ela construir suas atividades está associado e é o mesmo que é valorado pelo indivíduo.

- Transformação do Trabalho e do Indivíduo: O indivíduo não é a organização. Há não identificação do indivíduo com a organização, há alteridade e negação da identidade organizacional. Há antagonismo, uma vez que indivíduo não valora o conhecimento que a organização valora aquele que é determinado pelas estruturas de hierarquia e poder. Não há esforço de encaixe na IO por parte dos indivíduos. Há questionamento, conflito e estratégias de sobrevivência no ambiente.

- Criação Emergente para a Vida: O indivíduo é diferente da organização. Há alteridade organizacional; indivíduo e organização são entidades separadas, dissociadas e, portanto, valoram conhecimentos diferentes - a organização valora o conhecimento que traz resultado, enquanto o indivíduo valora o conhecimento que gera aprendizagem. Para permanecer na organização o indivíduo aceita as diferenças, avalia os 
riscos e decide, caso a caso, se acata o conhecimento por resultado ou propõe conhecimento generativo.

Esse mecanismo de identificação com a identidade organizacional foi explorado por outros autores (ANTONACOPOULOU, 2006; COLMAN e LUNNAN, 2011; NAG et al., 2007; RAVISHANKAR e PAN, 2008). Nesses estudos, os sujeitos tendem a proteger e adotar conhecimentos que mantém sua identidade organizacional. Diferentemente, no presente estudo, as várias concepções de valoração do conhecimento evocam distintos comportamentos de identificação ou não com a IO. Nas três primeiras concepções (Aplicação no Trabalho, Consideração Trabalho-Indivíduo, Realização do Indivíduo no Trabalho), o indivíduo protege a identidade organizacional existente ao alinhar, ajustar ou associar, respectivamente, a sua concepção de conhecimento de valor àquela interpretada e atribuída à organização. Os sujeitos terminam por legitimar e reproduzir a concepção de conhecimento de valor dominante da organização, caracterizando assim, uma faceta de poder intrínseca ao mecanismo de IO (também identificada nos trabalhos de ANTONACOPOULOU, 2006; COLMAN e LUNNAN, 2011; NAG et al., 2007) e de construção identitária (ANTONACOPOULOU, 2006; HARMAN, 2012).

Entretanto, o indivíduo também pode não possuir identificação com a IO, assumir alteridade para com a organização, conflitar com a IO existente e resistir em adotar o conhecimento valorado dominante naquele ambiente (concepção da Transformação do Trabalho e do Indivíduo), e, nesse caso, os aspectos de poder já são inerentes à própria concepção.

Portanto, pode-se sugerir que também o mecanismo de poder permeia a valoração de conhecimentos circulantes na organização - seja por mecanismos sutis de identificação, seja por mecanismos de dominação e conflito declarados na disputa pela autoridade sobre o estabelecimento do conhecimento de valor. Os estudos que investigaram a relação entre o poder e o estabelecimento do conhecimento de relevância reiteram essas duas vertentes. Conforme já mencionado, Antonacopoulou (2006) e Harman (2012) identificaram aspectos de poder sobre o conhecimento, seu conteúdo e exercício, nas ações comuns do cotidiano organizacional, tais como nas ações de treinamento gerencial ou na aprendizagem diária no contexto do trabalho, que formatam o que o indivíduo deve "ser" no trabalho. Essa vertente traz o processo de poder sutil, inerente aos 
mecanismos de identificação e identidade, e relacionado às concepções da Aplicação no Trabalho, Consideração Trabalho-Indivíduo, Realização do Indivíduo no Trabalho.

Na segunda vertente, Oborn e Dawson (2010) e Heizmann (2011) sugerem que, a partir de identidade e identificação intergrupos, o processo de estabelecimento do conhecimento é contestado e conflituoso entre os grupos concorrentes, manifestando a hierarquia organizacional na aceitação do conhecimento imposto pelos grupos centrais e dominantes das organizações (matriz, alta gestão) e silenciando e constrangendo os conhecimentos propostos pelos grupos de menor força e hierarquia. É um processo de poder declarado e perceptível aos membros organizacionais, assim como o narrado na concepção da Transformação do Trabalho e do Indivíduo.

A autonomia no trabalho surgiu como um tema presente em todas as categorias e mencionado na narrativa de todos os entrevistados, quando perguntados sobre as condições que propiciam e impedem a valoração do conhecimento no contexto do trabalho. Esse tema, entretanto, não foi encontrado como relacionado à atribuição de importância ao conhecimento pelas percepções dos indivíduos em qualquer estudo anterior.

Em todas as concepções, com exceção feita à Consideração do TrabalhoIndivíduo, a autonomia no trabalho emergiu com uma condição fundamental para favorecer a valoração do conhecimento no trabalho. Para cada concepção, os sujeitos relacionam a autonomia no trabalho como pressuposto para o conhecimento de valor emergir, a saber:

- Aplicação no Trabalho: fazer o que é necessário para o trabalho dar resultado.

- Realização do Indivíduo no Trabalho: escolher o modo de ação adequado e necessário à questão emergente no trabalho.

- Transformação do Trabalho e do Indivíduo: possuir liberdade de tomar decisões.

- Criação Emergente para a Vida: propor e seguir novos meios ou objetivos no trabalho, adequados às situações e contextos organizacionais. 
Desse modo, os conceitos de autonomia no trabalho emergentes na pesquisa revelam a percepção de que o conhecimento considerado importante para os indivíduos apenas poderá surgir ou ser aplicado na organização a partir de um ambiente que crie condições onde a responsabilidade e os meios para a execução do trabalho estejam sob o controle do indivíduo.

Contudo, na concepção da Consideração do Trabalho-Indivíduo, a autonomia no trabalho aparece como uma barreira ao conhecimento de valor que considera e reconhece o trabalho do indivíduo, e deve ser tolhida pela liderança. $\mathrm{Na}$ percepção dos entrevistados, a autonomia dos demais indivíduos (pares, equipes, gestores) pode questionar, desconsiderar ou sobrepor aquele processo ou atividade que representa o conhecimento de valor implementado pelo sujeito, com autorização da liderança, reduzindo o seu valor, seu status e sua posição perante os demais membros.

\subsection{Nem Organizacional, Nem Individual: Proposição Teórica acerca do Conhecimento Valorado como uma Relação}

Após a análise das entrevistas e ao fim da classificação em cinco categorias descritivas, ao recontextualizar os sujeitos verificando as organizações relacionadas às suas experiências narradas, foi uma surpresa ver emergir e identificar que a cada conjunto de modelos organizacionais corresponde uma concepção de valoração do conhecimento própria. Quem desconhecesse o método e o trabalho empreendido pela pesquisadora poderia facilmente pressupor que a pesquisa buscou os modelos organizacionais e de gestão existentes e, a partir deles, analisou as concepções dos entrevistados naquele universo, e não o inverso. Ou seja:

- Aplicação no Trabalho: Estrutura hierarquizada; gestão centralizada na matriz; cultura, práticas e processos muito estruturados, rotinizados e fortemente disseminados. Foi caracterizada pelos entrevistados, especialmente, em empresas multinacionais.

- Consideração do Trabalho-Indivíduo: Estrutura tradicional hierarquizada; alto grau de centralização das decisões; baixo grau de estruturação e 
formalização das atividades. Foi caracterizada, principalmente, em empresas nacionais familiares de médio porte com presença do dono.

- Realização do Indivíduo no Trabalho: Estrutura achatada, orgânica, modelos participativos (times, projetos, equipes ad-hoc); alto grau de descentralização das decisões e autonomia; médio grau de estruturação e formalização das tarefas e processos. Foi caracterizada em empresas nacionais de grande porte com gestão profissional.

- Transformação do Trabalho e do Indivíduo: Estrutura tradicional hierarquizada; gestão burocrática; alto grau de centralização das decisões com baixíssimo grau de autonomia; alto grau de estruturação e formalização das atividades, mas dependente da hierarquia para seu cumprimento. Foi caracterizada em empresas privatizadas do setor público e empresas nacionais familiares de médio porte com presença do dono.

- Criação Emergente para a Vida: Estrutura achatada, orgânica, modelos participativos; gestão descentralizada com alto grau de autonomia e pouca hierarquia; alto grau de formalização das tarefas e processos existentes e situações $a d-h o c$ de baixa estruturação/ formalização das atividades. Foi caracterizada em empresas multinacionais e nacionais de grande porte com gestão profissional.

Daí emerge outro achado do estudo: o encaixe da concepção do indivíduo acerca da valoração do conhecimento ao tipo de organização onde esse sujeito está inserido, que foi descrito e narrado por ele mesmo, da forma como ele o percebe. De outro modo, pode-se reiterar a existência da inter-relação entre os atores - indivíduo e organização - na construção do modelo mental e padrão estruturante, relacionados ao conhecimento de valor, e do arranjo organizacional/coletivo que o comporta.

Retomando a construção social do fenômeno de acordo com Latour (2012), a interação entre os atores produz não apenas a concepção de valoração do conhecimento expressa pelo indivíduo por meio de suas narrativas, como também o arranjo organizacional/coletivo (para não utilizar as palavras estrutura e contexto) onde ela se insere. Constrói, também, o próprio indivíduo completo e competente para atuar, trabalhar, desempenhar nesse coletivo (LATOUR, 2012). Afinal, os entrevistados procuram expressar e justificar em suas narrativas o 
cenário completo: desde o conhecimento valorado por ele, o qual se alinha ou não ao conhecimento de valor para a organização, as justificativas para tal encaixe ou não, resultando na figura profissional competente no ambiente organizacional onde se inserem.

Elkjaer (2003), no enfoque da aprendizagem social pragmática, ratifica a inseparabilidade entre os indivíduos e o social, os contextos e/ou as organizações onde atuam: os indivíduos são e tornam-se aquilo que vivem e experimentam. Os indivíduos, o social e a organização/contexto se constituem mutuamente, tanto como seres humanos quanto como conhecedores (ELKJAER, 2003). Desse modo, os indivíduos e organização, juntamente, constroem o mundo e as regras de se viver, de valorar, de ser e de se comportar nele - de modo competente.

Assim, sugere-se que:

Proposição 5: Para cada arranjo organizacional (tipos estruturais de organização e modelos de gestão) corresponde uma concepção dominante de valoração do conhecimento, uma vez que a construção relacional resultante das interações entre os atores daquele coletivo produzem tanto a forma de conceber o arranjo organizacional como o conhecimento valorado nele.

Na proposição acima, foi utilizado o termo concepção dominante para a concepção associada ao modelo organizacional, uma vez que não se pode esquecer da existência de outras concepções convivendo no ambiente organizacional, conforme informado pelos participantes do grupo de foco. A coexistência das várias concepções na organização decorre dos vários agrupamentos/arranjos que se encontram inseridos nesse ambiente, produzindo suas concepções de organização e de conhecimento de valor associada.

Reitera-se também que os atores humanos possuam cognoscibilidade (LATOUR, 2012; ORLIKOWSKI, 2002) e, portanto, sejam conscientes e livres para atuar (LATOUR, 2012). Essa relação conforma o coletivo e, por consequência, qualquer mudança nas relações e conexões entre os atores pode alterar o coletivo, suas crenças e o seu mundo.

Em face do exposto, é sugerido que o conhecimento nas organizações não seja apenas um fenômeno individual que gera impacto na esfera organizacional, nem seja apenas um fenômeno organizacional que gera impacto na esfera 
individual. E, de acordo com Elkjaer (2003), tampouco sejam tratados como dois fenômenos separados, isolados. Reforça-se, com base em Latour (2012), que o conhecimento valorado nas organizações seja um fenômeno construído na relação entre os atores indivíduo-organização, ou seja, nas conexões entre os atores humanos e não humanos durante a produção daquele coletivo. Desse modo, o conhecimento individual e o conhecimento organizacional são uma produção única, baseada em percepções do que é importante valorar para aquele arranjo e possui validade provisória enquanto durar as interações e conexões do agrupamento que o produziu.

\subsection{Os Impactos da Valoração do Conhecimento nas Práticas Organizacionais}

Com base nas narrativas dos sujeitos, explorou-se o impacto da concepção do conhecimento valorado pelo indivíduo na utilização desse conhecimento de valor nas rotinas da organização. Desse modo, retomando a aplicação do conhecimento valorado nas práticas e rotinas organizacionais em cada categoria, foram encontrados os seguintes aspectos:

- Aplicação no Trabalho: Dados os processos muito estruturados e rotinizados pela própria organização, e que regulam tanto a organização como a concepção do conhecimento técnico aplicado para obter resultado, a incorporação do conhecimento individual no conhecimento organizacional (nas práticas e rotinas) é muito limitada; é utilitária; com objetivo adaptativo ao contexto existente. Propõe-se que os indivíduos reproduzem continuamente a organização, de forma mimética, sem questionamentos de seus modos de fazer as atividades.

- Consideração do Trabalho-Indivíduo: Considerando-se a busca de alinhamento reflexivo do sujeito para com a organização, o conhecimento técnico e as experiências práticas do indivíduo estão a serviço da criação das rotinas organizacionais (aprovadas pelo líder ou alta gestão), que geram controles para avaliar o desempenho no trabalho e recompensar os demais funcionários. Além disso, a rotina organizacional cria/assegura a posição social, de status e o 
reconhecimento do sujeito. Pode-se sugerir que a incorporação do conhecimento individual no conhecimento organizacional ocorre mediado e controlado pela liderança ou alta gestão.

- Realização do Indivíduo no Trabalho: As rotinas organizacionais são a consequência do trabalho. São constituídas a partir da prática, sendo depois formalizadas e institucionalizadas na organização e sofrem alterações a partir de nova necessidade identificada no desempenhar da atividade. Desse modo, as rotinas são criadas do modo como as coisas são feitas, considerando as regras implícitas da cultura. As rotinas objetivam mais o registro para conservação e disseminação de uma prática já comprovada, resultado de algo conhecido e valorado pelos indivíduos coletivamente Sugere-se que a incorporação do conhecimento individual no conhecimento organizacional por meio das práticas e rotinas é um processo fluido e retroalimentado.

- Transformação do Trabalho e do Indivíduo: Considerando-se a ambiguidade e o conflito - decorrentes do alto grau de estruturação e formalização das atividades e a dependência da hierarquia para seu cumprimento (ou não), ambos internalizados na cultura organizacional a forma de trabalhar já existe, já é dada. A flexibilidade nas práticas e rotinas só ocorre por determinação de quem possui poder ou pela posição avalizada pelo cargo, mas não necessariamente para aprimorar a rotina, e sim para atender à demanda específica de alguém com autoridade para tal. Sugere-se que a contribuição do conhecimento individual ao conhecimento organizacional é muito baixa, a menos que seja requisito da função/cargo ou advenha de uma demanda do líder, o que gera muita frustração e questionamento por parte dos sujeitos.

- Criação Emergente para a Vida: Dada a situação ad-hoc de baixa estruturação das atividades, há espaço para experimentação e erro. Contudo, as experiências, generativas de novas práticas, mesmo sendo bem sucedidas, têm dificuldade de serem traduzidas em rotinas organizacionais, implicando em que a incorporação do conhecimento individual no conhecimento organizacional é muito pequena. Sugere-se que a baixa capacidade da organização de integrar novas práticas, nos processos organizacionais estabelecidos, por meio dos indivíduos e 
gestores, que ameaçam o modus operandi da organização, advém da dificuldade das organizações em extrair aprendizado a partir de novas formas de fazer processos convencionais em função do foco e pressão em resultados de curto prazo, falta de visão de longo prazo e medo de assumir riscos.

Observa-se que, em cada concepção, a aplicação nas rotinas e práticas de trabalho do que é o conhecimento de valor assume diferentes gradações: desde quase inexistente ou muito baixa, na Aplicação no Trabalho, até muito fluida, na Realização do Indivíduo no Trabalho, passando por controle explicitamente mediado pela liderança e alta gestão nas demais concepções. Porém, ressalva-se, implicitamente determinado pelos padrões estruturantes em todos os casos.

A Realização do Indivíduo no Trabalho foi a única categoria onde a contribuição individual e coletiva do conhecimento emergente da prática e da ação gerou os processos e atividades em si da organização, que foram incorporados consistentemente nas rotinas organizacionais. Já a Criação Emergente para a Vida, foi a concepção em que se encontrou a contribuição do conhecimento individual de forma emergente da ação para as atividades organizacionais com conteúdo inovador e instigando a quebra de paradigmas. Entretanto, foram experiências únicas, onde pouco do que foi experimentado e aprendido pelo indivíduo e o coletivo se incorporou nas rotinas da organização, demonstrando pouca capacidade do modelo e das práticas organizacionais em absorver e aprender com a experiência.

Ressalta-se que nas categorias da Aplicação no Trabalho, Consideração Trabalho-Indivíduo e Transformação do Trabalho e do Indivíduo há contribuições às práticas organizacionais, mas essas se resumem a traduzir ou introduzir rotinas e práticas que mantêm a forma como a organização já trabalha, a gerar novos ou mais controles e modos de desempenho, a responder às demandas já definidas ou autorizadas pela alta gestão. As rotinas respondem mais às necessidades da organização, e não dos indivíduos e do uso de seus conhecimentos no trabalho.

Conforme discutido, a construção social que produz o coletivo onde o indivíduo está imerso, o conhecimento valorado e as regras de viver nesse coletivo, adicionados à identificação com a identidade organizacional e aspectos de poder, contribuem para moldar as relações de troca e de incorporação do 
conhecimento de valor na interação individual-organizacional, de acordo com determinados padrões estruturantes inerentes ao arranjo.

Portanto - se é que é possível observar o fenômeno do conhecimento individual-organizacional de modo fragmentado e separável - de uma forma geral, pode-se inferir que a contribuição do conhecimento individual e coletivo (construído na ação compartilhada) ao conhecimento organizacional por meio da incorporação nas rotinas organizacionais demonstra ser muito limitada em seu conteúdo e controlada em escopo. Em todas as concepções, pouco do conhecimento do indivíduo ou do coletivo contribui para modificar, criar ou compor algo que contribua de modo novo, instigante ou desafiante ao conhecimento já existente. Isso não quer dizer que contribuições menores não ocorram ou deixem de ser aceitas, mas sugere-se que contribuições significativas do ponto de vista da percepção de valor por parte dos indivíduos, e que geram impacto na prática organizacional, repensam a organização e sua forma de trabalhar, são difíceis de ocorrer.

O estudo sugere que mudanças significativas nas práticas e rotinas organizacionais parecem continuamente advir da alta gestão e liderança, principais atores mediadores da organização, que autorizam, patrocinam, demandam ou permitem alterações e/ou inclusões de práticas e rotinas na vida organizacional - com alguma exceção feita à concepção da Realização do Indivíduo no Trabalho, onde há uma construção compartilhada, pressupondo certa liberdade e autonomia de ação dentro de parâmetros preestabelecidos, porém mais amplos.

Assim, sob um olhar mais abrangente, o que foi identificado no estudo revela que, normalmente, o conhecimento organizacional (por meio das rotinas, práticas, modo de fazer as coisas, cultura organizacional, planejamento, liderança e alta gestão, entre outros) estabelece o conhecimento individual, formatando o que o indivíduo e o coletivo devem conhecer e valorar (o que será aproveitado e valorado naquele contexto), e como conceber isso em cada contexto/arranjo organizacional.

Em todos os casos, independente da categoria, essa relação entre organização e indivíduo ensina como o indivíduo deve ser ou se tornar no ambiente de trabalho (ANTONACOPOULOU, 2006; ELKJAER, 2003), a fim de permanecer na organização: seja aplicando seus conhecimentos para o resultado 
da organização; seja utilizando seus conhecimentos para organizar controles e procedimentos da organização; seja compartilhando seu conhecimento para criar os processos e a organização em si; seja conflitando seus conhecimentos com a organização, porque ela não deseja transformar-se; seja experimentando e conhecendo novos processos quando demandado e só quando demandado.

\subsection{Uma Reflexão Final: E Quanto ao Conhecimento Valorado?}

E, finalmente, quanto ao conhecimento de valor no contexto do trabalho? Sandberg (2000) descobriu, com relação às competências dos indivíduos no trabalho, que para a Volvo desenvolver as competências de seus engenheiros de motores, a companhia 'simplesmente' deveria mudar a concepção (hierarquia acima no espaço de resultado) do indivíduo com relação ao que é ser um engenheiro de motores competente. No presente estudo, se a organização deseja que os indivíduos valorem determinados conhecimentos e adotem comportamentos relacionados, bastaria a ela mudar a concepção dos indivíduos acerca do que é conhecimento de valor no contexto do trabalho?

- Da mera aplicação de conhecimento formal no trabalho com base em rotinas definidas;

- à utilização de conhecimento, formal e da experiência prática, para identificar processos e controles mais adequados;

- ao compartilhamento do conhecimento de diversas naturezas, situados nos indivíduos no desempenho do trabalho, para criar os processos e atividades que vão moldar a organização e seu modo de trabalhar;

- à aplicação do conhecimento para transformar o trabalho em compartilhamento;

- à geração de experimentos que façam o indivíduo, coletivo e organização aprenderem conjuntamente e quebrarem paradigmas.

Realizar essa mudança de concepção, entretanto, não é nada simples quando se trata de conhecimento, porque pressupõe a mudança da própria organização e, por extensão, do seu arranjo e seu coletivo. Talvez esse aspecto explique porque tantos estudos exploram a inter-relação entre conhecimento e mudança organizacional (COLMAN e LUNNAN, 2011; HEUSINKVELD e BENDERS, 
2005; INKPEN, 2008; MENON e PFEFFER, 2003; MULLER-SEITZ e GÜTTEL, 2012; NAG et al., 2007; OBORN e DAWSON, 2010; RAVISHANKAR e PAN, 2008; RENZL, 2008; STURDY et al., 2009).

O conhecimento não é apenas algo que os indivíduos trazem para ou fazem no trabalho: é algo que fala a respeito de quem eles são enquanto pessoas e profissionais (ELKJAER, 2003; LATOUR, 1012). O conhecimento individual-organizacional é fruto das interações que constroem a organização e a fazem ser, conhecer e valorar o que são. Nos tópicos precedentes foram vistas as influências dos mecanismos de identificação com a IO, construção da identidade e poder permeando essa construção social. Mudar uma concepção acerca do conhecimento valorado significa modificar as relações e os contextos já estabelecidos em padrões estruturantes daquele arranjo; portanto a grande dificuldade decorrente de modificar a concepção de conhecimento existente em uma organização.

Além disso, com relação ao conhecimento valorado e o indivíduo, há uma relação intrincada: o indivíduo, para tornar-se um ator competente e um ser humano completo, tende a ser o que o coletivo onde está imerso é - participar do arranjo que produz a organização e as regras de viver nela - com o objetivo de nele permanecer. Assim, o indivíduo tende a valorar o que a organização valora, seja por construção social, seja por mecanismos de identificação e poder, já discutidos anteriormente. Imerso no coletivo, o indivíduo é o que conhece. E com base no que conhece, o indivíduo contribui para a organização. Nesse inesgotável círculo vicioso, quem apresentará conhecimento de real valor para a organização? Quem questionará os fundamentos dos conhecimentos existentes, incorporados em práticas e rotinas, os objetivos, a direção da organização - e não somente o modo como ela conduz suas atividades e práticas? Como o arranjo coletivo pode dar ouvido a vozes que falam palavras destoantes, arriscadas, de resultado duvidoso?

Antecipando aspectos da conclusão, os resultados e questionamentos advindos do presente estudo não significam que a pesquisa não tenha apontado caminhos para uma construção de conhecimento que use do pleno potencial e da capacidade humana e coletiva. Ao contrário, o modelo participativo (por times, projetos, equipes ad-hoc) em estruturas achatadas e flexíveis, com alto grau de 
descentralização das decisões e autonomia, e utilização performativa das tarefas e processos, surgem como elementos de um arranjo propício à disseminação de conhecimento compartilhado, distribuído e emergente, produzindo indivíduos com alto grau de envolvimento nas atividades que constroem a própria organização. Ainda que a Realização do Indivíduo no Trabalho não questione paradigmas ou caminhos da organização, o modelo que permeia o arranjo dessa concepção é inclusivo do indivíduo com uso de suas potencialidades.

Ademais, é na abertura e autonomia para a quebra de paradigmas, apontadas nas experiências únicas e situações $a d-h o c$ não estruturadas da concepção da Criação Emergente para a Vida, que são permitidos a experimentação, o erro e a aprendizagem para além do conhecimento compartilhado existente. Esse arranjo, mesmo que momentâneo, provisório, específico e situado, é aquele capaz de gerar criação e inovação, fazendo uso de outras competências e habilidades dos indivíduos para além do conhecimento formal, experimentado, vivenciado e social. Trata-se do arranjo mais favoravelmente relacionado à absorção dos conhecimentos dos indivíduos em sua forma mais plena. 


\section{8 \\ Conclusão, Recomendações e Sugestões para Futuras Pesquisas}

Retomando o percurso realizado para o desenvolvimento do presente estudo, o objetivo final foi apresentar proposições teóricas acerca dos diferentes modos pelos quais os membros organizacionais percebem e experimentam a valoração do conhecimento no contexto do trabalho e seus impactos nas práticas organizacionais. No caminho para esse fim, buscou-se identificar o que é conhecimento no contexto do trabalho para os indivíduos e os diferentes modos pelos quais eles percebem e experimentam a valoração do conhecimento no contexto do trabalho, bem como analisar as respectivas significações atribuídas às distintas experiências de valoração do conhecimento e os impactos na incorporação, utilização e compartilhamento do conhecimento, pelos membros, nas práticas organizacionais, em decorrência das percepções e significações atribuídas ao conhecimento valorado.

O Método Fenomenográfico (MARTON, 1981; MARTON e BOOTH, 1997; SANDBERG, 2001) foi a escolha metodológica para esse intento, cuja busca pela variedade nos modos de conceber o fenômeno propiciou a descoberta de cinco concepções relativas ao fenômeno de valoração do conhecimento nas organizações, a saber: Aplicação no Trabalho, Consideração do TrabalhoIndivíduo, Realização do Indivíduo no Trabalho, Transformação do Trabalho e do Indivíduo, Criação Emergente para a Vida. Essas categorias são o resultado das 22 entrevistas em profundidade conduzidas com profissionais da área de Recursos Humanos, em 22 empresas de 18 setores, desde o cargo de analista a diretor para a América Latina, com experiências de trabalho variando entre 3 a 36 anos, e formação acadêmica diversa.

As concepções compuseram um caminho continuum e fluido (bidirecional e transitório) no mapa do espaço de resultado, demonstrando ser utilizadas pelos indivíduos de modo muito mais dinâmico e ativo do que o abordado no próprio método. Assim, duas proposições teóricas foram expostas, no sentido de explorar 
novas possibilidades de análise relacionadas ao método Fenomenográfico e o presente fenômeno.

A Fenomenografia permitiu revelar a construção social acerca da valoração do conhecimento diante dos olhos do pesquisador, por meio das narrativas das vivências acessadas pelos entrevistados, enquanto a Sociologia da Associação, Tradução, Translação ou das Ciências (LATOUR, 2012), inserida no próprio enfoque do conhecer (knowing) na prática e na ação (GHERARDI, 2002; 2006; ORLIKOWSKI, 2000; PATRIOTTA, 2003a), comportou a dimensão explicativa. As práticas organizacionais foram abordadas pela perspectiva das rotinas inseridas na ação (FELDMAN e ORLIKOWSKI, 2011; FELDMAN e PENTLAND, 2003; PARMIGIANI e HOWARD-GRENVILLE, 2011). Foram três os principais achados que o estudo traz com relação a esse aspecto.

Primeiro: as diferentes dimensões de interação social exercem distintas influências sobre as várias concepções acerca da valoração do conhecimento, em função da consciência focal do indivíduo e da consequente importância atribuída pelos sujeitos a estes níveis/grupos para a construção social do fenômeno. Em decorrência, determinados grupos, notadamente a organização e seus mediadores imediatos, exercem mais influência do que outros atores no processo de valoração de conhecimento do indivíduo.

Segundo: a identificação com a identidade organizacional (ASHFORTH et al., 2008; CORLEY et al., 2006) emerge como um mecanismo pelo qual os indivíduos expressam o alinhamento entre a sua concepção de conhecimento de valor e o conhecimento valorado pela organização. Como implicação, também se identificou mecanismos de poder sutis (ANTONACOPOULOU, 2006; HARMAN, 2012) e explícitos (OBORN e DAWSON, 2010; HEIZMANN, 2011).

Terceiro: a cada arranjo organizacional, onde concorrem tipos estruturais de organização e modelos de gestão, corresponde uma concepção dominante de valoração do conhecimento, uma vez que a construção relacional resultante das interações entre os atores daquele coletivo produzem tanto a forma de conceber o arranjo organizacional como o conhecimento valorado nele; constrói tanto o indivíduo competente para aquele arranjo quanto as regras de viver nele.

Adicionalmente, encontrou-se que o fenômeno do conhecimento nas organizações é relacional entre indivíduos, pares e grupos, liderança, alta gestão e organização, tratando-se de um fenômeno único e inseparável entre conhecimento 
individual-organizacional (ELKJAER, 2003; LATOUR, 2012). Também foi revelado que, aparte da existência de uma concepção dominante, várias outras concepções coexistem no mesmo espaço organizacional em função dos diferentes arranjos coletivos que o compõe. Quanto à incorporação do conhecimento valorado pelos indivíduos nas práticas organizacionais, descobriu-se que a absorção por parte da organização é restrita e limitada. Sugere-se que há mediação por parte da alta gestão/liderança, sendo o conteúdo do conhecimento controlado por meio dos padrões estruturantes. Expôs-se, também, a dificuldade das organizações em aprender com questionamentos de seu paradigma e em experimentar novos modos de fazer suas atividades, em função do risco a ser assumido.

Conforme já antecipado no tópico 7.5. do capítulo anterior, a pesquisa aponta alguns caminhos na direção da construção do conhecimento de modo mais inclusivo do ser humano, pleno em suas potencialidades, no contexto organizacional. Por meio da percepção dos indivíduos, descobriu-se que os modelos participativos, com estruturas flexíveis, alto grau de descentralização das decisões com autonomia e utilização performativa das tarefas e processos configuram-se nos elementos essenciais para um arranjo apropriado à disseminação de conhecimento compartilhado, distribuído e emergente, produzindo indivíduos com alto grau de envolvimento nas atividades, que se percebem construindo a própria organização. As concepções da Realização do Indivíduo no Trabalho e a Criação Emergente para a Vida (nas situações únicas e $a d-h o c)$ trazem os aspectos que exemplificam esse modelo, no qual os sujeitos expressaram a maior contribuição dos seus conhecimentos com a realização do trabalho, e onde o trabalho ganha maior sentido e significado para esses sujeitos.

Entretanto, por outro lado, o estudo encontrou que o conhecimento valorado no contexto do trabalho demonstra ser principalmente autorreferencial e autorreproduzido nas organizações - com alguma exceção à concepção da Criação Emergente para a Vida. O conhecimento valorado trata-se do resultado da produção de um determinado coletivo, onde mais do que utilizar o potencial do indivíduo no trabalho, cria as regras do modo de ser reconhecido como humano competente, com os conhecimentos de valor, naquele arranjo coletivo. 
De modo mais amplo, o estudo reitera, que o modelo de conhecimento ainda preponderantemente utilizado no padrão estruturante das organizações segue a tradicional visão de que o conhecimento decorre da utilização de dados transformados em informação, acumulados ao longo do tempo de experiência e vivência da organização e do indivíduo, em que aprendizagem é o processo viabilizador (em maior ou menor grau entre as concepções). A finalidade última, independente da concepção e com as ressalvas já feitas à Criação Emergente para a Vida, é atender aos resultados e metas de curto prazo da organização, em que os interesses dos sócios e acionistas se sobrepõe aos demais. Conforme já discutido, trata-se de uma visão introvertida e autorreferencial, em que o modelo não expande o conhecimento de valor nem o que a organização-indivíduo já conhece. A dimensão do conhecimento é tradicional, insistindo na separação entre processo e resultado, entre aprendizagem e conhecimento. A figura 12 procura representar essa visão tradicional.

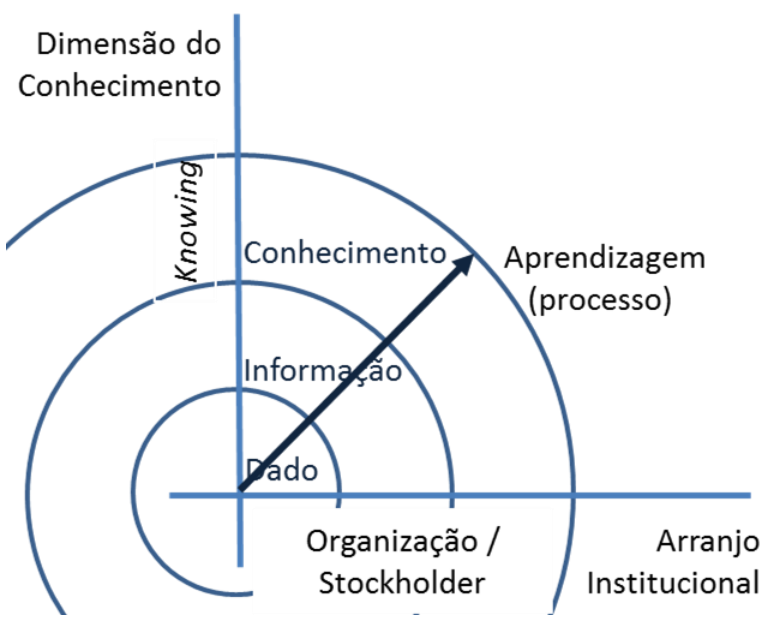

Figura 12: Modelo de Conhecimento nas Organizações - Visão Tradicional (modelado pela autora)

Não coincidentemente, o conceito do modelo não difere significativamente dos diversos modelos de gestão propagados nas organizações, como a gestão do conhecimento, a gestão de projetos (PMBOK®; PRINCE®), a gestão dos dados e informações (DMBOK®), governança e gestão corporativa de tecnologia da informação e comunicação (COBIT®; ITIL®) e mesmo a gestão da inovação e a gestão por processos $(\mathrm{CBOK} \AA)$, entre outros. São exemplos de tecnologias empresariais que fazem parte do padrão estruturante inseridos nos arranjos organizacionais. Alguns desses modelos mencionados sequer consideram os 
stakeholders, outros partem do foco interno do que a organização já possui. Tratam o conhecimento como objeto, um ativo ou um viabilizador para a entrega de valor, remetendo às perspectivas econômica (GHERARDI, 2000; 2006) e estrutural (PATRIOTTA, 2003a; 2003b), ou ao enfoque do conhecimento como antecedente para o valor estratégico, discutidos e classificados nos capítulos 2 e 3 da presente tese.

Em função desse aspecto, questiona-se tanto como os indivíduos podem utilizar plenamente seu potencial quanto como as organizações desenvolverão novas ações, se não se deixam questionar e não instigam novas formas de pensar, fora dos padrões estruturantes. Parece que, juntamente com tantos termos que entram nas modas e modismos gerencias - tais como qualidade, ética, inovação, mudança, sustentabilidade - o conhecimento se tornou mais uma palavra bonita de mencionar, porém complexa e desgastada de aplicar nas organizações.

Configura-se que, simplesmente, é difícil, para as organizações, aprender e conhecer. Representa adotar uma nova lógica, em que o conhecimento não possui a certeza, a estabilidade, a perenidade e a aplicabilidade imediata, que as organizações tanto desejam. Envolve risco, incerteza, não antecipação, uma vida própria que foge à necessidade dos controles organizacionais. Por consequência, também é difícil para os indivíduos lidar com essa ambiguidade e o risco pessoal-profissional inerente. Mas essa dificuldade não se encontra no processo de aprendizagem nem no conteúdo de conhecimento, encontra-se na ausência de sabedoria de aproveitá-los.

Propõe-se que, talvez, a palavra conhecimento deva ser expandida, levada a outro nível. Não falta conhecimento nas organizações. Pelo menos, não falta o conhecimento que mantém as estruturas, as rotinas, os arranjos, as coisas, as pessoas e o social como estão, em torno de padrões estruturantes. Falta, sim, sabedoria. Falta sabedoria do que fazer com o conhecimento individual-organizacional, de como deixá-lo livre a partir das iniciativas e das potencialidades humanas, de como deixá-lo fluir e de como usá-lo para dar direção às organizações em um espectro mais amplo, mais abrangente. Falta sabedoria para perguntar: Por que fazemos o que fazemos? Por que fazemos como fazemos? Podemos fazer diferente? O que fazemos tem futuro? O que fazemos é ético e responsável? Como fazemos é sustentável? Como fazemos expande valor para o social onde estamos inseridos? Como poderíamos fazer melhor? Falta 
sabedoria e humildade para o coletivo organizacional contestar a sua autorreprodução, na sua visão egocêntrica.

Latour (2012) sugere que tudo que ilumina o conhecimento vem do exterior, justamente porque introduz novas formas de olhar o já conhecido. Outra resposta no mesmo caminho, também tratando dessa visão exterior que estranha o modo já constituído das organizações, é apontada pelos estudos organizacionais que exploram a sabedoria nas organizações (wisdom in organizations). Só algo vindo de fora do arranjo coletivo autoproduzido e autorreproduzido pode trazer sabedoria ao conhecimento vigente.

Os estudos em sabedoria nas organizações (ACKTOFF, 1989; NEAL, 2013; ROONEY e MCKENNA, 2007) procuram avançar para além da dimensão da racionalidade instrumental-funcionalista, indo para as dimensões da lógica não racional, subjetiva/substantiva e dos valores da experiência humana; da ética e dos resultados virtuosos; das emoções e sentimentos; e da espiritualidade. A sabedoria nas organizações parece ser um campo que busca conjugar o alinhamento entre indivíduos e organizações - entre indivíduos e stakeholders dessas organizações onde ambos desejariam ter uma nova concepção de Criação Emergente para Ambas as Vidas.

Esse caminho, portanto, parece fazer subverter a lógica até aqui existente, que se inicia da acumulação de informação, já disponível, para a geração de conhecimento de valor. O sentido unidirecional, do dado ao conhecimento, nunca será o sentido para atingir sabedoria. A sabedoria, mais ampla, é a força que questiona as perguntas corretas; aquelas darão direção ao conhecimento de valor em constante expansão para a busca de dados ou informação necessária. Como um paradigma de pensamento, a sabedoria nas organizações procura ampliar o valor do conhecimento para indivíduos e organizações.

Desse modo, dando um passo além, o presente estudo não deseja se furtar de apresentar uma proposta (mesmo que tentativa) que abraça essa visão. A figura 13 procura redesenhar o modelo tradicional de conhecimento nas organizações sob a lógica da sabedoria nas organizações. Para tanto, toda uma nova camada precisaria ser inserida entre o conhecimento e a sabedoria, a qual foi intitulada consciência: consciência da relevância da melhoria contínua da mudança organizacional em sintonia com a evolução organizacional de seus stakeholders. Acktoff (1989) denominou-a de compreensão (understanding). 
Nessa camada, se inseririam os principais propulsores da vida organizacional, como as novas ideias, os novos conceitos, as propostas de pesquisas, as propostas de inovação, os novos produtos e serviços, a nova arquitetura organizacional. Nela, os indivíduos deveriam ser instados a questionar a si mesmos, a questionar a própria organização, a abrigar as expectativas e o movimento fomentado pelos processos de demanda dos stakeholders (e seus indivíduos), a assumir um maior escopo e abrangência de riscos da mudança.

À medida que a organização se torna mais permeável e sensível às questões dos públicos e ambientes que a cercam, maior consciência e, consequentemente, maior sabedoria para direcionar suas práticas e maior orientação em torno de conhecimento de real valor. Longe de haver uma visão unidirecional, a sabedoria se assemelharia a um diálogo em torno do conhecer que expande valor.

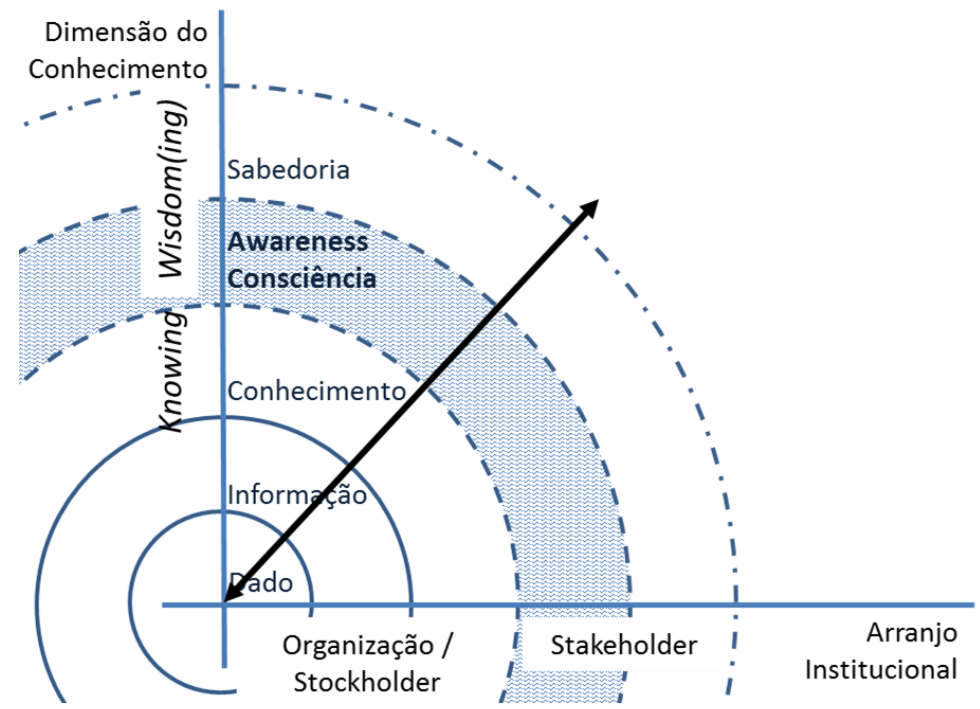

Figura 13: Modelo de Sabedoria nas Organizações (modelado pela autora)

Cabe ressaltar as limitações e as restrições existentes no estudo. A principal delas diz respeito à amostra intencional delimitada à área de Recursos Humanos. Os resultados encontrados acerca da valoração do conhecimento podem se conformar de modo diverso em outra área organizacional (por exemplo, área de Planejamento Estratégico, Marketing ou Financeira), uma vez que os profissionais possivelmente estarão imersos em outro padrão estruturante e inseridos em outra forma de arranjo coletivo, que podem gerar outras formas de produzir a realidade, atuar o trabalho, valorar o conhecimento e ser competente. Portanto, compete 
sempre lembrar o caráter situado, provisório e emergente da ação, em que se insere o olhar da presente pesquisa.

Especialmente a questão secundária, dos impactos nas práticas organizacionais, pode ganhar uma resposta diferente em função da área organizacional onde se está avaliando a percepção dos indivíduos acerca da valoração do conhecimento. Embora a área de Recursos Humanos, desde o fim dos anos 1990, procure ganhar uma dimensão estratégica alinhada ao negócio central das organizações, ainda se observa, em vários casos, uma posição de submissão e subordinação às áreas fins do negócio (representada, nesse trabalho, pelos pares, alta gestão e liderança), que não pode ser descartada do contexto do estudo.

Também é preciso consciência de que o Método Fenomenográfico acessa as narrativas dos sujeitos acerca da concepção do fenômeno/realidade (percepçãopensamento-ação), e outros métodos qualitativos naturalísticos são desenhados para observar mais adequadamente a experiência direta do sujeito com o fenômeno, tais como observação participante e método etnográfico, a fim de capturar a prática e ação situada do conhecer (knowing) no ato performativo de sua realização. Entretanto, ressalta-se a dificuldade de conduzir pesquisas dessa natureza no Brasil.

Aparte ao tema do conhecimento nas organizações, o estudo revelou questões que merecem ser exploradas em projetos futuros de pesquisa e dizem respeito a pontos que não puderam ser aprofundados adequadamente, ao estar além do escopo direto do presente trabalho.

A pesquisa empírica revelou que os sujeitos possuem diferentes conceitos quando se fala em rotinas organizacionais, envolvendo distintos aspectos de entendimento, fruto das experiências vividas. Deste modo, do estudo emergiram quatro conceituações distintas de rotina organizacional: rotina da conformidade; rotina da certeza; rotina tropicalizada; rotina da inovação. Descobriu-se que elas evocam diferentes formas de intervenção e comportamento dos indivíduos diante das atividades da organização, o quanto ordenam, controlam e mensuram a vida organizacional, ou o quanto os auxiliam na realização e atuação do trabalho.

As rotinas organizacionais em si, como tema de estudo, não foram profundamente tratadas neste trabalho, uma vez que o escopo secundário da questão dos impactos nas práticas organizacionais não permitiu maiores 
detalhamentos e inferências. Entende-se que explorar as diferentes concepções das rotinas organizacionais necessita de estudos próprios, com metodologias próprias que aprofundem na observação do modo de fazer o trabalho, estudem diretamente o desempenho dos sujeitos frente às rotinas, seus comportamentos e ações. Do presente estudo, entretanto, ainda emergem as questões acerca da dificuldade de transformar, traduzir e incorporar novos conhecimentos nas práticas da organização, mesmo com a visão relacional do conhecimento individualorganizacional. Talvez a maior questão centre-se em como ocorre a formação do padrão estruturante, construída na interação entre os atores, que permite ou impede as condições para introdução dos conhecimentos nas rotinas.

Aspecto similar foi encontrado com relação ao tema da liderança nas organizações. No estudo, ao se referirem à liderança, os entrevistados aludem também a uma diversidade de conceitos que pode remeter: ao líder da organização na figura do presidente ou CEO; ao grupo de gestores que ocupam a alta gestão da organização juntamente, ou não, com o presidente; à chefia imediata, que pode ser um gerente intermediário, um diretor ou outro; a uma entidade actante, abstrata, sem nome nem cargo, mas que desempenha um papel de ator e de mediador da organização, fazendo os sujeitos agirem em função dela.

A liderança emergiu como um dos temas mais mal definidos pelos sujeitos durante o estudo, uma miscelânea de significados que se modificavam no decorrer das narrativas, cabendo de tudo debaixo de seu nome, inclusive todas as justificativas para as ações. Parece ser muito apropriado um estudo Fenomenográfico a respeito do que a liderança representa e significa para os membros organizacionais, a influência e seu papel diante das ações dos sujeitos.

Como a presente pesquisa não se tratou de um estudo de caso, não foi possível analisar em qual medida o mecanismo de identidade individual e social (entre membros dos grupos da organização) afeta a percepção dos indivíduos acerca dos conhecimentos de valor no trabalho e interfere na identificação com a identidade organizacional. Dada a construção social do valor do conhecimento, pode-se apenas tirar ilações de que a identidade social também é um mecanismo presente, como já apontado em outros estudos indiretos. Maiores investigações acerca do tema devem ser tratadas em pesquisas futuras. As concepções da Consideração do Trabalho-Indivíduo e da Realização do Indivíduo no Trabalho abrem uma porta para as questões acerca da formação das identidades intragrupo e 
intergrupos no contexto do trabalho, da autocategorização identitária, e do reflexo de ambas na percepção e significação do conhecimento de valor.

Quanto à valoração do conhecimento da perspectiva do indivíduo enquanto uma linha de estudo na área de conhecimento organizacional, parece que esse trabalho cumpriu seu intento, ao fornecer um entendimento da percepção do fenômeno. O Método Fenomenográfico proveu uma plataforma que serve de ponto de partida para novas investigações, tais como: pesquisa Fenomenográfica comparada com profissionais de outras áreas; estudo de caso, com uso de Fenomenografia ou observação não participante, para analisar a dinâmica de coexistência das diversas concepções acerca da valoração do conhecimento em uma mesma organização; e, principalmente, estudos para o entendimento mais aprofundado das relações de interação indivíduo-organização para construção do conhecimento coletivo.

Por fim, cabe ampliar a linha de pesquisa do conhecer nas organizações, englobando uma dimensão maior de sabedoria, valores e espiritualidade nos estudos organizacionais, que iluminem e transformem as formas, modelos e paradigmas de pensamento dos atores - indivíduos e organizações. 


\section{9 \\ Referências Bibliográficas}

ABS. Academic Journal Quality Guide. v. 4., London: The Association of Business Schools, 2010.

ACKOFF, Russell L. The circular organization: an update. The Academy of Management Executive, v. 3, n. 1, p. 11-16, 1989.

AGTERBERG, Marlous et al. Keeping the wheels turning: The dynamics of managing networks of practice. Journal of Management Studies, v. 47, n. 1, p. 85$108,2010$.

AKERLIND, Gerlese S. Learning about phenomenography: interviewing, data analysis and the qualitative research paradigm. In: BOWDEN, John A.; GREEN, Pam. (Orgs.) Doing Developmental Phenomenography. Qualitative Research Methods Series, Melbourne: RMIT University Press, p. 63-73, $2005 \mathrm{a}$.

AKERLIND, Gerlese S. Phenomenographic methods: a case illustration. In: BOWDEN, John A.; GREEN, Pam. (Orgs.) Doing Developmental Phenomenography. Qualitative Research Methods Series, Melbourne: RMIT University Press, p. 103-127, 2005b.

AKERLIND, Gerlese S.; BOWDEN, John A.; GREEN, Pam. Learning to do phenomenography: a reflective discussion. In: BOWDEN, John A.; GREEN, Pam. (Orgs.) Doing Developmental Phenomenography. Qualitative Research Methods Series, Melbourne: RMIT University Press, p. 74-100, 2005.

ALVESSON, Matts. Knowledge work: ambiguity, image and identity. Human Relations, v. 54, n. 7, p. 863-886, 2001.

ANAND, N.; GARDNER, Heidi K.; MORRIS, Tim. Knowledge-based innovation: emergence and embedding of new practice areas in management consulting firms. Academy of Management Journal, v. 50, n. 2, p. 406-428, 2007.

ANTAL, Ariane B.; LENHARD, Uwe; ROSENBROCK, Rolf. Barrries to organizational learning. In DIERKES, Meinholf; CHILD, John; NONAKA, 
Ikujiro. (Orgs.). Handbook of organizational learning and knowledge. p. 865-885, Oxford University Press, 2001.

ANTONACOPOULOU, Elena P. The relationship between individual and organizational learning: New evidence from managerial learning practices. Management Learning, v. 37, n. 4, p. 455-473, 2006.

ANTUNES, Maria Thereza P.; MARTINS, Eliseu. Capital intelectual: Seu entendimento e seus impactos no desempenho de grandes empresas brasileiras. $B A S E$, v. 4, n. 1, p. 5-21, 2007.

ARAUJO, Luis. Knowing and learning as networking. Management Learning, v. 29, n. 3, p. 317-336, 1998.

ARGOTE, Linda; EPPLE, Dennis. Learning curves in manufacturing. Organization Science, v. 23 920-924, 1990.

ARGOTE, Linda; REN, Yuging Transactive memory systems: A micro foundation of dynamic capabilities. Journal of Management Studies, v. 49, n. 8, p. 1375-1382, 2012.

ARGYRIS, Chris; SCHÖN, Donald. Theory in practice: Increasing professional effectiveness. Oxford: Jossey-Bass, 1974. 224 pp

ARGYRIS, Chris; SCHÖN, Donald. Organizational learning: a theory of action perspective. Reading, Massachusetts: Addison-Wesley, 1978. 344 p.

ASHFORTH, Blake E.; HARRISON, Spencer H.; CORLEY, Kevin G. Identification in Organizations: an examination of four fundamental questions. Journal of Management, v. 34, n. 3, p. 325-374, 2008.

BARNACLE, Robyn. Interpreting interpretation: a phenomenological perspective on phenomenography. In: BOWDEN, John A.; GREEN, Pam. (Orgs.) Doing Developmental Phenomenography. Qualitative Research Methods Series, Melbourne: RMIT University Press, p. 47-62, 2005.

BARNEY, Jay B. Firm resources and sustained competitive advantage. Journal of Management, v.17, n.1, p. 99-120, 1991.

BARNEY, Jay B. Gaining and sustaining competitive advantage. Mass: AddisonWesley Pub. Co., 1996. 
BETTIS, Richard A.; PRAHALAD, Coimbatore K. The dominant logic: Retrospective and extension. Strategic Management Journal, v. 16, p. 5-14, 1995.

BETTIS, Richard A.; WONG, Sze-Sze. Dominant logic, knowledge creation, and managerial choice. In EASTERBY-SMITH, Mark; LYLES, Marjorie (Orgs.). The Blackwell handbook of organizational learning and knowledge management. p. 343-355, Blackwell Publishing. 2003.

BLACKLER, Frank. Knowledge, knowledge work and organizations: An overview and interpretation. Organization Studies, v. 16, n. 6, p. 1021-1046, 1995.

BLACKLER, Frank; CRUMP, Norman; MCDONALD, Seonaidh Organizing processes in complex activity networks. Organization, v. 7, n. 2, p. 277-300, 2000.

BOLAND, Richard J.; TENKASI, Ramkrishnan V. Perspective making and perspective taking in communities of knowing. Organization Science, v. 6, n. 4, p. 350-372, 1995.

BONTIS, Nick. Intellectual capital: an exploratory study that develops measures and models. Management Decision, v. 36, n.2, p. 63-76, 1998.

BONTIS, Nick. Assessing knowledge assets: a review of the models used o measure intellectual capital. International Journal of Management Reviews, v. 3, n. 1, p. 41-60, 2001.

BONTIS, Nick et al. The knowledge toolbox: a review of the tools available to measure and manage intangible resources, European Management Journal, v. 17, n. 4, p. 391-402 2002.

BONTIS, Nick; FITZ-ENZ, Jac. Intellectual capital ROI: a causal map of human capital antecedents and consequents. Journal of Intellectual Capital, v. 3, n. 3, p. $223-247,2002$.

BOONE, Tonya, GANESHAM, R.am; HICKS, Robert L. Learning and knowledge depreciation in professional services, Management Science, v. 54, n. 7, p. 1231-1236, 2008

BOURDIEU, Pierre. Outline of a theory of practice. Cambridge: Cambridge University Press, 1977. 
BOWDEN, John A. Reflections on the phenomenographic team research process. In: BOWDEN, John A; GREEN, Pam. (Orgs.) Doing developmental phenomenography. Qualitative Research Methods Series, Melbourne: RMIT University Press, p. 11-31, 2005.

BOWDEN, John A; GREEN, Pam. Doing developmental phenomenography. Qualitative Research Methods Series, Melbourne: RMIT University Press, 2005. BOWDEN, John A.; WALSH, Eleanor. Phenomenography. Qualitative Research Methods Series, Melbourne: RMIT University Press, 2000.

BROWN, Andrew D.; STARKEY, Ken. Organizational identity and learning: A psychodynamic perspective. Academy of Management Review, v. 25, n. 1, p. 102$120,2000$.

BROWN, John S.; DUGUID, Paul. Organizational learning and communities-ofpractice: Toward a unified view of working, learning, and innovation. Organization Science, v. 2, n. 1, p. 40-57, 1991.

BROWN, John S.; DUGUID, Paul. Organizing knowledge. California Management Review. v. 40, n. 3, p. 90-111, 1998.

BROWN, John S.; DUGUID, Paul. Knowledge and organization: A socialpractice perspective. Organization Science, v. 12, n. 2, p. 198-213, 2001.

BRUCE, Christine S. Workplace experiences of information literacy. International Journal of Information Management, v. 19, p. 33-47, 1999.

BRYANT, Antony; CHARMAZ, Kathy. (Orgs.). The Sage handbook of grounded theory. Thousand Oaks: Sage Publications, 2007.

CALLON, Michael. The state and technical innovation: A case study of the electrical vehicle in France. Research Policy. v. 9, p. 358-376, 1980.

CALLON, Michael. Techno-economic network and the irreversibility. In: LATOUR, Bruno. A sociology of monsters: Essays on power, technology and domination, p. 132-161, 1991.

CALLON, Michael. Actor-network theory: The market test. In: LAW, John; HASSARD, John. (Orgs). Actor Network Theory and After. Oxford: Blackwell Publishers, p. 181-195, 1999. 
CARLILE, Paul R. A pragmatic view of knowledge and boundaries: boundary objects in new product development. Organization Science, v. 13, n. 4, p. 442 $455,2002$.

CARLILE, Paul R. Transferring, translating, and transforming: an integrative framework for managing knowledge across boundaries. Organization Science, v. 15, n. 5, p. 555-568, 2004.

CHARMAZ, Kathy. Constructing grounded theory: a practical guide through qualitative analysis. Thousand Oaks: Sage Publications, 2006.

CHEN, Ping; PARTINGTON, David. An interpretive comparison of Chinese and western conceptions of relationships in construction project management work. International Journal of Project Management, v. 22, p. 397-406, 2004.

CHEN, Ping; PARTINGTON, David. Three conceptual levels of construction project management work. International Journal of Project Management, v. 24, p. 412-421, 2006.

CHEN, Ping; PARTINGTON, D.; QIANG, M. Cross-cultural understanding of construction project managers' conceptions of their work. Journal of Construction Engineering and Management, p. 1-12, 2009.

CHEN, Ping; PARTINGTON, David.; WANG, Jia N. Conceptual determinants of construction project management competence: A Chinese perspective. International Journal of Project Management, v. 26, n. 6, p. 655-664, 2008.

CHERMAN, Andrea; MACEDO-SOARES, Teresia D.V.A. Knowledge transfer within the organization: investigating the international literature. $37^{\text {th }}$ EIBA Annual Conference Proceedings, European International Business Academy, Bucharest, December, 2011.

CHERMAN, Andrea; ROCHA-PINTO, Sandra R. Valoração do conhecimento nas organizações: significação e identidade na ação organizacional. RAE Revista de Administração de Empresas, v. 53, n. 2, mar /abr., p. 142-155, 2013.

CIBORRA, Claudio U.; LANZARA, Giovan F. Formative contexts and information technology: understanding the dynamics of innovation in organizations. Accounting, Management \& Information Technology, v. 4, n. 2, p. 61-86, 1994. 
COHEN, Michael D. et al. Routines and other recurring action patterns of organizations: Contemporary research issues. Industrial \& Corporate Change, v. 5, n. 3, p. 653-688, 1996.

COLMAN, Helene L.; LUNNAN, Randi. Organizational identification and serendipitous value creation in post-acquisition integration. Journal of Management, v. 37, n. 3, p. 839-860, 2011.

CONTU, Alessia; WILLMOTT, Hugh. Comment on Wenger and Yanow, knowing in practice: A 'delicate flower' in the organizational learning field. Organization, v. 7, n. 2, p. 269-276, 2000.

CONTU, Alessia; WILLMOTT, Hugh. Re-embedding situatedness: The importance of power relations in learning theory. Organization Science, v. 14, n.3, p. 283-296, 2003.

COOK, Scott D.N.; BROWN, John S. Bridging epistemologies: The generative dance between organizational knowledge and organizational knowing. Organization Science, v. 10, n. 4, p. 381-400, 1999.

COOK, Scott D.N.; YANOW, Dvora. Culture and organizational learning. Journal of Management Inquiry, v. 2, n. 4, p. 373-390, 1993.

CORBIN, Juliet; STRAUSS, Anselm. Basics of qualitative research: Techniques and procedures for developing grounded theory. $3^{\text {rd }}$ ed., Thousand Oaks: Sage Publications, 2008.

CORLEY, Kevin G.; GIOIA, Dennis A. Semantic learning as change enabler: Relating identity and organizational learning. In: DIERKES, Meinholf; CHILD, John; NONAKA, Ikujiro. (Orgs.). Handbook of organizational learning $e$ knowledge, p. 621-636, 2001.

CORLEY, Kevin G. et al. Guiding organizational identity trough aged adolescence. Journal of Management Inquiry, v. 15, n. 2, p. 85-99, 2006.

CRESWELL, John W. Qualitative inquiry and research design: Choosing among five traditions. Thousand Oaks: Sage Publications, 1998.

CYERT, Richard M.; MARCH, James G. A behavioral theory of the firm. Oxford: Blackwell, 1963. 
D'ADDERIO, Luciana. Configuring software, reconfiguring memories: the influence of integrated systems on the reproduction of knowledge and routines. Industrial and Corporate Change, v. 12, n. 2, p. 321-350, 2003.'

D'ADDERIO, Luciana. The performativity of routines: Theorising the influence of artefacts and distributed agencies on routines dynamics. Research Policy, v. 37, n. 5, p. 769-789, 2008.

DAFT, Richard L.; WEICK, Karl E. Towards a model of organization as interpretation systems. Academy of Management Review, v. 9, n. 2, p. 284-295, 1984

DALL'ALBA, Gloria; SANDBERG, Jorgen. Educating for competence in professional practice. Instructional Science, v. 24, p. 411-437, 1996.

DALL'ALBA, Gloria; SANDBERG, Jorgen. Unveiling professional development: A critical review of stage models. Review of Educational Research, v. 76, n. 3, p. 383-412, 2006.

DARR, Eric D.; ARGOTE, Linda; EPPLE, Dennis. The acquisition, transfer, and depreciation of knowledge in service organizations: Productivity in franchises. Management Science, v. 41, n. 11, p. 1750-1762, 1995.

DAVENPORT, Thomas H.; PRUSAK, Laurence. Conhecimento empresarial: Como as organizações gerenciam o seu capital intelectual. Rio de Janeiro: Campus, 1998.

DE GEUS, Aries. Planning as learning. Harvard Business Review, v. 66, n. 2, p. 70-74, 1988.

DENRELL, Jerker; ARVIDSSON, Niklas; ZANDER, Udo. Managing knowledge in the dark: An empirical study of the reliability of capability evaluations. Management Science, v. 50, n. 11, p. 1491-1503, 2004.

DENZIN, Norman K.; LINCOLN, Yvonna S. (Orgs.) Handbook of qualitative research. Thousand Oaks: Sage, 1994.

DIERKES, Meinholf; CHILD, John; NONAKA, Ikujiro. (Orgs.) Handbook of organizational learning e knowledge. Oxford University Press, 2001. 
DRUCKER, Peter F. The new society of organizations. Harvard Business Review, september-october, p. 95-104, 1992.

DUNKIN, Ruth. Using phenomenography to study organizational change. In BOWDEN, John A.; WALSH, Eleonor. (org.) Phenomenography, p. 4-103, Melbourne: RMIT University Press, 2000.

DUTTON, Jane E.; DUKERICH, Janet M.; HARQUAIL, Celia V. Organizational images and member identification. Administrative Science Quarterly, v. 39, n. 2, p. 239-263, 1994.

EASTERBY-SMITH, Mark; LYLES, Marjorie A. (Orgs.) The Blackwell handbook of organizational learning and knowledge management. Blackwell Publishing, 2003.

EASTERBY-SMITH, Mark; LYLES, Marjorie A. Introduction: Watersheds of organizational learning and knowledge management. In EASTERBY-SMITH, Mark; LYLES, Marjorie A. (Orgs.) The Blackwell handbook of organizational learning and knowledge management. p. 1-15, Blackwell Publishing, 2003.

EISENHARDT, Kathleen M.; MARTIN, Jeffrey A. Dynamic capabilities: What are they? Strategic Management Journal, v. 21, n. 10-11, p. 1105-1121, 2000.

ELKJAER, Bente. Social learning theory: Learning as participation in social processes. In EASTERBY-SMITH, Mark; LYLES, Marjorie A. (Orgs.). The Blackwell handbook of organizational learning and knowledge management. p. 38-53, Blackwell Publishing, 2003.

EPPLE, Dennis E., ARGOTE, Linda; DEVADAS, Rukmini. Organizational learning curves: A method for investigating intra-plant transfer of knowledge acquired through learning by doing. Organization Science, v. 2, n. 1, p. 58-70, 1991.

FANG, Christina. Organizational learning as credit assignment: A model and two experiments. Organization Science, v. 22, n. 3, p. 1-16, 2011.

FELDMAN, Martha S. Organizational routines as a source of continuous change. Organization Science, v. 11, n. 6, p. 611-629, 2000.

FELDMAN, Martha S.; ORLIKOWSKI, Wanda J. Theorizing practice and practicing theory. Organization Science, v. 22, p. 1-14, 2011. 
FELDMAN, Martha S.; PENTLAND, Brian T. Reconceptualizing organizational routines as a source of flexibility and change. Administrative Science Quarterly, v. 48, p. $94-118,2003$

FELIN, Teppo et al. Microfoundations of routines and capabilities: Individuals, processes and structure. Journal of Management Studies, v. 49, n.8, 2012.

FELIN, Teppo; HESTERLY, William S. The knowledge-based view, nested heterogeneity, and new value creation: Philosophical considerations on the locus of knowledge. Academy of Management Review, v. 32, n. 1, p. 195-218, 2007.

FOUCAULT, Michael. A microfísica do poder. Rio de Janeiro: Graal, 1980.

FRIESL, Martin; LARTY, Joanne. Replication of routines in organizations: Existing literature and new perspectives. International Journal of Management Reviews, v. 15, p. 106-122, 2013.

GAIMON, Cheryl; ÖZKAN, Gülru F.; NAPOLEON, Karen. Dynamic resource capabilities: Managing workforce knowledge with a technology upgrade. Organization Science, v. 22, n. 6, p. 1560-1578, 2011.

GAO, Ying F.; RILEY, Michael. Knowledge and identity: A review. International Journal of Management Reviews, v. 12, n. 3, p. 317-334, 2010.

GERBER, Rod; VELDE, Christine. Clerical-administrative workers' conceptions of competence in their jobs. Journal of Vocational Education and Training, v. 48, n. 4, p.1-12, 1996.

GERBER, Rod; VELDE, Christine. A competence model for professional practice in the clerical-administrative occupations. Journal of Vocational Education and Training, v. 49, n. 3, p. 1-21, 1997.

GHERARDI, Silvia. Practice-based theorizing on learning and knowing in organizations. Organization, v.7, n. 2, p. 211-223, 2000.

GHERARDI, Silvia. Organizational knowledge: The texture of workplace learning. Malden: Blackwell Publishing Ltd., 2006.

GHERARDI, Silvia; NICOLINI, Davide. To transfer is to transform: Circulation of safety knowledge. Organization, v.7, n. 2, p. 329-348, 2000. 
GHERARDI, Silvia; NICOLINI, Davide. The sociological foundations of organizational learning. In DIERKES, Meinholf; CHILD, John; NONAKA, Ikujiro. (Orgs.). Handbook of organizational learning e knowledge. p. 35-59, Oxford University Press, 2001.

GIDDENS, Anthony. A constituição da sociedade. Rio de Janeiro: Martins Fontes, 1984.

GIDDENS, Anthony. Modernidade e identidade. Rio de Janeiro: J. Zahar, 2002.

GLASER, Barney G.; STRAUSS, Anselm L. The discovery of grounded theory: Strategies for qualitative research. New Brunswick: Aldine Transaction, 2006.

GOLDMAN, Alfred E.; MCDONALD, Susan S. The group depth interview: principles and practice. Englewood Cliffs: Prentice-Hall, 1987.

GRAEBER, David. Toward an anthropological theory of value: The false coin of our own dreams. New York: Palgrave, 2001.

GRANT, Robert M. Toward a knowledge-based theory of the firm. Strategic Management Journal, v. 17, winter, p. 109-122, 1996.

GREEN, Pam. A rigorous journey into phenomenography. In: BOWDEN, John A.; GREEN, Pam. (Orgs.) Doing developmental phenomenography. Qualitative Research Methods Series, Melbourne: RMIT University Press, p. 32-46, 2005.

GROYSBERG, Boris; LEE, Linda-Eling; NANDA, Ashish. Can they take it with them? The portability of star knowledge workers' performance. Management Science, v. 54, n. 7, p. 1213-1230, 2008.

HAAS, Martine R. Knowledge gathering, team capabilities, and project performance in challenging work environments. Management Science, v. 52, n. 8, p. 1170-1184, 2006.

HAAS, Martine R.; HANSEN, Morten T. When using knowledge can hurt performance: The value of organizational capabilities in a management consulting company. Strategic Management Journal, v.26, n., p. 1-24, 2005.

HALES, Mike; TIDD, Joe. The practice of routines and representations in design and development. Industrial and Corporate Change, v. 18, n. 4, p. 551-574, 2009. 
HARGADON, Andrew .B. Brokering knowledge: Linking learning and innovation. Research in Organizational Behavior, v. 24, p. 41-85, 2002.

HARMAN, Kerry. Everyday learning in a public sector workplace: The embodiment of managerial discourses. Management Learning, v. 43, n.3, p. 275$289,2012$.

HARQUAIL, Celia V.; KING, Adelaide W. Organizational identity and embodied cognition: a multi-level conceptual framework. Proceedings, Academy of Management, Seattle, WA, 2003.

HASSELGREN, Björn.; BEACH, Dennis. Phenomenography: A "good-fornothing brother" of phenomenology? or Phenomenography is what phenomenographers do when doing phenomenography. Reports from the Department of Education and Educational Research, Göteborg University, Sweden, No. 1996:05.

HAYEK, Friedrich A. The use of knowledge in society. American Economic Review, v. XXXV, n. 4, 1945.

HEDBERG, Bo; WOLFF, Rolf. Organizing, learning, and strategizing: From construction to discovery. In DIERKES, Meinholf; CHILD, John; NONAKA, Ikujiro. (Orgs.). Handbook of organizational learning e knowledge. Oxford University Press, p. 535-556, 2001.

HEIZMANN, Helena. Knowledge sharing in a dispersed network of HR practice: Zooming in on power/knowledge struggles. Management Learning, v. 42, n., p. $1-15,2011$.

HEUSINKVELD, Stefan; BENDERS, Jos. Contested commodification: Consultancies and their struggle with new concept development. Human Relations, v. 58, n. 3, p. 283-310, 2005

HODGSON, Geoffrey M. The mirage of microfoundations. Journal of Management Studies, v. 49, p. 8, 2012

HSIAO, Ruey L., TSAI, Stephen D.; LEE, Ching F. The problems of embeddedness: knowledge transfer, coordination and reuse in information systems. Organization Studies, v. 27, n. 9, p. 1289-1317, 2006. 
INKPEN, Andrew C. Knowledge transfer and international joint ventures: The case of Nummi and General Motors. Strategic Management Journal, v. 29, n., p. $447-453,2008$

JACOBS, Claus; COGHLAN, David. Sound from silence: On listening in organizational learning. Human Relations, v. 58, n. 1, p. 115-138, 2005.

JCR, Journal of Citation Reports 2010. ISI Web of Knowledge, Thomson Reuters, acesso em 01/10/2011.

KANG, Sung C., MORRIS, Shad S.; SNELL, Scott A. Relational archetypes, organizational learning, and value creation: Extending the human resource architecture. Academy of Management Review, v. 32, n. 1, p. 236-256, 2007.

KARAMANOS, Anastasios G. Complexity, identity and the value of knowledgeintensive exchanges. Journal of Management Studies, v. 40, p. 7, p. 1872-1890, 2003.

KARATAS-ÖZKAN, Mine; MURPHY, William D. Critical theorist, postmodernist and social constructionist paradigms in organizational analysis: a paradigmatic review of organizational learning literature. Journal of Management Reviews, v. 12, n. 4, p. 453-465, 2010.

KING, Adelaide W.; ZEITHAML, Carl P. Measuring organizational knowledge: A conceptual and methodological framework. Strategic Management Journal, v. 24, n., p. 763-772, 2003.

KNORR-CETINA, Karin D. The manufacture of knowledge: an essay on the constructivist and contextual nature of science. Oxford: Pergamon, 1981.

KUMAR, Krishan. Da sociedade pós-industrial à sociedade pós-moderna: Novas teorias sobre o mundo contemporâneo. Rio de Janeiro: Jorge Zahar Ed., 1997.

LATOUR, Bruno. On recalling ANT. In LAW, John; HASSARD, John (orgs). Actor network theory and after. Oxford: Blackwell Publishers, p. 15-25, 1999.

LATOUR, Bruno. A esperança de Pandora: Ensaios sobre a realidade dos estudos científicos. São Paulo: Ed. da Universidade do Sagrado Coração, 2001.

LATOUR, Bruno. Reagregando o social: Uma introdução à teoria do atorrede. Salvador: EDUFBA/EDUSC, 2012. 
LATOUR, Bruno; WOOLGAR, Steve. Laboratory life: The construction of scientific facts. Thousand Oaks: Sage, 1979.

LAVE, Jean; WENGER, Etienne. Situated learning: Legitimate peripheral participation, Cambridge: Cambridge University Press, 1991.

LAZARIC, Nathalie; DENIS, Blandine. Routinization and memorization of tasks in a workshop: the case of the introduction of ISO norms. Industrial and Corporate Change, v. 14, n. 5, p. 873-896, 2005.

LAW, John. Notes on the theory of the actor-network: Ordering, strategy, and heterogeneity. Systemic Practice and Action Research, v.5, 1992.

LAW, John. After ANT: Complexity, naming and topology. In LAW, John; HASSARD, John. (Orgs). Actor network theory and after. Oxford: Blackwell Publishers, p. 1-14, 1999.

LAW, John; HASSARD, John. (Orgs). Actor network theory and after. Oxford: Blackwell Publishers, 1999.

LEVINE, Sheen S.; PRIETULA, Michael J. How knowledge transfer impacts performance: A multilevel model of benefits and liabilities. Organization Science, n. 22, p. 1-19, 2011.

LOPES, Ana L.S.V. Autonomia no trabalho: Um estudo fenomenográfico. Tese de doutorado. Universidade Federal do Rio de Janeiro, COPEAD, 2012.

LUPSON, Jonathan; PARTINGTON, David. Accountability for public sector it projects and the senior responsible owner: A theoretical background and research agenda. Working paper Cranfield School of Management, p. 3-25, 2005.

MADSEN, Peter M.; DESAI, Vinit. Failing to learn? The effects of failure and success on organizational learning in the global orbital launch vehicle industry. Academy of Management Journal, v. 53, v. 3, p. 451-476, 2010.

MAEL, Fred; ASHFORTH, Blake E. Alumni and their alma mater: A partial test of the reformulated model of organizational identification. Journal of Organizational Behavior. v. 13, n. 2, p. 103-123, 1992. 
MAINARDES, Emerson W., LOURENÇO, Luis; TONTINI, Gerson. Percepções dos conceitos de qualidade e gestão pela qualidade total: Estudo de caso na universidade. Revista Gestão.Org, v. 8, n. 2, p. 279-297, 2010.

MAJCHRZAK, Ann, MORE, Philip H.B.; FARAJ, Samer. Transcending knowledge differences in cross-functional teams. Organization Science, v. 23, n. 4, p. 951-970, 2012.

MARCH, James G.; SIMON, Herbert A. Organizations. Oxford, England: Wiley, 1958.

MARTON, Ference. Phenomenography: Describing conceptions of the world around us. Instructional Science, v. 10, p. 177-200, 1981.

MARTON, Ference; BOOTH, Shirley A. Learning and awereness. Mahwah: Lawrence Erlbaum Inc. Publishers, 1997.

MARTON, Ference; SÄLJÖ, Roger. On qualitative differences in learning: Outcome and process. British Journal of Educational Psychology, v. 46, n.1, p. 411, 1976.

MASSINGHAM, Peter. Measuring the impact of knowledge loss: More than ripples on a pond? Management Learning, v. 39, n. 5, p. 541-560, 2008.

MATURANA, Humberto R.; VARELA, Francisco J., Autopoiesis and cognition: The realization of the living. Dordecht: D. Reidel Publishing Co., 1980.

MAURER, Indre, BARTSCH, Vera; EBERS, Mark. The value of intraorganizational social capital: How it fosters knowledge transfer, innovation performance, and growth. Organization Studies, v. 32, n. 2, p. 157-185, 2011.

MENON, Tanya; BLOUNT, Sally. The messenger bias: A relational model of knowledge valuation. Research in Organizational Behavior, v.25, n., p.137-186, 2003.

MENON, Tanya; PFEFFER, Jeffrey. Valuing internal vs. external knowledge: Explaining the preference for outsiders. Stanford Research Paper Series, Research Paper No. 1776, 2003.

MENON, Tanya; THOMPSON, Leigh; CHOI, Hoon S. Tainted knowledge vs. tempting knowledge: People avoid knowledge from internal rivals and seek 
knowledge from external rivals. Management Science, v. 52, n. 8, p. 1129-1144, 2006.

MORGAN, Gareth. Imagens da Organização. São Paulo: Atlas, 1996.

MOUSTAKAS, Clark. Phenomenological research methods. Thousand Oaks: Sage Publications, 1994.

MÜLLER-SEITZ, Gordon; GÜTTEL, Wolfanfg. Network congregating: A practice-based perspective on absorptive capacity at the organization-network nexus in a semiconductor industry consortium Management Learning, v. 43, 2012.

NAG, Rajiv, CORLEY, Kevin G.; GIOIA, Dennis A. The intersection of organizational identity, knowledge, and practice: attempting strategic change via knowledge grafting. Academy of Management Journal, v. 50, n. 4, p. 821-847, 2007.

NDOFOR, Hermann A.; LEVITAS, Edward. Signaling the strategic value of knowledge. Journal of Management, v. 30, n. 5, p. 685-702, 2004.

NEAL, Judi (Ed.). Handbook of Faith and Spirituality in the Workplace: Emerging Research and Practice. Springer, 2013.

NELSON, Robert; WINTER, Sidney G. An evolutionary theory of economic change. Massachusetts: Harvard University Press, 1982.

NONAKA, Ikujiru. A dynamic theory of organizational knowledge creation. Organization Science, n. 5, p. 14-37, 1994.

NONAKA, Ikujiru.; TAKEUCHI, Hirotaka. Criação de conhecimento na empresa: como as empresas japonesas geram a dinâmica da inovação. $7^{\mathrm{a}}$ Ed., Rio de Janeiro: Ed. Campus, 1997.

NONAKA, Ikujiru; TOYAMA, Ryoko; BYOSIÈRE, Philippe. A theory of organizational knowledge creation: Understanding the dynamic process of creating knowledge. In DIERKES, Meinholf; CHILD, John; NONAKA, Ikujiro. (Orgs.). Handbook of organizational learning e knowledge. p. 491-517, Oxford University Press, 2001. 
OBORN, Eivor; DAWSON, Sandra. Learning across communities of practice: An examination of multidisciplinary Work. British Journal of Management, v. 21, p. 843-858, 2010.

ORLIKOWSKI, Wanda J. Knowing in practice: Enacting a collective capability in distributed organizing. Organization Science, v. 13, n. 3, p. 249-273, 2002.

ORLIKOWSKI, Wanda J. Sociomaterial practices: Exploring technology at work. Organization Studies, v. 28, n. 9, p.1435-1448, 2007.

ORR, Julian E. Talking about machines: An ethnography of a modern job. New York: Cornell University Press, 1996.

ORTENBLAD, Anders. A typology of the idea of learning organization. Management Learning, v. 33 n. 2 p. 213-230, 2002.

PARMIGIANI, Anne; HOWARD-GRENVILLE, Jennifer. Routines revisited: Exploring the capabilities and practice perspective. The Academy of Management Annals, v. 5, n.1, p. 413-453, 2011.

PARTINGTON, David; YOUNG, Malcolm. Configuring knowledge in practicegrounded research networks: A contemporary example. Academy of Management Annual Meeting Proceedings, p. 9-14, 2002.

PARTINGTON, David; PELLEGRINELLI, Sergio; YOUNG, Malcolm. Attributes and levels of programme management competence: An interpretative study. International Journal of Project Management, v. 23, n. 2, p.87-172, 2005.

PATRIOTTA, Gerardo. Organizational knowledge in the making: How firms create, use and institutionalize knowledge. New York: Oxford University Press, 2003a.

PATRIOTTA, Gerardo. Sensemaking on the shop floor: Narratives of knowledge in organizations. Journal of Management Studies, v. 40, n. 2, p. 350-375, 2003 b.

PENTLAND, Brian T. Grammatical models of organizational processes. Organization Science, v. 6, n. 5, p. 541-556, 1995.

PENTLAND, Brian T.; FELDMAN, Martha S. Designing routines: On the folly of designing artifacts, while hoping for patterns of action. Information and Organization, v. 18, p. 235-250, 2008. 
PELLEGRINELLI, Sergio; PARTINGTON, David; YOUNG, Malcolm. Understanding and assessing programme management competence. Europe Paper, p. 1-10, 2003.

PELLEGRINELLI, Sergio; GARAGNA, Luciano. Facilitating selection and development: The case of the "accidental professionals" - project and programme managers. IPMA, p. 1-8, 2010.

PENROSE, Edith. Teoria do crescimento da firma. São Paulo: Ed. UNICAMP, 2006 (original, 1959).

PITELIS, Christos N. The co-evolution of organizational value capture, value creation and sustainable advantage. Organization Studies, v. 30, n.10, p. 11151139, 2009.

POLANYI, Michael. The tacit dimension. New York: Doubleday \& Co., 1966.

POLESIE, Pim, FRÖDELL, Mikael; JOSEPHSON, Per E. Implementing standardisation in medium-sized construction firms: facilitating site managers' feeling of freedom through a bottom-up approach. Proceedings 17th Annual Conference of the International Group for Lean Construction, p. 317-326, 2009.

POSEN, Hart E.; LEVINTHAL, Daniel A. Chasing a moving target: Exploitation and exploration in dynamic environments. Management Science, v.57, n., p. 1-15, 2011.

PRAHALAD, Coimbatore K.; HAMEL, Gary. The core competence of the corporation. Harvard Business Review, v. 68, n. 3, p. 79-91, 1990.

RAVISHANKAR, M.N.; PAN, Shan L. The influence of organizational identification on organizational knowledge management (KM). International Journal Management Science, v. 36, p. 221 - 234, 2008.

REAGANS, Ray; ARGOTE, Linda; BROOKS, Daria. Individual experience and experience working together: Predicting learning rates from knowing who knows what and knowing how to work together. Management Science, v. 51, n. 6, p. 869-881, 2005.

RENZL, Birgit. Trust in management and knowledge sharing: The mediating effects of fear and knowledge documentation. International Journal Management Science, v. 36, p. 206-220, 2008. 
REUS, Taco H. et al. An interpretive systems view of knowledge investments. Academy of Management Review, v. 34, n. 3, p. 382-400, 2009.

REYNAUD, Bénédicte. The void at the heart of rules: routines in the context of rule-following. The case of the Paris Metro Workshop. Industrial and Corporate Change, v. 14, n. 5, p. 847-871, 2005.

RICHARDSON, John T.E. The concepts and methods of phenomenographic research. Review of Educational Research, v. 69, n. 1, p. 53- 1999.

ROCHA-PINTO, Sandra R.; SILVA, José Roberto G.; SOARES, Claudia D. A experiência de ter sido empregado e a visão do empreendedor. Revista Alcance Eletrônica, v. 17, n. 3, p. 278-294, 2010.

ROCHA-PINTO, Sandra R.; CARPIO, Gisele R.A.M.D. Fatores críticos para a implantação do Balanced Scorecard: A visão de consultores organizacionais. $B A S E$, v. 8, n. 4, p. 311-324, 2011.

ROONEY, David; MCKENNA, Bernard. Wisdom in organizations: Whence and whither. Social epistemology, v. 21, n. 2, p. 113-138, 2007.

RYLE, Gilbert. The concept of the mind. Chicago: University of Chicago Press, 1949.

SANDBERG, Jorgen. Competence as intentional achievement: A phenomenographic study. Annals of International Human Science Conference, Goteborg, Sweden, 1991.

SANDBERG, Jorgen. Understanding human competence at work: An interpretative approach. Academy of Management Journal, v. 43, n. 1, p. 9-25, 2000.

SANDBERG, Jorgen. Understanding the basis for competence development. International Perspectives on Competence in the Workplace, p. 9-25, 2001.

SANDBERG, Jorgen. Understanding of work: The basis for competence development. International Perspectives on Competence in the Workplace, p. 320, 2009. 
SANDBERG, Jorgen; PINNINGTON, Ashly H. Professional competence as ways of being: an existential ontological perspective. Journal of Management Studies, v. 46, n. 7, p. 1138-1170, 2009.

SCHARF, Edson R.; SORIANO-SIERRA, Eduardo J. A gestão do conhecimento e o valor percebido: Estratégia competitiva sustentável para a era do conhecimento. Revista da FEA, v. 5, n. 1, p. 87-108, 2008.

SCHEIN, Edgard. Organizational culture and leadership. San Francisco: JosseyBass, 1985.

SILVA, José Roberto G. Comunicação e Mudança em Organizações Brasileiras: Desvendando um Quadro de Referência sob a Ótica do Sujeito e da Reconstrução de Identidades. Tese de Doutorado, Pontifícia Universidade Católica do Rio de Janeiro PUC-Rio, Rio de Janeiro: 2001.

SIMON, Herbert A. Administrative behavior. New York: Free Press, 1947.

SOLE, Deborah; EDMONDSON, Amy. Situated knowledge and learning in dispersed teams. British Journal of Management, v. 13, p. 17-34, 2002.

SPENDER, John C. Organizational knowledge, collective practice and Penrose rents. International Business Review, n. 3, p. 353-367, 1994.

SPENDER, John C. Organizational knowledge, learning and memory: Three concepts in search of a theory. Journal of Organizational Change Management, v. 9, n. 1, p. 68-73, 1996.

SPENDER, John C.; GRANT, Robert M. Knowledge and the firm: Overview. Strategic Management Journal, v. 17, winter, p. 5-9, 1996.

STAR, Susan L. Ecologies of knowledge: Work and politics in science and technology. New York: State University of New York Press, 1995.

STARBUCK, William H.; BARNETT, Michael L.; BAUMARD, Philippe. Payoffs and pitfalls of strategic learning. Journal of Economic Behavior $e$ Organization, v. 66, p. 7-21, 2008.

STARBUCK, William H.; HEDBERG, Bo. How organizations learn from success and failure. In DIERKES, Meinholf; CHILD, John; NONAKA, Ikujiro. (Orgs.). 
Handbook of organizational learning e knowledge. p. 327-349, Oxford University Press, 2001.

STEWART, Thomas A. O capital intelectual. Rio de Janeiro: Ed. Campus, 1998. STRATI, Antonio. The aesthetic understanding of organizational life. Academy of Management Review. v. 17, n. 3, p. 568-581, 1992.

STRATI, Antonio. Sensible knowledge and practice-based learning. Management Learning, v. 38, n. 1, p. 61-77, 2007.

STURDY, Andrew; WRIGHT, Christopher. The active client: the boundaryspanning roles of internal consultants as gatekeepers, brokers and partners of their external counterparts. Management Learning, v. 42, n. 5, p. 485-503, 2011.

SUBRAMANI, Mani R.; VENKATRAMAN, N. Safeguarding investments in asymmetric interorganizational relationships: Theory and evidence. Academy of Management Journal, v. 46, n. 1, p. 46-62, 2003.

SUCHMAN, Lucy. Making a case: "Knowledge" and "routine" work in document production. In LUFF, P; HINDMARSH, J; HEATH, C (orgs.) Workplace Studies: Recovering work practice and informing system design. Cambridge: Cambridge University Press, 1999.

SVEIBY, Karl E. A nova riqueza das organizações. Rio de Janeiro: Ed. Campus, 1998.

SVENSSON, Lennart. Learning environments of employees in knowledgeintensive company units. International perspectives on competence in the workplace. p. 159-182, 2009.

SWAN, Jacky et al. The object of knowledge: The role of objects in biomedical innovation. Human Relations, v. 60, n.12, p. 1809-1837, 2007.

SWART, Juani. That's why it matters: How knowing creates value. Management Learning, v. 42, n. 3, p. 319-332, 2011.

SZULANSKI, Gabriel. Exploring internal stickiness: Impediments to the transfer of best practice within the firm. Strategic Management Journal, v. 17, special winter issue, p. 27-43, 1996. 
SZULANSKI, Gabriel. The process of knowledge transfer: A diachronic analysis of stickiness. Organizational Behavior and Human Decision Processes, v. 82, n. 1, p. 9-27, 2000.

TAGLIAVENTI, Maria R.; MATTARELLI, Elisa. The role of networks of practice, value sharing, and operational proximity in knowledge flows between professional groups. Human Relations, v. 59, n.3, p. 291-319, 2006

TEECE, David J. Explicating dynamic capabilities: The nature and microfoundations of (sustainable) enterprise performance. Strategic Management Journal, v. 28, p. 1319-1350, 2007.

TEECE, David J.; PISANO, Gary; SHUEN, Amy. Dynamic capabilities and strategic management. Strategic Management Journal, v. 18, n. 7, p. 509-533, 1997.

TELL, Fredrik. What do organizations know? Dynamics of justification contexts in R\&D activities. Organization, v. 11, n. 4, p. 443-471, 2004.

THOMAS-HUNT, Melissa C.; OGDEN, Tonya Y.; NEALE, Margaret A. Who's really sharing? Effects of social and expert status on knowledge exchange within groups. Management Science, v. 49, n. 4, p. 464-477, 2003.

THOMPSON, Mark P.A.; WALSHAM, Geoff. Placing knowledge management in context. Journal of Management Studies, v. 41, n. 5, p. 726-747, 2004.

TSOUKAS, Harimos. The Firm as a distributed knowledge system: A constructionist approach. Strategic Management Journal, v. 17, Winter Special Issue, p. 11-25, 1996

ULRICH, David. A New Mandate for Human Resources. Harvard Business Review, n.1, jan/feb, 1998.

VAAST, Emmanuelle. What goes online comes offline: Knowledge management system use in a soft bureaucracy. Organization Studies, v. 28, n. 3, p. 283-306, 2007.

VILLAS, Marcos V.; MACEDO-SOARES, Teresia D.V.A; RUSSO, Giuseppe M. Bibliographical research method for business administration studies: a model based on scientific journal ranking. BAR. Brazilian Administration Review, v. 5, n. 2, p. 139-159, 2008. 
WATSON, Sharon; HEWETT, Kelly. A multi-theoretical model of knowledge transfer in organizations: Determinants of knowledge contribution and knowledge reuse. Journal of Management Studies, v. 43, n. 2, p. 142-173, 2006.

WEBB, Graham. Deconstructing deep and surface: Towards a critique of phenomenography. Higher Education, v. 33, n. 1, p. 195-212, 1997.

WEICK, Karl E. Sensemaking in organizations. Sage, 1995.

WENGER, Etienne. Communities of practice and social learning systems. Organization, v. 7, n. 2, p. 225-246, 2000.

WENGER, Etienne. Communities of practice: learning, meaning, identity. $18^{\mathrm{a}}$ reimpressão, New York: Cambridge University Press, 2008 (original 1998). 318p.

WERNERFELT, Birger. A resource based view of the firm. Strategic Management Journal, v. 5, n. 3, p. 171-180, 1984.

WINOGRAD, Terry; FLORES, Carlos F. Understanding computers and cognition. Nowood: Ablex Publishing, 1986.

WONG, Sze-Sze. Judgments about knowledge importance: The role of social referents and network structure. Human Relations, v. 6, n. 11, p. 1565-1591, 2008. YANOW, Dvora. Seeing cultural learning: A 'cultural' view. Organization, v. 7, n. 2, p. 247-258, 2000.

ZBARACKI, Mark J.; BERGEN, Mark. When truces collapse: A longitudinal study of price-adjustment routines. Organization Science, v. 21, n. 5, p. 955-972, 2010.

ZOLLO, Maurizio; WINTER, Sidney G. Deliberate learning and the evolution of dynamic capabilities. Organization Science, v.v13, n. 3; p. 339-351, 2002. 


\section{Apêndice}

\subsection{Apêndice 1: Roteiro Semiestruturado - Valoração do Conhecimento \# 2}

\section{Introducão:}

A pesquisa é sobre os entendimentos e experiências que as pessoas possuem acerca da valoração do conhecimento no contexto do trabalho. Eu vou fazer algumas perguntas sobre sua vida profissional, e sinta-se à vontade para abordar todos os aspectos que você considera relevantes.

Todos os dados são mantidos sob confidencialidade, nenhum entrevistado será identificado sob nenhum aspecto. Nossa conversa será gravada para facilitar a retomada do conteúdo, posteriormente.

\section{Pergunta Introdutória:}

1) Inicialmente, para contextualizar a nossa conversa, você poderia me falar qual a sua formação e tempo de experiência profissional?

2) Você poderia me falar um pouco sobre sua trajetória profissional até o seu trabalho atual, em recursos humanos?

3) Você poderia me dizer o que é conhecimento para você?

\section{Perguntas Intermediárias:}

4) Você poderia me dar um exemplo de alguma situação, dentro das experiências que você acabou de citar, na qual você considera que teve seus conhecimentos MAIS valorados no contexto do trabalho? Onde, quando, com quem?

5) Você poderia me dar outro exemplo, mas agora de uma situação na qual você NÃO teve seus conhecimentos valorados OU teve seus conhecimentos MENOS valorados no contexto do trabalho?

6) Como você percebe que os conhecimentos valorados são incorporados nas práticas/rotinas de trabalho? 


\section{Perguntas de acompanhamento:}

a. Por que você considera essa situação um sinal de (valoração ou falta de valoração)?

b. Qual foi o significado (disso) para você?

c. O que (isso) representou?

d. Quais pessoas estavam envolvidas com essa situação?

e. No contexto do trabalho, quem tem influência na valoração do conhecimento?

f. No contexto do trabalho, quais situações ou fatos tem influência na valoração do conhecimento? Como? De que modo?

g. Como essa (pessoa, regra, situação) possibilitou ou evitou a valoração do seu conhecimento?

\section{Perguntas Finais:}

7) Agora, eu gostaria de voltar um pouco e, a partir do que conversamos e dos exemplos que você me deu. Vou te pedir para você pensar e me dizer, de uma forma resumida, o que a valoração do conhecimento no contesto do trabalho significa para você. (perguntas auxiliares: o que você entende por valoração do conhecimento no contexto do trabalho OU como você definiria a valoração do conhecimento no contexto do trabalho).

8) Você gostaria de acrescentar algo ao que você disse anteriormente ou dizer alguma coisa sobre o assunto que não foi abordado na nossa conversa?

\section{Finalizacão:}

Agradecimentos. 


\subsection{Apêndice 2: Perguntas Apresentadas nas Rodadas de Debate do Grupo de Foco}

\section{Concepções de Valoração do Conhecimento}

- Refletindo sobre essas cinco concepções, vocês as encontram coexistindo na organização onde trabalham?

- Todas elas ou somente algumas? Quais?

- Alguma concepção predomina mais fortemente sobre as demais? Qual?

- O que ocorre com alguém que possui uma concepção que não está alinhada com a concepção da organização acerca do conhecimento de valor?

\section{Mapa do Espaço de Resultado acerca da Valoração do Conhecimento}

- As concepções estão arrumadas em uma hierarquia lógica, da concepção mais estreita à concepção mais ampla?

- Refletindo sobre sua própria experiência profissional e de carreira, você sente que já transitou pelas categorias do Espaço de Resultado?

- Este trânsito é unidirecional ou bidirecional?

- Você já se sentiu entre concepções? 